\title{
TO WHAT EXTENT DO GOVERNMENTS EFFECTIVELY USE SOCIAL MEDIA? UNDERSTANDING GOVERNMENT AND USER INTERACTIONS ON IMMIGRATION AGENCIES' SOCIAL MEDIA
}

\author{
by
}

\section{Maria Gintova}

Master of Public Administration, University at Albany, 2008

Bachelor of Public Administration, Lomonosov Moscow State University, 2006

\author{
A dissertation presented to Ryerson University \\ in partial fulfillment of the \\ requirements for the degree of \\ Doctor of Philosophy \\ in the program of \\ Policy Studies
}




\section{Author's Declaration for Electronic Submission of a Dissertation}

I hereby declare that I am the sole author of this dissertation. This is a true copy of the dissertation, including any required final revisions, as accepted by my examiners.

I authorize Ryerson University to lend this dissertation to other institutions or individuals for the purpose of scholarly research.

I further authorize Ryerson University to reproduce this dissertation by photocopying or by other means, in total or in part, at the request of other institutions or individuals for the purpose of scholarly research.

I understand that my dissertation may be made electronically available to the public. 
To What Extent Do Governments Effectively Use Social Media? Understanding Government and User Interactions on Immigration Agencies' Social Media

Maria Gintova, Doctor of Philosophy, Policy Studies, Ryerson University, 2018

\section{Abstract}

Since 2011, Canada like many other countries, has been formally using social media as part of its open government policy. In the past few years, many federal and provincial departments and agencies in Canada have invested significant resources in social media initiatives and begun to build up their presence on social media platforms. This research examines if the use of social media makes a difference and adds value in public service delivery. The study focuses on immigration agencies in Canada - the federal government's Immigration, Refugees and Citizenship Canada (IRCC) and the Province of Ontario's Ministry of Citizenship and Immigration (MCI) - and comparison with Australia and New Zealand as two other jurisdictions using social media in immigration related matters. It is aimed at capturing and analysing the perspectives of both public servants and users of government social media, therefore, filling existing gaps in the literature related to how government immigration agencies are using social media and how that use relates to social media users' expectations and needs.

The methodology used in this study includes qualitative methods: document analysis, content analysis and semi-structured interviews. Content analysis of social media data is supplemented by analysis of government documents and interview data offering insights into the meaning of effective use of social media for government and social media users. Using existing secondary sources from the scholarly and practitioner literature, the study also defines and examines effective use of social media by government and includes recommendations for practitioners. Findings of this study add value to existing scholarship on public policy and administration and for policy makers and public servants responsible for the use of social media in government to improve existing policy and public service delivery. 


\section{Acknowledgements}

I would like to sincerely thank my supervisor Dr. Carolyn Johns who supported me throughout my studies and dissertation research and offered invaluable advice on making things happen. I would also like to thank my committee members Dr. Anatoliy Gruzd and Dr. John Shields for their support and guidance throughout the process. I am very grateful to all my research participants who took the time to talk to me and share their knowledge, experiences and perspectives. Finally, I would like to thank my family, especially my husband and my dad, fellow Ryerson students and professors, the fearless program administrator Mary Beth Halferty Kraay, friends and colleagues in Russia, Canada and the USA, and finally, last but not the least, my cats. This would not have been possible without you. 


\section{Table of Contents}

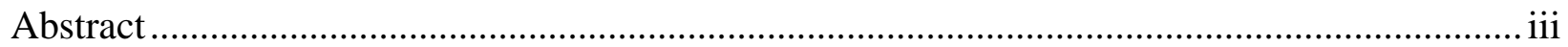

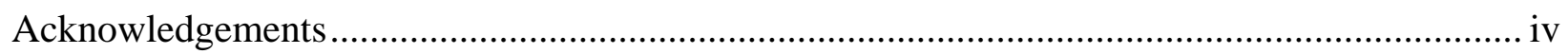

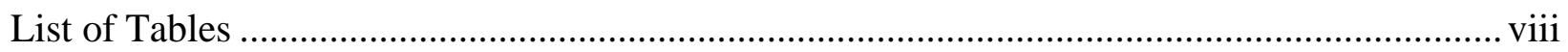

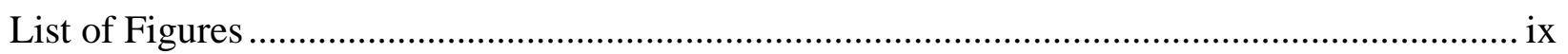

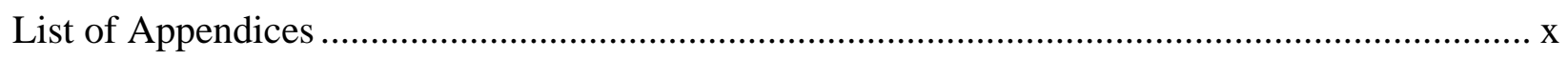

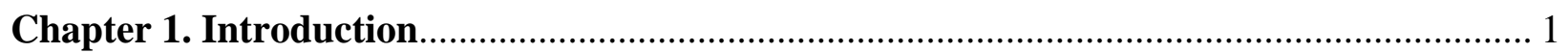

Open Government and Government Use of Social Media ................................................. 3

Purpose of the Study and Research Questions .......................................................... 10

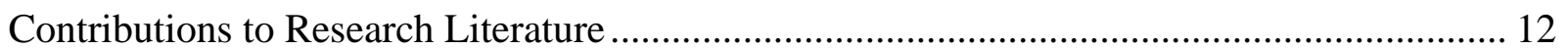

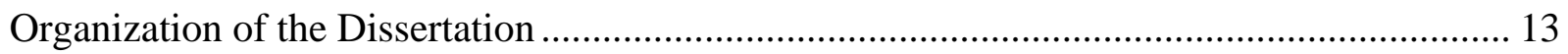

Chapter 2. Literature Review and Theoretical Framework .......................................... 15

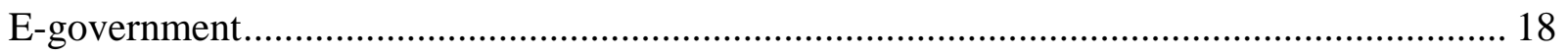

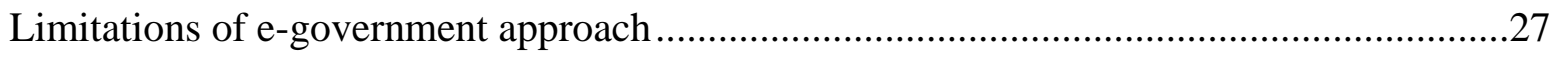

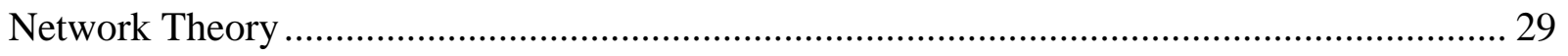

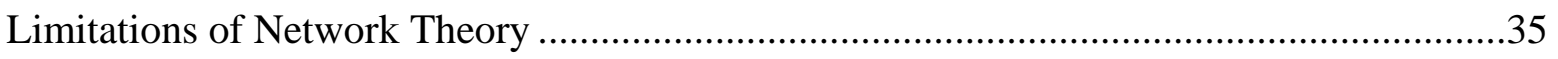

Migration Studies, Migrant Networks, Technology and Social Media ............................... 37

Limitations of Migration Studies' Approach.................................................................46

Theoretical Assumptions and Foundations of Research .................................................... 47

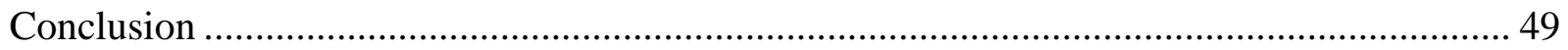

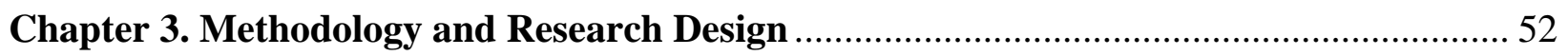

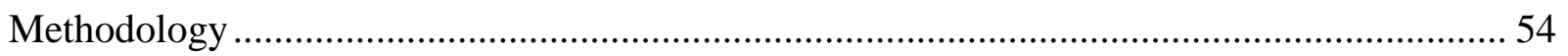

Analysis of Policies and Other Government Documents .............................................55

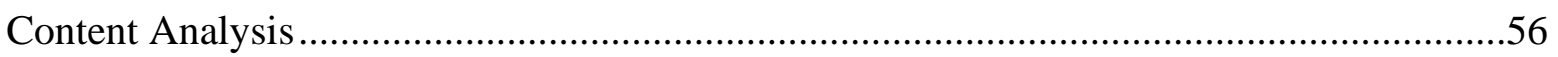

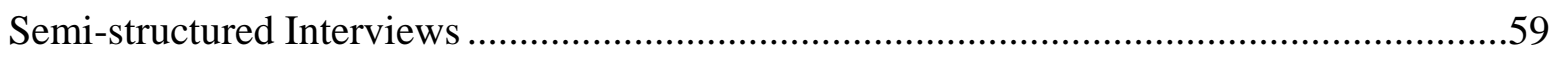

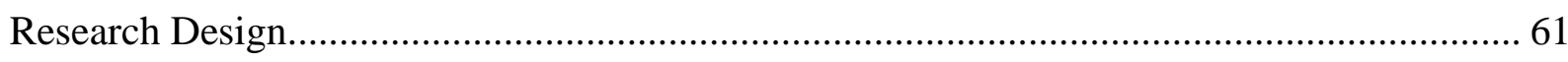

Collection and Analysis of Relevant Policies and Government Documents ......................63

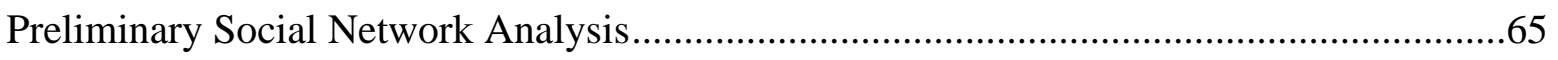

Social Media Data Collection and Analysis ..............................................................66

Semi-structured Interviews with Public Servants and Social Media Users .........................79

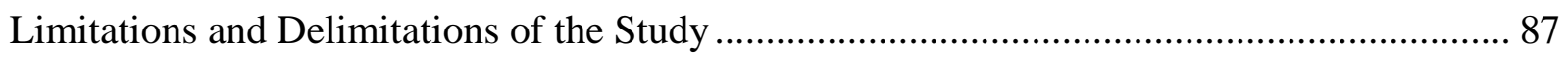

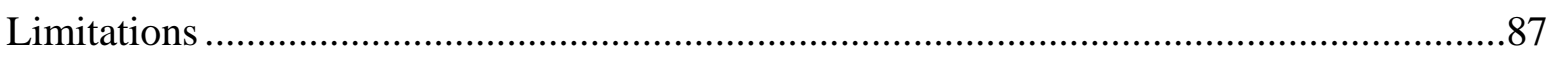

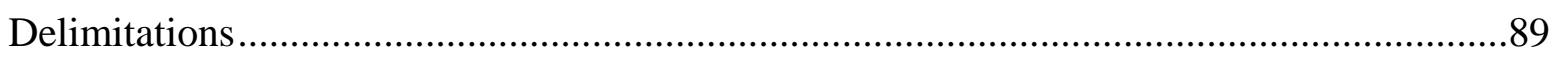

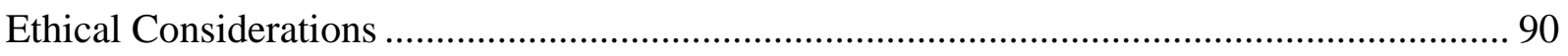

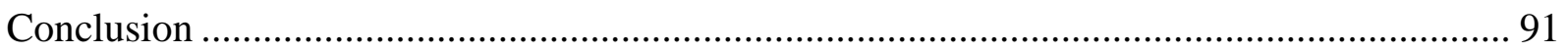


Chapter 4. Approaches to the Use of Social Media in Government in Canada, Australia and New Zealand

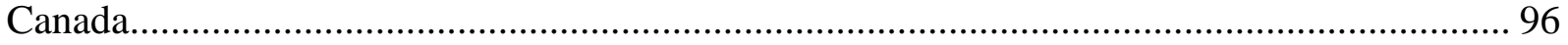

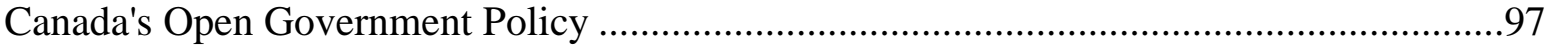

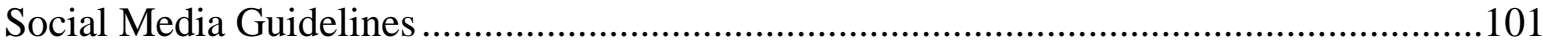

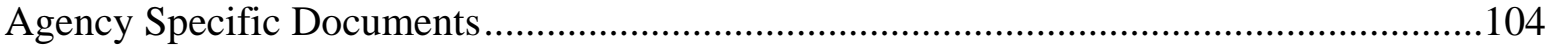

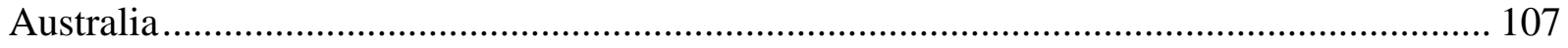

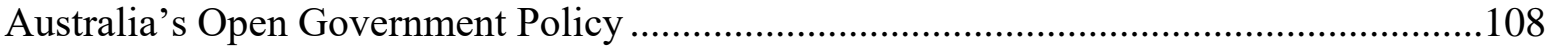

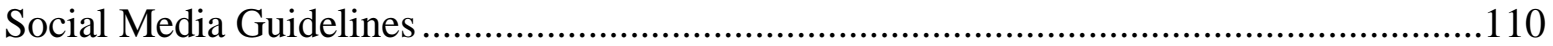

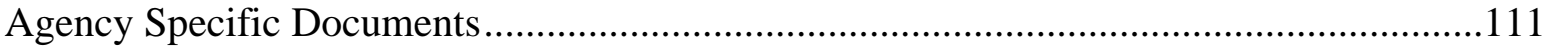

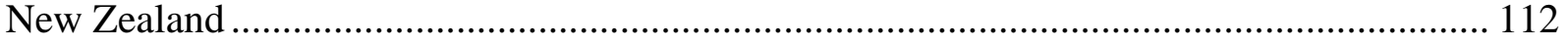

New Zealand's Open Government Policy ..................................................................113

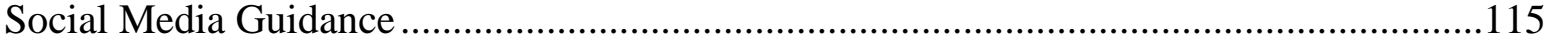

Agency Specific Documents ...............................................................................116

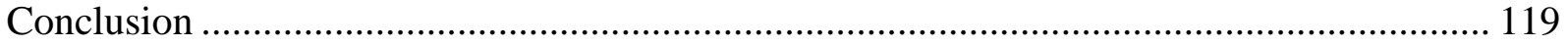

Chapter 5. Government Use of Social Media: Cases of IRCC and MCI......................... 124

Organization of the IRCC and MCI Facebook and Twitter Accounts................................ 125

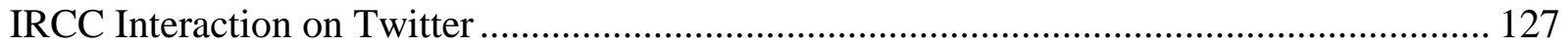

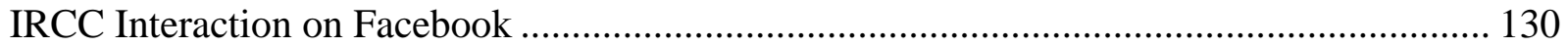

Differences in the IRCC Use of Twitter and Facebook .................................................... 132

Insights from Interviews with Public Servants from IRCC and MCI................................ 135

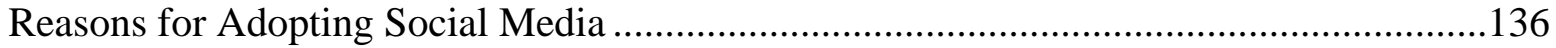

Three Main Social Media Goals: Customer Service Tool, Marketing Tool and

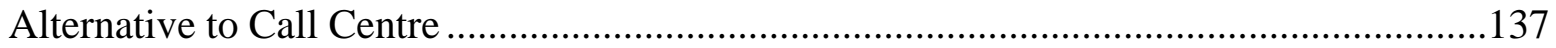

Social Media and Open Government Policy...............................................................140

Quality of Content Is Important but There Is Lack of Analysis of User Posts ..................141

Levels of Approvals and Time for Approval ...............................................................143

Value of User-to-User Conversations ......................................................................... 144

Difference in Use between Twitter and Facebook...........................................................145

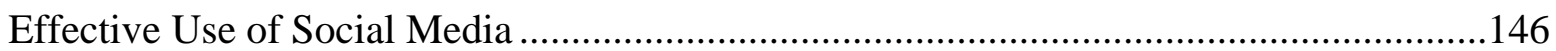

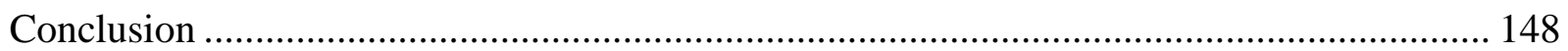

Chapter 6. User Perspectives: Migrants' Use of Government Social Media..................... 152

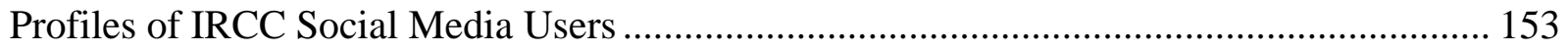

User Interaction on the IRCC Twitter......................................................................... 156

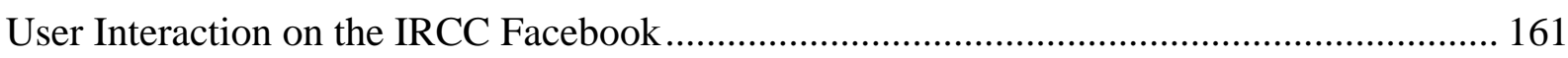

Differences in the Use of the IRCC Twitter and Facebook .............................................. 167 


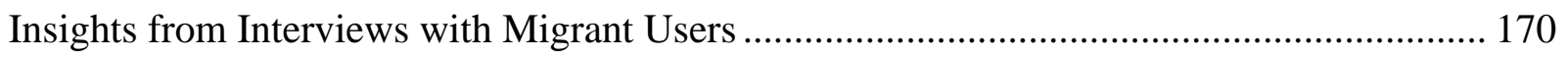

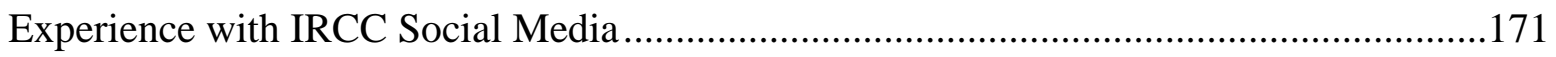

Importance of Getting a Response and Its Quality ........................................................173

Value of Answers by IRCC, Other Users and Two-way Interactions ................................174

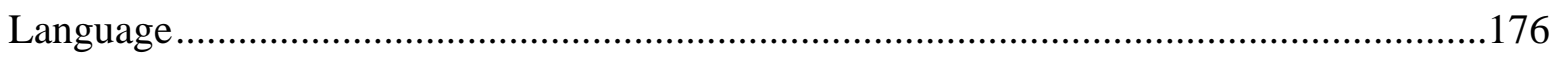

IRCC Website and Other Sources of Information .........................................................177

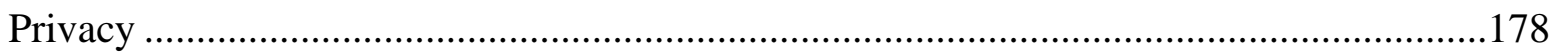

Effective Use of Social Media by Government ........................................................179

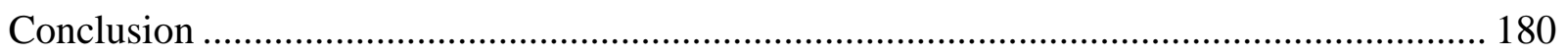

Chapter 7. Conclusions, Recommendations and Suggestions for Future Research ........... 184

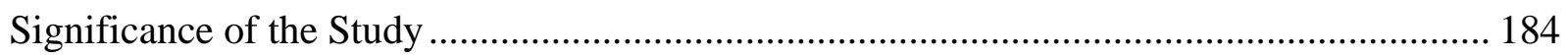

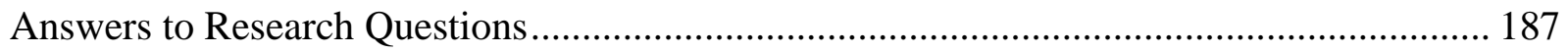

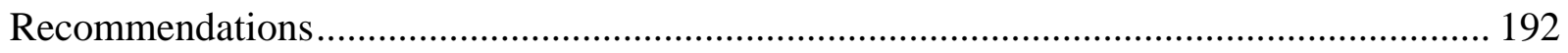

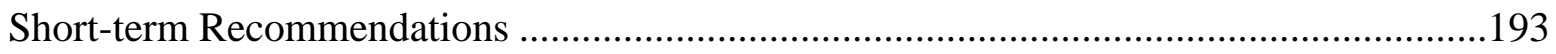

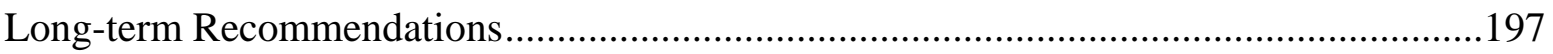

Suggestions for Future Research ................................................................................. 202

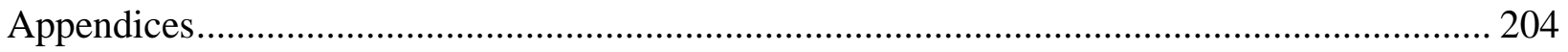

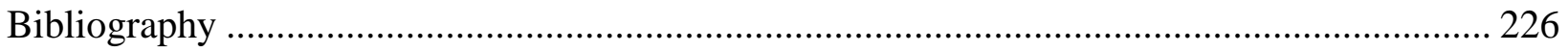




\section{List of Tables}

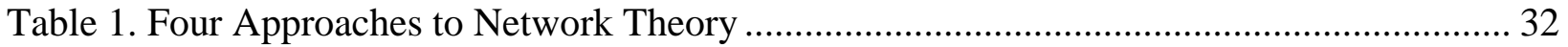

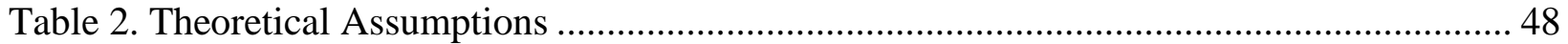

Table 3. Policy, Guideline and Procedural Documents that Regulate Social Media Use in Government in Canada, Australia and New Zealand................................................................ 64

Table 4. Canadian Federal Government Definitions and Open Government Priorities ............... 98

Table 5. Public Engagement Commitments of the Government of Canada Action Plans

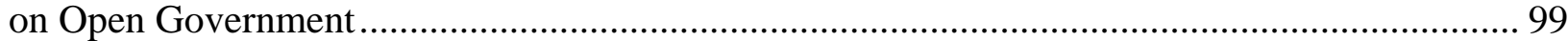

Table 6. Comparison of Open Government Policies and Social Media Strategies and

Guidelines in Canada, Australia and New Zealand ............................................................... 117

Table 7. Comparison of IRCC Answers on Twitter and Facebook ......................................... 135

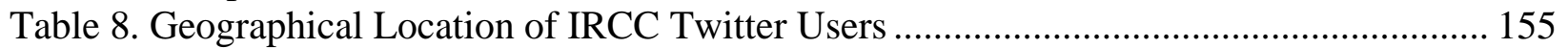

Table 9. Comparison of User Questions and Questions Receiving Answers from IRCC by Topic/Theme on the IRCC Twitter

Table 10. Comparison of User Questions and Questions Receiving Answers from IRCC by Topic/Theme on the IRCC Facebook 164

Table 11. Comparison of User Questions on the IRCC Facebook and Twitter accounts by topic/theme. 


\section{List of Figures}

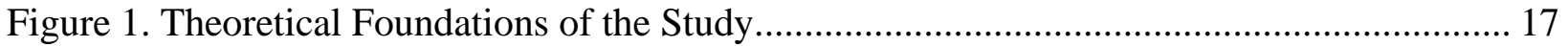

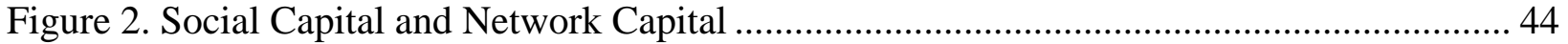

Figure 3. Activity on the IRCC Twitter (September 2015-August 2016) .................................. 73

Figure 4. Activity on the IRCC Facebook (September 2015-August 2016)............................. 74

Figure 5. IRCC Tweets (September 2015-August 2016) ........................................................ 128

Figure 6. Categories of IRCC Tweets ............................................................................... 129

Figure 7. IRCC Facebook Posts (September 2015-August 2016) ......................................... 131

Figure 8. Categories of IRCC Facebook Posts ..................................................................... 132

Figure 9. IRCC Tweets and Facebook Posts ....................................................................... 133

Figure 10. Differences in IRCC Use of Twitter and Facebook .............................................. 134

Figure 11. User Tweets on the IRCC Twitter Account ....................................................... 156

Figure 12. Categories of User Tweets by Types of Messages ............................................. 158

Figure 13. User Posts on the IRCC Facebook Account..................................................... 161

Figure 14. Categories of User Posts on the IRCC Facebook ................................................. 162

Figure 15. IRCC User Tweets and Facebook Posts September 2015 - August 2016 ............... 168

Figure 16. Differences in Use of the IRCC Twitter and Facebook by Users ......................... 169 


\section{List of Appendices}

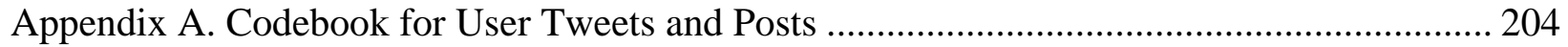

Appendix B. Codebook for IRCC Tweets and Posts .......................................................... 209

Appendix C. Recruitment Email for Public Servants ........................................................... 213

Appendix D. Consent Form for Public Servants ................................................................... 214

Appendix E. Interview Questions (Themes) for Public Servants .......................................... 217

Appendix F. Recruitment Messages for Social Media Users ................................................ 218

Appendix G. Consent Form for Social Media Users ........................................................... 219

Appendix H. Interview Questions (Themes) for Social Media Users .................................... 222

Appendix I. Codebook -Public Servant Interviews......................................................... 223

Appendix J. Codebook - User Interviews ................................................................... 225 


\section{Chapter 1. Introduction}

The digital transformation that is currently happening in governments around the world is not a new phenomenon (Mergel 2012; Roy 2013). Governments have been experimenting and implementing new technologies in their operations since adoption of computers in 1950s-1960s (Mergel 2012; Margetts 2012). The latest major change to the relationship between government and the public happened in late 1990s - early 2000s when governments made significant investments in the information technology infrastructure in order to provide public services online (Dunleavy et al. 2006). However, this transformation was mostly focused on streamlining government internal processes and provision of services for the public. The latest wave of transformation is known as transition from Government 1.0 to Government 2.0. The era of Government 2.0 calls for the use of Web 2.0 technologies and tools to create collaborative and interactive environment between government and non-government actors (Anttiroiko 2010; Dixon 2010; Dutil et al. 2010; Roy 2013). Social media is considered as one of the technologies that enable interactive collaboration between government and citizens.

The use of social media by government is spreading around the world and across different levels of government (Mergel and Greeves 2013; Bonson et al. 2012). Governments are currently facing a new reality: they can engage in communication with individuals in real time. However, they cannot control what can be said about them on these platforms as they used to when information was provided only on the government websites (Dutil et al. 2010; Mergel 2013a). Moreover, they are now one of the many social media users and need to be constantly present on social media in order to be heard by their target audiences. The key challenge for governments is to decide if it is worth exploring how social media can be used for their purposes or continue business "as usual". 
According to the research literature, governments are actively looking into new capabilities and opportunities created by social media (Mergel 2012; Criciado et al. 2013). They are also investigating potential risks and issues. However, as more and more government agencies around the world are creating their social media accounts, it is becoming obvious that they realize that social media is here to stay and they need to capitalize on opportunities rather than justify limiting the use of social media based on potential risks (Mergel 2013b, 2013c). Another pressure to use social media comes from other countries, levels of government and international organizations such as Open Government Partnership (OGP) and the Organization for Economic Co-operation and Development. Increasingly, jurisdictional "peers" are advocating for the need to use social media in government. This "peer pressure" contributes to the understanding of the need to keep up with the others in order to keep up with the new arising priorities.

The biggest challenge, however, is understanding how social media can be used and why it is important. Currently, government agencies in Canada are using a variety of different social media platforms such as Twitter, Facebook, YouTube, LinkedIn, Instagram, blogs and wikis. Although many of these accounts were created more than five years ago, public servants who are responsible for maintaining them still spend a significant amount of time talking to their colleagues to explain how these platforms can be helpful for the government agency as a whole and its individual divisions and program areas.

Government presence and interaction on social media continues to evolve, thus, constantly changing approaches and ways social media is used. This dynamic research environment is very much evident in the constant change observed throughout this study. For example, since the time data collection was initiated to the time of writing up the findings, one of the agencies examined 
in this study, the Ontario Ministry of Citizenship and Immigration (MCI) ${ }^{1}$, changed the name of its Facebook account, making it more generic and repositioning it for a broader audience. In June 2016, MCI also closed its Twitter account and created two new ones with a different focus - one account with a specific focus on Ontario citizenship and the second one on Ontario immigration. Another government agency selected for the study - the federal Department of Immigration, Refugees and Citizenship - has not drastically changed its social media accounts but added new ones - LinkedIn and Instagram.

Therefore, this is a very fluid area of research and certain findings of the study are obviously time bounded. At the same time, many identified issues reveal systemic challenges that government agencies and users are facing related to the use of social media. This fluidness, however, is quite important to acknowledge upfront as this research is aimed at contributing both to the scholarly literature on the government use of social media and providing practical recommendations that can be implemented.

\section{Open Government and Government Use of Social Media}

Governments and policy makers across the globe are initiating and implementing open government policies and strategies. When referring to governments, this research focuses on executive bodies on different levels (i.e. federal, regional and municipal) that are involved in implementation of policies and delivering of public services and programs. Open government is the most recent policy initiative aimed at ensuring the right of people to access and scrutinize government documents and information (Lathrop and Ruma 2010). Many governments who are

\footnotetext{
${ }^{1}$ Until June 2016, Ministry of Citizenship and Immigration in Ontario was known as Ministry of Citizenship, Immigration and International Trade (MCIIT). Before and when I conducted my interviews with public servants from the ministry, I referred to it as MCIIT.
} 
signatories to the OGP commit to increased transparency and effective use of technology in order to strengthen governance (OGP 2015). Therefore, governments are signaling that they interested in becoming more open and accessible in their open government policies (Johnson and Robinson 2014). In this research, the concept of policy is defined broadly - as courses of government actions, regulatory measures, laws and funding principles (formalized in a written form and not).

President Obama's Memorandum on Transparency and Open Government published in February 2009 is considered to be "a signal moment in the history of open government" (Lathrop and Ruma 2010: xix), however, the history of increasing transparency and accountability in government is quite long (Clarke and Francoli 2014; Lauriault and Francoli 2017). Moreover, Yu and Robinson (2012) argue that a government can be transparent, even if it does not use new ICTs: stakeholders can be well informed through other means to hold the system accountable. Therefore, open government should not be used as a synonym to e-government or digital government, which is primarily focused on the use of ICT to achieve policy goals and improve delivery of government programs and services (OECD 2018).

However, the wide access to the Internet and growing use of Web 2.0 platforms by the public sector is changing the relationship between governments and the public. In the past five years, governments across the globe have developed open government policies that declared that the use of these technologies makes it much easier for people to participate in government initiatives such as policy development and public service delivery, particularly through the use of social media. However, more recently, these policies have re-focused on broader public engagement initiatives, which do not necessarily involve the use of social media. It is also important to note that the approach to public engagement has evolved to focus on efforts to foster the culture of public participation. Thus, social media has become one of the many of possible 
tools for public engagement rather than being the primary technology to ensure public participation in policy development and public service delivery. In this dissertation, the concept of public engagement will be used in the way it was articulated in the earlier open government action plans - as a way to look for input from the public on public policy initiatives and public service delivery. It is important to note, however, that scholars note that the approaches to engage the public in policy-making and public service delivery can differ significantly (e.g. Nabatchi 2012).

It is also important to further distinguish between engagement and interaction on social media. According to International Association for Public Participation (IAP2), types of engagement can be placed on the following spectrum: inform, consult, involve, collaborate and empower (IAP2 2018). Interaction, on the other hand, just involves bi-directional communication between a government agency and the public and can happen regardless of how advanced the engagement process is (i.e. at the inform stage, a government agency can provide information to the public upon request).

Boyd and Ellison (2007: 211) define social media sites as "web-based services that allow individuals to: (1) construct a public or semi-public profile within a bounded system; (2) articulate a list of other users with whom they share a connection, and (3) view and traverse their list of connections and those made by others within the system". O'Reilly (2007) emphasizes that social media allows for the creation and exchange of user generated content. Moreover, according to Dutil et al. (2010), it provides an interactive and participative architecture for collaboration and information sharing among users as well as enables instant content creation and exchange. Mergel (2013) states that these functionalities enable government to engage citizens into collaboration on public policy and service delivery as well as benefit from citizens' involvement. Neither the Government of Canada nor other jurisdictions in Canada have formally defined social media in 
their publicly available government documents. When referring to social media they mean social networking platforms such as Facebook, Twitter, Instagram and YouTube.

As a member of the OGP, Canada has developed a policy framework and commitment to act. Both federal and provincial governments are implementing open government policies and initiatives across Canada and using social media platforms to communicate with the public. To date, the Government of Canada has implemented Canada's Action Plan on Open Government (2012-2014) and Canada's Action Plan on Open Government 2.0 (2014-2016) and launched its Third Biennial Plan to the Open Government Partnership (2016-2018). All action plans focus on three streams of initiatives: open data, open information and open dialogue. Within the open dialogue stream, action plans call for engagement with Canadians and the world to contribute to policy-making and improvement of public services. A special focus is placed on social media as a tool to reach out to target audiences and engage them in public consultations.

Thus, open government policy calls for the government use of social media in order to engage the public in government consultations, policy development and public service delivery. However, at present, the major focus remains on making government data publicly available, while other open government initiatives do not receive enough attention (Clarke and Francoli 2014, 2017; Craft 2013, Francoli 2014; Roy 2016). Thus, there is a disconnect between the official Government of Canada open government policy and individual government agencies approaches to social media use. This study focuses on understanding of this disconnect in more detail, particularly on understanding if open government policy and principles are operationalized in individual government agencies' approaches and practices on social media, including the use of this technology to engage the public in policy-making and public service delivery. 
Many federal and provincial government departments and agencies in Canada have invested significant resources in order to build up their presence on different social media platforms. They are currently using a variety of different social media platforms such as Twitter, Facebook, YouTube, blogs and wikis to share information about existing programs and services as well as connect with the public. However, as research shows, most communication of government agencies that occur through social media is aimed at retransmitting information already available on the government websites (Mergel 2012; Mergel and Greeves 2013; Lee and VanDyke 2015). Furthermore, in most cases when individuals ask for advice, they are instructed to consult the website or their request remains unanswered. Thus, evidence to date, indicates government agencies in Canada do not use social media for two-way interactions with the public (Francoli 2014; McNutt 2014).

This problem is acknowledged by the federal government itself. In the second action plan on open government, the Treasury Board of Canada Secretariat (TSB) made a commitment to provide guidance, tools and resources to ensure public engagement in the development and implementation of the policies and programs as well as to develop regulations to guide consultation processes (Government of Canada 2014). However, although TSB has developed policy instruments to advocate for the use of social media in government, there has been limited progress in terms of using social media as an engagement tool (TSB 2017).

It is important to understand challenges that government agencies across Canada face in order to engage in a meaningful conversation with the public about policies as well as service delivery or if they see any value in the use of social media. However, the analysis of these challenges should be complemented by the analysis of social media users' expectations and experiences. To date, public administration research has focused mainly on government agencies 
as institutions, public servants as representatives of these institutions and formal connections between government and the public. However, social media makes government just one of the actors in social networks that exist regardless of government needs and expectations. These networks are also dominated by other users, their interests and values (Deschamps and McNutt 2014). Therefore, the use of social media differs from public consultations as government does not only initiate conversations and gather feedback but has to be constantly involved in communication. Thus, research on government use of social media should take this into consideration.

There are many policy domains where government agencies across Canada are trying to advance the use of social media to achieve policy goals and improve service delivery. One of these is the area of immigration where social media is becoming more important because of the Government of Canada's interest in attracting highly skilled immigrants (Chase 2012). The case of immigration agencies' use of social media is also interesting because immigration agencies are “average" medium size government agencies whose clients are located inside and outside Canada. Furthermore, like most government agencies, they do have social media accounts. Therefore, the current state of social media use in the immigration policy domain can serve as a proxy for other government agencies operating in the social policy area. Nevertheless, as immigration agencies serve clients located within and outside Canada, they experience significant interest in immigration agencies' social media accounts, which users of other government agencies social media might not have. Therefore, caution should be used when comparing the amount of social media interactions, types of interactions and social media user preferences between government immigration agencies and other government agencies. The federal Department of Immigration, Refugees and Immigration (IRCC) and some of provincial immigration agencies, including the 
Ontario Ministry of Citizenship and Immigration (MCI) are all using social media as part of their communication strategies, which also allows for some comparative analysis. In addition, knowledge I gained through my previous employment with IRCC, provides a solid foundation to focus on government immigration agencies priorities generally and related to social media use.

In order to keep the scope of the study manageable, it is focused solely on IRCC and MCI use of social media. IRCC is the federal government department that is responsible for selection of immigrants, citizenship grants, passport program, protection to refugees and services for visitors, students, workers as well as Canadian permanent residents and citizens (IRCC 2017a). IRCC is the biggest immigration agency in Canada and works together with provincial immigration agencies to select immigrants and provide services for newcomers to Canada. IRCC is also the primary point of contact for those who are interested in immigration, acquiring Canadian citizenship or coming to Canada as a temporary resident. MCI's mandate includes attracting a skilled workforce in Ontario and helping newcomers and their families succeed in the province. MCI also works closely with the federal government to maximize economic benefits of immigration to Ontario (Government of Ontario 2016). Therefore, social media platforms of both IRCC and MCI are used to engage with people who can be located within and outside Canada. The assumption is that if social media channels are effectively and meaningfully used to ensure two-way interactions between government and migrants, it might help Canada to remain competitive in the international fight for talent.

Social media, however, is affecting the way migrants communicate as well. They can now instantly get information from the Internet, share it and create their own content. This is supported by recent studies showing that social media is providing migrants with new ways of interaction 
and facilitating the migration process (Dekker and Engbersen 2014; Dekker et al. 2016; Komito 2011).

However, these new realities can create false expectations about the migration process (Ros 2010) or disseminate unrealistic or even false information (Dekker and Engbersen 2014). Many social networks of migrants that are created on social media do not have government presence but circulate information about government programs and services based on the participants' experiences and opinions. Users of a particular social media website have an opportunity to read about individual experiences, ask the questions they have and get personalized responses, thus acquiring streetwise knowledge of migration (Dekker and Engbersen 2014; Dekker et al. 2016). Therefore, government websites are not the only source of information on the immigration policies and services. Although the information obtained through social media can be helpful and useful, it can also deceive people who want to understand formal procedures and established practices to make an informed decision about migrating and/or create unrealistic expectations.

\section{Purpose of the Study and Research Questions}

The purpose of this study is to understand how and why governments and migrants are using social media resources and if government immigration agencies can use them more effectively. In addition, one of my goals is to generate knowledge that is useful for policy makers, practitioners and the public by producing recommendations that flow from this research on the effective use of social media in the immigration domain and beyond. The study explores four major research questions:

The first research question - "how and why is social media being used by government immigration agencies" - explores current government approaches to the use of social media. In 
order to answer the 'how' part, I am exploring existing policies and practices as well as government posts on social media. By answering, the 'why' portion, I am also seeking to understand government reasoning behind current approaches to the use of social media in government, including capitalizing on existing opportunities and addressing challenges.

The second research question - "how and why do migrants use government social media resources" - explores current practices and strategies behind migrants' social media use. The 'how' part focuses on migrant's social media posts, thus, analysing existing practices, and the ‘why' portion explores reasons behind social media use.

The third question is: "Do relationships created between government agencies and migrants on social media matter and why?" This research question seeks to provide insights into the role of relationships on government social media platforms. The focus is on understanding the value of existing interactions between government and social media users and among social media users themselves.

Lastly, "to what extent do governments effectively use social media?" This research question explores current perceptions on effective social media use that exist in government and are envisioned by individual users. Although it is intuitive that governments and users see effective use of social media by government differently, it is also equally important to highlight the existing differences between these approaches and the need of taking into account the users' perspectives to ensure the effective use of social media by government.

Therefore, by examining social media use by government immigration agencies, this study hopes to draw conclusions about the effective use of social media that are specific for immigration agencies and migrants who use social media resources. At the same time, this research also reveals 
broader issues of effective use of social media in government that might be relevant for other government agencies.

\section{Contributions to Research Literature}

This study builds on several bodies of literature in public administration, information science, policy and migration studies. It advances the existing research by understanding the experiences and perceptions of public servants of government immigration agencies who develop and post the content for the social media platforms and migrants as well as their relatives and friends who used government social media resources. Moreover, it explores how government policies are operationalized in everyday routine functions of public administration by focusing on government-wide, open government policy documents, the principles in these documents and the ways these policies are reflected in agency specific social media documents. It also yields a series of recommendations for government immigration agencies specifically and the broader public sector. Therefore, this research will make contributions to literatures on e-government (introducing user perspective of effective social media use by government), network theory (understanding and conceptualizing government-user virtual networks on social media), migration studies (understanding the benefits of government social media for migrants) and policy implementation

(understanding operationalization of open government policy and social media use by governments in Canada, selected countries, and in selected agencies).

It is also important to note that this study is unique for the field of policy studies and public administration as it not only examines how government agencies and officials are using social media, it also explores the perspectives and experiences of one important stakeholder group - the public, which has limited engagement in the development of government policies and has not been 
the focus of existing research. The findings related to users of government social media are more explicitly discussed in Chapter 6 “User Perspectives: Migrants' Use of Government Social Media.” Moreover, the set of recommendations outlined in Chapter 7 includes considerations for everyday routine use of social media by government and also broader policy implications. These include specific recommendations and general recommendations on social media use in public administration and in terms of public engagement in public service delivery and policy-making.

\section{Organization of the Dissertation}

This dissertation is divided into seven chapters, with Chapter 1 being the introduction. Chapter 2 provides a literature review and discusses the theoretical framework for the study. The purpose of the literature review is to discuss academic literature in the fields of public administration, policy studies, information science and migration studies that my study draws from and also identify research gaps that need to be addressed.

Chapter 3 outlines the methodology and research design. It provides a detailed explanation of the methods used to conduct this study, specifically analysis of government documents, content analysis of social media data and qualitative semi-structured interviews with government officials and social media users. Further, it discusses my approach to analysis of government documents, social media data and interview data and explores how these different methods and data sources are used to complement and triangulate research findings.

The next chapters of my dissertation discuss research findings. Chapter 4 focuses on government documents that call for the use of social media in government. It compares documents

that specify approaches to the government use of social media adopted by Canada, Australia and 
New Zealand as well as the use of social media specifically by government immigration agencies in these three countries.

Chapter 5 explores government use of social media drawing on social media data from IRCC social media accounts as well as semi-structured interviews with public servants from IRCC and MCI. It analyses IRCC interaction on Twitter and Facebook, examines differences in use between the platforms and effectiveness of social media use in government from the perspective of public servants.

Chapter 6 examines migrants' use of government social media. Here, I analyse who IRCC social media users are, user interactions on the IRCC Twitter and Facebook, results of these interactions, including if they received a response or comment from IRCC, differences in use between the platforms and what effective use of social media by government means for its users. Findings are based on the analysis of social media posts as well as interviews with 22 user participants.

Finally, Chapter 7 discusses significance of the study, summarizes answers to research questions and provides recommendations for government agencies that are currently using social media. Although some recommendations are specific to immigration domain, many can provide important insights for government agencies responsible for social policy on different levels of government in Canada and abroad. The chapter concludes with suggestions for future research. 


\section{Chapter 2. Literature Review and Theoretical Framework}

The use of social media is studied across a number of different scholarly disciplines and practitioner communities. Social scientists are interested in a wide range of research questions about the uses and effects of social media for individuals, groups, organizations, networks, communities as well as international and global realms. Scholars from many different disciplines and sub-fields are trying to understand how state and societal actors are using social media related to global, international and domestic issues.

Researchers in policy studies are mainly interested in the role of new technologies in policy-making (e.g. McNutt 2006, 2010; Rethmeyer 2007), while researchers in public administration are focused on understanding how the new technology can be used to better serve the public as well as making government more open, transparent and accountable (e.g. Dutil et al. 2010; Mergel 2012, 2013a, 2013b; Linders 2012). Therefore, these disciplines are more interested in understanding the role of government in social networks and the ways social media is used.

Migration studies researchers, on the contrary, are more interested in the use of social media by individual immigrants and ways it helps them to access certain social networks (e.g. Komito 2011; Dekker and Engbersen 2014; Dekker et al. 2016). They build on the research agenda that focuses on the role of social capital and social networks and how social media is contributing or impeding the development of social capital and social networks. Furthermore, migration studies scholars are interested in information seeking behaviours of immigrants and understanding what kind of information they are looking for and sharing using social media. McGregor and Siegel (2013) note that current research on social media use by immigrants focuses on three major topics: 1) the role of social media in facilitating migration; 2) immigrants' integration through social 
media, and 3) social media and diaspora engagement. At the same time, these studies do not touch upon the ways migrant interact on government social media accounts.

Currently, government immigration agencies are using a variety of social media platforms in order to provide information about the host country and available public services (McGregor and Siegel 2013). Moreover, government agencies that are present on social media can directly reach out to social media users. However, the important question here is why the relationships between government and social media users do or should matter for government. This key topic is missing from current discussions in e-government and public engagement literature. However, the focus on the importance of relationships may greatly contribute to the understanding of how government use of social media can be more effective.

There are several bodies of literature one can look to advance knowledge and research related to why and how government organizations and officials are using social media, why and how immigration agencies and migrants are using social media; and how the public and government agencies can use them more effectively. This research requires an interdisciplinary approach. It uses and builds on theories and concepts from public administration (e-government, network theory), policy studies (network theory) as well as sociology, information and migration studies (social capital and social networks) to address the four central research questions.

This study draws on current e-government research on social media use by government. Egovernment literature was selected as a primary theoretical framework for the study as it allows to focus on government use of technology for public engagement and public service delivery. Therefore, it is used to review existing approaches to the effective use of social media in government, identify challenges government is facing and benefits of social media for public service provision and analyse existing social media evaluation frameworks. Moreover, network 
theory in policy studies and public administration allows for an examination of the importance of the relationships between government and social media users as part of policy and service delivery as well as the need to take these relationships into account to improve public service delivery. In addition to this public administration and policy literature, the scope of this study focuses on immigration agencies and also uses insights from research on social capital and social immigrant networks, to examine different ways users seek and share information with governments and other users via social media. Therefore, the main focus is on government and social media users as actors on government social media. However, a network perspective also allows for an examination of the extent and importance of relationships between government and users on government managed social media platforms. Figure 1 summarizes the theoretical foundations of this study.

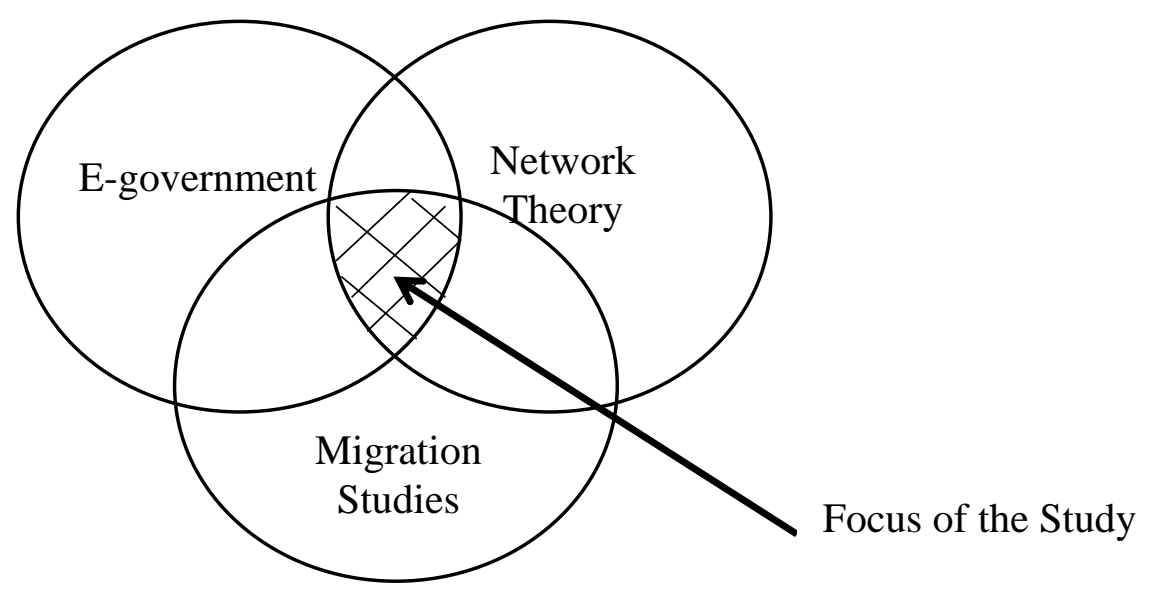

\section{Figure 1. Theoretical Foundations of the Study}

The most logical place to start related to answering research questions about use of social media in government is public policy and public administration literature. The next section reviews the e-government research that has grown significantly in the past decade to the point of now having its own journals and scholarly associations. The e-government perspective is important for understanding how technology in general and social media specifically is used and can be used to create and sustain interactions between government and citizens. This section is then followed by 
a section on network theory. Network theory in public policy and public administration emphasizes the need to understand the relationships between state and non-state actors as well as the importance of these relationships. The section on general network theory in public policy and administration is then followed by a section that reviews relevant theory and research from the field of migration studies, primarily drawing on theories of social capital and social networks. This is a particularly relevant body of theory and research given the focus on immigration agencies in this study.

\section{E-government}

Although there has been a long-standing interest in the impact of technology in public administration theory and research, for the past two decades a growing body of scholarship has emerged in public administration related to the impact of information communication technologies (ICTs), particularly alongside a period of significant public sector reform (Margetts 2012). This research has primarily focused on the use of ICT in government organizations, by government officials and on the interaction between government and the public through technology. Egovernment initiatives and scholarship evolved during a period of public sector reform associated with New Public Management (NPM) - a movement focused on reducing red tape in government and the costs of public service provision as well as having a customer orientation to public service delivery. Although the move toward provision of public services online contributed to cost reduction for service delivery (Roy 2006), the growing scope of e-government initiatives required considerable investment in information systems, new public-private partnerships, redesigning back office processes and workflows and training public sector employees. 
Therefore, most of the literature on e-government focuses on the effective and efficient use of ICT in government. This assumption is carried over by scholars who study digital government to certain extent - they are also interested in the value added of government use of technology for the public. Authors consider different factors leading to technology adoption, analyse why certain governments are more successful than others, evaluate e-government maturity levels and study best practices that can be shared between different levels of government and countries. Thus, the research on e-government is mostly focused on practice and lacks a substantial theoretical component.

Nevertheless, e-government scholars are borrowing and testing theories from other disciplines. For example, a number of studies draw upon technology adoption models and theories: the Technology Adoption Model (Lin and Liang 2011; Shyu and Huang 2011), innovation diffusion (Wang et al. 2007; Yeloglu and Sagsan 2009) and the Unified Theory of Acceptance and Use of Technology (Venkatesh et al. 2003). These studies focus on what makes citizens more likely to use the Internet to interact with government. These factors include citizen's trust in government, perceived risk, Internet safety, perceived value, ease of use, usefulness, compatibility and interpersonal influence (AlAwadhi and Morris 2009). However, these models do not account for the institutional factors that enable technology adoption in government agencies specifically (AlAwadhi and Morris 2009; Kumar et al 2007) and therefore need to be supplemented by empirical studies focused on government.

Dunleavy et al. (2006) and Mergel (2012) indicate the importance of understanding how ICT adoption happens in government. According to Dunleavy et al. (2006), the changes in technology before 1990s had very limited transformative effect on government operations. However, the growth of the Internet and online communication affected not only government 
back-office but relations between government agencies and civil society. Mergel (2012: 281) indicates that four waves of ICT adoptions are: “1) mainframes in the 1950s-1960s, 2) central timeshare systems (1970s-1980s), 3) minicomputers and LAN (1980-1990s), and 4) online eservices (1990s-2000s)" or Web 1.0 and argues and that currently government is experiencing the fifth wave of ICT adoption. The fifth way started with the introduction of Web 2.0 and social media applications. They allow for instant interaction between government and the public.

Dunleavy et al. (2006), Dunleavy and Margetts (2010) as well as Mergel (2012) acknowledge that the focus on electronic service delivery and bringing government online has transformed the way government interacts with businesses and the public: government has become more accessible than ever before. Moreover, ICTs and especially the Internet and online communication were at the centre of this transformation. Homburg (2008) and Henman (2010), however, argue that discussions about the crucial role of ICT in government are too abstract, dominated by deterministic views and begin with an assumption that technology is good for progress. Therefore, the scope of such discussions is limited to one viewpoint.

According to Linders (2012) and Criado et al. (2013), government use of social media is becoming one of the major topics in e-government research and practice around the world. As Web 2.0 technologies are being integrated in government routines, many scholars started talking about the rise of Government 2.0 - government that uses innovative technologies and tools to create collaborative and interactive environment between government and non-government actors (Anttiroiko 2010; Dixon 2010; Dutil et al. 2010; McNutt 2014; Roy 2013). Social media is considered to be one of these innovative technologies. Thus, it was proclaimed that the main goal for the use of social media is to "open new forms of communication between government and the 
people" (Office of Management and Budget 2009: 5), therefore, improving citizen participation and collaboration (Linders et al. 2013).

Therefore, government agencies around the world are considering how to include social media use into their missions and goals (Mergel and Greeves 2013). However, as the use of social media in government was initiated mostly outside governments themselves (Mergel 2013b), there is no clear understanding how these new capabilities can be used. Furthermore, government agencies are still trying to grasp what benefits social media brings. At the same time, government's use of social media platforms through direct presence in social networks and remaining active in these networks influences its popularity among the audience (Landsbergen 2011). As social media enables government to connect faster and more easily with the public, it allows to get quick feedback about government policies, programs and services. Therefore, if the government is willing to ensure meaningful interaction, citizens are included into decision-making or service delivery networks and the new technology enables them to voice their opinions and share experiences.

Although there is a general consensus that government should use social media (McNutt 2014; Mergel 2012), researchers note existing lack of comprehensive social media policies (Bennett and Manoharan 2017; Jukić and Merlak 2017), holistic evaluation metrics (Mergel 2017) and monitoring frameworks (Loukis et al. 2017). Moreover, governments are using social media simply to broadcast the content already published on the website but rarely focus on public engagement or networking (Landsbergen 2011; Mergel 2012; Lee and VanDyke 2015). Moreover, government agencies in Canada are using social media primarily to disseminate press releases and information about programs and services (Small 2012). 
Thus, as Mergel (2013a, 26) argues, government agencies are "in a reactive mode" to develop regulations, provide guidance and ensure the distribution of best practices as every social networking site is different and requires different ways of content creation and sharing. Moreover, government does not have any control over the rules imposed by third-parties (e.g. privacy regulations) and has no guarantee that no change will be made without its consent (Mergel 2013a).

Scholars state that the main purpose of social media is public engagement and identify two major approaches to research on social media use from an e-government perspective. The first discussion focuses mostly on citizens' participation in public policy, e-consultations and eengagement (e.g. Clarke 2012; Clarke and Craft 2017; Kavanaugh et al. 2012; McNutt 2010, 2014; Longo 2017) and the second discussion focuses primarily on public service delivery (e.g. Dutil et al. 2010; Mergel 2012, 2013; Linders 2012; Roy 2017; Small 2012). These studies stem from the assumption that e-government consequences are different for public engagement initiatives and for public service delivery initiatives. This study incorporates elements of both.

Criado et al. (2013) groups all studies of social media use in government into three broad categories:

1. Tools: what kind of social media resources government uses. Most of the scholars share an assumption that government should be present on the most popular social media tools such as Facebook, Twitter, YouTube, blogs, Flickr, and LinkedIn because they are mostly utilized in society;

2. Goals: what political, social and managerial goals of social media implementation are. Here, the assumption is that government's desire to become more transparent and open means that social media should be used; and 
3. Topics: what kind of theories and methods researchers should apply to study social media use by government. Most of the research is currently focused on social media use in the context of open government, transparency, citizen engagement and interagency collaboration. The most popular topic of discussion is the rise of Government 2.0 (where Government 2.0 is considered to be a new stage of e-government). The focus on topics allows researchers to apply existing theories and methods to the emerging field of the use of social media in government.

It is, therefore, important that research designs incorporate a focus on all these categories to gain new knowledge about why and how governments are using social media. This study, while exploring government use of social media platforms such as Twitter and Facebook (tools), also analyses the goals of government use of social media and apply existing theories of such as network theory, e-government as well as social capital and social networks (topics). Therefore, it explores how government agencies can be more open and transparent while ensuring meaningful interactions with citizens.

Overall, social media use is viewed as a technological innovation and a platform for transformation of communication between government and the public. However, as for previous waves of technology innovation, organizational and contextual factors are essential to understand the results of social media implementation in government (Meijer and Thaens 2013). Organizational factors include: type of government agency, organizational flexibility, management readiness to accept innovations and availability of resources (staff and funding being the most crucial). Contextual factors include: formal policy frameworks and formal guidance on e-government policies, program, initiatives and technologies from the top management. Mergel (2013c) also notes the need to take into account personal factors such as orientation of leaders 
within the agency toward implementing technological innovations, active interaction between leaders across government agencies that are implementing social media and networking.

Most researchers (i.e. Meijer and Thaens 2013; Mergel 2013a, Mergel and Greeves 2013) define effective social media use by government as the presence of interactive and bidirectional communication between government and citizens on government social media accounts. Furthermore, the networking stage where the public is involved in the development of policies and co-production of public services is considered to be the most advanced stage of social media use by government (Bertot et al. 2010). In other words, this indicates that the most important factor that signifies effective use of social media is two-way interactions between government and the public. Moreover, effective government social media content is popular with social media users it receives a high number of likes, comments and is shared between them (Goncalves et al. 2015) as well as generates positive sentiments and makes users come back to government social media (Kagarise and Zavattaro 2017). However, as most of the studies of social media use in government lack citizens' or user perspective, the meaning of effective use for the users' needs to be explored.

There is also a lot of e-government research related to best practices and some indication that best practices vary by policy and service delivery areas. To date, best practices related to the use of social media in government come from the area of emergency management and public safety (Mergel 2014) as well as parks and recreation (McNutt 2014). The goal of much of this research is to document and describe best practices that are then considered by other agencies that are passively observing innovators and learning from their experiences (Mergel 2013c).

Many scholars also explore challenges and barriers to the implementation of social media in the public sector. McNutt (2014: 63-65) mentions that the three most discussed issues in the literature are information management, privacy concerns and security. She also adds lack of 
"public sector social media guidelines and policy frameworks" as well as digital divide and lack of interest in incorporating citizens' feedback in decision-making. According to Mergel (2012), the most significant challenges are: (1) expectations of radical transparency (reluctance of government to provide open access to its operations and decision-making), (2) organizational challenges including strong government preference for top-down approach for information dissemination, and (3) lack of understanding how to measure social media impact, effectiveness and efficiency. Clarke (2012) also mentions accountability constraints caused by difficulty to separate private and official use of social media by public servants.

Therefore, in general, research to date indicates that government is reluctant to use social media because of government organizational culture and technical issues that need to be understood and resolved. At the same time, this new wave of technology adoption in government is still facing the same challenges as earlier phases or stages of e-government: lack of understanding of the need for citizen engagement, traditional public engagement that is bureaucracy-centred, lack of interagency and intergovernmental cooperation and collaboration, as well as silo approaches to tackling this issue from government agencies - all classic public administration and government organization challenges. Nonetheless, the growing scholarship on e-government and social media clearly indicates a need for research on how different jurisdictions and different policy domains are facing these new challenges.

Most of the e-government research remains focused on government organizations and government officials. At the same time, it is important to account for the perspectives of social media users and what they are looking for on government social media resources. Currently, research from this perspective is lacking ( $\mathrm{Lu}$ et al. 2016; Medaglia and Zheng 2017). As the needs of users differ across different policy domains and jurisdictions, it is also important to pay more 
attention to a specific area of government use of social media. Although certain issues and practices can be similar in a number of government agencies, some of them are unique to a specific policy domain. Therefore, there is a need for more research focused on a specific policy and service delivery domains.

In addition, there is now some consensus in the e-government literature that social media tools are very different from government websites where government has full control over administration and information that is being uploaded. The way governments deliver public services also has a potential for a major transformation: governments provide citizens with an innovative channel for information sharing, back-and-forth communication and education that a Web site cannot offer (Linders 2012; Mergel and Bretschneider 2013). By using these resources, citizens can interact not just with government but with each other by reviewing, creating and building on comments of others (Linders 2012). Clarke (2012) argues that social media has a potential to attract more public attention to discussions on public policy, reach out to more people and can provide low-cost option compared to other engagement models. New ways of citizens' participation in the discussion of government policies are becoming different: instead of inviting citizens to interact with government in officially created and run e-participation places, government now has to turn to platforms where citizens prefer to communicate and collaborate (McNutt 2014). Therefore, the use of social media should be included as a part of government agency's communication strategy (Mergel 2013a).

As the focus in public administration has shifted from government to governance, it is clear that ICTs, including social media, have contributed to networked government that emerged as a result of implementation of NPM initiatives and ICT have become a critical component in governing through networks (Henman 2010). Mergel (2013a) notes that social media platforms 
are supported and hosted by third-party organizations. Therefore, government agencies do not control changes that can be made to the interaction routines neither privacy policies. Thus, they become one of many users of social media and do not have any special privileges. By using Web 2.0 platforms, the public sector is becoming even more dependent on partnerships and networks of actors involved in service delivery as government agencies will be no longer be solely responsible for the information that is being shared (Dutil et al. 2010). This reinforces the need for research on government social media use to have a network approach.

\section{Limitations of e-government approach}

Some researchers, however, argue that discussions about the crucial role of the new information technology in government are too abstract, dominated by deterministic views and begin with an assumption that the use of new technology is always positive (Homburg 2008; Henman 2010). Therefore, the scope of such discussions is limited to a single viewpoint. Meijer et al. (2011) develop this by acknowledging that the way government uses new technology is determined by its structures and current practices. Political, social and institutional settings are crucial to understanding the use of technology in government. Thus, the focus should not be only on how technology is changing government and its operations but also on institutional context of its use. Literature on public engagement, civic participation and deliberation provides important context for government engagement efforts and well as discuss existing challenges for meaningful public engagement and the role of technology and different engagement platforms and methods.

Homburg (2008) also discusses popular misconceptions or myths that dominate egovernment and digital government initiatives. He notes an observed lack of cooperation between different government agencies. This leads to lack of integration between different organizational 
databases as well as lack of initiative for information and knowledge sharing thus impeding better public service delivery government agencies are striving for.

Furthermore, e-government and digital government initiatives are often considered to be rational and value free (Homburg 2008). Therefore, most of the times, the need for negotiation between different actors and the need to overcome existing organizational dependencies are unaccounted for. Thus, it is important to acknowledge the gap between the intention of government agencies to improve public service delivery and implementation results.

Furthermore, social media use in government cannot be approached from the positive angle only. Current social media practices in government agencies in Canada make the process of informing and responding to social media users quite cumbersome: there are multiple levels of approvals in order to get the post published, responses that are provided include information that is already available on the website and users who do not speak English or French are forced to communicate in these languages to interact with government officials. Nevertheless, by interacting with social media users, government can correct misunderstandings and ensure that they receive accurate and reliable information.

It is clear that public administration scholars have advanced our knowledge of government use of ICTs significantly in the past two decades. Drawing from this literature, this study is focused on understanding what contextual and organizational factors are contributing to the use of social media by government agencies. Personal factors of public servants are also important especially during the time when there is a lack of official guidance on government use of social media. Much can be learned from detailed examination of specific policies and service delivery domains. Indeed, it is argued here that policy domain and agency specific research is required to fully analyse the use of social media by governments and the relevant users. The e-government literature clearly 
demonstrates that such research can be valuable for those specific domains but also yield findings that are valuable and transferable from one agency to another and even from one jurisdiction to another. Another important body of literature that can aid in extending our understanding of government use of social media is network theory in public policy and administration as at the domain and agency scales it is useful to conceptualize social media use by governments and citizens through a network lens.

\section{Network Theory}

Network theory and research has advanced significantly in public policy and administration and been the foundation of research on a wide range of questions related to policy implementation and service delivery. Much of this research focuses on documenting the structure, function, significance and effectiveness of networks. There is a growing body of scholarship on theorizing networks and some research on the significance of ICT and social media related to networks that is particularly valuable related to this study.

Currently, governments are becoming more dependent on collaboration and networks (Agranoff et al. 2013). As everyday problems that governments face are getting more complicated or "tangled" (Dawes et al. 2009), government officials need to go beyond boundaries of the organizations they represent (Agranoff et al. 2013). By sharing knowledge and information government officials can resolve common issues or improve service delivery as well as facilitate network creation and reinforcement (Dawes et al. 2009). Therefore, government agencies on different levels of government need to interact with each other as well as non-profit organizations and other stakeholders to exchange information, provide better services, enhance capabilities and solve problems (Agranoff 2007). 
Moreover, new participants such as non-government organizations, different levels of government and the public are getting more involved in the policy-making process and public service delivery, thus, making the boundaries between politics and administration blurry (Skok 1995). Public service delivery and program administration experienced serious transformation with for-profit and non-profit organizations as well as regional and local governments becoming direct providers of public services and main implementers of government programs (Frederickson et al. 2012). Therefore, the underlining assumption of the research on the network theory is that understanding the relationships between the actors in a network and the network itself is crucial for understanding policy developments and implementation as well as public service provision.

The interest in networks has grown rapidly in the past decade (Isett et al. 2011; Lecy et al. 2014) and currently there is a lot of effort to understand the complexity of networks and enhance the theoretical base (Keast 2014). Although the research of public administration scholars builds a lot on the work of policy networks and inter-organizational theory (Borzel 1998), today, the agenda of public administration scholars overlaps increasingly with those interested in policy studies but differs from political scientists and sociologists.

The research agenda on networks is complicated because, to date, there is still no universally accepted definition of a network: it varies across different disciplines (Issett et al. 2011; Keast 2014). Raab and Kenis (2007: 188) identify at least four dimensions of the network concept: (1) network analysis as a methodological tool, (2) network as social structure that makes government administration more horizontal than vertical, (3) network as a form of governance that examines the network as a structure but also calls for understanding of the power dynamics and interdependencies among its members and (4) network theory that allows scholars to investigate a 
particular network of actors. Agranoff (2014: 193) also notes the confusion between "a network" and "to network".

Classification of networks differs greatly depending on the scholar's background. Lecy et al. (2014) argue that networks are studied by public administration scholars who are interested in policy formation and implementation. They argue that "it becomes increasingly valuable for individual researchers to clearly define not only the network studied but also the stage of the policy process they are most concerned with" (Lecy et al. 2014: 657). Together with the common terminology, this will facilitate network research. Therefore, the policy cycle approach is used to at least theoretically distinguish between two major types of networks: policy networks and implementation or public management networks.

Isett et al. (2011) distinguish between research on policy networks that are focused on decision-making, collaborative networks that are focused on service provision and governance networks defined as "entities that fuse collaborative public goods and service provision ... and focus on the coordination of organizations towards a common goal rather than the policies or products that networks actually produce" (Isett et.al. 2011: i158). They also distinguish between formal networks (created explicitly for public service provision) and informal networks (forming on ad hoc basis and not having any formally determined membership/involvement).

Networks scholars talk about effectiveness in terms of network performance. Mostly, scholars are interested in understanding if networks work well or fail and why. One approach is focused on examining if the network achieves goals that it was created for (McGuire and Silvia 2009). Another one focuses on network outcomes for each network participant by examining factors (organizational, structural and/or personal) that influence network performance (Provan and Milward 2001). 
Scholars who utilize network theory acknowledge that the focus and goals of public administration research is different from other disciplines. This does not, however, mean that the research in the field of public administration is separated from other disciplines. Lecy et al. (2014) argue that research on governance bring together scholars who are interested in studying policy formulation as well as policy implementation. However, the goals of researchers are different: policy formulation scholars are primarily interested in power dynamics and relations between different actors while policy implementation and public administration scholars are primarily interested in policy and program implementation as well as service delivery and its effectiveness (Agranoff 2014; Agranoff and McGuire 2003; Johns 2013; Kickert et al. 1997; Milward and Provan 2003; O'Toole 1997). There is also a growing recognition of the important role civil society plays in government decision-making (Doberstein 2016). However, there is little research on how individuals from the general public (citizens) impact these networks and if they play any role at all. Table 1 summarizes different approaches to network theory, provides definitions of a network within different research traditions and identifies units of analysis.

Table 1. Four Approaches to Network Theory

\begin{tabular}{|l|l|l|l|}
\hline & \multicolumn{1}{|c|}{ Network Definition } & \multicolumn{1}{c|}{ Unit of Analysis } & \multicolumn{1}{|c|}{$\begin{array}{c}\text { Major } \\
\text { Contributors }\end{array}$} \\
\hline Social Networks & $\begin{array}{l}\text { Set of actors (individuals, } \\
\text { groups, organizations, } \\
\text { nations) and relations } \\
\text { between them (i.e. } \\
\text { communication, trust, etc.) } \\
\text { (Wu and Knoke 2013: 154) }\end{array}$ & $\begin{array}{l}\text { Relations between } \\
\text { individuals, formal } \\
\text { and informal }\end{array}$ & $\begin{array}{l}\text { Borgatti and } \\
\text { Halgin (2011); } \\
\text { Haug (2008); } \\
\text { Burt (1992); } \\
\text { Granovetter } \\
(1973,1983)\end{array}$ \\
\hline Policy Networks & $\begin{array}{l}\text { "Set of public and private } \\
\text { corporate actors linked by } \\
\text { communication ties for } \\
\text { exchanging information, } \\
\text { expertise, trust and other } \\
\text { political resources" (Kenis } \\
\text { and Scheider 1991: 41 as }\end{array}$ & $\begin{array}{l}\text { Relations between } \\
\text { individuals (formal } \\
\text { and informal) and/or } \\
\text { organizations } \\
\text { (mostly formal) }\end{array}$ & $\begin{array}{l}\text { Knoke (2011); } \\
\text { Rethmeyer } \\
\text { (2007); }\end{array}$ \\
$\begin{array}{l}\text { Skogstad (2005); } \\
\text { Marsh and Smith } \\
\text { (2000); } \\
\text { Rhodes (1997) }\end{array}$ \\
\hline
\end{tabular}




\begin{tabular}{|c|c|c|c|}
\hline & $\begin{array}{l}\text { cited in Wu and Knoke } \\
\text { 2013: 154) }\end{array}$ & & \\
\hline $\begin{array}{l}\text { Public } \\
\text { Management/ } \\
\text { Policy } \\
\text { Implementation } \\
\text { Networks }\end{array}$ & $\begin{array}{l}\text { "Structures of } \\
\text { interdependence involving } \\
\text { multiple organizations or } \\
\text { parts thereof, where one unit } \\
\text { is not merely the formal } \\
\text { subordinate of the others in } \\
\text { some larger hierarchical } \\
\text { arrangement" (O'Toole } \\
\text { 1997: 45) }\end{array}$ & $\begin{array}{l}\text { Relations between } \\
\text { individuals (mostly } \\
\text { formal) } \\
\text { Relations between } \\
\text { organizations, mostly } \\
\text { formally established } \\
\text { Network as a whole } \\
\text { entity }\end{array}$ & $\begin{array}{l}\text { Keast 2014; } \\
\text { Agranoff et al. } \\
\text { 2013; Agranoff } \\
\text { and McGuire } \\
\text { 2003; Klijn and } \\
\text { Koopejan 2000; } \\
\text { O'Toole } 1997\end{array}$ \\
\hline $\begin{array}{l}\text { Virtual Policy and } \\
\text { Public } \\
\text { Administration } \\
\text { Networks }\end{array}$ & $\begin{array}{l}\text { "[W]eb-based... networks } \\
\text { that are structured through } \\
\text { the hyperlinks connections } \\
\text { of websites containing } \\
\text { content on a specific policy } \\
\text { topic" (McNutt 2010: 916- } \\
917) \\
\text { Virtual networks between } \\
\text { government agencies who } \\
\text { are represented by public } \\
\text { servants and social media } \\
\text { users }\end{array}$ & $\begin{array}{l}\text { Relations between } \\
\text { government/state } \\
\text { actors and non- } \\
\text { government actors } \\
\text { such as citizens, } \\
\text { advocacy groups and } \\
\text { non-government } \\
\text { organizations }\end{array}$ & $\begin{array}{l}\text { McNutt and } \\
\text { Wellstead 2010; } \\
\text { Petroczi et al. } \\
\text { 2007; McNutt } \\
\text { 2006, 2010, } 2014\end{array}$ \\
\hline
\end{tabular}

As noted above, there is no clearly established definition of a network. This creates more confusion for researchers using network theory: what they are studying - interpersonal relationships between individuals who are the members of networks or relations between organizations and more specifically between government and non-state institutions (Skogstad 2005). Therefore, the challenge is to understand whether "the attributes of network itself or the actors in the network ... are the primary focus" (Johns 2013: 14).

Skogstad (2005) notes that although the individual actors in the network are important, it is even more important to understand the network structure and context within which it is operating. Rhodes (2007) emphasizes the need to understand the link between individual actors in the network and the structure of the network. Public management scholars (Feiock and Scholz 2009; Isett and Provan 2005; McGuire and Agranoff 2014; Voets 2014) study networks from a 
utilitarian perspective - to understand public service provision (Isett et al. 2011). Therefore, they are mainly interested in formal networks of organizations and management roles of individuals within the networks. However, there are some network scholars interested in the significance of ICT for policy and public administration networks.

With the spread of the Internet, the access to any kind of networks (social, policy or public management) has become much easier than ever before. In order to reflect this technological development, scholars are differentiating between real and virtual networks (McNutt 2006, 2010; Petroczi et al. 2007). McNutt (2010) analyses virtual policy networks and points out that these networks use the Internet as a communication platform but their main goal is to include nontraditional actors such as non-profits, advocacy groups, think tanks, etc. in policy processes. Petroczi et al. (2007) believe that virtual social networks "mirror" the "real" ones. However, the policy and public administration role of virtual networks needs to be explored further.

This study analyses the existence of virtual public management and/or policy networks created and sustained by the government use of social media platforms and resources. Networks are conceptualized here as both policy implementation and public management networks and as virtual networks that are aimed at including individuals and non-government actors in policy development and public service delivery. However, the focus is primarily on existing virtual networks between government and members of the public, both domestic and international. Relationships and exchanges government agencies have with other organizational actors such as non-profits, commercial companies (e.g. law firms and immigration consulting companies) and advocacy groups are also examined.

Theoretically, by examining social media use at the agency level, this research hopes to be able to determine if such virtual networks exist, if public officials and users themselves identify as 
being part of networks and if so, how important these networks are to understanding social media use in government. For example, studying social media accounts of government agencies, theoretically and methodologically allows for some examination of interactions and relationships between government and the public on social media as well as the interactions and relationships between social media users themselves. It is important to note that the existence, boundaries, structures and functions of government social media networks are thus an open question related to governments and social media use.

\section{Limitations of Network Theory}

Whether networks exist, what actors are part of the network, network boundaries, structures, functions and significance are all important questions in public policy and public administration research. However, there are some important theoretical and methodological limitations that need to be highlighted when using network theory. Certain scholars believe that networks lack theoretical consistency as they describe rather than explain the process and outcomes (Borzel 2011; Salancik 1995; Dowding 1995; Klinj and Koopenjan 2000). Moreover, network scholarship in public administration often neglects to account for the role of power by placing too much emphasis on the need for collaboration. Thus, conflicts and power differences between network actors are not taken into account (Klinj and Koopenjan 2000).

Another challenge is lack of consistency between researchers in defining what a network is and abstractness of network theory (Keast 2014; Klinj and Koopenjan 2000; Lecy et al. 2014; Wu and Knoke 2013). Wachaus (2009) notes the fragmentation in the literature on networks and points out the different use of network in different context. Thus, some researchers use the term to

describe the structure and some to talk about the process; some believe that networks exist and 
some use network as a metaphor that helps to organize thinking about real life processes (Wachaus 2009).

Moreover, the confusion goes even further because networks are being used as a theory, method and concept. According to Wu and Knoke (2013), many researchers are confused if networks should be treated as dependent or independent variable or how networks concept is helpful for understanding network formation and development or predicting outcomes. Knoke (2011) notes that network theory failed to develop testable hypothesis and/or propositions. All these prevent researchers from getting empirically accurate results (Berry et al. 2004).

The problem becomes even more critical when scholars continue to mix different elements of network theory from different disciplines rather than focusing on specific elements of networks in the public sector. Therefore, Wachaus (2009) state that there is still lack of coherent scholarship on networks. Mandell (2014), Keast (2014) and Agranoff (2014) acknowledge the need for more theory-building and theory testing.

Another issue identified by Keast (2014) is methodological challenges and theory testing in network studies: currently researchers use qualitative methods (with single case study being the most popular one), quantitative studies with a mid-range number of networks under review and quantitative studies that apply social network analysis. Therefore, it is difficult to compare the results of different studies that use different methodologies and even more difficult to produce generalizable results.

Whatever research methods are used, it is possible to observe networks and it is clear from scholarship to date that networks do vary by policy domain and service delivery area. In this study, some of these limitations are overcome by focusing the research at the policy domain or organizational scale. Immigration agencies have been selected to see if such network exist on 
government-hosted social media platforms and whether network theory offers some potential for advancing our understanding of government and user actors in social media spaces. Given the focus on immigration agencies, a third body of interdisciplinary scholarship is also relevant to this study - the studies of immigration and use of social media.

\section{Migration Studies, Migrant Networks, Technology and Social Media}

One policy domain that is particularly valuable for examining use of social media within and across jurisdictions is immigration. The case of immigration agencies' use of social media is interesting because immigration agencies in Canada are using social media accounts to communicate with both domestic and international users, particularly related to attracting skilled immigrants to Canada. Scholars from a relatively new interdisciplinary field of migration studies have been interested in research questions related to policy, migration and use of technologies in the migration process in the past decade. Drawing on the interdisciplinary literature on social capital and social networks, this body of literature offers some important concepts and factors that can be examined related to the use of social media at the interface of governments, Canadian citizens and permanent residents as well as potential migrants - all different users in a complex policy and service delivery area.

In migration studies, there is a lot of focus on the concept of social capital in understanding migrant networks, immigration policy, the immigration process and the use of social media. The concept of 'social capital' is interpreted differently and used across a number of disciplines such as sociology, economics, political science, information science and business. It is a useful concept that can be used to further our understanding of social media exchanges between governments, Canadian citizens and residents as well as potential migrants. 
Although Field (2003: 1) notes that the essence of the concept of social capital can be summarized just in two words: "relationships matter". Lin et al. (2001) argue that lack of conceptualization of social capital can lead to oversimplification of its meaning. Bourdieu (1986) and Coleman (1990) are the founding theorists of the concept of social capital as they were the first ones to systematically introduce this concept (Häuberer 2011). It was further developed by Putnam $(1993,2000)$, Burt $(1992,2000)$ and conceptualized by Lin (2001).

The definition of social capital varies among different disciplines. Bourdieu (1986) states that social capital aggregates resources collectively owned by members of a network. These members relate to one another through mutual acquaintance and recognition. Coleman (1990), on the other hand, states that social capital belongs to any member but is shared as a public good, which makes it accessible for any member of a group. Scholars also differentiate between different types of social capital. Putnam (2000) introduces two different categories of social capital bonding social capital (getting benefits from interaction with people similar to oneself) and bridging social capital (getting benefits from interaction with people who are different from oneself but who might be able to provide assistance in specific situations such as job search or advice).

The concept of social capital is widely used in migration studies to explain migration decision-making and facilitation of migration (Massey et al. 1987; Flores-Yeffal 2013), migrant settlement and integration (Menjivar 2000; George and Chaze 2009a; Zhao et al. 2010) and employment patterns and choices (George and Chaze 2009b; Xue 2008). Boyd (1989) puts emphasis on importance of social capital rather than economic factors in fostering and facilitating migration. Furthermore, a lot of emphasis is given to the negative effects of social capital on migration such as inequality of access to benefits between migrants and members of receiving society, pressure on group members to act in a certain way, unrealistic expectations regarding 
opportunities for migrants and restrictions of personal freedom (Portes 1998; George and Chaze 2009a; Zhao et al. 2010).

Social capital is distributed through social networks and these networks increasingly use social media. Therefore, scholars in migration studies are interested in understanding how immigrant social networks are created and sustained. This work draws a lot on the work of Granovetter (1973) who distinguishes between the value of having family and friends (strong ties) and distant acquaintances (weak ties). He argues that weak ties are becoming more important in modern society as a mean of finding employment or getting a better job. Thus, building personal network becomes of paramount importance, as it gives access to employment opportunities and important professional connections.

Boyd (1989) stresses the importance of family and personal networks (strong ties) in migration process. At the same time, weak ties play equally important role in it. As originally noted by Massey et al. (1987), migrants rely a lot on their social networks (Liu 2013). Therefore, the underlining assumption of this body of literature is that migrants can draw upon these networks to gain access to foreign employment and other benefits through ties of kinship, friendship or simply because of sharing the same geographical location (Massey et al. 1993).

Migrant social networks can be both formal and informal. Formal networks involve official organizations, which offer services to meet various migrants' needs, and informal networks consist of friends and family that can be approached for help (George and Chaze 2009a). Thus, migration is understood as a dynamic movement that is dependent on social networks (Alonso and Oiarzabal 2010). As noted by Dekker and Engbersen (2014), the analysis of migrant social networks is really the key to understanding the dynamics of migration processes. Therefore, the concepts of social capital and social networks are crucial for my study in terms of understanding what information is 
being shared through social networks created on social media. However, the focus is not on collecting data to analyse social capital specifically but rather to use social capital as an important concept while analysing social network data related to the central research questions.

Although the dominant view in literature is that social networks assist in migration, Liu (2013) points out that there is still a lack of understanding of how exactly networks are benefiting or obstructing during the migration process. For example, as the initial desire to migrate might be shaped by family or friends, getting settled and finding employment will most likely depend on "weak ties". Furthermore, according to Liu (2013), the concept of ties might be relevant for the job search but is not necessarily capturing the complexity of migration process and the role of extended family and friends in it. Also, as noted by Flores-Yeffal (2013), most scholarly work in migration studies emphasizes the importance of migrant networks but fails to explain how exactly social support is exchanged, not only at the micro level of analysis but also at the macro level. There is also a lack of understanding of how social media is used in these networks of 'weak ties'. Thus, further research is needed to understand what motivates members of a social network to provide assistance to new members and in what the ways social media is being used in this policy domain. Therefore, the effective use of social networks can be considered as a use of "network resources' by a potential migrant in order to obtain personal benefits during the migration process. Social media is increasingly considered part of these network resources.

In recent years, as ICTs and social media have developed, it became even easier to gain access to social capital through social networks from any country in the world. Benckler (2006) points out a radical change in recent decades in the organization of information production that caused structural transformations in the society. Now social networks exist both in physical reality and in virtual reality. This new functionality encouraged Lin (1999) to go further than simply 
considering social networks as an element of social capital and develop a notion of cybernetworks. He claims that "cybernetworks are social networks in cyberspace" (Lin 1999: 42).

However, cybernetworks do not substitute existing social networks but rather compliment them. Online participation is an important tool to increase social capital, moreover, members of a network interact with each other because they are sharing similar interests rather than the same location (Hiller and Franz 2004). Furthermore, virtual social capital can be accessed through the use of ICT, including social media, during every step of migration process. In addition, it is not bounded by any geographical area.

New technologies ensure new level of connectivity and encourage dissemination of information among members of social networks including potential immigrants. However, the discussion aimed at understanding the role of ICT in immigration did not start until late 1990s. Much of the discussion was initiated by the work of Castells (2010) who pointed out that the revolution of communication technologies contributed to creation and sustainability of social networks in knowledge societies. This was further developed by migration studies scholars who note that the existence of migrant networks is greatly facilitated by ICT (Adams and Ghose 2003; Alonso and Oiarzabal 2010; Hiller and Franz 2004). However, this research is specifically focused on a certain ethnic group such as South Asians, Chinese, etc. and investigates this group's practices and routines online. Nevertheless, it is widely acknowledged that ICT facilitates information exchanges and knowledge sharing among migrants (Alonso and Oiarzabal 2010).

Another body of research looks at migrants' information needs (e.g. Caidi et al. 2010; Caidi 2008; Shoham and Strauss 2008). According to these scholars, migrants are a distinct group of information seekers with specific information needs. These include the need to understand how to get employment, access healthcare, schools, etc. (Caidi et al 2010; Shoham and Strauss 2008). At 
the same time, immigrants are interested in information about ethnic communities from their country of origin (Shoham and Strauss 2008).

Nowadays, with the widespread of the Internet, it has become a very important source for information on migration (Alonso and Oiarzabal 2010; Caidi et al. 2010). The literature on information-seeking behaviours of migrants is, however, primarily focused on understanding what resources a particular ethnic group uses to get information they are looking for (Hakim Silvio 2006; Kim 2013). As Kim (2013) notes, people usually reach out to their family and acquaintances for advice first but the Internet quickly has become a very popular alternative source for information on migration. Therefore, the Internet plays an important role in obtaining information (Ros 2010). However, little research examines how social media is used by migrants to Canada.

There are different theoretical models that are aimed at explaining why individuals and organizations are adopting technology. These include the Theory of Diffusion of Innovations, the Technology Acceptance Model, the Unified Theory of Acceptance Use of Technology and the Users and Gratifications Theory (Gruzd and Goertzen 2013). However, to date, the research on the use of ICT in migration is focused on examining how the ICT helps or hinders immigration and is based on assumption that, whenever possible, immigrants will use ICT to facilitate the migration process.

ICT use across borders and continents makes geographic boundaries blurry (Hiller and Franz 2004). Individuals are no longer isolated from their families and friends when they leave their home country (Komito 2011): they can communicate without spending too much money and find new friends and even potential employers. Therefore, the Internet gives migrants an opportunity to stay connected with their families and relatives, cuts communication costs and ensure the flow of information between immigrant's country of origin and the host country. 
Web 2.0 applications brought further significant changes in people's online experiences and interactions (Huang and Guney 2012). As recent studies (Komito 2011; Dekker and Engbersen 2014) show, significant number of migrants uses social media tools for different purposes: to obtain and exchange information, to stay in touch and to get introduced to useful connections. Although the primary reason for the use of social media is maintain connection with friends and family (Komito 2011; Dekker and Engbersen 2014), its role in creating and disseminating information should not be underestimated. As Dekker and Engbersen (2014) note, social media is being used to obtain information and to exchange streetwise knowledge on migration. They view it as an advantage for migrants who can now resist restrictive immigration policies. Thus, by using social media potential immigrants may get in touch with people in the destination country or even countries where they consider migrating. Therefore, Dekker and Engbersen (2014: 402) argue that social media "actively transform[s] the nature of [migrant] networks and thereby facilitate[s] migration". The use of social media by migrants is largely predetermined by its perceived value: information that can be obtained on social media platforms cannot be instantly obtained elsewhere.

Social media can also provide a means of communication with weak ties that can be used in the process of migration and settlement (Dekker and Engbersen 2014). Through communication within a social network, one can get in touch with people who can provide necessary assistance themselves or refer to somebody they know. Thus, it becomes a useful tool in developing and strengthening weak ties (Haythornthwaite 2002) and makes virtual social networks more accessible and easy to navigate through.

Another important discussion in the literature is about the role of social media in creating an infrastructure of latent ties (Haythornthwaite 2002, 2005; Komito 2011). Latent ties are evident through virtual social networks and can be transformed from latent to weak ties if users start to 
communicate with each other on a regular basis (Dekker and Engbersen 2014). Through access offered by social media, users can create networks and become their members based on commonly shared interest (Haythornthwaite 2005). Also, many social network groups within social media sites might not require a rigorous registration process: many have open access and can be joined by anyone who is interested and some require easy approval by the site administrator. Thus, most of the time, the only criterion to separate members from non-members is the ability to communicate in a certain language. Therefore, social media provides interested people with a point of entry to a social network and helps to connect individuals who otherwise will not know each other (Haythornthwaite 2005).

As shown on Figure 2, while both "real" (physical) social capital and network capital enable strong and weak ties, latent ties are unique attribute of network capital. They can be developed into strong or weak ties or can remain latent.

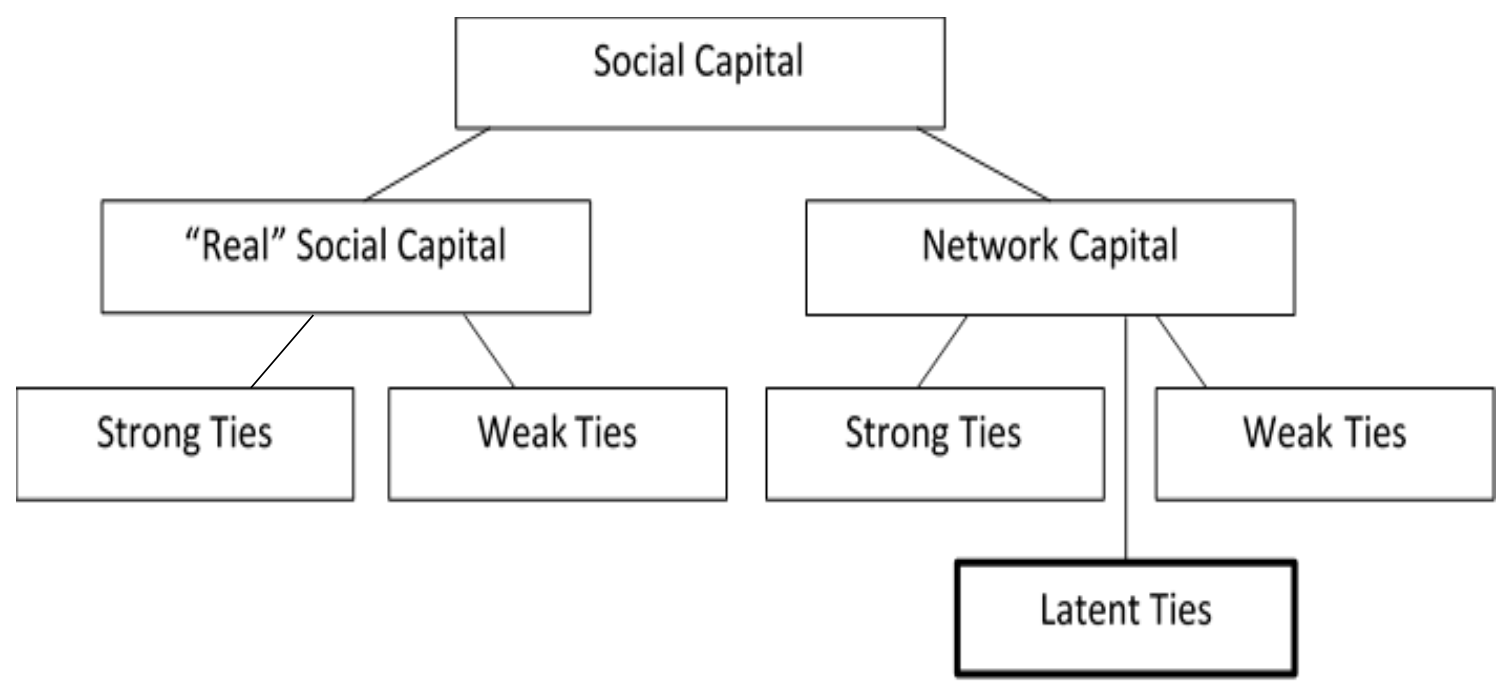

Figure 2. Social Capital and Network Capital

(developed from Haythornthwaite 2002, 2005; Komito 2011) 
This study integrates insights from network theory in public policy and administration with insights from this research in migration studies to try and examine the value of the concept of latent ties for understanding government and user interactions on social media. Members of a particular social media platform might not consider themselves as a part of a network and might not engage in conversations with other participants but simply use it as an information resource. The more authority a particular member has in a group, the more is the likelihood that his/her opinions and interpretations are considered as valid and truthful without questioning. This raises serious concerns about information available on migration process and the role of government actors and officials in these networks: although it can be helpful to get information (Dekker and Engbersen 2014), it can also deceive people who want to clarify government policies and practices. On the other hand, social media platforms have the potential to create virtual policy networks and/or virtual service delivery networks with latent ties that may develop into weak ties or even social capital where government officials, Canadian citizens and permanent residents, and potential migrants have an opportunity to read government responses as well as get information about individual experiences and acquire streetwise knowledge of migration. This research will, therefore, examine what kind of ties are evident in social media use and exchanges between government immigration agencies and different users.

Latent ties can play an important role on government social media. Users can just skim through posts and messages left by other users and government agencies. Therefore, the quality and accuracy of information that is shared through the online networks created by government and migrants is really important. Moreover, if online networks are underdeveloped, it may lead to nongovernment actors taking on the role of information providers on migration process. 


\section{Limitations of Migration Studies' Approach}

As an interdisciplinary field, migration studies have a number of limitations. First, as researchers come from a variety of disciplines, they tend to rely on theoretical and empirical traditions of these disciplines in their studies. This leads to differences in understanding of concepts, approaches to research methods and interpretation of results. Furthermore, studies of migrant use of ICT are predominantly qualitative and scholars tend to focus on a specific ethnic group of migrants and study them. This poses limitations on the findings as different ethnic groups have different history and experiences with migration (i.e. certain ethic groups are forced to leave their home countries to avoid persecution while others migrate to maximize economic opportunities). Finally, scholars who study migrant social media use tend to focus mostly on the positive effects this technology bring. They tend to assume the information on the Internet can help to make a decision about migrating and prepare for the new life in the host country. This, however, might not be necessarily the case as the Internet contains a lot of deceiving and false information. The main reason for why this topic remains largely unexplored is the primary focus on the migrant networks themselves and excluding other influential actors such as bona fide lawyers and immigration consultants as well as fraudsters posing for them.

This study addresses some of the limitations discussed above. It stresses the need for government to be a provider of reliable and accurate information on migration issues. It also touches upon deceiving and/or fraudulent information that is circulating on government social media resources and potential negative impacts it can have on migrants. 


\section{Theoretical Assumptions and Foundations of Research}

This study looks to overcome limitations of the individual bodies of literature it builds on to better understand the use of social media by government agencies generally and specifically related to migration and immigration. By combining, e-government, network theory scholarship and migration studies my research fills several existing research gaps in the literature. The analysis focuses on interactions and relationships between government immigration agencies and social media users created with the help of social media as well as on information that is shared during interactions and its quality. This helps to examine if relationships exist as well as consider how these relationships could or should develop to benefit migrants and government immigration agencies.

E-government research brings an important perspective on the use of social media in government: the value of social media resources both for government and for users. It also puts a lot of emphasis on the efficient and effective use of government resources and importance of public participation in government. The scholarship on e-government has clearly documented the widespread and varied use of ICTs for a wide range of public policy and public administration purposes, documented and described the evolution of e-government over various stages, and contributed to theories of adoption and use. The scholarship has also recently documented how e-government has evolved alongside of e-governance, outlining that research on social media use by governments need to move beyond just a focus on government agencies and officials and include a focus on both state and non-state organizations and actors.

Network theory allows this research to focus on individual actors in a network, the network itself as well as the relationships developed within the network. At the same time, it emphasizes the central role of government. This is very important for my research in order to examine existing 
relationships between government and migrants that are created with the help of social media. Virtual network approach and broader network theory developed in policy studies and public administration literature are used to conceptualize networks that can be developed on government social media platforms. This includes a focus on a set of actors (individuals, groups, organizations) and relations between them (i.e. communication, trust, etc.) (Wu and Knoke 2013: 154).

By drawing on research and concepts from migration studies, this research also takes into account policy domain and agency specific context and factors as well as a specific focus on users' needs and specifically migrants' needs and values related to government use of social media. This approach also allows for an examination of the possible consequences related to lack of government presence and activity in migrant social media networks such as dissemination of inaccurate information about government immigration programs, creating false expectations about the opportunities in the host country and discouraging applications from qualified candidates. Using an e-government, network theory, immigration policy domain and agency-specific approach also allows for analysis from a government perspective, which is crucially important related to the four central research questions.

In summary, Table 2 summarizes theoretical assumptions drawn from these bodies of literature.

Table 2. Theoretical Assumptions

\begin{tabular}{|l|l|l|}
\hline Literature & Theoretical Assumptions & $\begin{array}{l}\text { Importance for My } \\
\text { Research }\end{array}$ \\
\hline E-government & $\begin{array}{l}\text { 1. Government agencies should } \\
\text { use social media to ensure } \\
\text { two-way interactions with the } \\
\text { public. } \\
\text { Government agencies are } \\
\text { struggling with the effective } \\
\text { use of social media. }\end{array}$ & $\begin{array}{l}\text { Using an e-government } \\
\text { perspective will allow for an } \\
\text { assessment of the current } \\
\text { capacity, extent to which } \\
\text { governments are using social } \\
\text { media, and the effectiveness } \\
\text { of this use. It will also allow } \\
\text { for an analysis of whether the }\end{array}$ \\
\hline
\end{tabular}




\begin{tabular}{|c|c|c|}
\hline & $\begin{array}{l}\text { 3. Government official personal } \\
\text { factors matter in terms of } \\
\text { network outcomes. }\end{array}$ & $\begin{array}{l}\text { use of social media creates } \\
\text { any additional benefits for } \\
\text { government immigration } \\
\text { agencies that did not exist } \\
\text { before. }\end{array}$ \\
\hline Network theory & $\begin{array}{l}\text { 1. Social media creates ad hoc } \\
\text { network structures between } \\
\text { government agencies/actors } \\
\text { and migrants/users. } \\
\text { 2. Relationships between } \\
\text { government officials and } \\
\text { migrant users matter. } \\
\text { 3. Individuals may become new } \\
\text { or important actors in virtual } \\
\text { networks through the use of } \\
\text { social media. }\end{array}$ & $\begin{array}{l}\text { Analysing virtual networks } \\
\text { created by the use of social } \\
\text { media, allows for analysis } \\
\text { and conclusions about: } \\
\text { 1. what kind of social media } \\
\text { relationships exist } \\
\text { between government } \\
\text { agencies/actors and } \\
\text { migrant users; } \\
\text { 2. if these social media } \\
\text { networks exist or not; } \\
\text { 3. if these relationships } \\
\text { matter or are considered } \\
\text { by government actors in } \\
\text { the network. }\end{array}$ \\
\hline Migration studies & $\begin{array}{l}\text { 1. Use of social media is } \\
\text { facilitating migration. } \\
\text { 2. Migrants use social media to } \\
\text { gather information, share } \\
\text { experiences and expectations } \\
\text { about immigration programs } \\
\text { and services. } \\
\text { 3. Government is not present or } \\
\text { active in migrant social } \\
\text { networks. }\end{array}$ & $\begin{array}{l}\text { By examining the importance } \\
\text { of social media in } \\
\text { information gathering and } \\
\text { sharing, the research will } \\
\text { examine the importance of } \\
\text { two-way interactions between } \\
\text { government agencies and } \\
\text { migrants on social media. }\end{array}$ \\
\hline
\end{tabular}

\section{Conclusion}

To date, the research on social media use in public administration has been focused on perspectives of government officials, while the research in migration studies does not account for the government use of social media and presence in migrant networks. There is a lack of understanding about social media use in different policy domains and users' perceptions of social media content created by government agencies. This study fills an existing gap in knowledge by 
exploring social media use by both government and migrants, and exploring the value of conceptualizing government use of social media though a network perspective.

This study also further develops the notion of effective use of social media developed by e-government scholars and focuses on the importance of two-way interactions between government and the public on social media platforms. By taking into account perceptions of effective government social media use by users, this research attempts to use a social network/social capital effectiveness perspective and allows for analysis of the perceived benefits of using government social media platforms for migrants.

By combining theoretical assumptions and previous research findings from e-government, network theory and migration studies, this study seeks to advance and test three sets of factors related to four central research questions that can help explain why and how government and migrant users are using social media for policy and service delivery and what factors are most significant as determinants of effectiveness:

- Network factors: existence of loose virtual network between migrants and government actors; structure of the network; perceived function of the network; value of information exchanged in the network; importance of latent ties; frequency of interactions and information exchange; level of customization related to exchanges; network perceived as contributing to agency/immigrant goals, network/social media allows getting feedback that could not be gathered otherwise.

- Organizational factors: type of government agency, organizational flexibility and availability of resources (staffing, funding and available expertise); kind of information being shared; organizational culture. 
- Individual/personal factors: socio-demographic factors; characteristics of providers/users; experience with social media; personal goals related to use; leaders within the agency/immigrant group are oriented toward implementing technological innovations; perceived value of social media to officials' goals and users' goals. 


\section{Chapter 3. Methodology and Research Design}

The purpose of this study is to understand why governments and migrants are using social media and if government immigration agencies can use it more effectively. In addition, one of the goals is to generate knowledge that is useful for this policy domain but also more broadly for scholars, policy makers and practitioners. The research has been designed to generate data and analysis related to the four key research questions outlined in the Introduction:

- How and why is social media being used by government immigration agencies?

- How and why do migrants use government social media resources?

- Do relationships created between government agencies and migrants on social media matter and why?

- To what extent do governments effectively use social media?

As outlined in Chapter 2, both public administration and migration studies scholars have focused on understanding government and migrants' perspectives of social media use primarily using qualitative methods (Clarke 2012; Hrdinova et al. 2010; Francoli 2014, 2017; Komito 2011; Dekker and Engbersen 2014; Longo 2017; Small 2012). For example, Clarke (2012) used a research design that included content analysis of government Twitter accounts and 30 semistructured interviews with public servants from different federal departments of the Government of Canada to find out if government is using social media to engage with citizens and identify barriers for the social media use in government. Small (2012) collected Twitter data from 41 accounts of Canadian federal government agencies to conduct content analysis. Hrdinova et al. (2010) conducted 28 interviews with public servants from 14 government agencies and also reviewed 26 social media policies and guidelines to identify core elements of a government social media policy and the enablers for the use of social media in government. Longo (2017) analysed 
seven cases of citizen and stakeholder engagement in pre-digital and digital era in order to understand how governments are using new technology for public engagement. Lu et al. (2016) with the help of e-government agency of a major Chinese city recruited 40 Chinese citizens to discuss their experiences with the government microblogging platforms, examine their perceptions and solicit comments.

Studies of social media use by migrants mostly rely on in-depth interviews as a primary data collection method. For example, Komito (2011) conducted in-depth interviews with 65 immigrants in Ireland to find out if immigrants use social media to stay connected to their country of origin and in the processes of migration and integration. Dekker and Engbersen (2014) conducted in-depth interviews with 90 immigrant participants in the Netherlands to investigate ways social media affects migrant networks.

This study adopts a different approach: although the study looks to fill the gap in literature by understanding social media user practices and experiences with government social media, it also examines government social media posts and perspectives of public servants on the current state of social media use and suggestions for moving forward. It is, however, important to note that government social media users do not solely include those who post comments but also those who read through available content. Nevertheless, it is impossible to estimate how many people just skim through social media posts for information purposes and do not leave a comment. Thus, this study will focus on those users who left a comment. Government officials' experiences and existing networks created on government social media accounts are also studied in detail.

Therefore, qualitative methodology that relies on several qualitative methods such as content analysis, in-depth interviews and analysis of government policies is a natural choice for the study. According to Creswell (2013), qualitative inquiry relies on collection of data from 
different sources to complement each other. In addition, results from interviews, content analysis and analysis of government policies can be used to triangulate research findings, therefore, reinforcing them (Creswell 2013).

\section{Methodology}

The study develops its findings mostly from qualitative methods of inquiry (qualitative content analysis, semi-structured interviews and analysis of government policies) and analysis of social media data. However, it is important to note that social network analysis was also used during preliminary analysis to identify existing network structures and actors between government and social media users to determine both the government and the migrant users' to target for qualitative data collection.

This study uses the following methods:

1. analysis of existing open government policies and social media strategies;

2. content analysis of social media posts on immigration agencies social media accounts published by government officials and users;

3. semi-structured interviews with government officials and social media users.

The use of secondary sources and the qualitative foundations of research allows for data collection related to the context in which the study occurs: significant events happening at the time of the study, government structures and hierarchy that might influence the way government uses social media, as well as the policies and design of government social media platforms all happen within a certain context. Each of the methods used has strengths and weaknesses. However, by using a mix of research methods I am able to triangulate my findings as well as develop deeper understanding of the use of social media by government and users. 


\section{Analysis of Policies and Other Government Documents}

Since 1970s, public policy scholars have emphasized the need to examine policies and their outcomes between different jurisdictions within the same country and between different countries (Gupta 2012). They use a variety of theoretical frameworks and methods to discuss how and why policies are different and explain the differences they discover. Although policy outcomes are very much the primary focus of these research studies, scholars use officially published policy documents (such as legal documents, government directives and operational manuals) as a starting point for their analysis (e.g. Steinmo 2003).

This study, however, does not provide a comparative analysis of social media use by government in different countries. It mostly focuses on the Canadian context and experiences of Canadian immigration agencies. However, comparison of Canada's open government policy, approach to the government use of social media as well as social media strategies applied by government immigration agencies provides this study with valuable insights on how different countries approach social media use in government. Two developed countries - Australia and New Zealand - that are actively recruiting new immigrants (Ongley and Pearson 1995; Akbari and MacDonald 2014) were selected for analysis based on secondary data sources discussed above. Moreover, these countries are members of the OGP and are currently implementing open government policies.

Analysis of open government policies and social media strategies uncovers a set of principles the government itself and social media users are supposed to apply while interacting with the government on social media platforms. While open government policies speak more to government priorities in the use of social media, social media standards and guidance outline principles and rules that government agencies should follow while interacting on social media. 
Thus, analysis of these documents is important to determine how social media channels should be used by government agencies in different countries. The results of analysis of these government documents are discussed in Chapter 4.

At the same time, these documents do not specify every aspect of the use of social media in government. Moreover, the level of implementation of principles and practices proclaimed in these documents varies and depends on the government agency and its senior management. Thus, although these documents are important to understand government social media frameworks, they mostly discuss how social media should be used rather than how it is used in practice.

Contextual analysis of government documents offers important insights to the first central research question of the study - how and why is social media being used by government immigration agencies? It helps to situate government use of social media in a broader context of open government and e-government as well as allows to see how these broader principles are operationalized in social media documents that regulate government-wide and agency specific use of social media. Furthermore, analysis of these secondary sources provides a basis for comparison with the results of content analysis of collected primary social media data and for making conclusions about the differences in prescribed use of social media and its actual use.

\section{Content Analysis}

Content analysis is a popular research method in communication studies that equips researchers with tools to analyse text or visual material, including videos, photographs and other multimedia sources. It allows researchers to see the data not as static elements but as messages (articulated by text, image and/or other observable elements) that have a meaning for interpretation (Krippendorff 2004). Initially, content analysis was primarily used in media and communication 
studies but quickly spread into other social sciences (Krippendorff 2004). Today, it is used way beyond the fields it originated in - researchers in political science, psychology and business are adopting this method in their studies.

In its most conventional way, content analysis is viewed as a way to describe a phenomenon that is studied and interpret its meaning based on the data (Hsieh and Shannon 2005). Krippendorff (2004) notes that content analysis allows researchers to interpret text and other visual materials and determine the context of their use. It is most useful to identify key topics and other important trends that emerge from the data and systemically analyse large volumes of data (Hsieh and Shannon 2005). Thus, many texts and other visual material can be broken down into categories, ideas or topics (Drisko and Maschi 2016).

Messages that are contained within studied data have meaning that is attributed to the data themselves or is generated during data analysis (Krippendorff 2004). In other words, researchers rely on the characteristics of the data or on own interpretation of the content to make conclusions. Although these approaches are not mutually exclusive, the first one is mostly common for quantitative content analysis, where a researcher counts key words and/or other elements of content to make interpretations and describes it using statistics. Second approach, where a researcher interprets meaning of collected data through coding and identifying common themes, is more common for qualitative content analysis (Hsieh and Shannon 2005).

Content analysis is a popular research method to study social media data (e.g. Clarke 2012; Lai and To 2015; Chung and Zeng 2016). It allows researchers to better understand behavior, beliefs and values of those who use social media for different purposes (Lai and To 2015). Moreover, it equips researchers with tools to interpret social media users' views, sentiments and 
attitudes, both positive and negative. Therefore, researchers can make assumptions about user preferences and popularity of certain social media platforms.

Most studies rely on a combination of qualitative and quantitative content analysis. This study is no exception. Elements of both qualitative and quantitative content analyses are used to determine types of messages being shared and topics that are addressed by government and social media users. First, visible attributes of tweets and posts (such is if a post is @ user messages or is a reply, retweet or a share, mentions/tags another user or contains a link to a website) are identified. Second, tweets and posts are interpreted and classified based on their types (e.g. feedback, opinions, information) and topics/themes (e.g. related to a specific immigration program or service, technical issues or questions about application process). These categories and coding process are discussed later in this chapter.

Content analysis can be manual and computer-assisted. While in the past, researchers were mostly interpreting and categorizing text and other visual material manually, the development of lexical and semantic software provided them with a wide variety of tools for using computer algorithms to identify and code messages that they study. However, there is no single approach that can be applied to any study: the choice between manual and computer-assisted content analysis depends on the types and amount of data being analysed and research questions that need to be answered (Alexa 1997).

Computer-assisted content analysis works best in the situations when the interpretation of the meaning is relatively simple, i.e. to identify key words or if a message contains not just text but other visuals such as images, symbols and web links. However, the biggest disadvantage is that automatic coding does not account for the context of the message. 
Manual content analysis requires that the researcher or a team of researchers examines and interprets the data. Cavazos-Rehg et al. (2016) note that this approach allows to better understand the details of content and experiences of those who post. The biggest concern, however, is the consistency of manual coding over time and inability to process large volumes of data. In practice, researchers rely both on computers and own judgment to perform content analysis (Hsieh and Shannon 2005). Sampling techniques are used to make sure that analysis remains manageable but data integrity is not compromised.

As mentioned before, content analysis plays a key role in this study. It is used to analyse information/messages that are being shared on government social media platforms. This includes kinds of information shared by government agencies, kinds of information shared by users, if there is any misleading information and if there are references to official government websites. Thus, content analysis equips me with tools to make conclusions about the content that is being provided, if migrant users find it useful (share this information elsewhere, comment on it and their feelings about information that is being provided) and about the popularity of these resources among migrants.

\section{Semi-structured Interviews}

Interviews are one of the most popular qualitative research methods in social sciences (Kvale 2007). This popularity can be explained by the need to learn about participants' perspectives and experiences that cannot be obtained in any other way. By conducting interviews, a researcher gets access to the lived experiences of participants, who describe their actions, feelings and opinions. The conversation style of an interview also allows researchers to follow up on participants' answers to clarify and expand their statements (Kvale 2007). 
The researcher controls structure and purpose of the conversation during the interview by relying on an interview guide. Although the guide contains a number of questions that are asked to every research participant, the researcher also has a flexibility to probe for answers based on the direction of the conversation during the interview (Kvale 2007). Moreover, participants can share historical information that is not recorded or not publicly available (Creswell 2013). Therefore, interviews allow to obtain rich data that otherwise would not become available for analysis.

Scholars, however, note certain limitations of semi-structured interviews. First, the interview data are mostly descriptive and represent participants' points of view that can be influenced by researcher's questions (Creswell 2013). Second, researcher's control of the flow of the interview can create a power imbalance and thus may bias responses (Creswell 2013, Kvale 2007). Third, researcher can experience difficulties with recruitment of interview participants due to a variety of reasons such as lack of interest and motivation to participate in research, ethical issues and limited number of participants who qualify to participate. In addition, usually researchers are bound by time and budget constraints, so the number of participants they interview is limited. Finally, qualitative studies in general and studies relying on interviews in particular stress that the results of this form of inquiry are not generalizable to the broader population (Creswell 2013). Their advantage, however, is the detailed description of specific experiences and accounts of events.

By relying on a number of methods to complement each other, I am able to compensate for limitations of each individual methods, triangulate the findings as well as provide insights for the other stages of this research. Furthermore, this combination of methods ensures comprehensive answers for the research questions and development of qualitative and quantitative descriptions of the results. 


\section{Research Design}

The research design involves four stages that are briefly described here followed by a section containing the details on each stage. First, Canada's open government policy, directives on social media use in government and social media terms of use developed specifically by immigration agencies are compared to those of Australia and New Zealand. These countries were selected for analysis as they are interested in attracting highly-skilled immigrants thus competing for global talent (Ongley and Pearson 1995; Akbari and MacDonald 2014). Furthermore, all these countries have developed open government policies as well as a number of documents that specify how social media is intended to be used. Second, government and user posts on the federal Canadian immigration department - the IRCC - Twitter and Facebook accounts are collected and analysed by using quantitative and qualitative content analysis. These are followed by qualitative interviews with public servants who manage government social media accounts and users who used these accounts.

Data collection for the study covered the period from September 2015 until December 2016. Social media data were collected from September 2015 to August 2016 to ensure that the data collection period covered promotional campaigns as well as "routine" operations. Interviews with public servants were conducted from March 2016 until June 2016 and interviews with users were conducted from September 2016 until December 2016. Open government policies and official documents related to the government use social media were retrieved in February 2016 and again in December 2016 to compare for changes.

The research design continued to evolve while the study was progressing as data collection and analysis occurred simultaneously. As social media data were retrieved monthly in order to make analysis more manageable, this approach also allowed to conduct preliminary analysis and 
determine future steps. One of the methods used at this preliminary stage was social network analysis. By using social network analysis methods, I was able to identify that there were no consistent sustainable relationships between different actors in a network - an important network characteristic (Borgatti and Halgin 2011). Therefore, there were no key participants who were constantly participating in conversations with IRCC and/or with other users over a period of one year (this will be further discussed in the sub-section on preliminary network analysis). Thus, although social network analysis was not applied much as a method, results obtained during this preliminary social network analysis stage greatly contributed to my understanding of the network structures and determined further steps for the study, specifically analysis of social media data and recruitment of user interview participants.

The design of this study ensures that the results of analysis of open government policies and other government documents, and social media data were used to plan for the interviews with government officials and users of government social media accounts. Social media data content analysis as well as social network analysis and network data visualization provided invaluable insights to inform the direction of the study, including selection and recruitment of social media user interview participants and determining questions to be asked during interviews with public servants and social media users. Thus, semi-structured interviews build directly on the results of preceding analysis. Furthermore, multiple sources of data provide different insights into research questions. Analysis of policies and social media data help to answer how government and social media users use government social media. Semi-structured interviews help to understand why they are using it.

Therefore, data are collected from both primary and secondary sources to ensure rigorous data collection procedures and triangulation of findings. Primary sources of information include 
social media posts on government social media platform and interview data, while secondary sources include policy and other government documents related to open government and social media initiatives. Results that are obtained during each stage help to explain results at each consecutive stage. This is also true for the results obtained at later stages as they bring better and deeper understanding of earlier findings. Therefore, by combining these methods of analysis and three data sources this study provides in-depth insights on the government use of social media.

\section{Collection and Analysis of Relevant Policies and Government Documents}

In order to get insights on how governments intend to use social media, Canadian open government policies and other relevant documents were collected and compared to those developed in two other countries that are actively seeking to attract new immigrants - Australia and New Zealand. Australia and New Zealand are selected because, similarly to Canada, they have expansive immigration policies and are actively recruiting immigrants (Ongley and Pearson 1995; Akbari and MacDonald 2014). Therefore, they can be considered Canada's competitors in attracting new immigrants as well as high-skilled workers and international students (Akbari and MacDonald 2014). Moreover, the majority of immigrants to Canada, Australia and New Zealand come from China, India and Philippines (IRCC 2015; Department of Immigration and Border Protection 2015; Ministry of Business, Innovation and Employment 2016).

Three types of documents were selected for analysis. The first type of documents collected included open government policies adopted in Canada, Australia and New Zealand. These were selected to determine past (within last five years) and current priorities for the government use of social media. All three countries have action plans on open government and these were the starting point for the analysis. The analysis of the action plans was focused on the scope of government 
social media use (i.e. if government agencies should use social media to provide information, engage the public in policy development and/or service delivery).

Second, directives and guidance on government use of social media were examined. The main goal of this analysis is to understand how the overarching principles of open government and government social media use are reflected in operational documents that all government agencies are required to comply with. These documents contain a set of concrete requirements for the government social media channels, such as the roles and responsibilities of those who manage accounts, technical specifications, publishing requirements for social media content and moderating requirements.

Finally, social media terms of use developed by IRCC and MCI (Canada), DIBP (Australia) and Immigration New Zealand (New Zealand) were reviewed. These documents operationalize the principles for government social media use as well as government-wide social media requirements for immigration agencies. It is important to mention that although responsibility for immigration is shared between federal and provincial governments in Canada, in Australia and New Zealand, this is the sole responsibility of the federal government. Therefore, only Canadian agency-level documents cover both the federal department and the largest provincial ministry responsible for immigration in the province of Ontario - MCI. Table 3 describes documents that were analysed for this study.

Table 3. Policy, Guideline and Procedural Documents that Regulate Social Media Use in Government in Canada, Australia and New Zealand

\begin{tabular}{|l|l|l|l|}
\hline Country & $\begin{array}{l}\text { Open Government } \\
\text { Policy Documents }\end{array}$ & $\begin{array}{l}\text { Social Media } \\
\text { Guidance }\end{array}$ & $\begin{array}{l}\text { Agency Specific } \\
\text { Documents }\end{array}$ \\
\hline Canada & $\bullet$ Action Plans on & $\bullet$ Mandatory & $\bullet$ IRCC Social \\
& Open Government & Procedures for & Media Terms and \\
& $2012-2014,2014-$ & Social Media and & Conditions \\
& 2016 and 2016- & Web & $\bullet$ MCI Terms of \\
& 2018 & Communications & Use/Posting \\
\hline
\end{tabular}




\begin{tabular}{|c|c|c|c|}
\hline & & $\begin{array}{l}\text { (Appendix D) of the } \\
\text { Directive on the } \\
\text { Management of } \\
\text { Communications } \\
\text { - Technical } \\
\text { Specifications for } \\
\text { Social Media } \\
\text { Accounts } \\
\text { - Standard on Social } \\
\text { Media Account } \\
\text { Management }\end{array}$ & $\begin{array}{l}\text { Guidelines on } \\
\text { Facebook }\end{array}$ \\
\hline Australia & $\begin{array}{ll} & \text { Australia's First } \\
\text { Open Government } \\
\text { National Action } \\
\text { Plan 2016-2018 } \\
\text { - } \\
\text { Australia's Public } \\
\text { Service ICT } \\
\text { Strategy 2012 - } \\
2015\end{array}$ & $\begin{array}{l}\text { Circular 2012/1: } \\
\text { Revisions to the } \\
\text { [Australian Public } \\
\text { Service] } \\
\text { Commission's } \\
\text { Guidance on } \\
\text { Making Public } \\
\text { Comment and } \\
\text { Participating Online } \\
\text { (Social Media) }^{2}\end{array}$ & $\begin{array}{l}\text { Department of } \\
\text { Immigration and } \\
\text { Border Protection } \\
\text { (DIBP) Social } \\
\text { Media Terms }\end{array}$ \\
\hline New Zealand & $\begin{array}{l}\text { Action Plans on } \\
\text { Open Government } \\
\text { 2014-2016 and } \\
2016-2018\end{array}$ & $\begin{array}{l}\text { Social Media in } \\
\text { Government } \\
\text { Guidance: High- } \\
\text { Level Guidance, } \\
\text { Hands-On Toolbox } \\
\text { and How to Handle } \\
\text { a Mishap Guide }\end{array}$ & $\begin{array}{l}\text { Immigration New } \\
\text { Zealand: Terms } \\
\text { of Use for New } \\
\text { Zealand Now and } \\
\text { New to New } \\
\text { Zealand } \\
\text { Facebook Pages }\end{array}$ \\
\hline
\end{tabular}

\section{Preliminary Social Network Analysis}

Social network analysis was used at the early stages of this research. It was used to analyse existing relationships between different actors in a network (Borgatti and Halgin 2011). I was looking to identify the structure of a network, key contributors and intensity of interactions and information exchanges. Results obtained at this stage were crucial for further analysis as they showed that most of interactions were between IRCC and user accounts but interaction between

\footnotetext{
${ }^{2}$ This document is no longer in force. Currently, there is no guidance on social media that applies to all federal government agencies in Australia. Each government agency can create its own social media policy and make it publicly available. Australian Public Service Values and Cond of Conduct in Practice only provides guidance on how public servants should use social media for personal reasons.
} 
users themselves were limited. Moreover, with a few exceptions, users did not interact with IRCC on a continuing basis. In addition, there were very few network actors who could be considered as key contributors on the IRCC Twitter and Facebook.

IRCC, however, was a very important actor in the network as the vast majority of communication was addressed directly at the department. Therefore, although social media data was not analysed by applying measures such as centrality and density it was determined that there are no consistent networks on IRCC social media. This finding influenced social media user participants' interview recruitment strategy.

The analysis revealed that there was no constant virtual network between IRCC and social media users. It, however, also showed that the bilateral user-to-IRCC communication exists on Twitter but there were very few interactions between IRCC and users on the IRCC Facebook account.

\section{Social Media Data Collection and Analysis}

Social media posts were collected for a period of one year (September 2015 to August 2016). This allowed for a comparison of the level of activity on social media pre-federal election in 2015 and post-federal election. Social media data came solely from government social media accounts as the purpose of this study is to explore how IRCC and MCI use social media platforms. However, it is important to note that the vast majority of conversations on government policies and the delivery of programs and services unfold on non-government social media.

Data for this study were collected from four social media accounts: the IRCC Twitter, the IRCC Facebook, the MCI Twitter and the MCI Study, Work, Stay Facebook. These accounts were selected for analysis for the reasons discussed below. 


\section{Social Media Data}

At the time the study was conducted, MCI maintained several Twitter accounts, including own Twitter account as well as the Ontario Women Directorate and the Ontario Senior Directorate accounts. The ministry also managed a Facebook account which at the time of data collection was called "Study, Work, Stay: Opportunities Ontario" account. In July 2016, MCI split its Twitter account into two separate accounts - one for citizenship and one for immigration and changed the name of the Facebook page to a more generic one - Ontario Immigration. In addition, French versions of all social media accounts were created. MCI also has a Flickr account.

Data were collected from MCI own Twitter account and Study, Work, Stay: Opportunities Ontario Facebook page. The main goal of collecting these data was to compare the use of social media by IRCC and MCI. However, I made a decision to exclude these data from analysis. This decision was informed both by data collected as well as interviews with public servants from MCI and is based on several considerations:

1. There was very little interaction on the MCI Twitter account that was related to immigration programs and services. At the time of the data collection, this account was mostly used to post information about celebrations of holidays in different ethnic communities.

2. From September 2015 to August 2016, there were only 171 user posts on the MCI Facebook page. Furthermore, this account allowed users to send a private message as opposed to post publicly. This made it hard to estimate how many interactions would be not captured by the data collection tool that was used. 
3. MCI was responsible not only for the MCI Twitter account but for the accounts of the Ontario Women Directorate and the Ontario Senior Directorate. Messages posted on one of these accounts could be duplicated on all three.

4. MCI changed the Twitter handle for the Twitter account in July 2016 and some data were lost. Moreover, the main Twitter account was re-purposed to focus on Ontario Citizenship, i.e. target those users who were already living in Ontario.

Therefore, although these collected data provided important insights on the use of social media platforms by a provincial immigration agency (e.g. lack of immigration specific focus and limited interaction between government and users), they could not be compared to the data retrieved from IRCC social media platforms due to the limitations discussed above. Furthermore, as MCI's approach to managing these accounts has changed during the study, data collected in the beginning of the study would not be comparable to data collected after the changes have occurred.

However, it is important to note that there was a significant difference in terms of number of posts between MCI and IRCC social media accounts. The IRCC Twitter averaged 3,965 tweets per month compared to the MCI Twitter with 326 tweets and the IRCC Facebook averaged 1,822 posts a month compared to 27 posts a month on the MCI Facebook page. Chapter 5, however, discusses and compares the way IRCC's and MCI's Twitter and Facebook accounts are set up and what functionality is offered to users, as this is an important context to keep in mind when analysing volume and content of social media posts as well as existing approaches to the use of social media.

\section{$\underline{\text { IRCC Social Media Data }}$}

IRCC maintains a number of social media accounts including general Twitter and Facebook accounts (in English and French), YouTube account and newly opened LinkedIn and 
Instagram accounts. The department also maintains program specific Twitter and Facebook accounts (in English and French), which are exclusively devoted to the International Experience Canada program. ${ }^{3}$

Social media data analysis is this study is based on posts retrieved from IRCC general English-language Twitter and Facebook accounts. These accounts were selected for four main reasons: 1) they are listed on the main page of the IRCC website, 2) English is the preferred language of the vast majority of those who use IRCC social media, 3) they target broader audiences than just a specific client group, and 4) they have highest number of followers among all IRCC social media accounts.

To collect tweets on the IRCC Twitter, I used a program called Netlytic - which is "a cloud-based text and social network analyzer that can automatically summarize large volumes of text and discover social networks from online conversations on social media sites such as Twitter, YouTube, blogs, online forums and chats" (Netlytic 2013). Netlytic is a community-supported program maintained by the Social Media Lab and Ted Rogers School of Management, Ryerson University. Posts on the IRCC Facebook page were collected by Netvizz. Netvizz is an open access program can be used to retrieve posts and certain user characteristics from different sections of Facebook (Rieder 2013). It allows to collect social network data, identify most active users and the most popular posts. Therefore, both programs allow to retrieve social media data for social network and content analysis. It is important to note that tweets were collected pro-actively (i.e. data collection was set up every month) while Facebook posts were retrieved retroactively (i.e. I retrieved all posts in September 2016 before I started my analysis). Thus, some of the Facebook posts could have been deleted by the time of data retrieval.

\footnotetext{
${ }^{3}$ International Experience Canada provides youth with an opportunity to travel and work in Canada.
} 
Netlytic captured Twitter posts included from and to the IRCC Twitter account @CitImmCanada. These include original tweets originated from this account, user tweets @CitImmCanada, retweets, mentions and all responses to users (@user tweets). Netvizz retrieved all Facebook posts on the IRCC Facebook page: messages by IRCC, user responses to those messages, IRCC responses to users, shares of posts from other accounts as well as user comments and tagging.

Data for each month were collected separately to make the collection process easier and data analysis more manageable. Both Netlytic and Netvizz gather posts in a spreadsheet format and include the following data elements: link to the post, author of the post, date of publication, the post itself and some attributes of the post. Netvizz also provides information if the post is an original, a comment or a reply to a comment. I further separated posts into two spreadsheets per each account (the IRCC Twitter and the IRCC Facebook): one for the messages that were posted by the government agency and one for the messages posted by users. Therefore, I ended up with four databases for content analysis: IRCC tweets, tweets by users on the IRCC Twitter, IRCC Facebook posts and posts by users on the IRCC Facebook. It is also important to note that the collection of social media data is supplemented by observations on how these platforms are set up as this is an important part of user experiences and interaction.

Netlytic and Netvizz provided data that are central for the study. The analysis discussed below differs from most of studies on government use of social media, as they do not tend to focus on those who post but rather than the posts themselves. I am, however, interested in learning about government and user posts as well as their interactions on social media. Thus, one of the most important data collection features is the ability to separate user generated content and government 
generated content as well as content-unique attributes. This was successfully done by using Netlytic and Netvizz as well as spreadsheets.

It is important to note that the way IRCC sets up its Twitter and Facebook accounts predetermined what data could be collected for the study. Twitter users can tweet and send a direct (private) message to the department. However, user account has to be followed by IRCC social media team before the direct message can be sent. Thus, although certain interactions between IRCC and Twitter users could unfold via direct messages, it is safe to assume that the number of such conversations is quite small and, thus, cannot significantly affect results of the study. All interactions on Facebook (with the exception of user messages that could have been deleted) were captured and represent the vast majority of Facebook posts published over a period of one year.

The activity on the IRCC Twitter and Facebook was influenced by several important events. These events could have influenced the number of posts on social media by both IRCC and users. First, there was a change in government in November 2015. Liberal party led by Justin Trudeau came to power and promised significant changes to immigration policies of the previous Conservative government led by Stephen Harper. Although only two months of data were collected for the Harper government, it is worth noting that the amount of tweets and Facebook posts was significantly lower compared to the amount of tweets and posts under the newly elected Liberal government (Figures 3 and 4).

Second, one of the campaign promises of the Liberal party was to assist with resolving humanitarian crisis in Syria and to bring 25,000 refugees in Canada as a first order of business (Liberal Party of Canada 2015). Most of this campaign unfolded between December 2015 and February 2016 thus accounting for the spike in messages from both IRCC and users. 
Finally, as a result of re-allocation of government resources and more specifically IRCC resources, already long processing times for sponsorship applications for spouses of Canadian citizens and permanent residents residing in Canada and abroad continued to increase. Only in June 2016 did IRCC respond to this issue with a commitment to prioritize family reunification (IRCC 2016). The lack of action before June 2016 has led to an influx of social media posts by Canadian sponsors related to challenging government priorities and demanding faster processing times.

Other events that could have influenced the amount of posts per month but less significantly include problems with electronic travel authorization ${ }^{4}$ (eTA) applications experienced by users and delays with student visa processing. It is also important to mention that IRCC runs a number of promotional and awareness campaigns each month (e.g. black history, Asian history and fraud awareness) but two campaigns lasted for longer durations - eTA awareness campaign (throughout the whole year the data were collected for) and awareness campaign for Canadian dual citizens to obtain a Canadian passport for travelling to Canada.

Between September 2015 and August 2016, a total of 46,288 tweets was collected. IRCC tweets accounted for about $8 \%(\mathrm{~N}=3,799)$ and the reminder $92 \%$ of tweets $(\mathrm{N}=42,489)$ were left by users. The number for Facebook was significantly less: a total of 22,584 Facebook posts were collected, where IRCC posts accounted for only $2 \%$ of all posts $(\mathrm{N}=501)$ and user posts accounted for remaining $98 \%(\mathrm{~N}=22,083)$.

\footnotetext{
${ }^{4}$ Electronic travel authorization (eTA) is a newly introduced program for visitors who do not need a visa to come to Canada.
} 
The differences between the number of tweets and Facebook posts for Harper and Trudeau governments are quite significant. For September and October, the number of Tweets posted on IRCC account (by IRCC and by users) totaled 1,777 and 1,410 tweets respectively. For November 2015 to August 2016, the average number of tweets was 4,310 per month (with the lowest number in August 2016 - 2,676 tweets and highest in December 2015 - 5,888 tweets). Therefore, under the Trudeau government, the number of tweets per month more than doubled Figure 3 presents the breakdown of tweets by month.

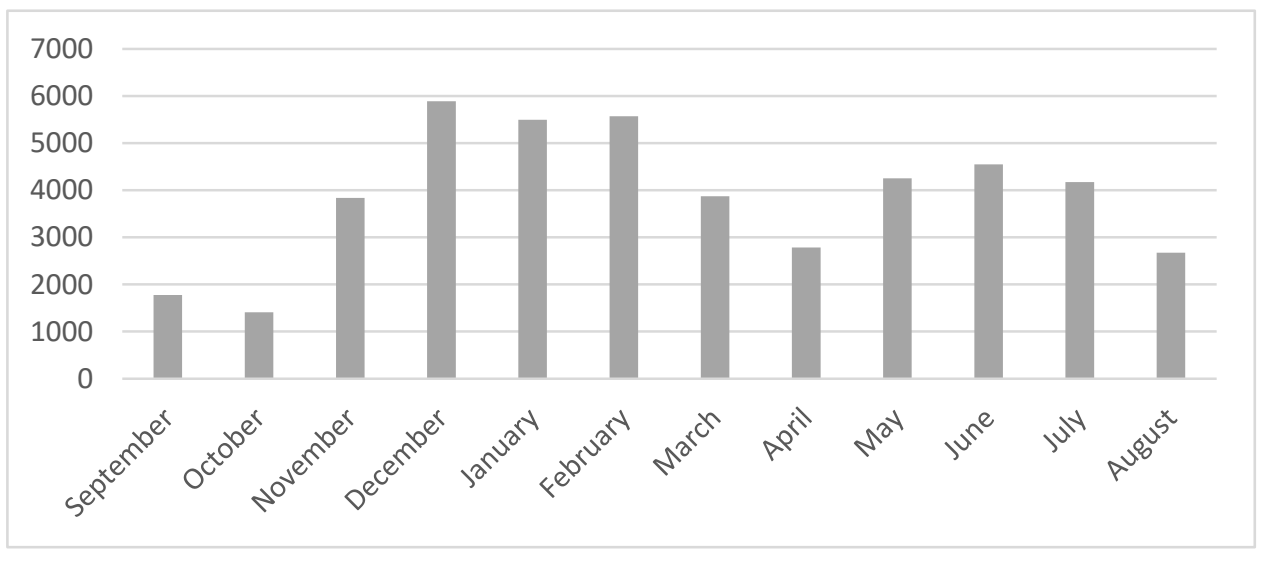

Figure 3. Activity on the IRCC Twitter (September 2015-August 2016)

Although the number of posts on the IRCC Facebook was generally lower compared to Twitter, the same observation can be made and the difference is even more significant: the number of Facebook posts on IRCC account grew up three times under the Trudeau government. For September and October, the number of posts by IRCC and by users totaled 502 and 257 posts respectively. For November 2015 to August 2016, the average number of posts was 2,183 per month (with the lowest number in June 2016 - 1,008 posts and with the highest number in February 2016 - 3,592 posts). Figure 4 presents the breakdown of Facebook posts by month. 


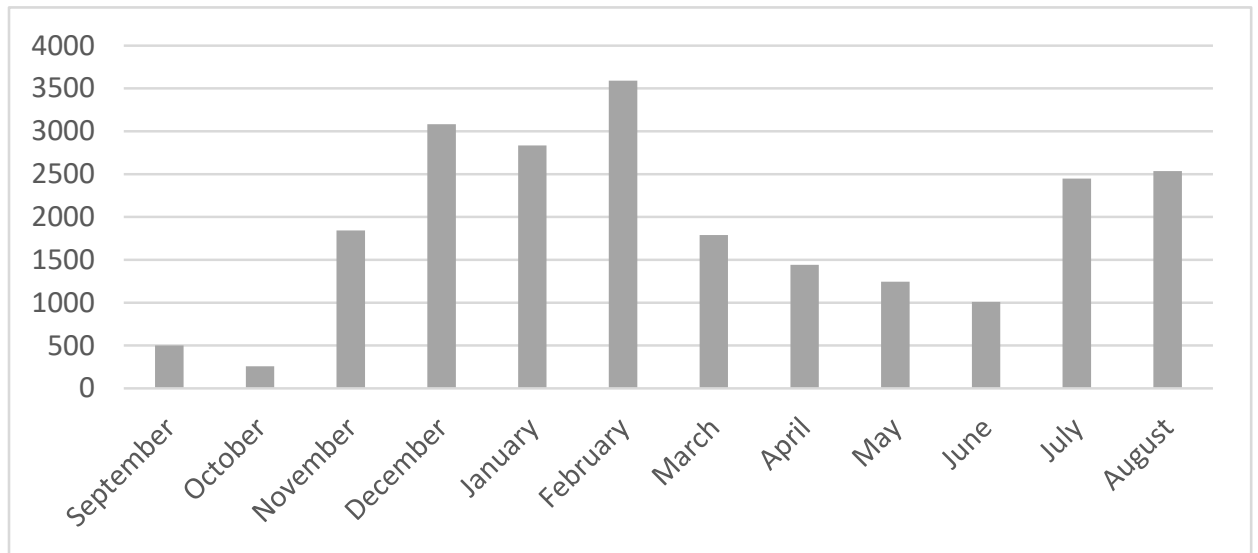

Figure 4. Activity on the IRCC Facebook (September 2015-August 2016)

As the social media data show, the level of activity on the IRCC Facebook and Twitter fluctuates every month. Further, there are significantly more tweets than Facebook posts. This is primarily driven by user activity, however, IRCC is also more active on Twitter than Facebook.

\section{$\underline{\text { Social Media Posts by IRCC }}$}

As mentioned before, IRCC and user posts on Twitter and Facebook were organized in separate databases. Analysis of IRCC activity on social media is based on tweets posted by account @CitImmCanada and Facebook posts sent by account CitCanada. Tweets included all original tweets sent from this account, all retweets and all user responses (@ user tweets). Facebook posts included original messages, responses to users and shares of posts from other accounts. IRCC tweets and Facebook posts were separated in two databases for analysis.

Between September 2015 and August 2016, 3,799 IRCC tweets and 501 IRCC Facebook posts were collected. IRCC tweeted the most in July $2016(\mathrm{~N}=441)$ and the department tweeted the least in September 2015 (N=178). IRCC left most of Facebook posts in August $2016(\mathrm{~N}=85)$ and the lowest number in September $2015(\mathrm{~N}=5)$. Chapter 5 further examines how and why IRCC interacts on its social media accounts. 


\section{$\underline{\text { Social Media Posts by Users }}$}

Analysed user activity on IRCC social media accounts included tweets that were addressed to or mentioned account @ CitImmCanada and Facebook posts that were attributed to original posts by CitCanada Facebook page. Tweets included those originated from user accounts, all retweets and mentions. Facebook posts included responses to posts by CitCanada: comments to IRCC posts, responses to comments and mentions of other people's names, so they will pay attention to the content - also known as tagging. Again, user tweets and Facebook posts were separated in two databases - user tweets and user Facebook posts - for analysis.

Between September 2015 and August 2016, 42,489 user tweets and 22,083 user Facebook posts were collected. Users tweeted the most in December $2015(\mathrm{~N}=5,587)$ and the least in October $2015(\mathrm{~N}=1,222)$. The highest number of Facebook posts was left in February $2016(\mathrm{~N}=3,524)$ and the lowest number - in October $2015(\mathrm{~N}=251)$. Chapter 6 further examines how and why social media users interact on IRCC social media accounts.

\section{Coding of Social Media Data}

Coding of tweets and Facebook posts was a done by one researcher (i.e. myself) who manually coded tweets and Facebook posts for each month of collected data. Data were organized into four separate spreadsheets: IRCC tweets, IRCC Facebook posts, user tweets and user Facebook posts. Two types of coding were used for IRCC messages: 1) computer-assisted coding to determine if they contain a simple referral to the website or an original message and 2) manual coding to explore different types of messages (e.g. information, feedback) and messages' topics/themes for the feedback messages and information posts (e.g. if they are about programs and services, processing times or technical issues). 
Similar approach was used for coding of user messages: they were manually coded to explore different types of messages (e.g. information, questions, opinions) and topics/themes for messages containing questions to IRCC and messages that contained an expression of opinion. I also manually verified which user tweets and Facebook posts got a response or comment from IRCC. This information is crucial for understanding government priorities on social media, i.e. what questions are more likely to be answered and which ones remain unanswered. Manual coding was performed to ensure that not only general categories of posts but also more detailed information about tweets and posts is captured. It is important to note that each tweet or post was assigned only one category for the type of message and only one category for the topic/theme for responses and information messages for IRCC as well as questions and messages expressing opinion for users.

Systematic sampling was used for manual coding of social media messages (Krippendorf 2004). Given the volume of user tweets and Facebook posts, a sample of every tenth tweet $(\mathrm{N}=1,740)$ and every tenth Facebook post $(\mathrm{N}=2,172)$ was manually analysed and coded. This approach is widely used in studies that rely on qualitative content analysis of social media data (e.g. Segerberg and Bennett 2011; Clarke 2012). For IRCC tweets, I took a different approach: I analysed and coded every second tweet $(\mathrm{N}=1,893)$ and every second Facebook post $(\mathrm{N}=244)$ to more accurately capture the differences in use during specific promotional campaigns and "regular" time.

All spam messages and user retweets were excluded from the analysis. Retweets were excluded as they do not contain as much thought as an original tweet and can create bias in the data (Godfrey et al. 2014). However, in this study, retweets by IRCC were not removed as they show what kind of information the department considers important to share. Further, Facebook 
spam posts that contained an immigration related advertisement were not excluded. The significance of these advertisements and the lack of government monitoring of such content will be discussed in Chapter 6. Interestingly, user messages on Twitter did not include such advertisements.

The unit of analysis was a tweet as opposed to a complete message or response that could contain several tweets. For Facebook posts, the unit of analysis was a post, although in a small number of cases IRCC used several posts to respond to a question. This unit of analysis was selected because a full message could contain several topics of interest (e.g. a message consisting of two tweets can discuss processing times in the first tweet and the need to use a web form to contact IRCC in the second one).

A combination of deductive and inductive methods was used to prepare codebooks for analysis of tweets and Facebook posts. Deductive codes originated from the review of research literature (e.g. based on studies by Segerberg and Bennett 2011; Clarke 2012), while inductive coding was based on two research questions - how government agencies use social media and how migrants use government social media. Although the qualitative content analysis also touches upon the "why" part of research questions, data collected to answer this part of the research question was primarily collected through the semi-structured interviews with public servants and users.

A sample of 100 IRCC tweets, 100 user tweets, 100 user Facebook posts and 20 IRCC Facebook posts was initially coded to develop inductive codes. Two codebooks were created: one for the IRCC tweets and Facebook posts and another one for user tweets and Facebook posts. Tweets and posts were assigned only one category for the type of message and one category for the topic/theme. In other words, the same message does not have multiple codes. 
For IRCC messages, the categories of information and retweets/sharing of content were developed based on the literature, while the category responses stemmed from the data. After it was identified that IRCC responds to users' questions, coding for the responses category was further developed to analyse the quality of responses that are provided. All tweets and Facebook posts in this category were classified into following categories: a simple referral to a website and a response that includes a certain degree of personalization in response - e.g. an explanation of the information that is being provided. Response and information topics/themes were also identified. These are important as they show what questions IRCC is answering and what kinds of information the department is interested in disseminating. Topics for response and information categories were identified from the data.

Categories for user tweets and posts are somewhat similar to IRCC ones and I mostly relied on inductive coding to create categories for the types of messages and messages topics/themes. Six categories for the types of messages were identified (see Appendix A for complete codebook):

1. Question - where users ask IRCC or other users to respond;

2. Opinion - where users express a view or judgment (positive or negative) about their experiences, IRCC and its programs and services, etc. not necessarily based on fact or knowledge;

3. Response - where users respond to the tweet/post by other users with the intention to engage in a conversation;

4. Information - where users share information with IRCC and/or other users (may contain a link to a website, video, news article, etc.);

5. Amicable ties - where users express gratitude such as thanking somebody and/or congratulating on something. Messages can be addressed to IRCC or other users. 
6. Tagging - where users are making sure that a specific user will see the post by including their user name into a reply to the post. This category is only applicable to Facebook posts. All IRCC and user messages were also coded based on themes/topics. Identifying topic/themes is important as it provides insights of what information is important to users and what information is likely to be shared by government. Thus, responses and information messages posted by IRCC are further analysed based on their topics/themes (Appendix B). For user messages, I examined topic/themes for questions and opinion messages as together represent $64 \%$ of all user tweets and $61 \%$ of user Facebook posts.

\section{Semi-structured Interviews with Public Servants and Social Media Users}

$\underline{\text { Interviews with Public Servants }}$

I conducted semi-structured interviews with public servants from IRCC $(\mathrm{N}=3)$ and MCI $(\mathrm{N}=3)$ to gain an in-depth understanding of current social media strategies and tools, assumptions about user groups and perspectives on effectiveness of social media use in government. The relatively small number of interview participants reflects that both government agencies have small teams responsible for social media. At the time of the interviews, the IRCC social media team included four full-time staff and the MCI social media team included three full-time staff. It is important to note, however, that other communication branch employees have certain amount of their time devoted to assist and guide social media teams.

Another consideration for interview participant recruitment was their direct experience with social media policies and practices in government immigration agencies. Therefore, public servants from central agencies (such as TBS on the federal level and Cabinet Office in Ontario) 
who were involved in the development of the approach to the government use of social media were not interviewed. Their perceptions and experiences can be explored in future studies.

During interviews, the data about the importance of all three groups of factors that signify effective use of social media were collected: network factors (perceived function of the network; recognition of the importance of latent ties level of customization related to exchanges; network perceived as contributing to agency/immigrant goals; network/social media allows getting feedback that could not be gathered otherwise), organizational factors (type of government agency; organizational flexibility and availability of resources (e.g. staffing and funding); kind of information being shared; organizational culture) and personal factors (socio-demographic factors; characteristics of providers/users; experience with social media; personal goals related to use; leaders within the agency/immigrant group are oriented toward implementing technological innovations; perceived value of social media to personal/career goals).

Purposeful sampling was used for selecting research participants and public servant interview participants were found through publicly available information in online government employee directories. Six participants were recruited: three participants from IRCC and three participants from MCI. This sample included those public servants who were directly responsible for providing government social media content and their direct supervisors. The recruitment process took some time as I was waiting for the participants to follow proper approval channels in order to participate. Although there was a minor delay with interviewing IRCC participants, it took about three and a half months to receive consent from MCI participants who requested permission to participate from Cabinet Office. ${ }^{5}$ That is why interviews with IRCC staff were conducted in March 2016 and interviews with MCI staff were delayed until June 2016.

\footnotetext{
${ }^{5}$ Cabinet Office is a ministry of the Government of Ontario. It provides advice to the Premier of Ontario and his/her Cabinet.
} 
All interviews were conducted in person in Ottawa and Toronto. It is important to note that all public servant participants preferred to be interviewed at their work location and provided their responses speaking on behalf of their agency. Interviews took 45 to 60 minutes. All participants received an initial invitation to participate in the research (Appendix C) followed by a follow-up email with details of the interview and location and attached consent form (Appendix D). Therefore, all participants could ask questions about the study and the interview before or during the interview itself. Five interviews were audio-recorded with the permission of participants and I took notes during one interview as the participant preferred not to be taped. No participant experienced or admitted to any issues and/or discomforts during the interview and I was able to ask all the questions in my interview guide (Appendix E).

Data collected from these interviews revealed existing concerns about social media use as well as its perceived value and approaches to interactions between government and users on social media. Moreover, interviews revealed what is considered as effective social media use in government and goals of social media use. Participants also discussed existing limitations and concerns as well as opportunities going forward.

From six public servants interviewed for the study, four were responsible for creating and publishing content on social media and two were direct supervisors responsible for approving the work of their staff. In order to guarantee their confidentiality, their job titles are not disclosed.

It is important to note that both agencies had several other staff who were involved in the delivery of social media content. However, they were either not a part of the core social media team (in both IRCC and MCI) or were employed on a casual, short term basis (IRCC). Thus, on a regular basis social media channels are being supported by small teams of four to five people in both government agencies. 
Moreover, although MCI have been using social media since 2008, job titles of MCI public servants still do not reflect that they are responsible for social media. Interview participants mentioned that they were hired to do other work but slowly maintaining social media channels became their primary responsibility. This is yet, however, to be reflected in their job titles.

All interview participants are professionals with the background in communications and media. Their work experience in their current position varied: some had it for several years and some were quite new - a year or less. However, all of them had experience working with social media prior to their current role.

\section{$\underline{\text { Interviews with Social Media Users }}$}

All social media user interview participants were recruited online on Twitter and Facebook. Nonprobability sampling was used to select participants for this study. The main criterion for the selection was participants' experience using government social media resources. All participants were recruited from those who posted on the IRCC Facebook and Twitter accounts. Unfortunately, only one participant had experience with IRCC and MCI social media.

Thus, I knew that they had experience with government social media before an invitation to participate was sent out. It is important to note, however, that those who agreed to participate might have been interested in the topic and decided to participate in an interview because they saw value in the government use of social media. There were also users who declined the invitation to participate because they either did not have enough experience with government social media or it was very unsatisfying. In addition, one participant who agreed to be interviewed stated that he did not believe that it was an effective means of communication between government and the public. The rest of the interviewees, however, saw the value in government use of social media 
and thus the results of the interviews have this limitation - i.e. believing that this is an appropriate means to interact with government.

In-depth interviews with social media user participants were aimed at understanding their reasons for the use of government social media, expectations from government social media and perspectives on effectiveness. Therefore, during the interviews data about the importance of factors that signify effective use of social media were collected: network factors (perceived function of the network; value of information exchanged in the network; recognition of the importance of latent ties; level of customization related to exchanges; network perceived as contributing to migrant goals, network/social media allows getting feedback that could not be gathered otherwise) and individual/personal factors (socio-demographic factors; characteristics of providers/users; experience with social media; personal goals related to use; perceived value of social media to personal/migrant goals).

As it was determined at the preliminary stages of analysis that there are no key contributors who consistently continue to interact over a period of several months, I decided to send out invitations to participate to everyone who posted on the IRCC Twitter and Facebook as well as the MCI Facebook. As mentioned before, MCI Twitter account was excluded from consideration. For IRCC participant recruitment, I primarily used social media data collected for August 2016 to send out invitations to participate in the study. The month of August was selected because users who posted then had the most recent experience (interviews began in September 2016). Once I reached out to all the users who posted in August, I switched to July, however, was unsuccessful in recruiting participants from this timeframe while soliciting participation in late November-early December 2016. That is why four participants (2 Twitter users and 2 Facebook users) came from those who used the IRCC Facebook and Twitter in November and early December 2016. Thus, 18 
participants come from users who posted on the IRCC Facebook and Twitter during the same time that social media data were collected and four participants posted outside this timeframe.

MCI Facebook page had considerably less activity than IRCC platforms. Although it is because of its specific focus on international students who apply for the Ontario Immigrant Nominee Program, another significant event influenced the amount of interactions on this page a temporary hold on applications as the province reached its quota for nominees in May 2016. Therefore, there was little activity on this page and I was able to only recruit one participant who used it (in addition to the IRCC Facebook).

In order to get insights for government Facebook and Twitter use, I was aiming for equal number of participants who used these platforms. Thus, 12 participants used IRCC Twitter, two participants used both the IRCC Twitter and Facebook, seven used the IRCC Facebook and one used the IRCC Facebook and the MCI Facebook. Only those who used English to communicate were invited to participate.

Study specific Twitter and Facebook accounts were created, which were used to send out invitations to participate. Twitter users were invited to participate via a tweet or direct message (if this functionality was enabled on their profiles). Facebook users were contacted via private message (again, if this was enabled on their profiles). Initial message (Appendix F) included invitation to participate and a link to my Ryerson blog (http://socialmediastudy.blog.ryerson.ca/) that contained information about the study, invitation to participate, explanation of recruitment process as well as consent forms. If the participant responded to my message but wanted more information about the study, it was provided in the following messages. All participants received consent form in advance (Appendix G) and had a chance to ask questions about the study before 
or during the interview. I also explained confidentiality and voluntary participation before the interview.

Interviews were conducted in person, on the phone, Skype, Facebook voice call and Viber. Three participants preferred to answer in writing via Twitter and Facebook messages. All interviews were conducted in English and sometimes participants experienced problems with understanding certain questions. In this case, I would rephrase the question or type it in a chat box Skype, Facebook or Twitter. Each interview took between 30 minutes and an hour. Before each interview started, participants provided a statement in writing that he/she agreed to be interviewed. Participants were provided with honorarium of \$20 in cash or Skype credit to compensate for their time. However, some participants chose not to receive it.

The interviews were focused on data collection related to types of social media used, purposes of use and users' perspectives on effectiveness of social media practices by government agencies (interview guide - Appendix H). The interviews also revealed what factors are considered to be important for efficient interactions on government social media accounts.

Interviews were audio-recorded with the permission of research participants. One participant did not want to be taped. I also took notes during interviews and, as mentioned before, three participants provided their responses in writing.

In total, 22 social media user participants were interviewed. Although an attempt was made to have equal representation of Twitter and Facebook users in the sample, the final sample had more Twitter users $(\mathrm{N}=12)$ than Facebook users $(\mathrm{N}=8)$. Two participants stated that they used both Twitter and Facebook. Most of participants were male $(\mathrm{N}=16)$ and six participants were female. The age of participants ranged from teens to 60 , with the majority being in 20 s and 30 s. The vast majority of interviewees were working professionals $(\mathrm{N}=16)$ with at least Bachelor's degrees 
$(\mathrm{N}=17)$. Four participants were students and two were unemployed at the time of the interview. In terms of geographical location, most study participants were in North America (Canada or USA) when they interacted with IRCC $(\mathrm{N}=9)$. This is followed by Middle East (Jordan, UAE, Israel, Iraq) (N=5), South Asia (India and Pakistan) $(\mathrm{N}=2)$, Australia $(\mathrm{N}=2)$, Africa (Angola and Egypt) $(\mathrm{N}=2)$, United Kingdom $(\mathrm{N}=1)$ and Peru $(\mathrm{N}=1)$.

\section{Coding of Interviews}

Similar to coding of social media data, coding of interview transcripts and notes was done by one researcher. Again, both on inductive and deductive coding were used to code qualitative interview data (Saldaña 2009). Initially, coding started with a list of ideas based on the literature review and included codes such as value of social media, issues and challenges, effective use, network etc. These were refined and extended while analysing the data in Nvivo 10 - a qualitative data analysis software package. It is also important to mention that some of the codes are the same for public servant interviews and user interviews but most are different because of officials and users have different reasons for the use of social media and experiences with it.

Open and axial coding (Corbin and Strauss 2008) and existing frameworks were used to determine the meaning of the effective use of social media from government and user perspectives as well as to identify benefits and challenges associated with social media and perspectives on how government practices can be improved. The intention, however, was not to build a theory based on the interview data but rather further develop understanding of the reasons behind social media use or the why part of research questions: why government immigration agencies use social media and why migrants use government social media resources.

Data analysis in Nvivo led to further developing and refining of initial codes. The program also allowed to group open codes in broad categories or "parent" nodes. This approach is known 
as a "tree" approach that is used to create hierarchical structure of codes and check for related themes to avoid duplication (Bazeley 2007). Two codebooks were developed - one for public servant interviews (Appendix I) and one for social media user interviews (Appendix J). While interpreting interview data I relied on: 1) research literature, 2) related social media policy documents (including terms of use), 3) results of content analysis, and 4) results of preliminary social network analysis.

\section{Limitations and Delimitations of the Study}

\section{Limitations}

The underlining assumption of this study is that government agencies should use social media and interact with the users. Therefore, I did not analyse in detail what the alternatives to social media for both engagement and interactions with the public on policy development and public service delivery can be.

Moreover, while conducting the study, I have excluded certain populations. First, the study focuses only on those migrants who have access to the Internet and thus can access government social media. Secondly, it is important to acknowledge existing digital divide (migrants from certain countries do not have access to the Internet as well as lack knowledge on how to use it). In addition, not everyone is using ICTs throughout their migration process. Furthermore, older people tend to prefer other information gathering tools than the Internet (Veenhof and Timusk 2009). Thirdly, social media users can only communicate with government agencies in Canada in either English or French. Therefore, those who do not speak either of the languages cannot interact with Canadian government officials on government social media platforms. Finally, using the Internet for obtaining and sharing information does not necessarily mean that an individual is using social media and/or government social media resources. The reasons for not using social media can range 
from lack of interest in exposing private life to lack of knowledge about existence of such resources. At the same time, users might have a preference for a specific social media platform (for example, choosing Twitter over Facebook). This makes the datasets made of posts from Twitter and Facebook not comparable to each other. However, by having datasets from these two platforms, I am able to gain better understanding on the differences in use between them.

Moreover, data from government social media platforms were collected for a period of one year and, therefore, show only interactions on social media within this timeframe. Furthermore, datasets collected from social media posts and interviews with public servants and migrant social media users cannot be compared to each other as interviews were conducted at a specific point in time. Moreover, user interviews continued four months after the social media data collection was finished. However, social media data and interview data are analysed to complement each other.

It is important to note, however that all application forms for immigrant and non-immigrant visas are now available online only. Furthermore, the Express Entry system that was launched in January 2015 requires certain immigrants to create an online profile in order to be eligible for receiving permanent residency (IRCC 2017b). Therefore, the vast majority of potential migrants have to go online in order to obtain necessary information and documents. The question of how many of them are interested in communicating with the government on social media, however, is very difficult to answer as there are no available data.

However, it is safe to assume that many potential immigrants may not have interest in using government social media resources or do not know that they exist. Thus, this research is limited only to analysing the experiences of migrants or potential migrants who used government social media resources but cannot explain why people are not using them. This can be a topic for a separate study. 
The limited number of interview participants poses another limitation. However, as the purpose of this study is not to produce generalizable results but rather analyse different perspectives, a semi-structured interviews allow me to collect rich data to offer insight in users' and government's perspectives on the effective use of social media.

Results of my study are not fully generalizable as the needs and experiences of migrants may be very different from those of Canadian citizens who use government social media. Moreover, the goals of social media use can vary across different government agencies and jurisdictions. Some findings, however, may apply to any kind of government social media use and may offer knowledge about users' needs that will be valuable for different jurisdictions. The finding will be also more broadly relevant to e-government scholarship as well as emerging scholarship on open government.

\section{Delimitations}

As research on government use of social media is new and evolving, it is important to go beyond the analysis of solely government policies and practices of social media use and take into account user needs and experiences. It is also necessary to acknowledge that although some social media policies and practices can be shared across different government agencies, certain social media practices should be unique for each department as different government agencies serve different clients. This study attempts to advance policy and public administration knowledge by focusing on user perspectives and the policy domain of immigration, thus addressing the research gap that currently exists. It also produces a series of recommendations on the effective use of social media tools based on the experiences of public servants and user groups in Canada. 


\section{Ethical Considerations}

The recruitment process of interviewees started only after an ethical approval from Ryerson's Research Ethics Board was received. During the ethics approval process I finalized my data collection methods, recruitment materials, consent forms and interview guides. I also paid specific attention to the following ethical issues.

All participants were provided with any information regarding the study before agreeing to participate in the project. This information included background of the study, interview guides, consent form, etc. They were also ensured that their participation was voluntary. This was done in recruitment emails for public servants and Facebook/Twitter messages for social media user participants. The consent form providing details of the data collection instruments, confidentiality requirements and details of participation was explained before the interview started and a copy of it was given to all participants. Immigrant participants were provided with an honorarium of $\$ 20$ in cash or in the form of Skype credit. The amount was not too significant to influence their decision about participation in the study. Public servants did not receive honorarium as are already compensated for their work with government social media as public employees. All participants were informed that there were no direct benefits for participating in the study.

Although this study involved minimal risks for the participants, they could feel uncomfortable answering certain questions due to their professional and/or personal circumstances. Public servant participants could also feel the need to provide "correct" answers to the interview questions as the development of the content for social media resources is their work responsibility. Social media users could have experienced emotional discomfort because of the experiences they went through during the migration or application process. I tried to minimize these risks by focusing on past experiences of the social media use or development of its content. 
Social media user participants could also share their opinion about Canada and their concerns about IRCC.

In addition, all participants were informed that if they did not feel comfortable answering a particular question, they could skip it or terminate the interview or withdraw from the study at any time without negative implications. They were also advised that if they experienced an emotional distress, they could take a break from the interview, finish the interview at another time or withdraw from the study entirely. No participants expressed any concerns but some were not comfortable with the interview being taped. Thus, I took notes instead of recording these interviews.

\section{Conclusion}

This research relies on multiple sources of data. It draws from document analysis of open government policies and existing social media guidelines, analysis of social media resources developed by immigration agencies, as well as interviews with public servants and users of government social media. Analysis of open government policies and content analysis of social media posts and exchanges provide insights on how government agencies are using social media and interviews with public servants explore in more details why they are using it. Similarly, content analysis of user social media posts investigates how migrants are using government social media platforms while interviews with users explore why they use government social media platforms and allow for an analysis of various reasons for use and user experiences.

Overall, different types of data were collected not only to complement each other but also to allow for triangulation of findings and comprehensive analysis. Thus, results from each of the stages of this research were constantly reviewed against each other to generate findings that capture 
different aspects of social media use that no single method can catch. By using a combination of research methods the researcher was able to get insights into the differences between officially declared ways social media is used in government as stated in policy and other documents and how these principles and rules are used in practice. The selected research design also used data collection and analysis tools that allowed for analysis of user perspectives, experiences and expectations and comparison with government approaches.

Although social media data content analysis yielded most of the results that will be discussed in the following chapters, analysis of government policies and other publicly available documents on the government use of social media as well as interviews with public servants and government social media users provided important insights and informed social media data analysis. In addition, the results of preliminary social network analysis allowed for some analysis of the extent to which government managed social media platforms can be viewed as virtual networks and also determined the recruitment strategy for social media users.

The qualitative nature of the research allowed the researcher to gain a complex and detailed understanding of participants' experiences (Creswell 2013). It is important to mention, however, that this research is aimed at exploring perspectives of public servants who develop and publish social media content as well as users of immigration agencies social media resources. Therefore, its results are not generalizable in statistical terms. Some findings, however, may be used in future qualitative, quantitative or mix methods studies in order to formulate research questions, test hypotheses and advance knowledge on social media use by government officials and other types of users.

Upcoming chapters will explore the results of data analysis. Chapter 4 will cover the results of the analysis of open government policies, social media guidelines and terms of social media use 
developed by immigration agencies in Canada, Australia and New Zealand. Chapter 5 explores the results of government social media data content analysis and qualitative interviews with public servants from IRCC and MCI. Finally, in Chapter 6, the results of the migrant users' social media data content analysis and qualitative interviews with social media users are presented. 


\section{Chapter 4. Approaches to the Use of Social Media in Government in Canada, Australia and New Zealand}

Governments around the world are increasingly engaged with Digital Era Governance (Dunleavy et.al. 2006), open government, Web 2.0 and the use of social media to improve and enhance public policy and public administration. Many jurisdictions now have formal open government policies and social media strategies that apply across the public service and in specific

policy areas. However, very little research exists on how these are being used and implemented in public sector organizations.

As this research examines social media use in government, it is important to understand the context, policy and legislative frameworks in which governments operate. Open government policies and social media documents offer insights on how government use of social media is envisioned and regulated, therefore, providing important insights to the first central research question of this study - how and why is social media being used by government immigration agencies. They also offer important basis for comparison between prescribed use of social media and its actual use by government immigration agencies.

This chapter presents findings from an analysis of publicly available government documents focused on three countries that have expansive immigration policies - Canada, Australia and New Zealand. In addition, these countries are members of the OGP, have developed and are currently implementing open government action plans and government immigration agencies in these countries are using social media. Open government action plans and related documents provide a broader context for social media use. Social media related documents discussed below apply to all government agencies within a specific level of government (i.e. all federal or provincial/territorial government agencies) and some are agency specific. 
The first group of documents collected and analysed included open government policies. It is important to note that open government policies in countries that are members of the Open Government Partnership (OGP) - an international non-profit organization that promotes open government and spreads its values and practices around the world - are produced in a form of an action plan on open government (OGP 2017). OGP also identifies priorities and initiatives that each government should commit to deliver. Therefore, the initiatives of an action plan on open government can build on activities that already exist in the member country or compliment work underway. Many of these policies and action plans include commitments to 'open dialogue' using social media strategies, platforms and tools which are viewed as an integral part of open government.

The second group of documents include government-wide frameworks and social media guidelines. They provide general guidelines on the use of social media in government and are aimed at ensuring consistency among all government social media accounts.

Third group of documents collected and analysed include social media strategies of a particular government agency (that is usually an internal document and thus not publicly available) as well as terms and conditions of social media use. These are developed to reflect a given agency's approach and practices of social media use.

This contextual analysis and content analysis of documents helps to understand the boundaries in which government agencies are operating when using social media. It also provides important insights on how open government policies and specifically government-wide approach to the use of social media is operationalized in documents developed by individual government agencies. 
The analysis is structured as follows. First, open government policies in Canada, Australia and New Zealand are analysed. Second, documents that specify how social media should be used by government agencies are examined. It is important to note that although Canada and New Zealand use more standardized approach to government social media accounts, Australian government only defines high level principles of social media use and it is up to individual government departments to develop a social media strategy or framework. Finally, terms and conditions of social media use developed by immigration agencies in Australia (DIBP), New Zealand (Immigration New Zealand) and Canada (IRCC and MCI) are reviewed.

\section{Canada}

Open government and the use of social media are relatively new components of egovernment in Canada. The Canadian federal government, provinces and municipalities began to implement e-government initiatives in the mid-1990s (Roy 2006). The main focus of these initiatives was transition to online services in order to ensure better, quicker and more efficient service delivery as well as adding value for citizens and businesses. By 2005, the Government of Canada declared 'government online' commitment was fulfilled. In the last report on its Government Online initiative, it was stated that the way government interacts with citizens and businesses was fundamentally changed (Government of Canada 2005). After that, e-government lost its position of being in the center of attention for the federal government (Roy 2006; Geist 2013) and Canada is now lagging behind other countries in implementing innovative online public service delivery solutions (Roy 2017). By 2010, the Canadian federal government, and other levels

of government, began focusing on open government and the use of information and 
communication technologies (ICT) in improving public policy, public administration and use of public data for a range of innovation, modernization and other purposes.

\section{Canada's Open Government Policy}

Open government initiatives have revived interest in government use of ICT. Canada's Plan on Open Government that was introduced on April 12, 2012 used to be the only policy document that called for implementation of ICT initiatives across all federal government departments and agencies. Similar initiatives have also emerged across Canadian provinces, territories and municipalities. Currently, these initiatives are primarily focused on open data, however, the province of Ontario announced its own comprehensive open government policy.

The Government of Canada is currently implementing its third open government action plan titled Third Biennial Plan to the Open Government Partnership (2016-2018). It is aimed at further advancing open government principles, increasing openness and transparency and resolving issues identified during the implementation of the first Action Plan on Open Government (2012-2014) and the second Action Plan on Open Government 2.0 (2014-2016).

Action plans on open government define commitments of the Government of Canada and outline implementation milestones. Although previous action plans on open government were focused on three streams of activities: open information, open data and open dialogue, the Third Biennial Plan to the Open Government Partnership introduces a new approach and defines the Government of Canada commitments in four priority areas: 1) open by default, 2) fiscal transparency, 3) innovation, prosperity and sustainable development, and 4) engaging Canadians and the world. The addition of this fourth priority area makes a focus on immigration agencies particularly timely, however, most of the commitments still fall into the three original priority 
streams. Table 4 compares definitions of streams of activities/priority areas on open government for the Government of Canada.

Table 4. Canadian Federal Government Definitions and Open Government Priorities

\begin{tabular}{|c|c|c|}
\hline $\begin{array}{l}\text { Activity } \\
\text { Stream/Priority } \\
\text { Area }\end{array}$ & 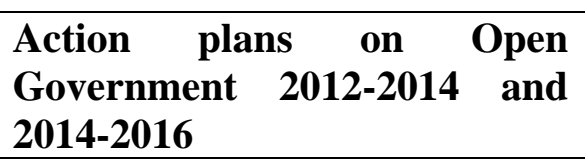 & $\begin{array}{l}\text { Third Biennial Plan to the Open } \\
\text { Government Partnership 2016- } \\
2018\end{array}$ \\
\hline \multirow[t]{2}{*}{$\begin{array}{l}\text { Open Data and } \\
\text { Information }\end{array}$} & $\begin{array}{l}\text { Open Information aimed at } \\
\text { proactively sharing } \\
\text { government information and } \\
\text { making it more accessible } \\
\text { and searchable for users. }\end{array}$ & \multirow{2}{*}{$\begin{array}{l}\text { - Open by Default aimed at } \\
\text { making government data and } \\
\text { information available in open, } \\
\text { standardized, digital formats } \\
\text { and providing easy and } \\
\text { standardized access to it. } \\
\text { - Fiscal Transparency aimed at } \\
\text { greater transparency of } \\
\text { government spending } \\
\text { providing information on it in } \\
\text { reusable formats. } \\
\text { Innovation, Prosperity, and } \\
\text { Sustainable Development } \\
\text { aimed at making agricultural } \\
\text { and geographical data, } \\
\text { information and the results of } \\
\text { scientific research available to } \\
\text { the public. This area also } \\
\text { includes building partnerships } \\
\text { with provincial, territorial and } \\
\text { municipal governments to } \\
\text { create common standards and } \\
\text { principles for open data and } \\
\text { information. }\end{array}$} \\
\hline & $\begin{array}{l}\text { Open Data aimed at making } \\
\text { raw government data } \\
\text { available in machine readable } \\
\text { formats. }\end{array}$ & \\
\hline Public Engagement & $\begin{array}{l}\text { Open Dialogue aimed at } \\
\text { engaging Canadians in two- } \\
\text { way interactions with the } \\
\text { Government of Canada on } \\
\text { government policies and } \\
\text { public service delivery by } \\
\text { using social media platforms. }\end{array}$ & $\begin{array}{l}\text { Engaging Canadians and the } \\
\text { World aimed at using new } \\
\text { technology to engage the } \\
\text { public in policy development } \\
\text { process and promote the } \\
\text { principles of open government } \\
\text { globally. }\end{array}$ \\
\hline
\end{tabular}

Source: Action Plan on Open Government (2012-2014), Action Plan on Open Government 2.0 (2014-2016) and Third Biennial Plan to the Open Government Partnership (2016-2018). 
All three action plans on open government emphasize that the Government of Canada strives to be "open by default" (Government of Canada 2012, 2014, 2016). This principle is also stated in the core policy document on open government - Open Government Directive. The directive specifies mandatory requirements and activities for federal departments aimed at ensuring that Canadians have access to most of government information and data. This is a core document for the open government policy in Canada and federal departments and agencies have to implement its requirements within five years (Government of Canada 2016).

When compared to other priority areas of open government, the area of public engagement does not have as many commitments as open data or open information streams. However, the number of commitments in this area has significantly increased in 2016-2018 action plan. It is also important to note that although the first and the second action plans emphasized the need to use new technology to increase public engagement, Third Biennial Plan to the Open Government Partnership mostly focuses on the need to enhance public participation in policy-making rather than emphasizing the role of technology plays in this process. This priority change could be associated with lack of achievements in use of social media for public engagement purposes. Table 5 summarizes public engagement commitments as outlined in action plans on open government.

Table 5. Public Engagement Commitments of the Government of Canada Action Plans on Open Government

\begin{tabular}{|c|c|c|}
\hline Action Plan 2012-2014 & Action Plan 2014-2016 & Action Plan 2016-2018 \\
\hline $\begin{array}{l}\text { Consulting Canadians: } \\
\text { developing and } \\
\text { implementing a new } \\
\text { interactive platform to } \\
\text { simplify access and } \\
\text { participation in public } \\
\text { consultations }\end{array}$ & \multirow[t]{2}{*}{$\begin{array}{l}\text { Next generation consulting } \\
\text { with Canadians: developing } \\
\text { new and innovative } \\
\text { approaches and solutions in } \\
\text { order to facilitate access to } \\
\text { federal public consultations }\end{array}$} & $\begin{array}{l}\text { Engage civil society on open } \\
\text { government: developing and } \\
\text { maintaining a mechanism for } \\
\text { dialogue with civil society on } \\
\text { open government }\end{array}$ \\
\hline $\begin{array}{l}\text { Open Regulation: increasing } \\
\text { public engagement on }\end{array}$ & & $\begin{array}{l}\text { Enable open dialogue and open } \\
\text { policy-making: enhancing }\end{array}$ \\
\hline
\end{tabular}




\begin{tabular}{|l|l|}
\hline $\begin{array}{l}\text { regulatory activities by } \\
\text { providing annual regulatory } \\
\text { plans for each department } \\
\text { and posting service } \\
\text { standards }\end{array}$ & $\begin{array}{l}\text { citizen participation within and } \\
\text { across government initiatives }\end{array}$ \\
\cline { 2 - 2 } & $\begin{array}{l}\text { Promote open government } \\
\text { globally: undertaking leadership } \\
\text { roles to promote open } \\
\text { government principles in the } \\
\text { global open government } \\
\text { community }\end{array}$ \\
& $\begin{array}{l}\text { Engage Canadians to improve } \\
\text { key Canada Revenue Agency } \\
\text { (CRA) Services: consulting } \\
\text { with the public on matters } \\
\text { related to CRA to ensure that it } \\
\text { delivers high quality services }\end{array}$ \\
\hline
\end{tabular}

Despite fewer commitments in open dialogue stream, the Government of Canada did not complete these activities during implementation of the action plans of 2012-2014 and 2014-2016 (Francoli 2014; TBS 2017). Moreover, some of the commitments were carried over to the third action plan and the Open Regulation commitment was dropped.

The federal Treasury Board Secretariat notes a few successes in the open dialogue stream of the action plans (TBS, 2017). In May 2016, the department issued the new Policy on Communications and Federal Identity and the Directive on the Management of Communications. These documents emphasize the need to use digital media as well as social media and the web for government communication. However, they advocate for the use of social media rather than call for development of concrete implementation plans to ensure public engagement in the development and implementation of policies, programs and/or public service delivery on social media platforms.

Research on open government in Canada has been highlighting the implementation challenges. Researchers have raised concerns with the goals and structure of action plans on open government. Craft (2013) notes that open information and open data commitments significantly 
outnumber open dialogue initiatives. According to Francoli $(2014,2017)$ the main reason for the lack of implementation of open dialogue commitments is the primary focus on open data initiatives and technological solutions. She states that the Government of Canada views open government as "a subset of open data" (Francoli 2014: 9) and that implementation of other commitments creates only incremental changes in open government practices (Francoli 2017; Roy 2016). Thus, the major emphasis is on making government data and information open in order to generate value for the public (Johnson et al. 2017) as well as mandatory reporting on open government progress. However, more attention needs to be paid to public engagement and open information initiatives (TBS 2013, 2017).

Another important issue is the way the role of social media is viewed - it is primarily considered as a tool for public engagement on policy-making. Neither of the action plans acknowledge the role it can play in public service delivery. The closest commitment to this approach for the use of social media in government is Canada Revenue Agency's (CRA) initiative to consult with Canadians - commitment number 22 in the newest action plan on open government. CRA is focusing its efforts on three initiatives for public engagement: (1) measuring satisfaction with tax publications and related data, (2) clarification of rules for charities' political activities, and (3) understanding gaps preventing indigenous Canadians from accessing tax benefits. Thus, the importance of social media in providing customer service, engaging users of services, and improving public service delivery is not currently reflected in the Government of Canada open government policy documents.

\section{Social Media Guidelines}

TBS has developed a number of guidelines and standards on social media that ensure that all Government of Canada social media accounts have a common approach to social media 
management and use. In May 2016, the Policy on Communications and Federal Identity and the Directive on the Management of Communications came into effect and replaced the Communications Policy of the Government of Canada and the Standard on Social Media Account Management. This, according to TBS (2017), created "clear processes, coordination and a common approach for managing social media accounts." Moreover, the Directive on the Management of Communications introduces a more comprehensive approach to the regulation of government communication on digital channels as it covers requirements for a number of digital media and platforms, including social media. Social media analytics is also highlighted as a key component for evaluation of social media impact (TBS 2017).

Mandatory Procedures for Social Media and Web Communications (Appendix D) of the Directive on the Management of Communications lists requirements that all Government of Canada departments and agencies (with a few exceptions ${ }^{6}$ ) have to follow. These include using the Government of Canada's web management platform tool to publish social media content, following established content style guides and templates as well as the web management platform and mobile application processes and ensuring that the content about policies, programs and services is also available on the agency's official website (TBS 2016a).

Therefore, each Government of Canada department has to duplicate the content published on social media on its official website to ensure that the public can access this information. At the same time, the document does not specify the ways government agencies should use social media in order interact with the public or call for such interaction. Mandatory Procedures for Social Media and Web Communications, however, do not assign responsibilities for social media within

\footnotetext{
${ }^{6}$ The requirements of the directive do not apply to the Office of the Auditor General of Canada, the Office of the Chief Electoral Officer, the Office of the Commissioner of Lobbying of Canada, the Office of the Commissioner of Official Languages, the Office of the Public Sector Integrity Commissioner of Canada and the Offices of the Information and Privacy Commissioners.
} 
a specific government agency as the Standard on Social Media Account Management did. The standard stated responsibilities on social media management and monitoring for any agency's senior management, heads of communication and TBS itself. Therefore, the new directive provides more discretion on social media management for government agencies but does not call for the need for two-way interactions between government and the public.

Technical requirements for the government use of social media are captured in Technical Specifications for Social Media Accounts. The purpose of this document is to ensure that the Government of Canada is identified in the same way on all Government of Canada social media platforms. It also states that all government social media accounts should contain a link to terms of use and privacy provisions in order to inform government social media users of their rights and responsibilities when interacting with the Government of Canada on social media (TBS 2016b). Therefore, all Government of Canada social media accounts have to be set according to these requirements. However, again, there is no requirement to ensure that government social media accounts are used to interact with the public.

It is also important to mention that TBS is encouraging government agencies to adopt a hosted Social Media Account Management Solution (Hootsuite) (TBS 2017). Moreover, an Interdepartmental Task Force on Social Media and the Social Media Community of Practice have been established between 2014 and 2015. These groups are tasked with providing guidance and encourage cultural change to evolve social media use within the Government of Canada (TBS 2017). 


\section{Agency Specific Documents}

Government agencies in Canada develop their own social media documents outlining their approach to the use of social media. Most of them are for internal use only, such as social media strategy and social media guidance. However, as per requirement of the Technical specifications for social media account, the Government of Canada agencies establish and publish own terms of use as well as privacy requirements for social media accounts.

IRCC social media use is regulated by Terms and Conditions document published on the official IRCC website. This document explains how IRCC and Service Canada - the department that manages social media related to the passport program - interact on social media. It also outlines rules government social media users have to follow when interacting on IRCC social media platforms.

Terms of use apply to all IRCC social media accounts and are available in both English and French. Currently, IRCC maintains 14 social media accounts. Twitter and Facebook accounts include generic accounts as well as International Experience Canada program accounts available in English and French. IRCC also manages two YouTube accounts, two LinkedIn accounts and two Instagram accounts. English and French accounts are managed separately.

The Terms and Conditions document begins with the acknowledgement that IRCC uses "social media accounts as an alternative method to sharing the content posted on [IRCC] website and interacting with [the] stakeholders" (IRCC 2017c). It is also recognizes that social media is a "24/7 medium" but the department is active on its social media during workdays only (IRCC 2017c). In addition, IRCC is committed to respond to questions within eight business hours. However, the department states that it reads comments and participate in discussions on social media "when appropriate" (IRCC 2017c). 
Furthermore, IRCC's Terms and Conditions outline when the department does not respond and/or interact with the users of its platforms. These include questions and comments about politics, questions about individual cases and messages containing personal information. The department also reserves the right to edit or delete posts, including posts that violate the Canadian Charter of Rights and Freedoms, are offensive and/or express hateful message, contain coarse language, encourage illegal activity, contain an advertisement, encourage illegal activity and are written in a language other than English or French (IRCC 2017c).

Thus, IRCC declares that it uses social media for interaction with the public, specifically to answer people's questions. The terms of use do not mention any approach to the public engagement on social media - the approach to the use of social media that open government policy in Canada has been calling for.

As a government agency of the Province of Ontario, MCI does not have to follow requirements on social media use established by federal government. Moreover, in October 2013, the Province of Ontario launched its own open government initiative that was selected by the OGP for a regional open government pilot program in 2016 (Government of Ontario 2017a). Open government commitments in Ontario include initiatives on open data, open information and public engagement. However, public engagement initiatives are mainly focused on creating special web platforms for public consultations and a consultation directory and do not call for the use of social media to interact with the public. Thus, social media use in the government agencies in Ontario is not directly related to the open government policy.

Nevertheless, the Government of Ontario has developed and published Social Media Terms of Use which all government agencies in Ontario have to follow. However, the document states that some of the Ontario government social media accounts may have more detailed terms of use 
or different hours of operation and that users should check individual accounts to obtain these terms of use (Government of Ontario 2017b).

According to Social Media Terms of Use, "some" government agencies would not respond to users' posts or private messages. Moreover, Ontario government does not make a commitment to respond to every question or being able to answer each question completely and accurately but "will try to respond" to questions during business hours (Ontario Government 2017b).

Terms of use also include requirements for posts on Ontario government social media accounts: for example, no personal information, hateful and/or offensive comments, unauthorized advertising and/or spam messages are allowed. At the same time, Ontario government states that it will not respond to posts that violate these rules. However, no other topics that would not receive a response are identified.

As of July 2017, MCI does not have own terms and conditions of social media use, and references the Ontario Government Social Media Terms of Use on its social media channels. The ministry, however, used to have a separate set of terms of use for its Facebook account, which stated that MCI could not commit to "replying to all comments and/or moderating all discussions on Facebook" (MCI 2016).

It is also important to note that since this dissertation research project began, MCI has changed all its social media accounts, splitting its Twitter account into two separate accounts one for citizenship and one for immigration. MCI Facebook also changed from being solely focused on the Ontario Immigrant Nominee Program to a generic "Ontario Immigration" account. Similar to IRCC, the ministry started to manage English and French accounts separately. In addition, MCI also has a Flickr account. 
Thus, Ontario government acknowledges that government agencies should review and respond to user comments on social media. However, it also makes an exemption for unidentified government agencies that do not have to interact with the public on social media. There is also no direct link between interaction between government and the public on social media and the open government initiatives in Ontario.

It is clear from a review of existing open government and social media policy documents in Canada and Ontario that there is a disconnect between official open government policy and its focus on public engagement and individual agencies' approach to use social media to respond to people's questions. However, existing open government policy is important context for analysing the use of social media in these jurisdictions. It is also important for analysis related to the four key research questions to situate and analyse the use of social media by Canadian government agencies in the broader context of other jurisdictions. For this context and analysis, similar open

government and social media policy documents were examined in Australia and New Zealand, two jurisdictions with similar priorities for using social media in immigration policy domain.

\section{Australia}

Australia began to develop government online presence in 1990s and in 1997, Australia's Prime Minister, announced the commitment to make all appropriate government services online by 2001 (Australian Government 2000). Since the launch of the Government Online strategy in 2000, e-government constantly remained as a priority on the government radar. More recent initiatives also emphasize the need to rely on technology in order to make government more efficient. This is why, open government commitments prioritize the use of innovative technologies and their role in increasing government transparency (Bannister 2011). 


\section{Australia's Open Government Policy}

Although Australia has introduced Australia's First Open Government National Action Plan in December 2016, Australian Government has quite extensive history with open government. Australia declared its interest in open government and started promoting its principles in late 2000s. The Report of the Government 2.0 Taskforce titled Engage: Getting on with Government 2.0 states the need to ensure the use of tools and capabilities of Web 2.0 to "achieve more open, accountable, responsive and efficient government" (Department of Finance 2009). According to the report, social media is considered to be as a technology that can enhance interaction between government and citizens, and increase collaborative relationships. The report also acknowledges that creating Government 2.0 requires leadership, policy and cultural change (Department of Finance 2009).

In response to the report, in July 2010 the Minister for Finance and Deregulation made a declaration of open government (OECD 2011). The federal government of Australia declared its commitment to open government based on engagement, better access and use of government information as well as innovative use of technology (Minister for Finance and Deregulation 2010). The declaration states three major principles in support for government openness and transparency:

- Informing: ensuring access to government information as well as making it more accessible and usable, and establishing a pro-disclosure culture across Australian Government agencies;

- Engaging: involving citizens in government policy and service delivery; and

- Participating: ensuring that government becomes more consultative and participative.

Therefore, from the very early days of the open government policy in Australia Australian government has been emphasizing the need for more interaction and engagement with the public 
on the issues of policy and public service delivery. It also stressed the importance of collaboration between government and the public by making it a major priority of open government.

These principles are further developed in Australian Public Service ICT Strategy 2012 2015 that calls for maintaining Australian Government's position as a world leader in the use of ICT. The strategy identifies important priorities for Australian Government - deliver high quality personalized public services, improve efficiency of government operations by using ICT and enable open communication between government and communities (Department of Finance 2012). It also acknowledges the importance of social media in engaging the public to participate in public service delivery and policy development. It is important to note that there is lack of publicly available evaluations of the strategy.

However, there was a recent significant shift of responsibility for open government policy in Australia: the responsibility for policy development of open government initiatives was assigned to the Department of the Prime Minister and Cabinet and the responsibility for implementation of government digital transformation agenda moved to the newly created Digital Transformation Agency. The Department of the Prime Minister and Cabinet was in charge of developing Australia's First Open Government National Action Plan 2016-18 and conducting engagement sessions to inform the action plan development (Department of the Prime Minister and Cabinet 2016).

The action plan builds on Australian Government open government achievements and identifies areas of commitments. These areas include:

- transparency and accountability in business;

- open data and digital transformation;

- access to government information; 
- integrity in the public sector, and

- public participation and engagement (Australian Government 2016).

Although the document does not specify how social media should be used as an engagement tool, it calls for the use of "digital channels for engagement" (Australian Government 2016). Further, the document mentions existing lack of investment in social media and on-line tools that encourage public participation in government decision-making.

Thus, Australia recognizes the need for public engagement in its open government policy. It also calls for a variety of digital channels to facilitate public engagement. Prior to the existing action plan, Australian Government also emphasized the importance of social media for the delivery of public services. However, it is unclear if any deliverables of Australian Public Service ICT Strategy 2012 - 2015 were completed. More information will be available when Australian Government has to submit a self-assessment and independent report on its progress on the action plan.

Thus, for a period of time social media was viewed by Australian Government as a key component for creating more open and accessible government. Moreover, Australian Government had specified that social media should be used for engaging citizens in both government policy development and service delivery. However, this vision has recently changed. With the adoption of the new open government policy in December 2016, Australian government has shifted its focus from social media's role in public engagement to the use of different digital channels to facilitate public participation in government decision-making.

\section{Social Media Guidelines}

As previously mentioned, Australia currently does not have a document that regulates social media use across all federal government agencies. The Australian Public Service 
Commission (APSC) has issued a guide titled Australian Public Service Values and Code of Conduct in Practice but this document only covers public servants' use social media for personal reasons. The previous guidance - Circular 2012/1: Revisions to the Commission's guidance on making public comment and participating online (social media) - stated requirements for public servants who make comments on social media in official capacity as well as for personal reasons. The document emphasized that comments on social media should be apolitical and should not disclose confidential government information (APSC 2012).

Agency Specific Documents

DIBP has developed agency specific social media user policy and manages Twitter, Facebook, YouTube, Instagram, LinkedIn accounts and its own migration blog. In July 2015, DIBP and the Australian Customs and Border Protection Service (ABF) were integrated into one department. That is why, currently DIBP also manages ABF social media accounts.

DIBP states that the main goal for the use of social media is to provide information about Australia's migration and multicultural policies as well as visa and citizenship services (DIBP 2017a). The department (2017a) commits to provide information and respond to questions posted on social media in a timely manner by referring to useful information on the official website (if appropriate). Information via social media is provided during business hours and questions asked after hours are addressed on the next business day (DIBP 2017a).

The department further specifies that it does not provide immigration advice or respond to questions about an individual situation or application (DIBP 2017a). However, DIBP Twitter account description suggests that the department does not respond to "client or migration queries on Twitter" (DIBP 2017b). The department, however, responds to people's questions on its 
Facebook page and Twitter users are advised to use Facebook to get a response. This practice is not reflected in the social media user policy.

While using DIBP social media channels, users have to follow a number of rules such as no offensive or hateful language, use of plain English for conversations, no advertisements and no political content. The department reserves the right to enforce the policy at its discretion and remove messages that violate user policy.

Therefore, similar to Canadian immigration agencies, DIBP is present on social media to provide information about existing programs and services as well as respond to people's questions. However, DIBP only responds on Facebook while Twitter is not seen as a platform for "client or migration queries". Furthermore, the department does not commit to engaging with the public on policy issues or encourage public participation in government decision-making. Therefore, there is no direct link between open government policy and DIBP social media practices.

\section{New Zealand}

New Zealand started to implement e-government initiatives in mid 1990s (Millar 2004). Boyle and Nicholson (2003) state these initiatives were focused on increasing efficiency of government's use of ICT and improving efficiency and simplifying interactions between government and citizens. Since that time, New Zealand Government achieved significant progress and was recognized by the United Nation as one of the leaders in e-government (Boyle and Nicholson 2003). New Zealand Government introduced its first E-Government Strategy in 2001 and the second e-government strategy - Enabling Transformation was introduced in 2006.

New Zealand's open government initiative derives from its e-government work. In October 2010, New Zealand Government declared its commitment to the principles and values of open 
government (Department of Internal Affairs 2010). Directions and Priorities for Government ICT (2010) that replaced the 2006 e-government strategy states called for open and transparent government through:

- improvement of access to government data and information;

- engagement of the public, communities and businesses in policy development and performance improvement; and

- maximizing opportunities for reusing government data and information.

These commitments were further developed in the Government ICT Strategy and Action Plan to 2017. This document focuses not just on open government but broader transformation of ICT use in government. Furthermore, improvement of online service delivery is considered to be the major priority for the government and open government is primarily associated with the availability of government information and datasets for public use (New Zealand Government 2013). Until recent changes that were made to the strategy in 2015, New Zealand Government was particularly interested in using social media to engage stakeholders in the process of service delivery improvement. Moreover, it was expected that social media would make online consultations and engagement more accessible and prompt (New Zealand Government 2013). However, presumably due to the lack of progress on implementing this initiative, it was dropped from the revised version of the strategy.

\section{New Zealand's Open Government Policy}

The connection between e-government and open government is further reflected in the New Zealand's Open Government Partnership National Action Plans 2014-2016 and 2016-2018. Both of the action plans are linked to documents that describe broader government transformation 
initiatives, including Government ICT Strategy and Action Plan to 2017. In fact, all commitments of the first action plan are based on the initiatives that were developed and started to get implemented before the action plan came into effect. These include initiatives to improve delivery of public services, develop ICT infrastructure and engage with the public (Price 2017). Moreover, New Zealand Government (2016) emphasizes that the action plan cannot fully capture all work on open government that is currently being done across government thus focusing only on a number of initiatives.

Nevertheless, commitments of both action plans focus on three areas: open data, open information and civil society engagement in decision-making and public service delivery improvement. However, Price (2017) notes that although New Zealand Government consulted civil society organizations on public engagement practices, it is lagging behind on the commitment to produce guidelines on public participation in government decision-making.

Therefore, New Zealand Government recognizes that social media is an important component of public engagement. However, it emphasizes that public engagement should be done in a number of ways, applying both face-to-face and online methods to attract as many participants as possible. Thus, the role of social media is acknowledged but there is no commitment to use it as a primary tool for engagement with the public on policy development and/or public service delivery improvement.

Similar to Australia, New Zealand Government's approach to the use of social media by government agencies changed over years. In 2013, there was a lot of enthusiasm about the potential of this new technology for public engagement on public service delivery improvement. However, the approach of the action plans on open government is a more cautious one: social media is acknowledged but just as one of the public engagement/consultation tools. 


\section{Social Media Guidance}

The New Zealand government social media guidance was developed by the Department of Internal Affairs in 2011. Since that time, the guidance has evolved and was amended with new practices. Currently, the Social Media in Government Guidance includes three documents: highlevel guidance, hands-on toolbox and how to handle a mishap guide. The purpose of these documents is to encourage social media use by government agencies, provide helpful templates and tools as well as describe strengths, weaknesses, benefits and risks of using social media in government (Department of Internal Affairs 2014).

This high-level guidance provides background information about social media and its role in New Zealand society as well as identifies a spectrum of government use of social media as passive involvement, active presence and engaged participation (Department of Internal Affairs 2011a). Interestingly, the "engaged" stage of government use of social media is defined as the "need to post regularly, moderate comments as appropriate and check regularly for messages that require a response" and does not include any requirements for public engagement on social media (Department of Internal Affairs 2011a: 7). At the same time, in the very beginning of the document, community engagement and policy consultations are mentioned as possible goals for the use of social media in government. It is also important to mention that the document emphasizes that social media requires quick communication, thus, staff should be delegated appropriate authority to ensure the real or near-real time communication.

The purpose of the Hands-on Toolbox document is to assist practitioners who are directly involved with setting up social media accounts, managing and maintaining them (Department of Internal Affairs 2011b). It also introduces best practices of social media use and calls for the need to quantitatively and qualitatively evaluate activity on government social media accounts. 
Finally, the How to Handle a Mishap document provides guidance on how government agencies should respond when everything "goes terribly wrong" on social media (Department of Internal Affairs 2012). This guide describes what should be done before, during and after the mishap event happens and offers strategies to respond to it.

Therefore, New Zealand Government has developed a rather comprehensive guidance on the use of social media in government. This guidance is recognized by the Open Government Guide - an initiative to support the OGP. ${ }^{7}$ However, this guidance focuses primarily on social media risks and the ways of handling them, and offer cautious suggestions on the ways social media can be used in government. Furthermore, there is no concrete guidance on public engagement and conducting public consultations on social media.

\section{Agency Specific Documents}

Immigration New Zealand, which is a division of the Ministry of Business, Innovation and Employment, has a number of social media accounts. They include two Facebook accounts - one for those who are arriving to live in New Zealand (New to New Zealand) and one for those who are interested in moving to New Zealand (New Zealand Now), one Twitter account for those interested in living and working in New Zealand and one YouTube account.

There is no single terms and conditions of use document that apply to all Immigration New Zealand social media. Moreover, two Facebook accounts have different posting policies and Twitter account does not refer to any terms of use. Furthermore, Immigration New Zealand does not commit to any kind of engagement with the public on social media in its social media posting policies. The main goal of these disclaimers on Facebook pages is to ensure that posts are

\footnotetext{
7 This initiative collects best practices on different open government initiatives from the OGP member countries.
} 
acceptable for the public and do not offend others, contain coarse language or advertisements and/or encourage illegal activity (Ministry of Business, Innovation and Employment 2015, 2017). In addition, there is a warning that information provided on Facebook pages is not professional or legal advice and "specific advice should be sought from qualified professionals" (Ministry of Business, Innovation and Employment 2017).

Therefore, unlike IRCC, MCI and DIBP, Immigration New Zealand does not declare its intention to interact with the public on its social media platforms. It is also unclear what the division's main purpose for the use of social media is. Posting policy of the New to New Zealand Facebook page just encourages new migrants to share their experiences, ideas, answer questions and enjoy interacting with others on this platform (Ministry of Business, Innovation and Employment 2015).

Therefore, Canada, Australia and New Zealand have developed open government policies as well as social media guidance. In addition, federal government immigration agencies in these countries are using social media as a part of their communication routines. Table 6 summarizes the findings of this chapter and provides a comparison between Canada, Australia and New Zealand.

Table 6. Comparison of Open Government Policies and Social Media Strategies and Guidelines in Canada, Australia and New Zealand

\begin{tabular}{|l|l|l|l|}
\hline & Canada & Australia & New Zealand \\
\hline $\begin{array}{l}\text { Does open government policy } \\
\text { exist? }\end{array}$ & Yes & Yes & Yes \\
\hline $\begin{array}{l}\text { What is the role of social } \\
\text { media in initial open } \\
\text { government policy (2012- } \\
\text { 2014)? }\end{array}$ & $\begin{array}{l}\text { To simplify access } \\
\text { and participation } \\
\text { in online public } \\
\text { consultations }\end{array}$ & $\begin{array}{l}\text { Key technology for } \\
\text { creating } \\
\text { Government 2.0 }\end{array}$ & $\begin{array}{l}\text { Key technology for } \\
\text { public engagement } \\
\text { on improvement of } \\
\text { public service } \\
\text { delivery }\end{array}$ \\
\hline $\begin{array}{l}\text { What is the role of social } \\
\text { media in the newest open } \\
\text { government policy? }\end{array}$ & $\begin{array}{l}\text { No mention in } \\
\text { commitments on } \\
\text { open dialogue. }\end{array}$ & $\begin{array}{l}\text { No specific mention } \\
\text { of social media. } \\
\text { Calls for more }\end{array}$ & $\begin{array}{l}\text { No specific } \\
\text { mention of social } \\
\text { media. Calls for the }\end{array}$ \\
\hline
\end{tabular}




\begin{tabular}{|c|c|c|c|}
\hline & $\begin{array}{l}\text { Calls for } \\
\text { conducting online } \\
\text { public } \\
\text { consultations with } \\
\text { Canadians }\end{array}$ & $\begin{array}{l}\text { effective use of } \\
\text { digital channels for } \\
\text { public engagement }\end{array}$ & $\begin{array}{l}\text { need to engage on } \\
\text { open government } \\
\text { topics by using a } \\
\text { variety of means, } \\
\text { including online } \\
\text { platforms }\end{array}$ \\
\hline $\begin{array}{l}\text { Do social media guidelines/ } \\
\text { standards/ strategy exist? }\end{array}$ & $\begin{array}{l}\text { Mandatory } \\
\text { Procedures for } \\
\text { Social Media and } \\
\text { Web } \\
\text { Communications } \\
\text { (Appendix D) of } \\
\text { the Directive on } \\
\text { the Management } \\
\text { of } \\
\text { Communications } \\
\text { developed by TBS }\end{array}$ & $\begin{array}{l}\text { Public Service ICT } \\
\text { Strategy } 2012- \\
2015 \text { included high- } \\
\text { level guidance on } \\
\text { how to use social } \\
\text { media. } \\
\text { Each government } \\
\text { agency develops } \\
\text { own social media } \\
\text { guidelines }\end{array}$ & $\begin{array}{l}\text { Social media: high- } \\
\text { level guidance, } \\
\text { hands-on toolbox } \\
\text { and how to handle } \\
\text { a mishap guidance } \\
\text { developed by the } \\
\text { Department of } \\
\text { Internal Affairs }\end{array}$ \\
\hline $\begin{array}{l}\text { Do federal government } \\
\text { immigration agencies use } \\
\text { social media? }\end{array}$ & $\begin{array}{l}\text { Four Twitter } \\
\text { accounts, four } \\
\text { Facebook } \\
\text { accounts, two } \\
\text { YouTube } \\
\text { accounts, two } \\
\text { Instagram } \\
\text { accounts and two } \\
\text { LinkedIn accounts }\end{array}$ & $\begin{array}{l}\text { Twitter, Facebook, } \\
\text { YouTube, } \\
\text { Instagram, LinkedIn } \\
\text { and migration blog }\end{array}$ & $\begin{array}{l}\text { Twitter, two } \\
\text { Facebook accounts, } \\
\text { YouTube }\end{array}$ \\
\hline $\begin{array}{l}\text { Do federal government } \\
\text { immigration agencies commit } \\
\text { to interacting with the public } \\
\text { on social media? }\end{array}$ & Yes & Yes & No \\
\hline $\begin{array}{l}\text { Number of followers for } \\
\text { Twitter and Facebook }{ }^{8}\end{array}$ & $\begin{array}{l}\text { Generic Twitter } \\
\text { (English) }-132 \mathrm{~K} \\
\text { Generic Twitter } \\
\text { (French) }-7.2 \mathrm{~K} \\
\text { Generic Facebook } \\
\text { (English) }-1.2 \mathrm{M} \\
\text { Generic Facebook } \\
\text { (French) }-181 \mathrm{~K}\end{array}$ & $\begin{array}{l}\text { Twitter }-15.7 \mathrm{~K} \\
\text { Facebook }-456 \mathrm{~K}\end{array}$ & $\begin{array}{l}\text { Twitter }-2.8 \mathrm{~K} \\
\text { Facebook: } \\
\text { New to New } \\
\text { Zealand)- } 48 \mathrm{~K} \\
\text { New Zealand now } \\
-1.7 \mathrm{~K}\end{array}$ \\
\hline
\end{tabular}

${ }^{8}$ These data are as of July 7, 2017. 


\section{Conclusion}

Analysis of open government policies and social media documents of Canada, Australia and New Zealand allows this study to situate its findings within a broader international open government agenda and at the same time, provides an opportunity for contextualizing the findings in relation to the central research questions. Moreover, it offers important insights on how government approach to social media use has developed overtime and helps to explain the disconnect between open government principles and routine everyday use of social media by government agencies, thus setting the context for this study. This disconnect will be further discussed in Chapter 5.

As the findings of this chapter show, since their initiation in 2010-2012, open government policies in Canada, Australia and New Zealand have evolved and are currently focused on opening up government data and information as well as public engagement. However, as these three countries made quite significant progress on their open data commitments, the public engagement stream of activities remains a work in progress. Moreover, the role of social media in "opening up" government has shifted as well. In 2010-2012, social media was viewed as a primary platform for public engagement and conducting public consultations on public policy and public service delivery. Furthermore, governments were calling for two-way interactions between government agencies and the public on social media. Now these ambitious statements have disappeared. In their latest action plans on open government, Canada, Australia and New Zealand are pointing out that social media is one of the many ways to engage with the public and are committing to engage the public in government decision-making in a variety of ways.

In addition, independent review reports of open government action plans note that implementation of public engagement commitments are incomplete (Francoli 2014, 2017; Price 
2017). This issue, however, is not new for government agencies. Scholars note that government leaders and officials lacks an understanding of the need for public engagement in government decision-making, regardless if it is virtual or in person (Clarke 2012; McNutt 2014). This situation is even more difficult given the lack of interagency and intergovernmental cooperation and collaboration as well as the 'siloed' approach that is used by government agencies to tackle and advance the use of social media related to open government.

The findings of this research confirm those from existing literature. The existing open government policy of the Government of Canada is not the only reason for the government use of social media. Clarke and Francoli (2014, 2017), Craft (2013), Francoli (2014) and Roy (2016) note that the focus of Government of Canada remains on open data and open information initiatives while there is no significant progress in regards to open dialogue initiatives. Furthermore, although the third action plan on open government calls for increased public engagement, there is no specific mention of the need to use social media for this purpose. In addition, TBS (2017) in its evaluation of the second action plan implementation admits that there was no significant progress in any open dialogue initiatives and this commitment is evaluated as incomplete.

Moreover, Canada's open dialogue initiatives are limited only to engaging with the public on policy-making matters. At the same time, governments of Australia and New Zealand clearly state the importance of social media in public service delivery in their open government documents. However, neither Canada nor Australia or New Zealand identify social media as a significant part of open government action plans or service delivery channel, thus, limiting its use to customer service function. Furthermore, terms of social media use for IRCC and MCI in Canada and DIBP in Australia that government agencies will provide information about programs and services as well as respond to questions. However, government agencies reserve the right to 
participate in discussions and answer questions when appropriate (DIBP 2017; IRCC 2017; MCI 2017).

Thus, social media use in government in its current form has developed without direct impact from open government policies. However, within this broader context of digital government and open government policies and action plans, federal governments in Canada, Australia and New Zealand have developed social media guideline documents that encourage government agencies to use social media and interact with social media users. Furthermore, reviewing open government policy documents allows to situate individual government agencies' use of social media in the broader digital government and open government context. Analysis of different types of social media documents also shows that these countries approach social media use from different perspectives: while New Zealand has a more centralized approach that implies that all government agencies should follow a number of centrally established guidelines, Australia and Canada have a more decentralized approach, where individual government agencies have more flexibility in establishing own social media policies. Further research is needed to investigate, which model is more appropriate, however, the importance of social media strategy either at a central (national) level or at an individual government agency level cannot be underestimated.

Examining specific policy documents and guidelines related to social media use is an important part of the analysis related to the central research questions. Again, analysis of government-wide social media guidelines helps to contextualize importance and existing practices of social media use. For example, of the jurisdictions reviewed only the New Zealand government specifically acknowledged the need to respond to people's questions on social media when a government agency is at the "engaged stage" of government use of social media (Department of Internal Affairs 2011a). Canada and Australia do not specify concrete ways social media should 
be used in government. Thus, there is no obvious connection between open government policies, open dialogue priorities and two-way interactive uses of social media. If the role social plays in public service delivery in recognized in open government policy documents, government agencies could feel encouraged to use this technology for public service delivery in a number of ways, including customer service and potentially seeking public feedback on government services and programs.

Moreover, it is clear from the social media document analysis that federal immigration agencies in Canada, Australia and New Zealand are primarily using social media to provide information about programs and services. Although Canada is far ahead of Australia and New Zealand in terms of the number of followers of IRCC on Twitter and Facebook, there are important similarities in approach to the use of social media between the federal immigration agencies in each country. Interestingly, none of the federal immigration agencies indicate that they look to engage with the public on policy matters, service delivery or other two-way exchanges with users on social media in their written social media terms of use. However, IRCC in Canada and DIBP in Australia do state that they are committed to respond to people's questions on their social media platforms. Immigration New Zealand is currently only providing a space for social media users to interact with each other and share their experiences. At the same time, this current customer service function of social media - providing answers to people's questions - is not reflected in open government policies.

Therefore, social media use by immigration agencies in Canada and Ontario is a result of specific agency efforts and investments and does not flow from central agency or open government policy documents. As will be outlined later in Chapter 5, this is supported by experiences of federal and Ontario public servants who note that there is no direct connection between the goals of social 
media use in their agency and the goals of open government policy. They did however, emphasize that they adhere to the "spirit" of open government. Therefore, despite the focus of earlier Canadian open government action plans on the need to use of social media to engage the public in consultations and policy-making, as the cases of IRCC and MCI show in subsequent chapters, they are only considering social media to be a customer service and information dissemination tool.

Comparison of open government policies and social media documents in Canada, Australia and New Zealand sets important context for the study. As noted, Canada is not the only country experiencing a disconnect between its open government policy and social media practices of individual government agencies. At the same time, Australia and New Zealand used to acknowledge the importance of social media use for public service delivery, which can be an important addition and focus of open government policy in Canada.

Analysis of policy and other government documents indicates that social media use in public administration is best examined in a specific policy domain but taking into account the broader context of national and subnational policies and practices. The next two chapters focus on government use of social media by two Canadian immigration agencies - the federal government's immigration agency (IRCC) and the Province of Ontario's immigration agencies (MCI) - and then specifically on the perspective of users of immigration agencies' social media. 


\section{Chapter 5. Government Use of Social Media: Cases of IRCC and MCI}

The now vast and growing literature on e-government, open government and Web 2.0, emphasizes the benefits of social media use and calls for its government-wide adoption. However, the research to date shows that governments are mostly using social media to publicize the content from their official websites but rarely focus on public engagement or networking (Landsbergen 2011; Mergel 2012; McNutt 2014). Thus, although there is a general agreement that government should use social media (McNutt 2014; Mergel 2012), there is lack of understanding why government should go beyond the one-way transmission of existing content based on government provider-citizen receiver approach.

Mergel (2013b) argues that this approach is happening because governments lack clear understanding of how social media can be used and how they can benefit from using it. In addition, the consequences of not using it are also quite vague. Researchers describe them as a missed opportunity to "democratize democracy" - collaborate with the public and include citizens in government decision-making by using new technology that enables to instantly voice opinions and share experiences (Mergel and Greeves 2013: 23).

Lu et al. (2016) describe three levels of interaction between government and the public on government social media. The first level is one-way interaction or use of social media solely to provide information. Governments are interested only in spreading their own information by using a new way to disseminate it. However, the content that is being shared is usually available on the official website and is just being retransmitted through a different communication channel (Mergel 2012). The second level involves two-way interaction between government and the public. Here, government agencies and the public are engaged in a dialogue and social media can be used as a new platform for public consultations to gather opinions and ideas. Finally, the highest level of 
interaction is collaboration among the government and the public through the co-development of policies and co-production of public services (Bertot et al. 2010). Therefore, the network developed on government social media becomes self-sustainable and contributes toward achieving common goals of making improvements to public policy and public service delivery.

As the review of social media related government documents show, government agencies do not specify how social media can be used for engagement with the public. However, IRCC and MCI social media terms of use point out that both government agencies are committed to answering questions on their social media platforms. Therefore, the purpose of this chapter is to explore in more detail how government agencies are using social media and why they are interested in using it.

The analysis is based on social media data retrieved from the IRCC Twitter and Facebook accounts as well as in-depth interviews with IRCC and MCI public servants. The chapter is organized as follows. First, it examines how IRCC interacts on Twitter and Facebook. Second, differences in the use between the platforms are discussed. Finally, data from in-depth interviews with IRCC and MCI public servants are used to identify government priorities for the use of social media as well as factors that enable and hinder its use. The chapter also focuses on what the effective use of social media looks like for the perspective of public servants.

\section{Organization of the IRCC and MCI Facebook and Twitter Accounts}

Before I start to discuss IRCC use of social media, it is necessary to describe how the IRCC Facebook and Twitter accounts are set up. This is important for two reasons: first, the functionality enabled on the account determine what publicly available data can be collected and second, it helps to understand what types of communication is encouraged on government social media as well as 
boundaries for interactions between government and users. IRCC and MCI approach to the layout of social media accounts, features enabled on them and overall user friendliness are also compared.

Both IRCC and MCI Twitter accounts provide basic information about these government agencies, contain a link to the terms of use and a handle for the French version of the account. However, IRCC only allows users to follow and tweet at IRCC. Therefore, they cannot send a direct (private) message to IRCC, as this feature is not enabled on the account. This issue is quite significant for users who have to ask IRCC to follow them in order to be able to leave a direct message. MCI, on the contrary, allows users to contact them via a direct message and do not require users to follow their account to be able to do that. MCI also makes visible Twitter streams of the accounts added to the "list" - a group of selected Twitter accounts that the ministry is a member of and is subscribed to. These include other government agencies, non-profits and individuals. However, this feature is enabled on the Ontario Citizenship Twitter and not available on the Ontario Immigration Twitter. Therefore, MCI offers its Twitter users information about different accounts and does not limit them solely to government ones. Moreover, MCI allows users to send a direct message without publicly revealing that a user seeks to engage with the ministry on social media.

Facebook pages of IRCC and MCI provide basic information about the agencies as well as links to official website and existing electronic services. There is also an option to view pages that these accounts liked and presumably get more information. However, the IRCC Facebook page can be a challenge for users: they cannot leave a comment or ask a question other than by responding to an IRCC post. There is also no option to send a private message. Therefore, a question posted by a user might be totally unrelated to the topic of the post, which can create user confusion, especially if the user does not have a good command of English. MCI, on the other 
hand, allows users to leave "visitor posts" directly on the Facebook page as well as to send a private message. Therefore, users are not restricted to the single way of reaching out - by leaving a comment attributed to a specific Facebook post.

As mentioned in Chapter 3, due to a lack of reliable MCI data for both its Twitter and Facebook accounts, the decision was made to exclude them from analysis. Therefore, social media data analysis below is based on IRCC Twitter and Facebook data only.

\section{IRCC Interaction on Twitter}

The IRCC Twitter account allows users to follow and tweet to the department. There is no option to send a direct message before the user's account is followed by IRCC. Therefore, the only way to start interacting on the IRCC Twitter is to tweet @ CitImmCanada. Thus, the analysis of IRCC tweets covers the vast majority of responses and comments provided by the department to users. Some conversations, however, could continue via direct messages.

IRCC is quite active on its Twitter account. On average, IRCC left 317 tweets per month with the highest number of tweets in July 2016 and the lowest in September 2015. The spike in IRCC activity after the election and during the refugee campaign is also quite prominent. Increased activity in June and July can be potentially explained by availability of additional staff for summer as well as the public consultation on the future of immigration in Canada that was held in July 2016. It is also important to note the difference in a number of tweets IRCC left under the Harper government and the new Trudeau administration. Figure 5 shows the number of IRCC tweets between September 2015 and August 2016.

The following results are based on the analysis of 1,893 IRCC tweets (50\% of all collected IRCC tweets over the year of data collection). Analysis of twitter data indicates that although IRCC 
is responding to user questions, it is primarily using information that is available on its website or from existing government sources. More than two thirds of IRCC responses contain a link to the information available on the IRCC website. Pure referrals to the website (replies that do not have any information beyond a suggestion to check the Help Centre page of the website - a frequently asked questions page - or referring to web tools and forms) account for about a quarter of all responses. Therefore, most users have to look for information on the IRCC website even after receiving a response from the department. This confirms literature that indicates that government agencies are retransmitting information from their websites (Landsbergen 2011; Mergel 2012).

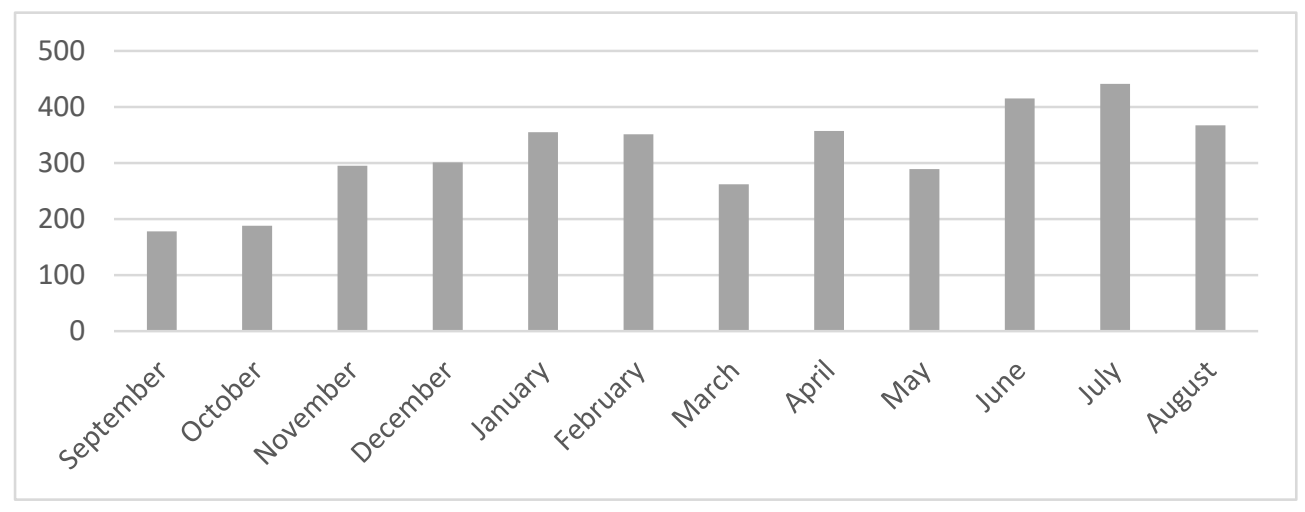

\section{Figure 5. IRCC Tweets (September 2015-August 2016)}

However, the dissemination of information is not one-directional. IRCC is involved in twoway interactions with the users on its Twitter account. Moreover, the department mostly uses its Twitter account to respond to user questions (67\% of IRCC tweets). Therefore, proving responses to users' questions can be seen as IRCC priority on Twitter.

Sharing information about department's programs and services is also quite important. This information as well as notifications about events such as citizenship ceremonies and events for newcomers to Canada account for $25 \%$ of IRCC tweets.

The department rarely retweets anything from other accounts (5\%) and the vast majority of these retweets are for messages from other official government accounts. IRCC also tweets to 
thank users, thus developing amicable ties (3\%). This mostly happens when users share pictures from citizenship ceremonies that are later compiled in a separate "congratulatory tweet" by IRCC. All other messages account for $1 \%$ of the tweets (Figure 6).

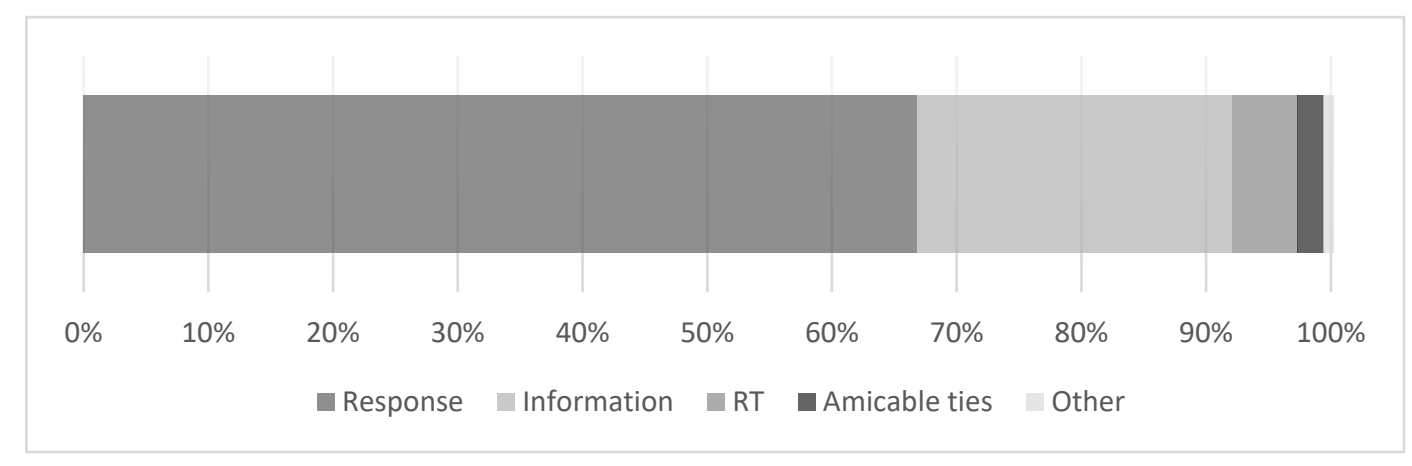

\section{Figure 6. Categories of IRCC Tweets}

In terms of topics and themes, most of the answers that IRCC provides are about specific programs and services (24\%) and application related matters (17\%). IRCC is answering less questions about processing times (14\%) and technical issues (12\%). It is also important to note that only less than $1 \%$ of the answers were about processing times for spousal sponsorships. Most of the responses (27\%), however, contain nothing but a referral to the department's Help Centre page, a specific webpage of IRCC website or a web form to request case specific information. All other matters account for $6 \%$ of tweets. Interestingly, only $1 \%$ of answers provided by the department are about the refugee programs. This topic, however, was extensively promoted by the department between November 2015 and March 2016.

On the other hand, IRCC leaves quite a few informational tweets about refugees $(28 \%)-$ the highest number among informational tweets. These are followed by information regarding eTA (14\%) and information about events such as citizenship ceremonies, celebration of holidays and fairs (9\%). Overall, IRCC mostly provided information about its programs and services (68\% of 
all informational tweets). Some of this information was targeted to specific user groups such as newcomers to Canada, visitors and Canadian citizens.

It is important to note that IRCC is monitoring if users are posting any personal information such as case numbers, emails and phone numbers and advise them to delete all tweets containing it. This is not, however, the case with any other forms of violations of terms and conditions of IRCC social media use, including coarse language, unproven accusations against certain individuals or organizations, tweets written in a language other than English or French - all these tweets continue to remain available to the public.

\section{IRCC Interaction on Facebook}

Navigating IRCC Facebook page presents serious difficulties for users: they cannot leave a comment or ask a question other than by responding to an IRCC post. Users also cannot send a private message. Therefore, a question or comment posted by a user might be totally unrelated to the topic of the post. Thus, a user is forced to violate terms of IRCC social media use stating that user social media comments should be relevant to the post (IRCC 2017c).

As IRCC does not send any private messages on Facebook, all IRCC posts on its Facebook page between September 2015 and August 2016 are included into the analysis. It is important to note that IRCC does not use Facebook as much as Twitter. 
Between September 2015 and August 2016, IRCC posted on average 43 times per month. Again, similarly to IRCC tweets, there was a significant difference in the number of posts before the elections and after the elections. The number of posts continued to grow during the refugee campaign and then again spiked in August (Figure 7). However, the highest number of IRCC Facebook posts was 85 posts in August 2016, which is much lower than the lowest number of IRCC tweets -178 tweets in September 2015. This difference can be partially explained by the different nature of platforms noted by public servant interview participants - i.e. Twitter requires more frequent updates in order for them to be noticed. However, the difference in responses to user questions is very significant.

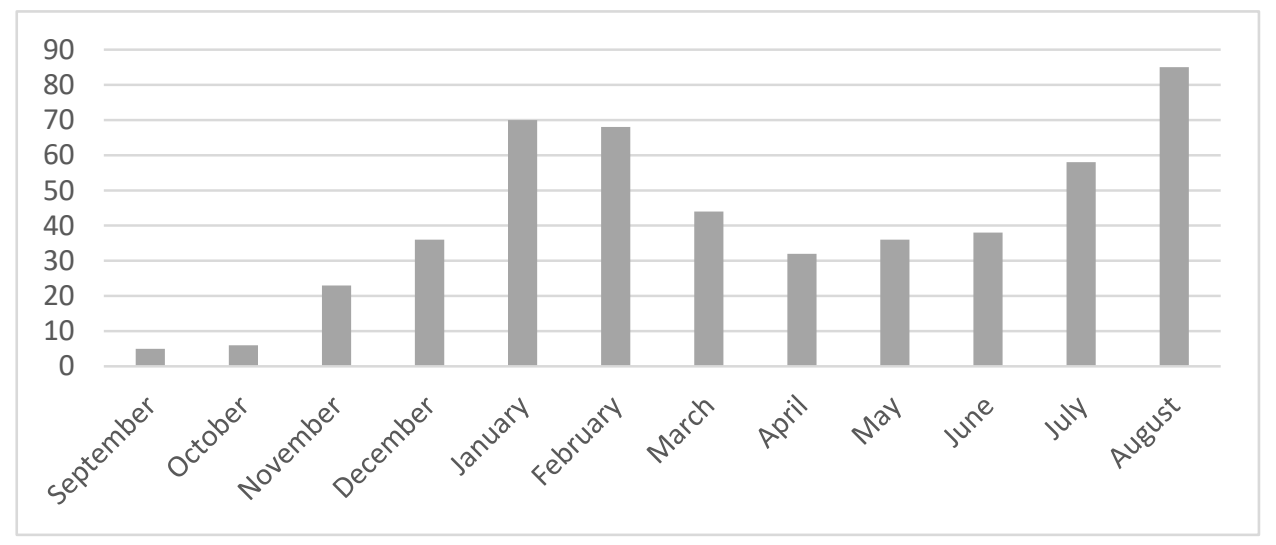

\section{Figure 7. IRCC Facebook Posts (September 2015-August 2016)}

In total, 244 IRCC Facebook posts were analysed. As the analysis shows, IRCC uses Facebook primarily to disseminate information about its programs and services (78\%). Only $21 \%$ of all analysed posts are responses to people's questions. Over a period of a year, IRCC responded to 110 people's questions. Sharing third party information accounts for remaining $1 \%$ of the posts (Figure 8). This supports the literature stating that governments are only interested in "pushing" their content but not seeking any feedback or engagement on social media (Lee and VanDyke 2015). 
Furthermore, $73 \%$ of responses contain a web link referring users to the website for further information and $21 \%$ do not contain any information other than a referral to the website. This finding is especially interesting considering the fact that Facebook does not have character limitations like Twitter and allows IRCC to provide all necessary information in the post itself. Almost half of all responses are devoted to IRCC programs and services followed by processing times (10\%), technical issues (8\%), application-related questions (6\%) and other matters (2\%).

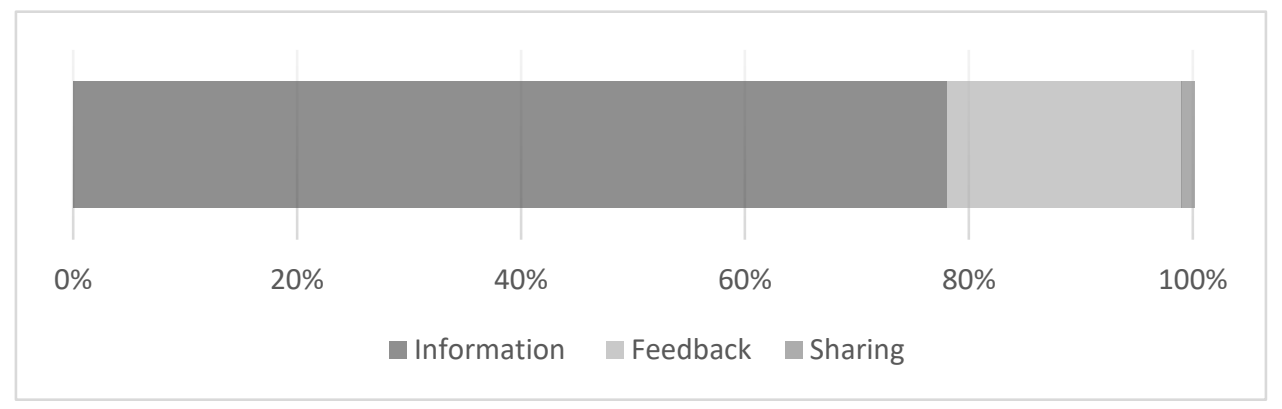

\section{Figure 8. Categories of IRCC Facebook Posts}

The department does not monitor user activity on its Facebook page. It also does not warn Facebook users about the inclusion of personal information or any other violated terms and conditions of use. This leads to a number of problems such as advertising of illegal activity, misleading information, etc. The department, however, was not named among government agencies that delete posts violating terms of use (Thompson 2017). These issues will be discussed in the next chapter.

\section{Differences in the IRCC Use of Twitter and Facebook}

IRCC communicates with users on both social media platforms. However, the department does not use Facebook as much as Twitter. An average number of IRCC tweets per month is 317, while the number of Facebook posts is significantly lower -43 posts per month. In November 
2015, after the change in government, the use of both platforms increased. Furthermore, the number of tweets and posts further grew in January and February - during the Syrian refugee campaign and slightly decreased after this campaign was over. After February, the number of Facebook posts declined until July. IRCC activity on Twitter fluctuated depending on the month but increased in June and July. Figure 9 compares IRCC use of Twitter and Facebook between September 2015 and August 2016.

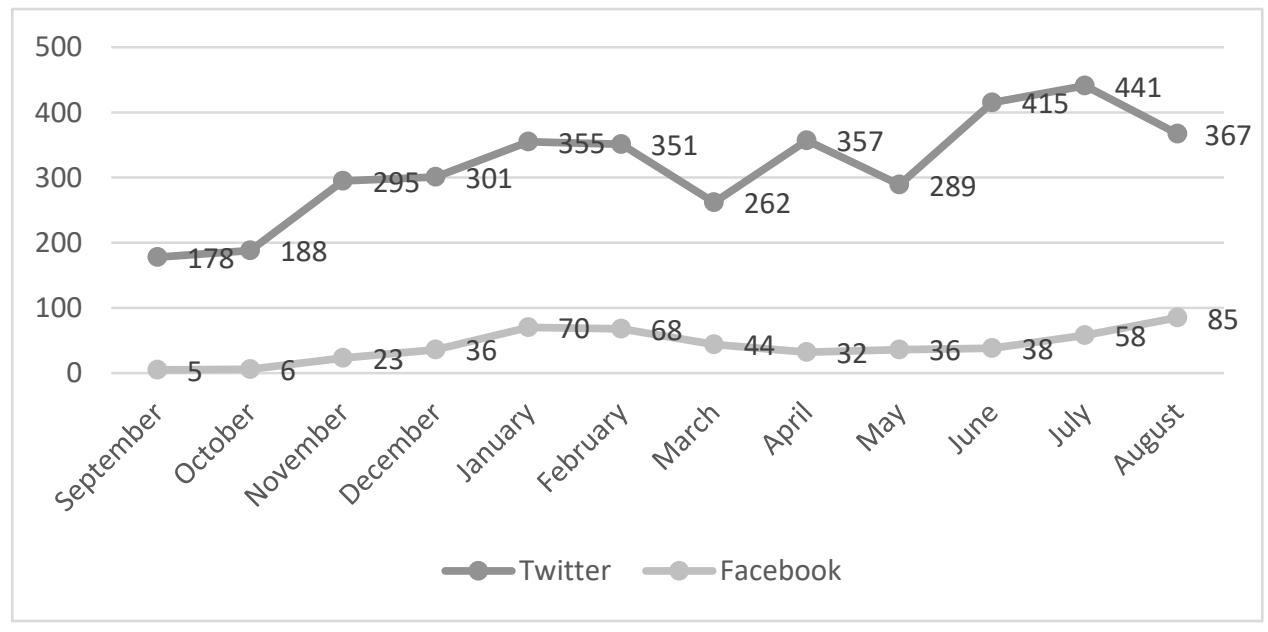

\section{Figure 9. IRCC Tweets and Facebook Posts}

The analysis shows that IRCC uses both Twitter and Facebook accounts for two main purposes: (1) to provide information and (2) to respond to user questions. However, there is a big difference in the ways the department approaches the use of these platforms (Figure 10).

As the results show, IRCC uses Twitter more actively compared to Facebook. First, there are seven times more IRCC tweets per month than Facebook posts. Second, IRCC responds on Twitter much more frequently: the lowest number of responses on Twitter in September is 154, while on Facebook IRCC responded 110 times over a period of a year. IRCC, however, does not retweet or share much of the third-party information on Facebook and when it happens, the vast majority of these shares are for the tweets or posts from other official government accounts. 


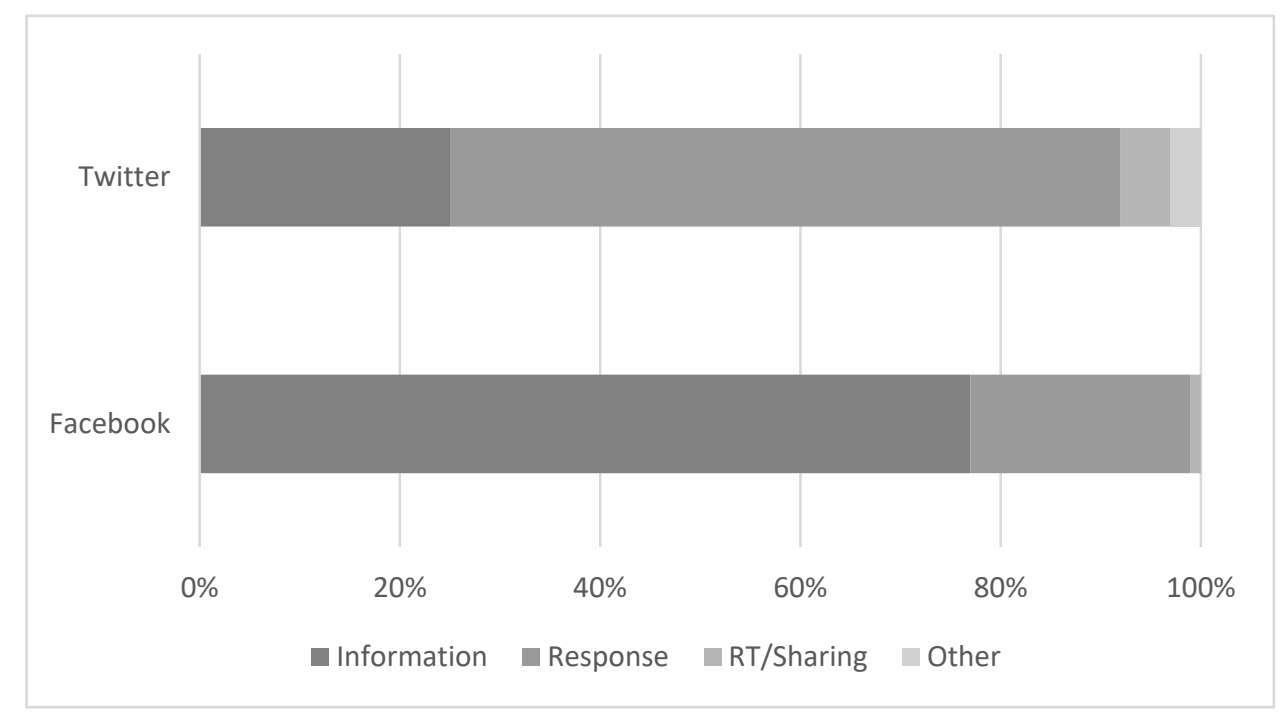

Figure 10. Differences in IRCC Use of Twitter and Facebook

Therefore, IRCC devotes more resources to maintaining its Twitter account than the Facebook page. This is acknowledged by IRCC public servants who manage social media. They note that Twitter has to be updated more frequently than Facebook. Furthermore, "legitimate questions" are being asked on the IRCC Twitter, while Facebook is dominated by "basic" questions that the department tends not to answer. Thus, those users who use only Facebook are at disadvantage because they cannot get a response to their questions on this platform and are forced to look for information elsewhere.

Although IRCC interacts with users on Twitter, this interaction is very limited in terms of topics being covered: IRCC responds to "neutral" questions - questions about programs, services and operations. Moreover, roughly one in four answers contains a suggestion to visit the Help Centre page, IRCC website or to fill in a web form without providing any additional information. It is also true for responses on the Facebook page (Table 7). 


\section{Table 7. Comparison of IRCC Answers on Twitter and Facebook}

\begin{tabular}{|l|c|c|}
\hline Topic/Theme Category & $\begin{array}{l}\text { Answers on } \\
\text { Twitter }\end{array}$ & $\begin{array}{l}\text { Answers on } \\
\text { Facebook }\end{array}$ \\
\hline Help Centre/Web site referral & $17 \%$ & $10 \%$ \\
\hline Case specific form and other web forms & $10 \%$ & $16 \%$ \\
\hline Technical issues & $12 \%$ & $8 \%$ \\
\hline Application & $17 \%$ & $6 \%$ \\
\hline Processing times & $14 \%$ & $7 \%$ \\
\hline $\begin{array}{l}\text { Programs/Services (including refugees and } \\
\text { spousal, ETA) }\end{array}$ & $24 \%$ & $49 \%$ \\
\hline Other & $6 \%$ & $2 \%$ \\
\hline
\end{tabular}

Therefore, IRCC uses Twitter as a customer service tool to respond to people's questions.

Facebook, however, is used as an announcement platform to promote available on the website. Furthermore, the department occasionally warns users who are violating the terms and conditions of use on Twitter but does not monitor user activity on its Facebook page, neither blocks them on Twitter nor Facebook. Thus, interaction between the department and social media users is limited to the IRCC Twitter and it does not go beyond referring social media users to information on the website and web forms to receive personalized feedback.

\section{Insights from Interviews with Public Servants from IRCC and MCI}

Interviews with public servants provide important insights on why government agencies are using social media and why there is a difference in use between the platforms for IRCC. Interview data presents perspectives of public servants from both IRCC and MCI as many approaches to the use of social media are shared by both government agencies. There is, however, an important difference between them: the IRCC Twitter and Facebook are quite popular with the users, while people's interest in MCI social media is significantly lower. This section discusses

\footnotetext{
${ }^{9}$ This analysis is based on a sample of 51 Facebook posts only. Therefore, caution was exercised when interpreting these results.
} 
major themes revealed during semi-structured interviews with public servants and their perspectives on the government use of social media.

\section{Reasons for Adopting Social Media}

Both government agencies have created their social media accounts in 2008-2010. In the very beginning, however, the main consideration was to use these platforms as a promotional tool to share information and post press releases. As participant \# 1 from MCI noted:

When we first started over Facebook page ... it was just a promotional tool, it was basically to give information, share information, encourage people... it was targeted to youth but it was also targeted to agencies that serve youth.

IRCC approach was quite similar: social media was solely oriented to provide informational updates. Originally, the IRCC Twitter was mostly used to publish news releases and the IRCC Facebook was devoted specifically to Canadian citizenship. There was also "no real concerted effort to develop content, strategies or use this social media presence to complement paid advertising campaigns."

Over time, both government agencies realized the benefits that social media can bring in terms of cheaper ways of running promotional campaigns and reaching out to audiences. For IRCC, this realization came in 2015 with the need to promote the newly developed program to attract skilled immigrants to Canada - Express Entry. As participant \#3 from IRCC noted:

We thought we knew the potential for social media to help us reach audiences, this system was quite transformative... with Express Entry we were going to seek the best and brightest literally and being in the place competing with other jurisdictions to recruit the talent... it changed what was expected of us, so we wanted to take full advantage of social media to help support our strategies to deal with it.

It also became obvious that the need to interact with users of the platforms meant the need for dedicated resources. This changed the approach to staffing social media positions within the agencies: there was an understanding that there should be a designated team responsible for 
creating social media content and maintaining social media accounts. Participant \# 2 from IRCC stated:

In December 2014, we decided to split the accounts by language and started using channels to promote the Express Entry... I was asked that we would use the channels to promote all our programs and services and everything else and we proceeded to do that. So, it would be really since March 2015 we use the accounts in the way they are recognizable today.

At the time of the interviews, social media teams in IRCC and MCI had two permanent staff who were directly responsible for creating social media content and maintaining the accounts. However, the job titles of MCI public servants did not reflect their social media duties - they had more generic communication/media job titles.

Three Main Social Media Goals: Customer Service Tool, Marketing Tool and Alternative to Call Centre

Both IRCC and MCI see social media as a platform for providing information and customer service. They are aiming to deliver up-to-date correct information about programs and services. As participant \# 2 from IRCC participant explained:

We tend to focus on our channels more as client delivery opportunities rather than discussion on policy. So, we do acknowledge criticism... but we don't engage with these people because there are more appropriate ways for them to be engaged.

She elaborated:

We also get questions asking us to justify our policy decisions, which we do not respond to those because this is not the [right] place for the discussion [on] why we make policy decisions.

Social media is also not seen as a service delivery channel or a way to engage public in discussions about policy. IRCC participants stated that the official website is the service delivery channel and the main objective of social media responses is to point where the correct information is located on the website or to provide clarification in the language that is used. At the same time, IRCC takes into account the needs of the department social media users. As IRCC participant \# 2 observed: 
At the same time, there was a lot of conversation in the media about unemployment in Canada, layoffs like issues in the West. And so, you kind of know what's coming. So, as much as you want to communicate about what you are doing, you also want to make sure that you are delivering what your audience wants to hear.

MCI participants' insights echoed those of IRCC. Participant \# 1 noted that the use of social media as in a customer service capacity is the "safest way to approach it". However, MCI considers its Facebook page primarily as a customer service tool "as opposed to a more general information channel". As participant \# 2 from MCI explained:

It was created to let international students know that [the immigration program] existed. We posted content but realized that people were un-liking the page and they tended to prefer that we are there in a customer service role.

Therefore, social media is not considered as a platform to engage the public in policymaking or public service delivery (Bertot et al. 2010; Linders 2012; Mergel 2013c). It is only seen as a medium for providing information about government programs and services (Small 2012). The main focus of immigration agencies is on its customer service and information provision.

Another important social media goal for government immigration agencies identified during interviews is the role of social media as a marketing and promotional tool. According to participants, part of the senior management buy into social media use can be attributed to the low cost of running promotional campaigns and promoting programs on social media as opposed to traditional advertising campaigns. At IRCC, there was also a desire to compete with other countries for immigrant talent. As IRCC participant \# 1 noted:

[Senior management] understood that there is a need to do marketing, outreach, run ad campaigns and have social media to have conversations and have visibility of our new system. We took advantage of that shift to run the pilot and then keep going beyond Express Entry.

At MCI, promotional campaigns vary based on the ministry's demands. Program areas ask social media team not "to push out information" when they have too many applicants. However, 
"when they are looking for more people to use services than we push out this information." This, information "push" (Mergel 2013b, 2013c; Lee and VynDyke 2015) plays an important role in existing approach to social media use by government immigration agencies.

All interview participants noted the importance of social media as an alternative to call centre. Both IRCC and MCI view social media as a tool that can considerably reduce the volume of calls to the call centre to obtain information, which does not require the need to share personal information. Therefore, although it does not fully replace the function of the call centre agents, it should help to ease their workload and reduce waiting times for those who are trying to reach the call centre.

MCI participant \# 1 also noted that the Ministry "noticed a direct correlation between a number of calls and the activity on this Facebook page." She elaborated:

We realized that people needed clarification about a particular program, [so that] they can more effectively apply to this program. Before we started the page, we received a lot of calls [regarding] how an international student who studies in Ontario gets a chance to have permanent residence. And the application process was not necessarily easy to understand. When we started the Facebook page, we perceived [two goals]: to decrease the number of calls and communicate the information in a more effective way...It did work -number of calls went down and number of applications went up.

IRCC participants did not specify if the volume of calls for IRCC call centre went down after the department started to interact with users on social media but mentioned that this is an important priority. IRCC participant \# 3 stated that as a part of providing client service, social media team was expected to respond to generic questions that did not contain any personal information. Therefore, social media is aimed at re-routing people's questions, saving money and relieving pressure off the call centre. There is also an assumption that migrants who are located outside Canada and thus do not have access to the call centre will turn to social media in order to get answers to their questions. Therefore, in addition to savings on paid advertising, it is expected 
that in the long term, social media will help to reduce costs associated with the call centre. There is also hope that these savings might result in additional resources available for the social media team.

Thus, reducing using technology to cut down costs is one of the primary goals of government. However, social media is not seen a service delivery channel nor a tool for leveraging public opinion to improve public service delivery (Roy 2017).

\section{Social Media and Open Government Policy}

Interview participants from IRCC and MCI did not believe the use of social media in their government agency was directly related to open government policy. However, there was an understanding that there is a need to "respond to [the public] on a personal level." At the time when I was conducting the interviews, neither of the government agencies was using social media to engage public in consultations on policy issues - the primary goal of social media use as per the public engagement/open dialogue stream of the open government policy. As stated by IRCC participant \# 1:

We certainly did not go out there and say - we want to improve our client service, electronic tools, do you have any advice for that. We haven't done that, it's going to take more time.

However, they also believed that what they did on social media aligned with the spirit of open government. As described by IRCC participant \#2:

I don't think there is an intentional linkage between open government and social media, I don't think that open government was in any way a catalyst to using the accounts. I think just the same type of principles and also the communication policy stipulates that we use a variety of different media to communicate with Canadians, this is somewhere where Canadians and other audiences are active and it is free of charge media for people, this is really from the [communication] policy side of things. But I don't think that open government thing... really [ever] came into consideration.

Open government policy in Ontario is a more recent development than at the federal level.

This can explain MCI participant \#2 position on the link between open government and the use of 
social media: “Open government...is a part of why we don't block conversation on Twitter." MCI participant \# 1 noted that the implementation of open government in Ontario is in its early stages and there is no clear understanding what it involved: "Open government in Ontario is open data and open dialogue... this is just starting to roll out, so we'll see how that works".

\section{Quality of Content Is Important but There Is Lack of Analysis of User Posts}

Participants noted that the quality of content they deliver on social media is very important to them. IRCC uses a special tool performance matrix for Twitter analytics and Facebook insights to determine number of followers, number of retweets and likes. This is a similar approach to the one described by Goncalves et al. (2015). However, current staffing levels are only enough to manage the content that is published by the agency as well as respond to questions. Staff does not always have an opportunity to analyse if the content was successful in reaching out audiences. IRCC participant \# 2 noted:

There are a lot of gaps particularly on the analysis part... It would be great to do analysis of what has been successful and ... more analysis of mentions or comments that we are getting. And also evaluation of our campaigns.

IRCC participant \# 3 elaborated: “We don’t do environmental analysis on our channels, we tend to look and do analysis on certain topics."

MCI participants discussed the same issue: there is a need to do more analysis of user responses and comments. They also noted the importance to go beyond the numbers of likes and retweets and do more quantitative analysis to understand if the content is meeting the needs of social media users. Therefore, there is a need to examine "breadth" and "depth" of government activity on social media (Kagarise and Zavattaro 2017).

IRCC also keeps track of posts and tweets that criticize the department as well as its programs and policies. This information, however, remains with those who manage the content 
and gets to senior management only if there is a special request for it. IRCC participant \# 2 explained:

Usually, there is a small group of critics and we recognize their accounts and we see what they are saying, so we are aware that there is criticism... but we don't relay this information up the chain because this is not really the place for this communication to occur.

Both government agencies, however, mentioned that they have been monitoring content that was shared by users on the platforms. Moreover, IRCC relies on a special social media managing platform Hootsuite for monitoring responses and feedback as well as capturing tweets and posts that mention IRCC. Monitoring ensures that user tweets and posts adhere to the terms of social media use established by the department. According to IRCC participant \# 2:

If somebody [says] something derogatory about Syrian refugees or they threaten Syrian refugees or they said something very political, obviously, on Twitter we cannot do anything - there is no moderation there. But on Facebook we would hide these comments as per our moderation protocol... no profanity, no foreign language content because we do not know what is being said, again, no threats, nothing avertedly political... and nothing with personal information. None of these things is acceptable and we hide those comments.

IRCC also strives to be proactive and develop content to respond to questions asked by users. For example, if users are asking questions about processing times or ways to immigrate to Canada, the department will prepare a separate post and/or tweet to cover these issues. However, certain topics are being avoided completely: IRCC participant \# 3 mentioned that all questions about spousal sponsorships are deemed case specific and no response is provided. IRCC also seeks to single out questions that do not have answers available in the help centre bank of responses.

MCI faces a different challenge: the ministry has considerably less users interested in its social media content. In order to make sure that Twitter users react to the content posted, ministry's staff sometimes calls key stakeholders to make sure that their Twitter content is "picked up". MCI participants \# 2 and \# 3 also noted the difference between its "paid content" and "organic content" - a paid promotional campaign on Twitter and its regular content that is published as regular tweets: 
Twitter feed is so fast now that it is hard to make [it seen] any the organic way...[you have] to budget up and pay for your stuff to be seen. You have to post 20 times organically to [achieve] the same effect.

\section{Levels of Approvals and Time for Approval}

Time that takes to approve a tweet or a Facebook posts depends on its topic as well as if it is an original post or a response. It usually takes several days to approve an original message and the approval process might require involvement of the Minister Office or, Ontario case, Cabinet Office and Premier's Office. An average time to respond to a question is much shorter - typically, a business day. Sometimes, there is also no need for approval or an approval by the program area is sufficient. IRCC participant \# 2 explained:

I would say 80 to 90 percent of the time the question is really basic. We can answer it to just pointing them to the web content. So, the first thing we do when we get a question, we look to see if it is in our Help Centre, which has something like a thousand FAQs in it. Wherever possible, we will just reply to that person saying hey, check out this Q and A in the Help Centre. And this does not require any approvals.

The majority of IRCC approvals end at the Director level. However, the Minister's Office

does get involved when deemed necessary. IRCC participant \# 1 noted:

In the past, there was a designated person for social media in [the Minister's Office] and that person brings a different lens to it ... sometimes they want us to create a bit of ... a blackout period, so we only emphasize our communication on one topic for that day.

At the same time, senior management is not really looking into social media content that needs to be approved but rather performs risk-management and compliance assessment. In case of MCI, the need for approvals from Cabinet Office is there for anything that might be considered as an issue: "Anything [that is controversial] gets vetted by Cabinet Office." Unsurprisingly, approval process takes significant amount of time. Participants \#2 and \#3 noted that during the campaign for resettlement of Syrian refugees, their content was approved relatively fast - it took four to five business days. They, however, noted that usually it would take longer as "in general, we are not a high priority". 
Thus, approval of social media content can be highly political process and require significant amount of time. It is, however, much faster for responses - an average of a business day. However, such short turnaround time can be explained by the fact that vast majority of answers contain a link to the content that is available on the official website.

\section{Value of User-to-User Conversations}

Interview participants noted the importance of conversations between users that occur on the government social media accounts. They also emphasized that they do not need to step into every conversation to correct misconceptions or present an official government position because a lot of times "the Internet usually regulates itself". Furthermore, users share their personal experiences and provide answers to others who are seeking information. Therefore, public servants view social media as a special space for discussion, experience and knowledge sharing. The quote from MCI participant \# 2 below summarizes this position:

We don't have to answer every question people put on our channels, sometimes other wellinformed people will actually go and answer them for us. And we don't have the capacity to validate that everything they say is 100 percent correct. But the community is selfregulated space, so this is very much a part of our vision that we don't need to be the moderators of every single conversation but we create space... and other people can come in and provide a response.

However, none of participants noted that their government agency is doing anything special to encourage user-to-user interaction, thus, facilitating and maintaining the network (Dawes et al. 2009). Neither is there a conscious attempt to monitor conversations between the users nor to understand factors influencing network performance (Provan and Milward 2001). 


\section{Difference in Use between Twitter and Facebook}

Participants acknowledge that they have different approach to the use of Twitter and Facebook. IRCC participants mentioned two main reasons for existing difference in use: the nature of the platforms and the types of user questions. IRCC participant \# 2 noted:

We use the both [Twitter and Facebook] for pretty much everything...We post more on Twitter than Facebook just because the half-life of a tweet is so short compared to the halflife of the Facebook post. But other than that consideration all things are considered equal. However, she went on to acknowledge:

Questions that we get on Facebook are very simple questions like I wanna immigrate to Canada, how do I immigrate to Canada. They are very rudimentary questions where we can just really drive people to our website. Where on Twitter we get far more specific questions, a lot of this functional guidance type of questions.

Her colleague (IRCC participant \# 3) went even further by noting that "90 percent of posts on Twitter are legitimate", while Facebook is dominated by questions on how one can come to Canada. It was also mentioned that as Facebook does not have character limitations that Twitter does, sometimes a tweet contains a link to a Facebook post, so that users can get more information. However, in general, public servants did not indicate that there was a significant difference in a number of IRCC responses on Twitter compared to Facebook. This, however, contradicts findings from social media data that demonstrate that IRCC is responding significantly more frequently to social media users' questions on Twitter than on Facebook.

MCI applies a different approach. MCI officials mention that they put different content on their Facebook page and Twitter as these platforms have different audiences. For the Facebook page, the main audience is international students studying in Ontario, while MCI Twitter is primarily focused on reaching out to Ontarians. They also use Facebook as a customer service tool and answer migrants' questions. Twitter is, however, used primarily for promotional campaigns. 


\section{Effective Use of Social Media}

Participants named several components of what they think the effective use of social media is. However, they also emphasized that effectiveness depends on the available resources and they believed that they are currently doing the best job they can with the amount of resources that are allocated for the social media team. Therefore, existing barriers and challenges with government social media use (Clarke 2012; McNutt 2014) predetermine the extent of its effective use. Taken into consideration existing challenges, several areas of improvement are identified.

First, there is a need for a government-wide support of social media and more leadership to promote benefits that social media brings. As IRCC participant \# 1 noted:

There has to be a larger government-wide and department-wide buy into social media... [New things] are scary for people. There is risk aversion... and this often is enough to shut something down. But there is a recognition at the senior management that we have no choice.

This is echoed by IRCC participant \#2:

Being a new team, we are trying to be on the radar for management because they might not realize the potential... we are trying to establish linkages. But I found that the best thing to do is to promote the current successes of the channels because people realize that wow, you can communicate to thousand people a week and this is something none of our other mechanisms can do.

Second, participants noted the importance of connecting social media users with the information they are looking for. Moreover, IRCC public servants acknowledged the need for interaction and engagement on social media platforms. The quote from IRCC participant \# 2 captures this spirit of interaction:

It is really about being iterative. It's about seeing who is following you and what they are saying and what is important to them and then responding based on what you are seeing... As long as I'm maintaining these channels, we will be engaging with people. Otherwise, I don't see the value of using the channels, to be honest.

IRCC participant \# 1 talked about how future interaction could look like:

With social media, with client questions or program related questions, if we had the right tool and enough licenses, we could engage, train staff that this is the part of the regular duties. If they are the experts in International Experience Canada or Express Entry or Francophone immigration, somehow they would be notified or they would watch the space 
to see these questions, so they can jump in and answer. And it doesn't need to be controlled by [communications]. But we are not quite there yet.

Third, although IRCC currently uses social media to point to information on the "proper pages on the website", there is also an understanding that users are looking for more personalized information as opposed to "generic and boring". By "bringing more human sentiments", IRCC can further enhance interactions with its social media users.

Fourth, participants emphasized the need to share knowledge and experience between government agencies that are using social media. In Ottawa, there is a federal government Social Media Community of Practice. Here, public servants exchange their ideas as well as gain important insights from their colleagues. At the time of the interviews, there was no such community of practice in Toronto where Ontario provincial government is located.

Fifth, it is important to develop a feedback mechanism to be able to hear back from social media users on the published content and the information they receive. This will add to the understanding about informational needs and will be taken into account when the content is being developed. However, no concrete steps on implementation of the feedback mechanism were recommended. Feedback from social media users is, however, crucial for informing social media strategies (Bennett and Manoharan 2017).

Finally, MCI participants called for a more holistic approach to the use of social media by the ministry. MCI participant \# 1 noted lack of understanding that "social media is a marketing tool as opposed to an announcement tool.” She elaborated:

What I like to see more [of] is specific social media planning that is separate from the announcement building. There is a marketing function that happens between your announcements.

Therefore, the efficient use of social media for MCI also includes a fully developed social media strategy that is supported by the senior management and implemented by the social media team. This supports findings of Bennett and Manoharan (2017) as well as Jukić and Merlak (2017) who 
emphasize the need to develop a comprehensive social media strategy in order to us this technology effectively.

\section{Conclusion}

The findings from the data analysis discussed above confirm findings in the existing literature to a certain extent but also offer some important new findings. IRCC does initiate twoway interactions with the users but only on the matters that are deemed appropriate for response. Therefore, the department goes beyond one-way information sharing as noted by Small (2012). This includes primarily responses related to specific programs and services, thus limiting the use of social media to a customer service function. Furthermore, there is a significant difference in the use of Twitter compared to Facebook: Twitter is considered to be a tool for providing responses to questions while Facebook is primarily used for broadcasting information. In addition, information that is provided in response to questions on the IRCC Twitter is available on the IRCC website.

Interviews with public servants give some insights to why this is the case. They note differences between the platforms: information on Facebook can be shared less frequently than on Twitter. Twitter requires constant updates in order for the message to be noticed by target audiences. Moreover, Twitter is believed to be the place for "legitimate questions" as opposed to Facebook where the most popular question is how one can come to Canada. Although IRCC participants do not acknowledge that they answer only "legitimate questions", it is quite obvious when the number of questions answered on Twitter is compared to the number of questions answered on Facebook. 
Thus, Facebook is primarily used by IRCC for sharing information about programs and services. Twitter, on the other hand, is more frequently used to respond to users' questions. The rationale for this, as per IRCC, is that Facebook allows one to post more content and that they proactively post information to answer the most popular questions on Facebook, including the most popular one about existing ways to come to Canada. Interestingly, the analysis of IRCC Facebook posts shows that IRCC tends to provide short answers to users' questions and sometimes breaks a message into several posts as they would responding on Twitter.

Furthermore, there are not enough proactive messages that contain information about ways to come to Canada: they are posted two-three times per month. In addition, sometimes they are posted in response to a conversation that is going on between users and do not align with the topic of the original IRCC post. Thus, it is not clear why the same type of question would be sometimes ignored and sometimes would get feedback from the department. In any event, users would have to search for this information and scroll through many posts in order to find it.

Moreover, IRCC response rate is also quite low: on Twitter, one in three questions is getting an answer and on Facebook, only 3\% of questions get a response. This puts those who use Facebook in a disadvantage, as they cannot get the same level of service as those who use Twitter. They are also forced to look for information elsewhere. The next chapter will discuss this finding in greater detail.

Existing practice also points out the discrepancy between IRCC's Terms and Conditions of Social Media Use and the department's practice of posting on social media. The document does not specify any differences in interactions on Twitter and Facebook. Thus, the practice should not be different or the users should be informed about the differences that exist and the reasons for this practice. Therefore, IRCC views social media as a new tool to provide customer service to its 
clients, thus, expanding the number of options people can use to communicate with the department. The two-way interaction is limited to question-answer communication and the majority of IRCC social media users disappear from the platforms after they get an answer or lose hope in getting one.

Finally, there are three groups of factors that constitute effective use of social media from the perspective of public servants. They include:

- network factors (specifically, perceived contribution of exchanges on the platforms to agencies' and migrant goals as well as feedback that is available on social media that would not be available otherwise). Here, the most important is the recognition of the value of user-to-user exchanges and the availability of space for the network to develop. Government agencies, however, do not specifically attempt to develop a consistent network (Dawes et al. 2009; Mergel 2017);

- organizational factors (specifically, organizational flexibility and availability of resources; importance of information that is being shared on the platforms and organizational culture). Both agencies admit the importance of the dedicated team that is fully devoted to managing government social media. This team has certain degree of flexibility when it comes to managing social media content (especially, when providing responses) but still is placed within a rigid hierarchical structure (McNutt 2014);

- personal factors (specifically, leaders within the agency are oriented toward implementing technological innovations and perceived value of social media to personal/career goals). The importance of leadership to ensure senior management buy into social media cannot be overestimated (Mergel and Greeves 2013; Mergel 2013a). This leadership comes from the social media team - by demonstrating benefits of social media use - and management 
team - by making a case for social media use for senior management. The role of personal and career goals is also important as young professionals who are directly managing social media resources learn how to navigate government structures in order to implement the vision they have and seek improvements. 


\section{Chapter 6. User Perspectives: Migrants' Use of Government Social Media}

Governments across the world are looking to engage the public on social media on policymaking and/or improving public services delivery. However, the way the public interacts with government agencies on social media platforms is currently understudied (Lu et al. 2016; Medaglia and Zheng 2017). As noted previously, the e-government literature is mostly focused on government agencies and their intentions and strategies of social media use. Interdisciplinary and immigration studies research on the migrant use of social media, on the other hand, is looking into their information seeking strategies and practices and the role social media plays in finding or disseminating information on migration. These studies, however, do not specifically focus on the migrants' use of government social media.

In public policy and administration, there are a few studies that examine the intentions and expectations of the public from interactions on government social media. Researchers are trying to understand the relationship between government use of social media and citizens' trust in government, attitudes toward government and government transparency (Nam 2012, Song and Lee 2015). Therefore, they do not specifically look into the intentions and experiences of those who use government social media resources. Lu et al. (2016) offer a different approach and study user experiences and expectations from interacting with the Chinese government on a microblogging platform. Overall, these studies rely on a single source of data to examine users' attitudes and experiences (e.g. Nam 2012; Song and Lee 2015 use survey data and Lu et al. 2016 use interview data).

Moreover, there is a gap in understanding how helpful information and customer service functions of government social media are for the public. Based on the findings from the previous chapter, these are the primary reasons behind the use of social media in IRCC as well as MCI. 
Thus, it is important to see how these government priorities match expectations of social media users.

This chapter explores the experiences, perspectives and attitudes of users who interacted on government social media with the two immigration agencies selected for analysis. It also discusses the results of user profiles analysis that reveals who IRCC social media users are. It is important to note that although the majority of the IRCC Twitter and Facebook users are migrants, these social media platforms are also widely used by Canadian citizens and permanent residents as well as friends and relatives of those who intend to come to Canada.

The analysis of user posts on the IRCC Twitter and Facebook follows the same logic as the analysis of tweets and posts made by department officials. First, different types of user messages are examined. However, analysis of user tweets and Facebook posts also takes into account IRCC responses: when the department responds or comments and what types of user messages are more likely to get a response. Second, differences in migrant use of the IRCC Twitter and Facebook are analysed. These are supplemented by insights from interviews with users. Finally, this chapter discusses user perspectives on the efficient use of social media by government. Thus, the study fills the existing research gap by analysing user experiences and expectations from government use of social media.

\section{Profiles of IRCC Social Media Users}

Collecting information on users through social media was not originally planned for this study. However, in late February 2016, Netlytic network analyser - the program used to collect Twitter data - introduced a new capability that allowed for user profile analysis. This new data that were collected included, where available, user bios posted on their profiles as well as user 
geographical location. It is important to note that this is self-identified information and, therefore, it is impossible to verify where the user is actually located. At the same time, this information provides additional insights into who IRCC social media users are and if the department is reaching out to people located inside and outside Canada.

User information was retrieved for a period of six months (between March and August 2016) from every tenth tweet posted by users on the IRCC Twitter account. Overall, 806 tweets were analysed and a total number of 565 unique users were identified. The number of users is lower than the number of tweets as the same user could leave several tweets when interacting with IRCC and/or other users. Users whose information was analysed for the study account for $18 \%$ of all users who tweeted @ CitImmCanada between March and August 2016. Users who left spam messages or retweets were excluded from this analysis.

As Twitter does not require users to identify their location and/or provide a proper name for it (e.g. several users mentioned that they were from the planet earth), only $68 \%$ of users $(\mathrm{N}=364)$ actually mentioned where they were from. Interestingly, the vast majority of IRCC Twitter users are located in Canada (53\%). In other words, the IRCC Twitter is mostly used by those migrants who are familiar with Canadian immigration system as they are already in Canada or by Canadian citizens. English-speaking developed countries such as UK, USA, Australia and New Zealand together account for $22 \%$ of users, while all other countries together account for remaining $25 \%$. Table 8 provides detailed information on the geographical location of IRCC Twitter users. 
Table 8. Geographical Location of IRCC Twitter Users

\begin{tabular}{|c|c|c|}
\hline Country & $\begin{array}{r}\text { Number } \\
\text { of users }\end{array}$ & Percent \\
\hline Canada & 193 & $53 \%$ \\
\hline UK & 43 & $12 \%$ \\
\hline USA & 31 & $9 \%$ \\
\hline Europe (excluding UK) & 18 & $5 \%$ \\
\hline Africa (Nigeria, South Africa, Uganda, Algeria) & 17 & $5 \%$ \\
\hline $\begin{array}{l}\text { Middle East (UAE, Iraq, Syria, Jordan, Saudi Arabia, Qatar, Iran, } \\
\text { Turkey) }\end{array}$ & 17 & $5 \%$ \\
\hline South Asia (India, Pakistan, Bangladesh, Nepal, Sri Lanka) & 14 & $4 \%$ \\
\hline South America and Carribean (Brazil, Mexico, Venezuela) & 14 & $4 \%$ \\
\hline East Asia (Japan, China, Singapore, Phillippines) & 10 & $3 \%$ \\
\hline Australia and New Zealand & 5 & $1 \%$ \\
\hline Other (Russia and Kyrgystan) & 2 & $1 \%$ \\
\hline
\end{tabular}

Thus, the majority of Twitter users who are active on the IRCC Twitter come from Canada and other developed English speaking countries. This can potentially mean that users from other countries, especially in those where English is not an official language, seek information and advice on migration process elsewhere. It can also mean that IRCC foreign language campaigns such as the one for the eTA where the message was translated in several different languages do not reach out to the target audiences. However, it is important to mention that IRCC maintains other Twitter accounts - generic French Twitter account and program specific (International Experience Canada) accounts in English and French. Thus, information needs of French speaking users can be addressed through these accounts. Nevertheless, further study is needed to understand users' characteristics and the role the language play in reaching out to those users who are located outside Canada.

In addition to users' geographical location, the data allowed for a determination of whether the user account belonged to an individual or an organization. This analysis was based on information/bios available on the user profiles. Again, this is self-identified information and it was 
not always possible to tell who the user is as there was no description for the account and the name could not provide any insights. However, it is important to mention that about $8 \%$ of users of the IRCC Twitter account are organizations such as other government agencies (including Canada's diplomatic missions oversees), non-profit organizations, media outlets and law firms or immigration consultants. This means that the vast majority of users $(\mathrm{N}=565)$ are individuals and IRCC should keep this in mind while interacting on social media.

Netvizz - the program used to retrieve Facebook data - does not possess the functionality to analyse profiles of those users who commented on a Facebook page. However, it is quite safe to assume that the majority of Facebook users are located outside Canada as the most popular questions they ask on this platform are regarding possible ways to migrate and work in Canada.

\section{User Interaction on the IRCC Twitter}

The IRCC Twitter account is a quite popular way of interaction between IRCC and users. On average, between September 2015 and August 2016, users left 3,541 tweets per month with the highest number of tweets in December 2015 and the lowest in October 2015. Figure 11 shows the number of tweets left by users during September 2015 and August 2016.

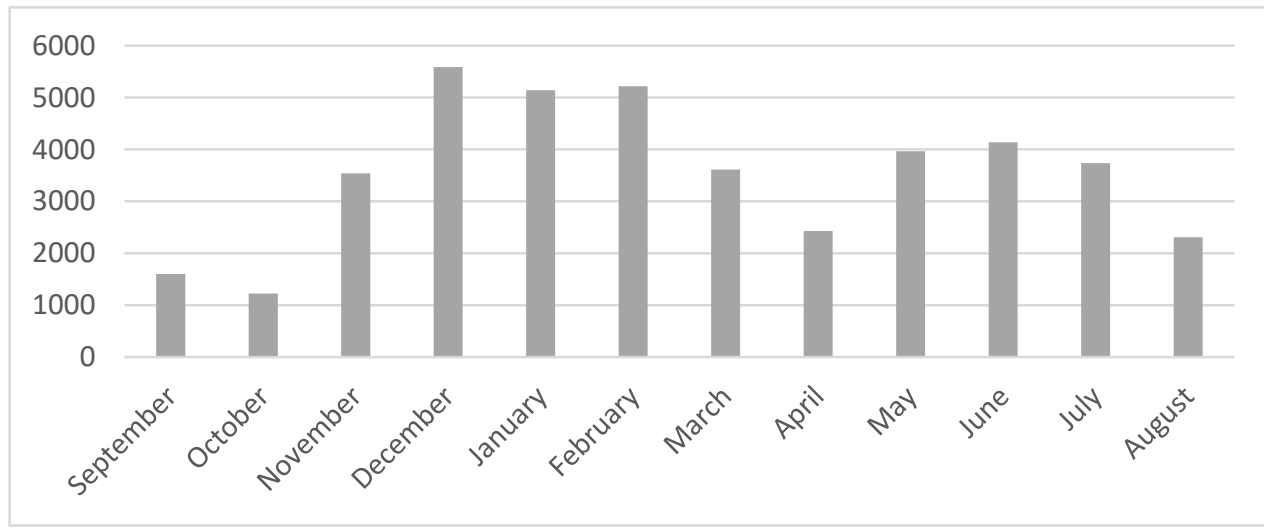

Figure 11. User Tweets on the IRCC Twitter Account 
As noted in Chapter 3, user tweets were cleaned of spam messages and retweets to more accurately reflect original messages and conversations between IRCC and users as well as between users. A total of 1,740 user tweets ( $10 \%$ of all user tweets that were selected for analysis) were coded.

Although retweets of IRCC posts were not analysed in detail, it is important to note that users do retweet a lot of IRCC messages. Moreover, for six months (November, January, February, April, June and July) the number of retweets of IRCC content by users was very close to the number of original user tweets. In other words, users are interested in sharing information that is provided by IRCC as much as they are interested in interacting with the department and other users on the IRCC Twitter account. Thus, there is a significant interest in the information and other tweets that are shared by IRCC.

Majority of user tweets (43\%) are questions and/or other prompts for feedback from IRCC. Therefore, IRCC social media users are mostly interested in customer service inquiries (Kagarise and Zavattaro 2017). This is followed by expressions of opinion on a specific immigration topic or a personal statement (21\%), sharing of information (15\%), responses to other users (15\%), thanking and/or expressing gratitude to IRCC or other users (5\%) as well as other matters $(1 \%)$ (Figure 12). Thus, IRCC users are interested in getting responses to their questions and/or sharing their opinions rather than interacting with other users on the IRCC Twitter account and providing information to them. Therefore, they are not really interested in "provid[ing] a "public" service themselves" (Linders 2012: 449).

Interestingly, only $30 \%$ of user questions and other prompts for feedback receive response from IRCC. This number is significantly lower for other types of user posts: $6 \%$ of messages that express gratitude and $2 \%$ of tweets containing information get a response. The department does 
not participate in the conversations between users and does not respond to tweets that express an opinion. Moreover, IRCC does not react to the use of inappropriate language and/or at tweets that insult others.

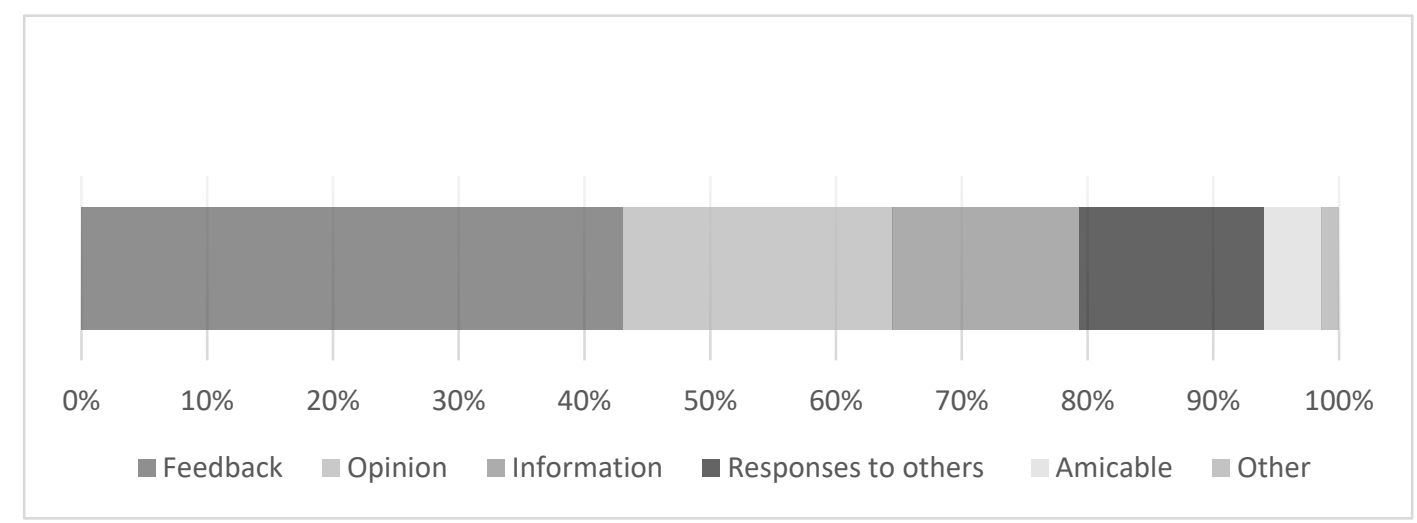

\section{Figure 12. Categories of User Tweets by Types of Messages}

Further, the most popular topic/theme for user questions is technical issues (24\%), followed by programs and services (23\%), processing times (19\%), questions about applications (15\%), spousal sponsorship (9\%) and other matters (10\%) (Table 9). It is also important to note that users ask most of questions about the following programs and services: refugees (4\%) and eTA (3\%). There are, however, no questions asked about programs and services available for newcomers.

Based on the results of the analysis, it is clear that not all user questions are treated similarly: the department is more likely to answer questions on certain topics. Thus, users are more likely to receive a response if they ask about an application related matter as well programs and services with the exception of refugee programs.

It is also important to note that no responses are provided for questions about processing times for spousal sponsorship although they account for $9 \%$ of all questions asked by users. Users who are asking about questions regarding refugees also received fewer answers compared to the number of answers for other programs and services. Moreover, users are less likely to get an answer about technical issues. IRCC public servants interviewed for the study acknowledged that 
tweets regarding spousal sponsorship were deemed containing personal information and remained unanswered. They also noted that the department does not participate in discussions on policy issues. Therefore, the department is not responding to tweets that can be considered controversial.

Questions about eTA, on the other hand, received more answers despite the fact that there were fewer questions asked regarding this program compared to spousal sponsorship and refugee programs. Interestingly, IRCC was promoting both refugees and eTA programs but eTA was a less controversial issue compared to refugees. This can explain why eTA related questions received more answers than questions about refugees.

Table 9. Comparison of User Questions and Questions Receiving Answers from IRCC by Topic/Theme on the IRCC Twitter

\begin{tabular}{|l|c|c|}
\hline Topic/Theme Category & $\begin{array}{l}\text { Percent of user } \\
\text { questions }\end{array}$ & $\begin{array}{l}\text { Percent of } \\
\text { user questions } \\
\text { answered by } \\
\text { IRCC }\end{array}$ \\
\hline Technical Issues & $24 \%$ & $20 \%$ \\
\hline Application & $15 \%$ & $23 \%$ \\
\hline Processing times & $19 \%$ & $17 \%$ \\
\hline Spousal sponsorship & $9 \%$ & $0 \%$ \\
\hline Refugees & $4 \%$ & $2 \%$ \\
\hline eTA & $3 \%$ & $7 \%$ \\
\hline $\begin{array}{l}\text { Other programs and services (i.e. visiting, } \\
\text { studying, working, express entry, etc.) }\end{array}$ & $16 \%$ & $22 \%$ \\
\hline Contact & $2 \%$ & $2 \%$ \\
\hline Fraud & $1 \%$ & $1 \%$ \\
\hline Other & $7 \%$ & $6 \%$ \\
\hline
\end{tabular}

Nevertheless, spousal sponsorship (23\%) and refugees $(21 \%)$ are the two most popular topic/themes for users to express their opinion on. Together they account for almost half of all opinions expressed on the IRCC Twitter account. Other tweets are making comments regarding processing times (11\%), other immigration programs and services (10\%), politics and government (4\%), personal matters $(2 \%)$ as well immigrants and newcomers (2\%). All other tweets combined 
account for $27 \%$ of tweets that express opinions. As mentioned before, neither of these tweets got a comment from IRCC.

In summary, the analysis of user tweets show that users are interested in interaction on Twitter for two main reasons: 1) to ask IRCC a question and 2) to express an opinion regarding a program or service, IRCC as a government department and/or on a specific issue. Users are not interested in interacting between themselves, although they sometimes participate in a discussion that can transform into an argument. IRCC does not participate in such discussions nor warns the participants if inappropriate language and/or insults are used. Therefore, enforcement of the IRCC Terms and Conditions of Social Media Use is clearly lacking.

Furthermore, IRCC interacts with users by answering questions but only one in three questions are answered. In addition, users have limited interactions between themselves and rarely try to answer questions that others have. Thus, the majority of the questions remain unanswered and users have to seek information elsewhere.

It is also important to note that certain questions are more likely to receive a response from IRCC - specifically, application related questions and questions about programs and services. However, questions about spousal sponsorships do not receive any answers. At the same time, spousal sponsorship and refugees are the two most popular topics/themes for users to express their opinions on. None of the tweets that is simply a statement of one's opinion gets a comment from IRCC. This serves as a confirmation that answering people's questions is department's priority on Twitter. 


\section{User Interaction on the IRCC Facebook}

As Twitter, the IRCC Facebook account is quite popular with users. However, the level of activity is less: on average, users left 1,840 posts per month with the highest number of posts in February 2016 and the lowest in October 2015. Figure 13 shows the number of Facebook posts left by users during September 2015 and August 2016.

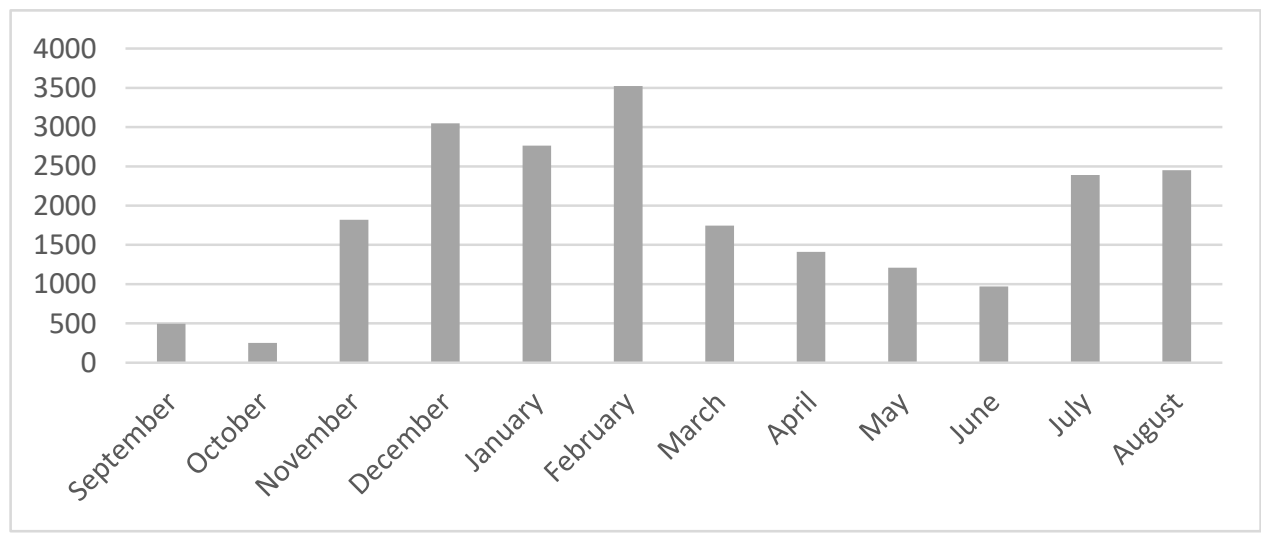

Figure 13. User Posts on the IRCC Facebook Account

Again, all user Facebook posts were cleaned of spam messages. However, spam messages that were advertising sale of travelling documents, visas and employment invitations were deliberately not excluded from analysis. These messages were not removed from the official government account, although they advertised suspicious and most likely illegal activity/services. A description and analysis of these posts are provided below. A total of 2,172 user posts (10\% of all posts that were selected for analysis) were coded.

The majority of user posts (35\%) are expressions of opinions on a specific topic or a personal statement. This is followed by questions or prompts for feedback (25\%), responses to other users (15\%), tagging other users, so they can see an IRCC post (15\%), thanking and/or expressing gratitude to IRCC or other users (4\%), sharing information (1\%) as well as other matters (4\%) (Figure 14). Thus, IRCC Facebook users are interested in sharing their opinions and/or 
getting responses to their questions rather than interacting with other users on the IRCC Facebook account and providing information to them. Again, this indicates that social media users lack interest and/or opportunity to "provide a "public" service themselves" (Linders 2012: 449).

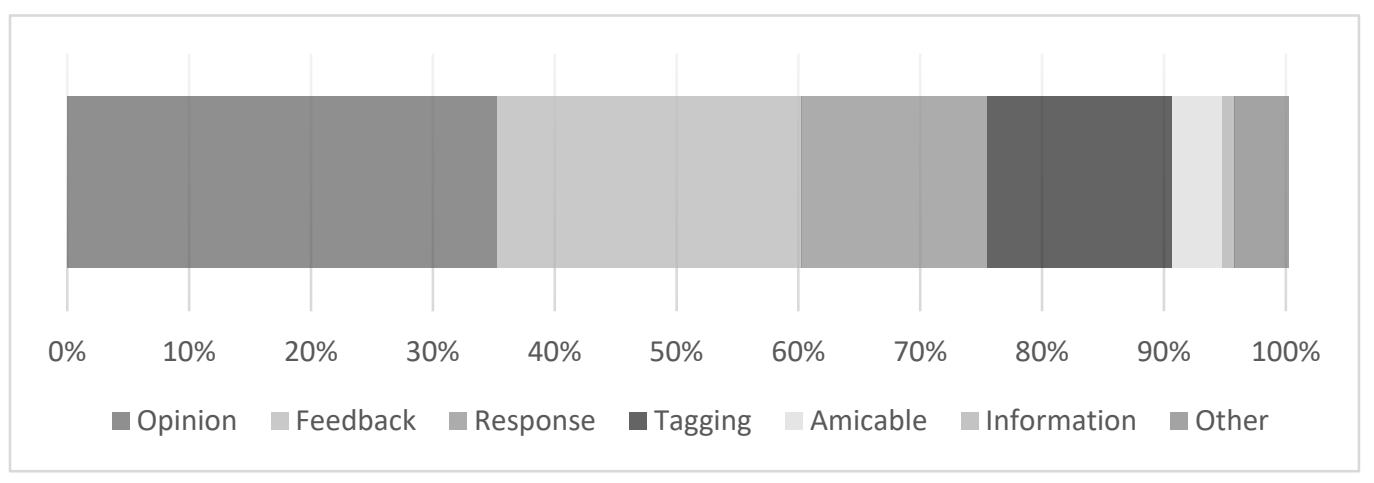

\section{Figure 14. Categories of User Posts on the IRCC Facebook}

The results of analysis of user Facebook posts also confirm the findings of the analysis of IRCC posts: IRCC answers a few questions and does not interact much on Facebook. Only 3\% or 14 user questions and other prompts for feedback received a response from IRCC. Moreover, this is the only type of posts that received feedback. The department does not participate in the conversations between users, does not respond to posts that express an opinion or gratitude. Moreover, IRCC does not react to the use of inappropriate language and/or at Facebook posts that insult others. This finding is especially concerning considering the fact that all Facebook posts were retrieved long after they were published and there was sufficient time for the department to remove or hide them.

The vast majority of user questions are about IRCC programs and services (74\%). This is followed by questions about application related matters (4\%), technical issues (3\%), processing times (3\%), ways to contact the department (3\%) and other matters (10\%) (Table 10). It is also important to note that users ask most of questions about the following programs and services: immigrating to Canada (45\%), working in Canada (10\%), refugees (7\%) and eTA (3\%). In other 
words, nine out of 10 program related questions users ask on Facebook are regarding one of these programs.

Although the number of responses is very low, the examination included an analysis of whether the department has any preferences in answering questions related to specific topics/themes. Similar to the analysis of IRCC responses to user tweets, the analysis of responses on Facebook shows that the department is more likely to answer certain questions. Thus, users are more likely to receive a response if they ask about programs and services (with the exception of questions related to immigration options and spousal sponsorship). It is, however, important to note that during the interviews with IRCC public servants, they mentioned that they do not respond to individual questions about ways to immigrate to Canada but rather post proactively on this topic. On the other hand, the number of information posts regarding this is quite low (only $7 \%$ of all information posts).

Furthermore, no responses are provided for questions related to available immigration options and about spousal sponsorship. These questions, however, account for $47 \%$ of all questions asked by users. Users are much more likely to get a response if they ask a question about any other program or service (e.g. visiting, studying, eTA, etc.).

Again, similar to the IRCC Twitter, questions about eTA are more likely to get a response although they account for $3 \%$ of all user questions. This can be explained by IRCC interest in providing response for eTA questions. However, the number of answers remains very low: only two eTA questions out of 15 were answered. Table 10 provides a comparison between the questions that are asked by Facebook users and questions that receive a response from IRCC. 
Table 10. Comparison of User Questions and Questions Receiving Answers from IRCC by Topic/Theme on the IRCC Facebook

\begin{tabular}{|l|c|c|}
\hline Topic/Theme Category & $\begin{array}{l}\text { Percent of user } \\
\text { questions }\end{array}$ & $\begin{array}{l}\text { Percent of } \\
\text { user questions } \\
\text { answered by } \\
\text { IRCC }\end{array}$ \\
\hline Technical Issues & $3 \%$ & $14 \%$ \\
\hline Application & $4 \%$ & $0 \%$ \\
\hline Processing times & $3 \%$ & $14 \%$ \\
\hline Immigrating (including questions about PR) & $45 \%$ & $0 \%$ \\
\hline Working & $10 \%$ & $7 \%$ \\
\hline Spousal sponsorship & $2 \%$ & $0 \%$ \\
\hline Refugees & $7 \%$ & $7 \%$ \\
\hline eTA & $3 \%$ & $14 \%$ \\
\hline $\begin{array}{l}\text { Other programs and services (i.e. visiting, } \\
\text { studying, travelling, etc.) }\end{array}$ & $10 \%$ & $21 \%$ \\
\hline Contact & $3 \%$ & $14 \%$ \\
\hline Fraud & $2 \%$ & $0 \%$ \\
\hline Other & $8 \%$ & $7 \%$ \\
\hline
\end{tabular}

As noted above, Facebook users mostly posts to express their opinion or make a personal statement. The most popular topics to express an opinion on are Canada as a country (18\%), immigration related matters (17\%), refugees (17\%) and other programs and services (15\%). The last category does not account for posts regarding spousal sponsorship, which accounted for only $2 \%$ of all posts in this category. Thus, this topic is significantly less popular on Facebook than on Twitter.

Based on the analysis of user Facebook posts, it is safe to assume that the vast majority of IRCC Facebook users are migrants interested in ways of coming to Canada and more specifically in immigrating. Their interests, however, are not addressed by the content that is provided by IRCC: the department focuses on posting information about eTA as well as information for newcomers - those individuals who are already approved to immigrate to Canada. Therefore, there

\footnotetext{
${ }^{10}$ The total does not add to $100 \%$ because of rounding.
} 
is an apparent mismatch in content that is provided by the department and information migrants are looking for on the IRCC Facebook.

In addition, due to lack of monitoring of user content, quite a few messages violate IRCC terms of social media use. Moreover, some user posts on Facebook promote illegal activity such as fraud. These posts are not being deleted by the department (Thompson 2017). Although the number of these posts is not high, the content is concerning and should be removed from an official government account. Below are couple of examples of such posts with contact details removed and emphasis is added by myself:

"We are the best producers of quality documents, with over 12 million of our documents circulating over the world. We offer only original high-quality real and fake passports, driver's licenses, ID cards, stamps and other products for a number of countries like: USA, Australia, Belgium, Brazil, Canada, Italia, Finland, France, Germany, Israel, Mexico, Netherlands, South Africa, Spain, United Kingdom. This list is not full. To get the additional information and place your order, just visit our website or you contact us via email Contact e-mail: XXXX."

"If you are interested in Skill Worker, Business Investor and different Provincial Nominee Program for permanent residence to Canada, please contact us. Qualification: For Skill Worker Program, Minimum graduate from any subject and minimum 2 years job experience from any occupation. For Investor program must have 2 years business experience and high profile financial condition. You may also visit our website link bellow: CONTACT: Address: XXXX Tell: XXXX Cell: XXXX Email: XXXX https://www.facebook.com/XXXX."

The first advertisement clearly calls for participation in illegal activity. Therefore, this information should be shared with the police rather than being available on the official government social media account. Second post is, however, more deceiving for those who are looking for legitimate ways to come to Canada. It advertises immigration services that on a first glance can look legitimate and potential migrants might consider using this company's services. Thus, by not monitoring user activity on its Facebook page and not providing accurate information on a regular 
basis, IRCC can be encouraging that users of its Facebook page seek immigration advice and information about immigrating to Canada by using services of fraudsters.

Due to lack of monitoring of user activity on the IRCC Facebook, many user posts also contain private information, including phone numbers and emails. Moreover, some users also share their immigration related information such as application numbers and other details of their applications. In addition, there are quite a few posts that are written in languages that are not English or French - yet another violation of IRCC social media terms of use. Finally, while conducting interviews with Facebook users, it was made apparent that some of them did not remember that they posted on the IRCC Facebook page. This could mean that some users do not realize that this Facebook page is maintained by a government agency.

To sum up, the analysis of user Facebook posts show that users are interested in interaction on Facebook for two main reasons: 1) to express an opinion and 2) to ask a question about program or service provided by IRCC. Users are not interested in interacting between themselves, although they sometimes participate in a discussion. Some user comments receive an answer from an advertiser who might be engaged in illegal activity such as fraud. Although the number of these messages is not high, they can be treated as legitimate posts by those not familiar with the context or even considered an endorsement by IRCC. Further, the department does not respond to any questions regarding fraud and fraudulent activity. Neither there are enough information Facebook posts on this topic - only nine posts over a year period.

In addition, it is quite obvious that the department is not interested in interacting with users on the platform as only $3 \%$ of questions are answered. As IRCC public servant mentioned during the interviews, they do not respond to generic questions about immigrating to Canada. Nevertheless, even if these questions are excluded from the analysis, IRCC response rate on 
Facebook is $5 \%$. Thus, the vast majority of user questions remain unanswered and users are forced to seek information and/or feedback elsewhere.

It is also important to note that certain questions are more likely to receive a response from IRCC - specifically, questions about programs and services. They are also the most common questions that are asked. In addition, the majority of Facebook posts (35\%) are a statement of one's opinion and none of them got a comment from IRCC.

\section{Differences in the Use of the IRCC Twitter and Facebook}

Users of IRCC social media platforms are more active on Twitter than Facebook. On average, users tweeted 3,451 times per month and left 1,840 Facebook posts. However, in July, the gap in use between the platforms began to decrease and in August the number of Facebook user posts for the first time outnumbered the number of tweets. There was a significant increase in activity on both platforms in November. This increase happened at the same time when IRCC became active - right after the change in government. As Figure 15 shows, user left the highest number of tweets and Facebook posts on IRCC accounts in December, January and February. Thus, user activity peaked during the Syrian Refugees campaign and decreased after it was over. The next spike in user activity on Twitter did not mirror user activity on Facebook. Twitter users became active again in May and June, while Facebook users' activity intensified in July and August.

As the analysis shows, there are many differences in the ways the IRCC Twitter and Facebook platforms are used by migrant users. However, there is one important similarity: users do not tend to interact with each other on either of the platforms. Furthermore, with an exception of a few, users do not consistently interact with IRCC nor between themselves: they ask a question 
or leave a comment that most likely will not receive a response and then disappear. This finding is supported by the interview data. Most of the users interviewed mentioned that they had a specific question or issue they wanted IRCC to address. Users who got an answer to their question tended to return to IRCC social media platforms. Others were forced to look for information elsewhere.

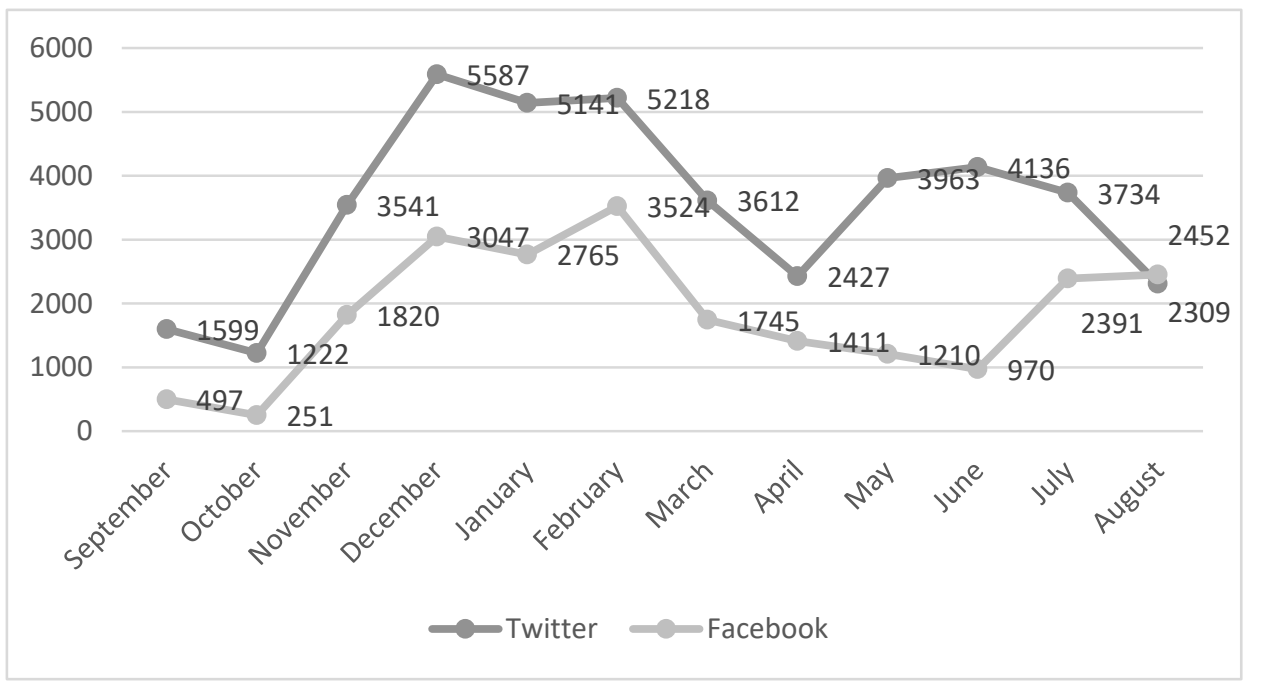

Figure 15. IRCC User Tweets and Facebook Posts September 2015 - August 2016

It is also important to note that users are far more likely to get a response or comment from IRCC on Twitter (30\% response rate) than on Facebook (3\% response rate). This motivated some users to go to Twitter to be able to address their issue although they do not use Twitter on a regular basis and/or prefer Facebook to Twitter. However, some of them reported that they had to ask their question several times on Twitter to get an answer.

In terms of types of messages that are posted, it is clear that users seek answers to their questions on Twitter while Facebook is primarily used to express their opinion (Figure 16). This can be explained by lack of responses and content from IRCC on Facebook and Facebook users' low expectations on getting a response. In addition, users on Twitter are more interested in sharing information about events and special occasions with IRCC and other users while users on 
Facebook are using its functionality to attract attention of specific users to content posted by IRCC by tagging them (Figure 16). ${ }^{11}$

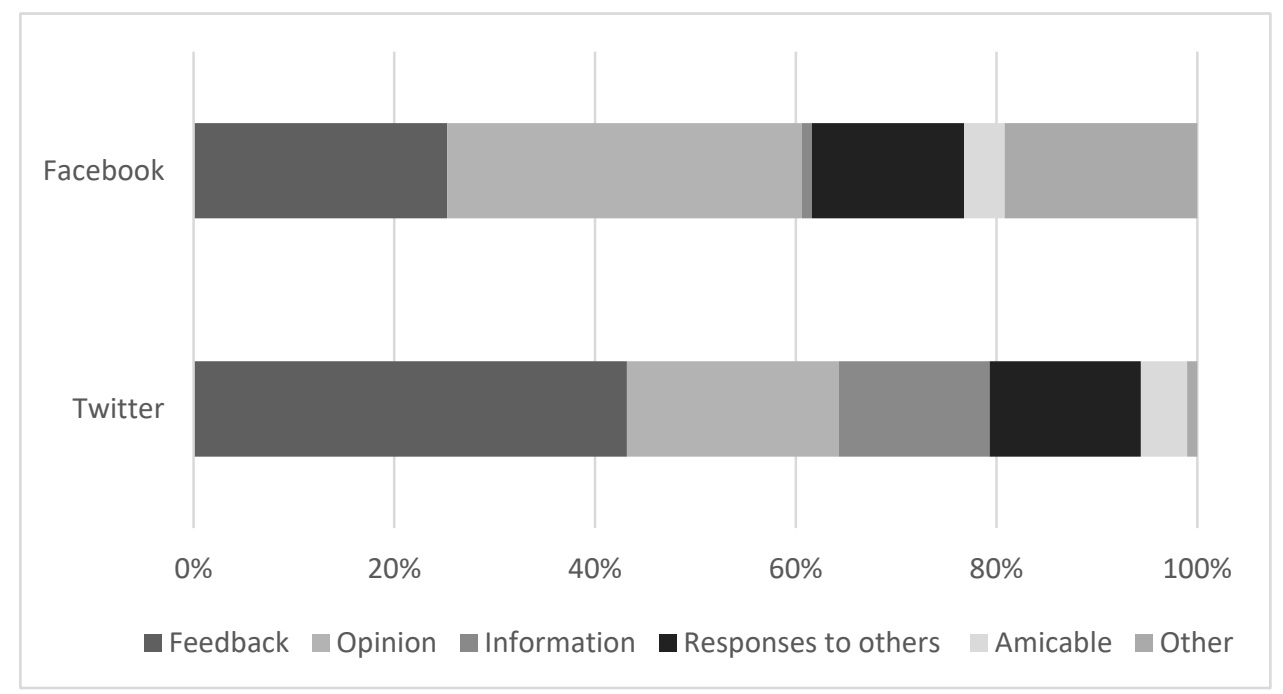

\section{Figure 16. Differences in Use of the IRCC Twitter and Facebook by Users}

Another important difference is types of questions being asked on the platforms. The most popular question on Facebook is about one's options to immigrate to Canada (45\%) followed by one's options to get employment in Canada (10\%). On Twitter, users are mostly concerned about technical issues that they are experiencing (24\%) and processing times (19\%) as well as processing times for spousal sponsorships (9\%). Table 11 breaks down user questions on Twitter and Facebook by topics/themes.

Table 11. Comparison of User Questions on the IRCC Facebook and Twitter accounts by topic/theme

\begin{tabular}{|l|c|c|}
\hline Topic/theme & Twitter & Facebook \\
\hline Technical Issues & $24 \%$ & $3 \%$ \\
\hline Application & $15 \%$ & $4 \%$ \\
\hline Processing times & $19 \%$ & $3 \%$ \\
\hline Spousal sponsorship & $9 \%$ & $2 \%$ \\
\hline Refugees & $4 \%$ & $7 \%$ \\
\hline eTA & $3 \%$ & $3 \%$ \\
\hline
\end{tabular}

\footnotetext{
${ }^{11}$ Figure 16 reflects these categories of Facebook posts in comparison to user tweets but as Twitter does not have a 'tagging' feature, these Facebook posts were included in the 'other" category.
} 


\begin{tabular}{|l|c|c|}
\hline Immigrating & $4 \%$ & $45 \%$ \\
\hline Working & $4 \%$ & $10 \%$ \\
\hline $\begin{array}{l}\text { Other programs and services (i.e. visiting, } \\
\text { studying, travelling, etc.) }\end{array}$ & $8 \%$ & $10 \%$ \\
\hline Contact & $2 \%$ & $3 \%$ \\
\hline Fraud & $1 \%$ & $2 \%$ \\
\hline Other & $7 \%$ & $8 \%$ \\
\hline
\end{tabular}

It is clear that IRCC approach of not responding to questions about immigration options is not working well as these questions continue to be asked on a regular basis. At the same time, the responses that users are getting might contain fraudulent information (as the examples discussed above). On Twitter, the situation is different as this platform is getting most of attention from IRCC staff. However, certain questions here that are more likely to get a response - specifically, questions regarding applications and program related questions. Questions about spousal sponsorship are mostly ignored and users asking for a comment on technical issues are less likely to receive a response.

Different types of questions also signal that IRCC have different types of users on Facebook and Twitter. As the analysis of Twitter user accounts shows, they are mostly located in Canada. However, as the most popular questions on Facebook are about options to immigrate and/or work in Canada, it indicates that the majority of Facebook users are migrants located outside the country. Therefore, IRCC needs to tailor its social media strategy to the audiences that are currently using the platforms. Further research is needed to identify who IRCC Facebook users are and where they are located. This will also help to identify gaps in social media outreach.

\section{Insights from Interviews with Migrant Users}

Interviews with users of IRCC social media platforms provide very important insights on their experiences with IRCC social media as well as suggestions on how the future interactions 
could be improved. As users note, the fact that IRCC responds to certain questions does not mean that the answers they receive actually contain information they are looking for. Moreover, the vast majority of participants mention the need for more meaningful interactions on government social media. It is also important to note that although only one participant who was interviewed mentioned that he did not see any value in government social media, several requests for an interview were not accepted and the reason stated was because users thought that IRCC social media was useless. Furthermore, several users noted limitations of constructive communication on social media - specifically Twitter's character limitation. This section discusses major themes that came up during interviews with user participants and are important for understanding user experiences and perspectives.

\section{Experience with IRCC Social Media}

Quality of interaction on government social media is important to its users. The opportunity to interact and hear directly from the government agency draws them to use this channel in the first place. They also anticipate that they are going to be engaged in a conversation not with "faceless" government as an institution but with real people. As participant \# 2 described: "Twitter actually looks like there is a person [answering people's questions]."

However, user experiences differ based on the platform they choose to interact on: while

users on Twitter talk mostly about the quality and frequency of exchanges between IRCC and users, some participants who use Facebook do not remember they left a comment or question on the official IRCC Facebook page. The quote from this participant \# 10 sums up this experience: "Maybe I entered Facebook for asking but I forgot." 
This confirms the findings from social media data: the IRCC Facebook page does not look like a well-maintained government social media account. Moreover, IRCC does not interact with users, so nothing really stands out for them to make this experience worth remembering.

However, getting a response is not the only reason why users are interested in government social media. Some users see value in quick informational updates from IRCC that they can get because of social media. Thus, there is no need to check the official IRCC website for updates anymore; they get all latest announcements as soon as they get on social media. Participant \# 21 described this:

I used my smart phone because I get notifications that helps a lot... it saves time. It helped me to get myself updated.

Another group of users includes those who come to government social media to express their opinion on a certain issue, including the quality of service that a government agency provides. In particular, users can be using social media to express frustration with the situation. Interestingly, they also have an expectation that they would hear back from the government agency. Two interview participants mention that although they used social media to vent, they were still expecting to hear back from IRCC. Participant \# 12 elaborated:

I was pretty annoyed. And the reason why I went to Twitter is to vent my frustration... And I never got a response from the Twitter team and I'm thinking that this because they knew that this was someone just venting.

This expectation to hear back is based on previous experiences of interacting with commercial companies on social media. According to interview participants, companies are good in acknowledging that something wrong could have happened and apologizing. Thus, it is important to keep in mind that user expectations can be influenced by their past interactions on social media. Therefore, they are expecting that government agencies will behave as commercial companies and provide the same level of customer service. 


\section{Importance of Getting a Response and Its Quality}

The vast majority of interview participants leave a question on IRCC social media. Some of them get a response and some of them do not. Needless to say that those who do not get a response are disappointed with such an outcome. However, some of those who do are also not satisfied with the result of their interaction. The two quotes below summarize the experiences of social media users who got an answer but were not satisfied with the information they are provided. Participant \# 2 stated:

Canada is the most amazing place I've been where everyone is actually nice to me. But when you go through $\mathrm{CIC}^{12}$ process, do it yourself on your computer and the answers are like, they are copy-paste, they are not from an actual person I believe. I don't know if there is someone there who types them.

Participant \# 7 noted:

They just pointed me to an article on their website. Yeah, it was not very helpful. I guess, most of their responses, I saw how they were communicating with other people... they were just pointing people to their articles and not giving any extra information. My experience communicating with them was mostly negative.

Some participants, however, were quite satisfied with the responses they receive. They noted that the responses were prompt and helpful. At the same time, the questions these participants asked were relatively uncomplicated. As participant \# 15 noted:

They managed to answer exactly what I needed to know and they did actually link to additional information on filling in the [application] form if I had additional questions. And it did address pretty weird questions like that.

Participants who use Twitter also mention that they decided to tweet @CitImmCanada because they saw that IRCC was responding to questions on this platform. This observation is the primary reason why they decided to interact by leaving a tweet. Moreover, two participants specifically mention that they decided to switch to the IRCC Twitter after looking into the IRCC

\footnotetext{
${ }^{12}$ Before November 2015, IRCC was called Citizenship and Immigration Canada (CIC).
} 
Facebook and realizing that questions posed by other users remained unanswered. Participant \#2 explained:

I use Facebook, I never understood Twitter...Actually, I did [use Twitter only to connect with IRCC]. I usually use Twitter when I am arguing with someone, which is very rarely.

Thus, participants who use Facebook are forced to use Twitter to try to get a response from IRCC. This is problematic because many of the participants who used Facebook did not use Twitter and one mentioned that there was no access to Twitter in his country. Others do not use Twitter because they have a clear personal preference for Facebook, do not like Twitter or do not have a Twitter account. Therefore, these users are at a disadvantage just because they choose Facebook to communicate with IRCC.

\section{Value of Answers by IRCC, Other Users and Two-way Interactions}

At the same time, interviews with users show that they are using IRCC social media because they are interested in getting personalized feedback directly from IRCC. Users also emphasized that the response from IRCC would contain accurate and reliable information, confirming findings of Lu et al. (2016) who note importance of government information and its quality for social media users. Moreover, social media users turn to IRCC social media to hear directly from the department. Participant \# 4 explained:

If they are asking about their application, I'm sure that nobody can help them but CIC themselves... Most people are asking about their own applications, their processing times and their countries. And sometimes people are having problem linking their applications online, I've seen that, I had friends who had that issue... In this case, no one can help really. Even if they wanted to, it depends on the system and I am not sure what went wrong there.

Some participants see value in answers/comments from other users who talk about their experiences and give advice. However, they also noted that this can be helpful for certain questions more than others. Several participants mentioned that they received comments from others or 
responded to other people's questions. This is specifically important for those who use Facebook: some participants emphasized that the responses they received from other users helped them. However, nobody mentioned that they were involved in a conversation for a prolonged period of time: mostly, other users were just trying to be helpful or comparing their own situations to situations others were facing.

Participant \# 7 also mentioned that the reason he was interested in other people questions and responses was just to make sure that his situation is not unique, i.e. there were others who were also waiting to hear from IRCC on their application and it was also taking them longer than processing times stated on the website. He mentioned that this should be corrected by the department by constantly informing about changes in processing times, so that applicants are aware that this is the case.

Users also look closely at how IRCC interacts with others on social media by skimming through messages and responses. They are also taking a note regarding the promptness of response. As participant \# 7 noted:

The response was after ten days. First time it was after two days or something. It was ok. But the next time I don't know why... And I'm seeing that they are responding to people, other people who posted after me... maybe they decided to take their time, they are checking things along.... A lot of people ask the same questions [regarding processing times] and they get the same answer while my question was something else and they needed sometime maybe to provide an answer for it.

Therefore, users can feel anxious that they are not getting a response from the government agency while others do. One suggestion to mitigate this anxiety provided by a user interview participant is to acknowledge the receipt of a question and that it would take time to respond. 


\section{Language}

The theme of language came up quite strongly in user interviews. There are two dimensions to this theme: first, people are noting that the language IRCC is using is hard to understand regardless if you are a native English speaker or not and second, participants note that the responses they receive are so impersonal that they feel they are "copy-paste". As participant \# 2 emphasized: "I sincerely doubt a person is writing [responses]."

The problem with understanding IRCC's written correspondence goes beyond social media. This is, however, typical for government correspondence in general (Mergel and Greeves 2013). Participants note that they had troubles with understanding rationale for IRCC decisions on their applications, information available on the IRCC website, IRCC emails, application forms and tweets. Participant \# 2 elaborated:

I read it than I asked my boyfriend to read it and I don't get it... I thought it was my problem with understanding English but when I was with my boyfriend, I was like how you do not understand this, your people wrote this. And he is like I don't know... And I understand that not everyone who wants to come to Canada has the language advantage that I have.

Thus, the issue of plain language communication between government and the public, as noted by OGP, is important for government communication across all communication channels, including social media. Immigration agencies, whose clients might not be able to understand English or French to the same extent that native speakers do, has to pay significant attention to this issue.

"Copy-paste" responses is another important issue that was briefly discussed above. Participants felt that they were not getting information they were looking for as everyone was getting a standard response. Some noted that they do not see any difference between getting such a generic response and no response at all. Thus, users are interested in a response tailored to their situation. 
Some participants also mentioned the need to know well English or French in order to be able to communicate with IRCC and/or access its information. They noted that this was the reason why they were interacting on IRCC social media on behalf of their friends and relatives who do not possess a good command of English. They also call for availability of IRCC's information in other languages.

\section{IRCC Website and Other Sources of Information}

Most people start their search for information on the official IRCC website. When they cannot find the information they are looking for there, they turn to IRCC social media and/or other sources of information. Participant \# 15 noted:

I had a very specific question. I was trying to help a friend to try to fill an online immigration form... I went to [the IRCC official website], which was very specific but unsurprisingly did not have this very specific, very odd question in it. And when I was not able to find that I turned to them on Twitter.

Therefore, most of participants who were looking for an answer from IRCC already did their research and were aware of the information available on the website. However, as participant \# 21 noted, the website itself can be quite challenging to navigate:

For Express Entry, I feel that information is very scattered. There should be some place on the website where you can get all your documents, it is not really structured.

Thus, although the website is the main starting point, users might not be aware where some of the information is located. However, many participants also note that they did a google search when looking for the information they required. Therefore, the IRCC website is an important starting point for those who come to IRCC social media. In addition, many participants learned about IRCC social media accounts because they saw the links to them on the website.

Some users, however, use additional sources of information: other social media accounts (some specifically mentioned that they used social media of Canadian missions abroad), forums 
(canadavisa.com being the most popular among interview participants), blogs, websites of lawyers and consultants, and websites of other government agencies. Sometimes users actively interact on other social media platforms and ask questions related to their situation. However, many interview participants note that they just review the content, note different experiences and never participate. Thus, they rely on the infrastructure of latent ties (Haythornthwaite 2002, 2005; Komito 2011) and existing migrant networks to get immigration-related information (Dekker and Engbersen 2014;

Dekker et al. 2016). Needless to say, sometimes information and advice can be helpful but sometimes participants might provide incorrect information or discourage prospective immigrants, workers or students from coming to Canada, thus revealing negative effects of social capital (Portes 1998; George and Chaze 2009a; Zhao et al. 2010).

It is also important to note that some users only use IRCC website and social media as sources of information, thus, it is really important to maintain high quality of these resources. As participant \# 7 emphasized this: "Processing times should be corrected ... [on the IRCC website] they are way off."

\section{Privacy}

The vast majority of participants did not have any concerns with privacy. Some, however, noted that they were concerned that other users were sharing their personal information such as application numbers, phone numbers and names. However, those users who criticized IRCC admit that they were concerned that their actions could jeopardize their cases. Participant \# 12 noted:

I even thought once, why did I comment on Twitter? Because I did not have my visa yet, they had all my documents and I think at some point they had my passport. And I was like, oh, what if they just deny my visa?

Overall, however, users are comfortable with using their existing social media accounts to interact with the department. They do not see the need to have a separate account and are 
comfortable that others see their posts as they do not reveal any personal information. They note, however, that the use of private messages that cannot be publicly seen is more appropriate for certain circumstances and situations.

\section{Effective Use of Social Media by Government}

Overall, participants feel that IRCC should be using social media more effectively. Effective use, from their perspective, has several components to it. First, they emphasize the need for better interaction. As participant \# 18 noted: "[There is a] need for interaction. Twitter cannot be just used to post information on the feed." Facebook users state the same: they need to hear back directly from IRCC.

Second, participants emphasize the value of personalized answers. Most interviewees felt that they were getting a "copy-paste" response and they were looking for a response that was tailored to their situations. They also felt that there is no value in providing same generic response to everyone. Some participants suggest that private messages could be used to share information that is more sensitive and note that some companies in Canada are currently providing personalized responses via private messages. Further, private messages do not have character limitations like tweets, which makes it easier to explain the situation without the need to break down a message into several tweets.

Third, Facebook users note that they would like IRCC to enable users to post directly on its Facebook page rather than having to comment on an IRCC post. This would greatly improve their user experience and would clearly identify information they are interested in.

Finally, users turn to government social media because they have the need to hear directly from the government agency. Furthermore, although some see value in answers and comments 
from other users, these are not considered as significant and helpful as government agency's responses.

Therefore, from users' perspective, efficient use of social media involves direct interaction between government and users that results in prompt provision of personalized information users are looking for. Users value the quality of information and note that it is important to them that it comes directly from government.

\section{Conclusion}

Users primarily interact on IRCC social media accounts to ask questions and express their opinions. However, regardless of the reason they tweet or post, they are most likely looking for some interaction between themselves and IRCC. However, as the analysis shows, they are likely to get a response or comment only if they choose Twitter and ask a non-controversial question related to their application or related to programs and services. However, users indicated that even if they receive a response it does not necessarily contain information they are looking for.

This finding needs to be explored in the context of customer service focus of IRCC social media as well as lack of opportunities for migrant users to communicate directly with IRCC. As noted above, some users express the need to be able to "talk to a real person" in order to get their issue resolved. However, those who are located outside of Canada are limited in options to contact IRCC: they can either send their question via a web form or use social media. They cannot contact the call center. Many participants note that they are frustrated with this situation. Users are getting discouraged by not being able to reach IRCC or if they get a response that do not answer their question. Therefore, they might look for other sources for information or decide to choose another country that they can visit, study or work in. This problem, however, is out of scope of this study. 
Nevertheless, it is important to keep it mind that it needs to be addressed, especially considering the IRCC goal to use social media as a valid alternative to the call center.

Further, the analysis of user tweets and posts show that migrants are not interested in interacting between themselves. Most interview participants point out that they came to the government social media platforms to hear the official government response and were not interested in other peoples' experiences. Some interviewees, however, mention that they see the value of other peoples' answers or comments.

The data analysis and interviews indicate that latent ties and social networks of peer migrants are important to migrant social media users. They rely on those to get information about the migration process that is not available on the official government website and/or is not provided to them directly (Komito 2011; Dekker and Engbersen 2014). Networks of peer migrants that develop and exist on other social media platforms are checked with it in order to get reassurance and solicit advice and personal experiences. Therefore, social media plays an important role in connecting people who otherwise would not know each other (Haythornthwaite 2005).

This is, however, less obvious on government social media where migrants are mostly interested in communication with government. Furthermore, they want to hear from government as they believe that only government agencies can provide reliable and accurate information about its programs and services. This confirms the findings from the literature that users look for twoway interactions and value information quality and content of government social media posts $(\mathrm{Lu}$ et al. 2016).

It is important to note that users are also using a variety of different information sources, including websites as well as forums, blogs and social media resources. From the user perspective, the main value of government social media is in the opportunity it gives to promptly connect with 
the government agency. However, users are interested in answers tailored to their specific situation. IRCC also should take into account that users are expressing their opinion mostly on the topics they cannot get responses for. For example, on Twitter, spousal sponsorship and refugees are the two most popular topics/themes for users to express their opinions on. On Facebook, they are sharing their thoughts on Canada and immigration related matters. This should be taken into consideration by the department when developing informational campaigns and website updates.

From the user perspective, the most important factors that signify the effective use of social media by governments are the following:

- network factors, especially the value of information exchanged during interactions, quality of this information and the possibility to getting feedback that could not be gathered otherwise. Participants also note the importance of latent ties but it is clearly acknowledged by users that government agency officials are the most important actors in the network - thus confirming the centrality of government in public service delivery networks (Frederickson et al. 2012);

- personal factors, specifically goals of social media use and perceived value of its use to personal/migrant goals. This is the primary reason why migrants turn to social media for information and expect government agencies to provide reliable information on their social media platforms;

- organizational factors, specifically a lack of organizational flexibility to provide content that is tailored to users' needs and expectations. Those participants who are looking for answers for more complex questions are more likely to rely on multiple sources of information, including other social media pages and groups, forums, personal blogs and a variety of websites. They turn to these other sources to have 
real-time conversations, share experiences or just for information purposes. This user group also clearly expressed that they are looking for personalized responses on government social media but are really discouraged and frustrated by the generic answers they received.

Other factors that play important role are user expectations formed based on interactions with commercial companies on social media and $24 / 7$ availability of social media as a communication platform. These factors should be accounted while determining social media policy and practices. 


\section{Chapter 7. Conclusions, Recommendations and Suggestions for Future Research}

The findings of this study demonstrate that government agencies in Canada are cautiously engaging in two-way interactions with the public on social media in limited ways. There is still significant work ahead to ensure that social media is understood and valued by senior management, public service officials, and is utilized to its full potential. At the same time, as the case of IRCC shows, government social media users are drawn to social media to connect directly with government officials. However, most of them are looking for personalized information and advice, and not a simple referral to the official website. They are also interested in more interaction between government and the public through more engaging content, participation in discussions and prompt meaningful responses.

This chapter discusses theoretical, methodological and practical significance of the study, and its conclusions. It also summarizes answers to four key research questions. This is followed by a series of recommendations to government agencies based on the research findings. The chapter concludes with a number of suggestions for future research.

\section{Significance of the Study}

This research makes important theoretical, methodological and practical contributions. Theoretically, it builds on three distinct bodies of literature - e-government, migration studies and network theory in public administration and policy studies. It identifies existing gaps and limitations of these theoretical frameworks and emphasizes the need to go beyond the analysis of government use and capabilities on social media. It specifically calls for taking into account social media users' preferences and expectations when developing and implementing government social media strategies and practices. 
As the analysis shows, all groups of factors that signify effective use of social media network, organizational and personal factors - are important to the government agencies (IRCC and MCI) and IRCC social media users. However, no one group of factors indicate effective use of social media but rather their combination and interdependency.

Another important theoretical contribution is a revised definition of the effective use of social media by government. Currently, it is generally defined in the literature as presence of interactive two-way communication between government and citizens on government social media (Meijer and Thaens 2013; Mergel 2013a; Mergel and Greeves 2013). However, this definition does not fully account for the quality of interactions and information sharing users are looking for. The findings of this study indicate that the quality and promptness of these two-way interactions are as important for the public as the existence of the interaction. Therefore, current definitions and studies related to the effective use of social media in government should be based on a broader definition:

Effective use of social media by government is interactive and bidirectional communication between government and the public on government social media that results in prompt and personalized information sharing tailored to the needs of social media users.

It is important to note, however, that social media is just one among many channels that government agencies use to provide information and interact with their clients. Although the use of social media in government is growing, traditional methods of providing personalized information and respond to queries such as call centres, on-line applications and in-person service are seen by government officials as service delivery channels while social media is not. Therefore, the potential of social media to become a service delivery channel is yet to be explored. 
In addition, from the perspective of the government officials interviewed for this study, effective use of social media is impossible without central agency (such as TBS) and individual government agency senior management understanding and buy-in to endorse both the technology side and engagement side of social media use in public administration. This is necessary to make a case for allocation of resources towards the use of social media.

Findings from this study also support the research outlining the need for public sector organizations to develop a comprehensive social media strategy (Bennett and Manoharan 2017; Jukić and Merlak 2017). These strategies should take into account needs and preferences of social media users, and clearly articulate how social media users' feedback is incorporated in government social media practices. However, due to existing differences among policy domains, it is recommended that the strategy should be created on an individual agency level or at a policy domain level (e.g. social policy, economic policy) to take into account specific public needs and expectations.

Methodologically, the study derives its findings from three qualitative methods of inquiry: analysis of policies and other government documents, content analysis of social media data and semi-structured interviews. These methods demonstrate the importance of relying on both quantitative and qualitative data when analysing social media use as well as the need to take into consideration broader government and societal structures (macro level) and individual experiences and perspectives (micro level). The approach and tools used to collect and analyse Twitter user profiles and IRCC Twitter and Facebook social media data can be adopted and used by government agencies and inform the qualitative analysis of their social media use that they are currently lacking. 
In addition, social network analysis informed this study at its preliminary stages. According to Mergel (2017: 491), this method should be used by government agencies to "understand the network structure of their followers online and shape the network structure of their followers." However, the cases of IRCC and MCI show that although these government agencies interact with the public on social media, they have not developed a constant network of users and do not have a lot of knowledge about their users. Basic social network analysis can help determine the various types of actors, key user participants, and the relationships between them. Therefore, importance and optimal structure of networks can be examined in future studies, especially aimed at understanding the use of social media in policy advocacy and development.

It is important to note that the findings of this study are based on the use of social media by government immigration agencies and migrant users. Although they could be applicable to other government agencies in social policy domains, caution should be exercised while making other kinds of generalizations.

\section{Answers to Research Questions}

This study focused on four central research questions that were explored and analysed based on two immigration agencies in Canada. Through a combination of secondary sources, document analysis, content analysis of social media data, and key informant interviews with government officials and users of immigration agency social media platforms, this study focused on answering the following questions.

The first question is: How and why is social media being used by government immigration agencies? 
As the analysis of open government policies and social media documents in Canada, Australia and New Zealand, as well as the cases of IRCC and MCI show, there is no direct link between the proclaimed open government policy and social media use by these government agencies. However, public servants note that open government approach informs social media use in government by promoting more transparency and creating space for the dialogue between government and the public. More specifically, immigration agencies are using social media "in a customer service function" to respond to people's questions and to keep the public informed about available programs and services. They are not engaging on policy matters or controversial issues. Furthermore, immigration agencies are not yet ready to engage with the public to advance policymaking and/or public service delivery.

The interaction between government agencies and the public differs depending on the social media platform: in case of IRCC, Twitter is primarily used to provide answers to people's questions, while Facebook is an announcement tool and there is very little interaction between Facebook social media users and the department. Responses that are provided on Twitter are referencing information that is already available on the official website and mostly do not account for personal circumstances. This difference in use is, however, not specified in the IRCC's terms of social media use.

Government interest in social media use is based on three main goals: promote and market programs and services, connect people with the right information they are looking for and reduce volume of calls to the call center. Nevertheless, public servants note the need for more interaction and personalized advice they are currently unable to provide due to existing resource limitations and hierarchical structures. 
There are also a number of existing issues with the government use of social media. They include lack of analysis and monitoring of social media content and focusing solely on the number of re-tweets and likes as a proxy for the social media content popularity and importance, central agency (Cabinet Office in Ontario) or political approval (Minister's Office for IRCC) processes for the social media content and very low response rates on social media.

The second research question is: How and why do migrants use government social media resources?

Migrants are drawn to government social media resources as they are looking for prompt personalized advice from government agencies. They also turn to social media to express their opinion or frustration, share information and respond to other people's questions and comments. However, the majority of migrant users are looking to hear directly from the government, even in the situation where they comment to vent their frustration.

Furthermore, users who are located outside Canada have to use IRCC social media in order to get prompt feedback as they cannot call the call centre and an email response can take up to 30 days. However, as the analysis shows, only $30 \%$ of questions on the IRCC Twitter and $3 \%$ of questions on the IRCC Facebook get a response from the department. This situation forces Facebook users to switch to Twitter in order to resolve their issue.

Moreover, migrant users on Twitter and Facebook are asking different types of questions. IRCC Twitter users are interested in resolution of technical issues, information about a variety of programs and services, and processing times. IRCC Facebook users are primarily interested in ways of immigrating and working in Canada. This situation signals that IRCC has different audiences on Twitter and Facebook and has to adjust its social media practices to meet the needs of these different audiences. 
In addition, the quality of the response matters for users as much as the fact they have received a response. They are not looking for a generic, "copy-paste" response but rather for an answer that is tailored to their specific situation. Furthermore, they call for the expanded use of private messages on Twitter and Facebook, so that more private issues can be discussed.

The third research question is: Do relationships created between government agencies and migrants on social media matter and why?

According to the analysis, there is no well-defined or constant network of users either on the IRCC Twitter nor the IRCC Facebook: users ask their questions, follow up on the response (if they receive one) and disappear. In addition, the vast majority of users are private individuals with a few exceptions of immigration consultants, lawyers and non-profit organizations that provide settlement services. Furthermore, due to lack of monitoring of users' content, the IRCC Facebook has presence of fraudsters who are promoting illegal activity.

Nevertheless, public servant interview participants stress the importance of developing and sustaining relationships with users on government social media. Government sees social media as the tool to provide the public with accurate and useful information. However, public servants note that government cannot participate in all conversations and correct all misunderstandings. Users, on the other hand, are capable of answering questions for the agency as well as sharing personal experiences and perspectives. However, there are no concrete efforts to encourage user-to-user interactions on government social media.

Migrant users also see value in interacting with other users on government social media. They note that answers provided by others helped them to better grasp the situation they were experiencing and/or compare their circumstances to those of others. Furthermore, they take time to look through information that is already available on social media, thus, leveraging latent ties. 
Nevertheless, users see government social media primarily as a place to get answers directly from government. Furthermore, they are not specifically seeking to engage in user-to-user conversations as they utilize other resources such as immigration forums and other non-government social media if they wish to discuss their case with others.

Finally, fourth research question is: To what extent do governments effectively use social media?

As noted, government and social media users have different perspectives on what the effective use of social media means in public administration. Public servants admit to current limitations of social media use but also emphasize that they are doing the best job they can with the amount of resources allocated for the social media team. Social media users, on the other hand, draw on their experiences of interacting on social media with commercial companies. The definition of effective use of social media discussed above stresses the importance of taking into account user perspectives when defining effective use of social media and developing metrics to measure its effective use.

Although significant challenges remain related to the inability of government organizations to personalize social media responses because of existing rigid hierarchical structures, financial constraints, communication protocols, the lack of flexibility to involve staff from areas that are directly responsible for public services provision, and overall risk intolerance, further research is needed to identify ways to increase effectiveness of social media use in government.

Furthermore, government agencies that strive for effective use of social media should be able to evaluate own performance on social media, both quantitatively and qualitatively (Kagarise and Zavattaro 2017). In addition, they should seek government social media users' feedback and incorporate it in performance reporting. 
In summary, this research provides some important scholarly and practical findings. It points out that the user perspective should be taken into account when developing the approach to the use of social media in government. It also shows that users are not interested in networking as a form of communication on government social media (Bertot et al. 2010; Linders 2012; Mergel and Greeves 2013) but rather use it to get prompt personalized advice directly from government. Public servants from immigration agencies, on the other hand, note importance of creating relationships with the public but also emphasize that they currently see social media as a customer service tool and are not considering engaging with the public through this communication channel (Landsbergen 2011; Mergel 2012; McNutt 2014; Small 2012).

Finally, this research makes a practical contribution by producing a series of recommendations to advance social media use in government. Thirteen recommendations are offered for consideration and potential inclusion in the overarching open government policies as well as specific government agencies' social media strategies and publicly available documents such as terms and conditions of social media use. These are grouped into two categories: shortterm recommendations that can be implemented without significant additional funding and longterm recommendations that require significant investments and cultural changes within government agencies.

\section{Recommendations}

This study makes a number of recommendations for practitioners involved in determining and advancing government agencies' social media priorities and practices. As the research shows, government agencies are facing a number of barriers in their use of social media. They include organizational and cultural factors such as lack of interest in incorporating citizens' feedback in 
decision-making (McNutt 2014), preference for top-down approach in disseminating government information (Roy 2016) and lack of understanding how to measure social media impact, effectiveness and efficiency (Mergel 2012). However, an important cultural shift needs to happen in order to overcome these challenges and this will take time. At the same time, there are also recommendations that can improve experiences of government social media users in the short term and are easier to implement. These recommendations are practically oriented and are "doable" for government agencies looking to enhance their social media presence. It is important to note that these recommendations are derived from the findings of the study and thus are more applicable to government agencies in the social services policy domains. However, a lot of them offer important insights to any government agency that use social media for interacting with its clients.

Recommendations are grouped into two categories. Short-term recommendations are easy to implement and do not require additional resources and/ or assistance from other government agencies. Long-term recommendations require significant investments and/or cultural changes that take time and might require support of other government agencies. These recommendations are based on the findings of social media practices of immigration agencies, and thus, can be more applicable to immigration and other government agencies that provide social services. At the same time, many of these recommendations are more generic and their implementation could benefit any government agency that uses social media.

\section{Short-term Recommendations}

Recommendation \#1 - Clearly define what questions from the public will be answered on social media 
Government agencies should clearly state what issues are going to be addressed on social media in its publicly available documents such as terms of social media use. Currently, IRCC terms of use specify that two categories - political questions and questions about individual case or application - will not get any feedback. There is no mention, however, that questions about existing immigration options or work opportunities in Canada will not be answered. Users will be able to form their expectations accordingly if they are aware of the range of issues they can anticipate an answer for.

It is also important to have a link to the terms of use published on the social media account for users to refer. If resources and staffing levels permit, government agencies can respond to those questions that cannot be answered on social media by referencing existing terms of use and providing a link to them in their response.

Recommendation \# 2 - Ensure that social media content is provided in plain language

Another important consideration is to ensure that the OGP commitment to plain language communication between government and the public is captured in terms and conditions of social media use. This should be also reflected in social media content that is published on social media platforms or provided in response to questions.

Recommendation \#3 - Acknowledge receipt of a question that requires time to look into Many interview participants note that they would like to have an acknowledgement that the question they ask is being reviewed and the answer will be provided in due time. This will help to address concerns of users who are waiting for an immediate communication as well as provide more time to look into the matter. It is important to note that this is a standard practice of commercial companies on social media and people's expectations are based on the previous experiences they have. In addition, users also check how fast other users are getting responses and 
feel concerned if somebody who asks a question later receives a response before them. By providing an acknowledgement of receipt, government agencies help to reduce anxiety of users who are waiting for a quick response.

Recommendation \#4 - Allow direct/private messages on Twitter and Facebook

It is important to set up social media accounts in a way that gives users options to communicate with the government agency. Providing information via private messages is one important consideration. Interview participants mention that some of the government social media users are not comfortable asking a question that can be seen by others. This does not necessarily mean that they want to share personal information or circumstances of an individual case. They, however, might not want to reveal publicly that, for example, their application was refused. By opening direct messages on Twitter and private messages on Facebook, government agencies will provide an additional way to reach out to them. Furthermore, there will be no need to use several messages or tweets to respond as direct messages on Twitter and private messages on Facebook can be rather lengthy. This will also help to ensure privacy of government social media users.

\section{Recommendation \#5 - Allow "guest posts" on Facebook}

A Facebook page of a government agency that is set up in a way that users can only comment on the posts published by the agency can be very confusing for users. They cannot ask their questions but are rather forced to comment on content that might be completely unrelated to the topic of their question. By allowing "guest posts" on its Facebook page, government agencies provide a clear way of reaching out to them if users have questions or would like to make a comment that is not related to a specific post. This will also help other users to more easily find information on the Facebook page. 
Recommendation \#6 - Do not prefer one social media channel to another

As the findings of the study show, with a few exceptions, users have a clear preference for a specific social media platform. Some users also note restrictions on use of certain platforms that might be in place in their country. At the same time, different social media channels reach different audiences that have different information needs and possibly expectations from government. Therefore, it is important to devote similar attention and resources to maintaining all government agency's social media platforms in order to provider same quality of interactions. Thus, all users, regardless of the social media platforms they prefer, will be able to interact with government official representatives on social media.

Another potential consideration is government agency's presence on a fewer social media platforms but increased interactions on existing social media resources. This can potentially increase the quality and frequency of interactions between government and the public. Most appropriate social media platforms for government presence can be determined based on users surveys and/or understanding of government social media user profiles.

Recommendation \#7 - Monitor user activity

Monitoring user activity on government social media accounts is crucial for ensuring that everyone follows established terms of its use. Presence of inappropriate language and insults can lead to people's reluctance to disclose a point of view or engage in a conversation. Moreover, as in case with the IRCC Facebook, lack of monitoring can result in "unmemorable" experience with a government social media account, i.e. people will not remember that they visited and /or interacted on it. Furthermore, it shows that the department does not pay much attention to the need to enforce the established rules. 
Another important issue is monitoring of spam messages as well as third-party advertisements. These messages can contain misleading and false information and/or encourage illegal activity. However, as they are published on official government social media accounts, users might decide that these messages are permitted and endorsed by the government agency. This issue is especially significant for immigration agencies, as migrants who interact on social media platform, might not be able to distinguish between quality of information that is available on government social media platform.

\section{Recommendation \# 8 - Participate in discussions}

The number of requests for responses on government social media can be overwhelming and public servants might feel reluctant to engage in discussions that unfold between users. However, as noted before, users are expecting that government agencies go beyond answering questions and engage more. By participating in user conversations, government agencies can correct misunderstandings, stimulate discussions or present an official government position. It will also make conversations on the platform more engaging. Therefore, it might help to start a shift toward collaboration between government agencies and the public on social media (Lu et al. 2016).

\section{Long-term Recommendations}

Implementation of these recommendations requires additional financial resources and might require a cultural shift within government agencies. In addition, implementation of certain recommendations requires leadership and collaboration between individual government agencies, TBS and the Interdepartmental Task Force on Social Media. 


\section{Recommendation \# 9 - Allocation of appropriate resources}

As users look for responses to their questions on government social media, adequate resources should be allocated to ensure that the feedback is provided. This means the opportunity for staff to develop and publish content, respond to posts, monitor user posts and perform analysis. Social media users are primarily interested in communicating with government directly and obtaining information they are looking for from government. Thus, the role of government as a sole provider of reliable and accurate information regarding its programs and services should not be underestimated. Moreover, if users are lacking this information from government, they are forced to look for it elsewhere and/or make decisions in the absence of necessary information.

Another important consideration is to have enough resources available for analysis of social media content. The importance of this analysis was mentioned by all public servant interview participants. The methodology used in this study can be adopted to the needs of government agencies in order to analyse different types of user posts, interactions between users and understanding the most important topics where users require more information and clarification. Such an analysis, however, requires significant time and thus dedicated staff resources. This could be done by individual departments but also by a unit within a central agency (i.e. TBS) or contracted out to a non-profit organization such as the Institute for Citizen-Centered Service. Furthermore, staff should receive appropriate training and clear direction on how the results of analysis can be communicated to the social media team, senior management as well as how they will inform existing social media strategy and practices.

It is also important to consider what social media platforms should be used and devote the resources to the use of the most important platforms (e.g. popular with social media users and 
available to them) and discontinue the use of others. This will allow to free up staff time to perform analysis and monitoring as well as to respond to questions.

Recommendation \# 10 - Acknowledge the need for public service delivery function of social media in open government policy documents

Interacting with the public and answering people's questions on social media is important priority of government agencies. They might, however, still be exploring the ways to consult with the public on policy issues. By recognizing the role social plays in public service delivery in its action plans on open government, the Government of Canada will encourage the use of social media in government for a variety of reasons, including improving public service delivery. This might serve as a signal for potential collaboration between TBS - the lead agency on open government and individual government agencies through the Interdepartmental Task Force on Social Media. It can also help to build on experiences of government agencies that are using social media as well as encourage information and best practices sharing though the Social Media Community of Practice.

Furthermore, the OGP can focus on explaining the need to acknowledge the usefulness of social media as a customer service tool in countries action plans on open government. In addition, the potential of social media to gather low-cost public feedback on government agencies performance can also be highlighted. Once government agencies are more comfortable with using social media to receive feedback from the public, they might consider extending its use to receive feedback on proposed policies and regulations.

Recommendation \#11 - Understanding audiences that are using government social media

One of the important reasons of government presence on social media is to promote existing programs and services and to distribute information about upcoming changes. Therefore, 
understanding who the users are and if government agencies are reaching out to target audiences they expect to attract is important. This can be done by analysing user profiles and/or conducting short surveys. If a crucial user group is missing, government agencies can strategize how to reach out to these users. Understanding audiences will also help to tailor information and promotional campaigns to the needs of those who are currently present on government social media.

Recommendation \# 12 - Personalize responses, tailor them to individual situations

Quality of responses users receive on government social media matter to them as much as the fact that they received a response. Many users form their expectations about interacting with government on social media based on their experience on social media platforms of commercial companies. Thus, they expect that their individual situation to be taken into account and the response they receive will reflect it.

Users also note that the reason they turn to social media is because the email responses or letters they receive from government are impersonal and hard to follow because of the bureaucratic language. Social media is expected to be a more personalized tool, where users can engage with a "real person" from government.

It is also important to note that some companies allow social media users to share their personal information in private messages, so they can provide assistance accordingly. Although privacy regulations might not permit this practice on government social media, it is possible to provide a more detailed and personalized answer based on individual circumstances via private messages. Understandably, this practice will require additional resources and collaboration between teams that are maintaining social media resources and program areas responsible for providing specific programs and services. Further analysis on how and when to provide personalized service across different government service delivery channels is also required. 


\section{Recommendation \# 13 - Government agencies should engage users}

Government social media users emphasize their interest in interacting on government social media. This goes beyond a need to receive a response and involves meaningful discussions. If government agencies are not ready to engage on policy development and hold public consultations on social media, they still can address this need. For example, they can organize a chat with a specialist who can answer questions that people have in real time. Moreover, the transcript of these chats can be made available for review and follow up questions. Furthermore, government agencies can invite users to share their experiences with a specific program or service. Public servants from the social media team can act as moderators in these discussions as well as offer advice and perspective. It is important to note, however, that government agencies should be ready to accept criticism and respond to it.

Better interaction between government agencies and social media users can help to establish a network of users who are constantly present on social media platforms. These users can offer their opinion and advice based on their personal experiences. They also can help to spread government information in their own networks, thus disseminating it to those people who might receive it otherwise.

As government agencies get more experience with social media and start to get more comfortable with it, there will be an increased demand for research in this area. The roles of academic community and the Social Media Community of Practice are especially important as currently social media teams within government agencies are relatively small and mainly focused on developing and publishing social media content as well as responding to questions. The research can inform social media strategies and practices of individual government agencies as well as open government policies of different levels of government. 


\section{Suggestions for Future Research}

The use of social media in government is a new and constantly evolving research topic. This study has explored a number of important research questions related to the use of social media by government immigration agencies and migrants to Canada. It is revealed that the main reason for government use of social media in the immigration domain is to provide information about existing programs and services as well as to respond to people's questions. There is, however, a number of barriers that government agencies face. These include the need to persuade senior management of the value added of social media to government's operations, lack of resources for analysis of people's posts and no existing mechanism to hear directly from social media users about their experiences and needs. Therefore, government agencies are operating within established boundaries and limited by the vision that government social media serves to point to information on the proper pages on the website.

The connection between open government policy and the use of social media is also an important topic for future research. As the results of this study show, social media is primarily used as a customer service tool and its suitability for public engagement on policy issues and public service delivery is yet to be explored. This will help to understand if creation of agency-specific public engagement IT platforms that is underway in Canada is justified and desirable.

Future research can also focus on studying cases of government agencies that are leaders in social media use to identify structural changes required for utilizing new capabilities that social media offers. This research can be grounded in the literature on citizen engagement, civic participation and deliberation to lay down important foundations to explore how to overcome existing challenges and barriers, especially the need for political leadership for digital government agenda (Roy 2017) as well as take into account social media users' needs and preferences. 
It is also important to continue developing understanding of user experiences and expectations from government social media due lack of such studies (Lu et al. 2016; Medaglia and Zheng 2017). As this study shows, migrants are actively using government social media resources. However, they are forced to use social media to get answers to their questions in real time, as they have very few other means to connect with government immigration agencies. This makes them a unique government social media user group. Nevertheless, migrants appreciate the opportunity to hear directly from the government but call for more personalized feedback. As future research focuses on experiences of users who interact on social media accounts of different government agencies, research results can be compared to the results of this study and further generalizations can be drawn.

Another important finding of this study that can be explored further is the importance of latent ties for social media users who just skim through social media posts for information and availability information of poor quality on government social media platforms. Future research can explore if social media users' decisions and actions are based on this information and strategies utilized by different user groups to mitigate the risk of being misinformed though social media.

A comparative analysis of government social media use in different countries is also an important research area. Although best practices and lessons learned from such comparison can be attributed to a specific context, they will offer a different perspective that might be useful for the government agencies in Canada. This analysis can also show how Canada is doing in terms of government social media adoption when compared to other countries. 


\section{Appendices}

\section{Appendix A. Codebook for User Tweets and Posts}

\section{Type of message}

\begin{tabular}{|c|c|c|c|}
\hline $\begin{array}{l}\text { Type } \\
\text { Category }\end{array}$ & Description & Sample Tweet & Sample Post \\
\hline Question & $\begin{array}{l}\text { Question addressed to } \\
\text { IRCC or other users }\end{array}$ & $\begin{array}{l}\text { @ CitImmCanada I need } \\
\text { to ask if I have a visitor } \\
\text { Visa, can I still visit } \\
\text { Canada although it will } \\
\text { expire in } 15 \text { th of } \\
\text { December? }\end{array}$ & $\begin{array}{l}\text { Dear sir how I can } \\
\text { apply for visit visa? }\end{array}$ \\
\hline Opinion & $\begin{array}{l}\text { Expresses a view or } \\
\text { judgement (positive } \\
\text { or negative) about } \\
\text { IRCC, Canada, } \\
\text { immigration } \\
\text { programs and } \\
\text { services, experiences } \\
\text { etc. that is not } \\
\text { necessarily based on } \\
\text { fact or knowledge }\end{array}$ & $\begin{array}{l}\text { Day } 8 \text { @ CitImmCanada } \\
\text { still hasn't fixed system } \\
\text { issues on their site. What a } \\
\text { time to be alive. }\end{array}$ & $\begin{array}{l}\text { Well done Canada. } \\
\text { Please never ever } \\
\text { become like Sweden } \\
\text { with it's open borders } \\
\text { to EVERYONE! I } \\
\text { admire you :) }\end{array}$ \\
\hline Information & $\begin{array}{l}\text { Shares information } \\
\text { with IRCC and/or } \\
\text { other users (may } \\
\text { contain a link to a } \\
\text { website, video, news } \\
\text { article, etc.) }\end{array}$ & $\begin{array}{l}\text { Travel Canada } \\
\text { https://t.co/19JFSc1D2k - } \\
\text { top stories by } \\
@ \text { CitImmCanada, } \\
@ \text { CanHCZA, } \\
\text { @ chavespazlegal }\end{array}$ & $\begin{array}{l}\text { The Central Somali } \\
\text { Community in India: } \\
\text { Www.csomalian.wordp } \\
\text { ress.com Read more } \\
\text { the Somali Refugees } \\
\text { hardships and } \\
\text { humanitarian } \\
\text { Corruption in India for } \\
\text { past two decades. }\end{array}$ \\
\hline $\begin{array}{l}\text { Response to } \\
\text { other users }\end{array}$ & $\begin{array}{l}\text { Responds to the post } \\
\text { by other user to } \\
\text { engage in a } \\
\text { discussion }\end{array}$ & $\begin{array}{l}\text { @ EvilLilGoat } \\
\text { @CitImmCanada I am } \\
\text { waiting on Citizenship } \\
\text { since } 2011 \text {, now } 4 \text { yrs } \\
\text { passed,way past posted } \\
\text { deadlines.ECAS old by } 3 \\
\text { yrs too!\#cdnimm }\end{array}$ & $\begin{array}{l}\text { Same with my } \\
\text { daughter's application } \\
\text { going on } 12 \text { months } \\
\text { since PER date }\end{array}$ \\
\hline $\begin{array}{l}\text { Amicable } \\
\text { ties }\end{array}$ & $\begin{array}{l}\text { Expression of } \\
\text { gratitude such as such } \\
\text { as thanking } \\
\text { somebody and/or } \\
\text { congratulating on } \\
\text { something. Messages }\end{array}$ & $\begin{array}{l}\text { @CitImmCanada thank } \\
\text { you. The instructions } \\
\text { really helped. }\end{array}$ & $\begin{array}{l}\text { Refugee is one of } \mathrm{z} \\
\text { parts of our life for all } \\
\text { mankind but differs our } \\
\text { cause for refugee. } \\
\text { Thank you Canada } \\
\text { people! }\end{array}$ \\
\hline
\end{tabular}




\begin{tabular}{|l|l|l|l|}
\hline Tagging & $\begin{array}{l}\text { can be addressed to } \\
\text { IRCC or other users. }\end{array}$ & & \\
\hline & $\begin{array}{l}\text { Making sure that a } \\
\text { specific user will see } \\
\text { the post by including } \\
\text { their user name into a } \\
\text { reply to the post. } \\
\text { This category is only } \\
\text { applicable to } \\
\text { Facebook posts. }\end{array}$ & N/A & $\begin{array}{l}\text { [user name] check it } \\
\text { bro. }\end{array}$ \\
\hline Other & $\begin{array}{l}\text { Other categories, not } \\
\text { covered by those } \\
\text { provided above }\end{array}$ & N/A & N/A \\
\hline
\end{tabular}

\section{Topic/theme for questions}

\begin{tabular}{|c|c|c|c|}
\hline $\begin{array}{l}\text { Topic/them } \\
\text { e for } \\
\text { responses } \\
\text { category }\end{array}$ & Description & Sample Tweet & Sample Post \\
\hline $\begin{array}{l}\text { Programs/ } \\
\text { services } \\
\text { (eTA, }\end{array}$ & \multicolumn{3}{|c|}{$\begin{array}{l}\text { Asks for feedback on specific program/service. Examples below include, } \\
\text { immigration programs and refugee programs as these were the most popular } \\
\text { topics for questions }\end{array}$} \\
\hline $\begin{array}{l}\text { refugees, } \\
\text { immigration } \\
\text { programs, } \\
\text { passport, } \\
\text { studying, } \\
\text { sponsorship, }\end{array}$ & Immigration & $\begin{array}{l}\text { @CitImmCanada hi I'm } \\
\text { from Bahrain as a finance } \\
\text { accountant I want live and } \\
\text { work in Canada. How can } \\
\text { get the job in Canada }\end{array}$ & $\begin{array}{l}\text { Please, can you help } \\
\text { me to migrate to } \\
\text { Canada? }\end{array}$ \\
\hline $\begin{array}{l}\text { travelling, } \\
\text { visa, } \\
\text { visiting, } \\
\text { working, } \\
\text { citizenship) }\end{array}$ & Refugees & $\begin{array}{l}\text { @ CitImmCanada Hi. So } \\
\text { what percent of the } \\
\text { refugees we take in go } \\
\text { back to their countries } \\
\text { when they are deemed } \\
\text { safe?thanks }\end{array}$ & $\begin{array}{l}\text { I can accommodate } 15 \\
\text { refugee families that is } \\
\text { coming to Canada. } \\
\text { Please let me know } \\
\text { how I can help and to } \\
\text { whom should I talk }\end{array}$ \\
\hline $\begin{array}{l}\text { Spousal } \\
\text { sponsorship }\end{array}$ & $\begin{array}{l}\text { Questions regarding } \\
\text { spousal sponsorship } \\
\text { program/delays in } \\
\text { processing }\end{array}$ & $\begin{array}{l}\text { @ CitImmCanada like } \\
\text { those numbers you for } \\
\text { refugees! How many } \\
\text { spousal sponsors did you } \\
\text { approve today? } \\
\text { @ RealChangeBot } \\
\text { https://t.co/G8cWuY3G8 } \\
\underline{\mathrm{D}}\end{array}$ & $\begin{array}{l}\text { How long it takes to } \\
\text { bring my husband to } \\
\text { Canada ..the } \\
\text { application received on } \\
\text { September } 2015 \text { by } \\
\text { CIC... I need answer } \\
\text { please... }\end{array}$ \\
\hline Application & $\begin{array}{l}\text { Questions and follow } \\
\text { up on matters related } \\
\text { to application (e.g. }\end{array}$ & $\begin{array}{l}\text { @ CitImmCanada hello, I } \\
\text { have a question, when I } \\
\text { log on to check my }\end{array}$ & $\begin{array}{l}\text { Canadian Immigration } \\
\text { and Citizenship - by } \\
\text { Colorado law, where }\end{array}$ \\
\hline
\end{tabular}




\begin{tabular}{|c|c|c|c|}
\hline & $\begin{array}{l}\text { how to pay the fees, } \\
\text { which forms to fill, } \\
\text { what documents to } \\
\text { provide) }\end{array}$ & $\begin{array}{l}\text { application status it only } \\
\text { says decision made: they } \\
\text { began processing jan5 }\end{array}$ & $\begin{array}{l}\text { we are applying, } \\
\text { notaries cannot certify } \\
\text { photocopies of vital } \\
\text { information such as } \\
\text { birth certificates and } \\
\text { passports - both } \\
\text { documents that are } \\
\text { required to be certified } \\
\text { copies for the } \\
\text { application. How do I } \\
\text { get around this? }\end{array}$ \\
\hline $\begin{array}{l}\text { Technical } \\
\text { Issues }\end{array}$ & $\begin{array}{l}\text { Questions about } \\
\text { problems with the } \\
\text { website, downloading } \\
\text { forms, outages and } \\
\text { trouble shooting }\end{array}$ & $\begin{array}{l}\text { @ CitImmCanada Also } \\
\text { I've tried using different } \\
\text { browsers (IE and Google } \\
\text { chrome ) on different } \\
\text { computers. But that } \\
\text { doesn't help :( }\end{array}$ & $\begin{array}{l}\text { How is it the website or } \\
\text { some parts is down for } \\
\text { so long??? }\end{array}$ \\
\hline Contact & $\begin{array}{l}\text { Questions about ways } \\
\text { to reach IRCC (by } \\
\text { phone, email and/or } \\
\text { private message on } \\
\text { social media) }\end{array}$ & $\begin{array}{l}@ \text { CitImmCanada I need } \\
\text { to speak to an agent since } \\
\text { I have a lot of questions, } \\
\text { but I am not able to get } \\
\text { through the telephone - } \\
\text { help! }\end{array}$ & $\begin{array}{l}\text { Hi, I have a question! } \\
\text { How can I contact you? }\end{array}$ \\
\hline $\begin{array}{l}\text { Processing } \\
\text { times }\end{array}$ & $\begin{array}{l}\text { Questions about } \\
\text { processing times for } \\
\text { applications }\end{array}$ & $\begin{array}{l}\text { @ CitImmCanada I } \\
\text { applied under the FSWP } \\
2014 \text { program } 4 \\
\text { immigration. Kindly } \\
\text { clarify why Warsaw visa } \\
\text { office is processing } \\
\text { applications so slow? }\end{array}$ & $\begin{array}{l}\text { For temporary resident } \\
\text { visa application, it says } \\
12 \text { days for processing. } \\
\text { Does your processing } \\
\text { time include weekends } \\
\text { or just weekdays? } \\
\text { Thank you. }\end{array}$ \\
\hline Fraud & $\begin{array}{l}\text { Questions about } \\
\text { potential fraud offers } \\
\text { to help with } \\
\text { immigration related } \\
\text { matters, suspicious } \\
\text { activity, ways to } \\
\text { check immigration } \\
\text { consultants and } \\
\text { lawyers }\end{array}$ & $\begin{array}{l}@ \text { CitImmCanada I } \\
\text { received call from } \\
6113261754 \text {, they said } \\
\text { they are calling from CPS, } \\
\text { Ottawa and demanded } \\
1050 \$, \text { How to report this } \\
\text { fraud scam? }\end{array}$ & $\begin{array}{l}\text { Bonjour, am from } \\
\text { lebanon and i filled an } \\
\text { application at canada } \\
\text { immigration and citizen } \\
\text { organization ; later } \\
\text { someone called me } \\
\text { from this organization; } \\
\text { and told me to open an } \\
\text { account and put the } \\
\text { money in this } \\
\text { organization name, } \\
\text { and } 7 / 8 \text { months visa } \\
\text { will come ....so is this } \\
\text { true??what i will do?? }\end{array}$ \\
\hline
\end{tabular}




\begin{tabular}{|l|l|l|l|}
\hline Other & $\begin{array}{l}\text { Other categories, not } \\
\text { covered by those } \\
\text { provided above }\end{array}$ & N/A $/ \mathrm{a}$ \\
\hline
\end{tabular}

\section{Topic/theme for opinion}

\begin{tabular}{|c|c|c|c|}
\hline $\begin{array}{l}\text { Topic/them } \\
\text { e for } \\
\text { responses } \\
\text { category }\end{array}$ & Description & Sample Tweet & Sample Post \\
\hline \multirow{3}{*}{$\begin{array}{l}\text { Programs/ } \\
\text { services } \\
\text { (ETA, } \\
\text { refugees, } \\
\text { immigration } \\
\text { programs, } \\
\text { passport, } \\
\text { studying, } \\
\text { sponsorship, } \\
\text { travelling, } \\
\text { visa, } \\
\text { visiting, } \\
\text { working, } \\
\text { citizenship) }\end{array}$} & \multicolumn{3}{|c|}{$\begin{array}{l}\text { Expresses opinion about specific program/service. Examples below include } \\
\text { immigration programs and refugee programs as these were the most popular } \\
\text { topics for expressing opinion }\end{array}$} \\
\hline & Immigration & $\begin{array}{l}\text { @ CitImmCanada limits } \\
\text { should not be hard and } \\
\text { fast there needs to be an } \\
\text { exception if a talented } \\
\text { immigrant applies and } \\
\text { should not be refused }\end{array}$ & $\begin{array}{l}\text { I am ready to go to } \\
\text { Canada, it is my future, } \\
\text { it is my country. }\end{array}$ \\
\hline & Refugees & $\begin{array}{l}\text { Great @ CitImmCanada } \\
\text { please focus on } \\
\text { integration policy much } \\
\text { needs to occur to } \\
\text { acclimatize naturally } \\
\text { \&amp; identify key areas } \\
\text { for Syrian support. }\end{array}$ & $\begin{array}{l}\text { Unfair to those who } \\
\text { work so hard and pay } \\
\text { pay pay and the } \\
\text { refugees the come here } \\
\text { shelter them give them } \\
\text { foods free medicines } \\
\text { everything is free free }\end{array}$ \\
\hline $\begin{array}{l}\text { Spousal } \\
\text { sponsorship }\end{array}$ & $\begin{array}{l}\text { Opinion about delays } \\
\text { with processing } \\
\text { spousal sponsorships }\end{array}$ & $\begin{array}{l}\text { @ michpottier } \\
\text { @ CitImmCanada } \\
\text { @ JustinTrudeau like you } \\
\text { inland families wants to } \\
\text { spend holidays with their } \\
\text { families why do they need } \\
\text { to SUFFER }\end{array}$ & $\begin{array}{l}\text { Inland } 2014 \text { apps are } \\
\text { being processed all } \\
\text { over the place in terms } \\
\text { of order. A few people } \\
\text { from January. A few } \\
\text { from February. All of } \\
\text { April. } 10 \text { people from } \\
\text { March. More from } \\
\text { January. More from } \\
\text { February. } 5 \text { people } \\
\text { from March. } 2 \text { from } \\
\text { August. All of } \\
\text { September. } 1 \text { more } \\
\text { person from March. } \\
\text { Remainder of January. } \\
\text { etc... No order at all. }\end{array}$ \\
\hline $\begin{array}{l}\text { Politics and } \\
\text { government }\end{array}$ & $\begin{array}{l}\text { Opinions about } \\
\text { Canadian politics and } \\
\text { government }\end{array}$ & $\begin{array}{l}\text { @ Krapperman } \\
\text { @ CitImmCanada once } \\
\text { trudeau gets done } \\
\text { lowering the price of my }\end{array}$ & $\begin{array}{l}\text { So your esteem country } \\
\text { going to invest in } \\
\text { Baluchistan's } 20 \text { power } \\
\text { projects for that reason }\end{array}$ \\
\hline
\end{tabular}




\begin{tabular}{|c|c|c|c|}
\hline & & $\begin{array}{l}\text { house, taking my guns and } \\
\text { giving everybody pot he'll } \\
\text { get on that. }\end{array}$ & $\begin{array}{l}\text { allowed Pakistanis to } \\
\text { get visa easily....just } \\
\text { wanted to ask your } \\
\text { great PM....Justin.... }\end{array}$ \\
\hline $\begin{array}{l}\text { Processing } \\
\text { times }\end{array}$ & $\begin{array}{l}\text { Opinions about } \\
\text { processing times for } \\
\text { applications }\end{array}$ & $\begin{array}{l}\text { I don't think checking } \\
@ \text { CitImmCanada website } \\
\text { three times a day is } \\
\text { healthy for me. Waiting } \\
\text { for DM for my hubby. }\end{array}$ & $\begin{array}{l}\text { Is this a joke CIC? } \\
\text { Back when we applied } \\
\text { we were told } 14 \\
\text { months...it's been } 35 \\
\text { and we are still waiting } \\
\text { so your website is a } \\
\text { joke }\end{array}$ \\
\hline Canada & $\begin{array}{l}\text { Opinions about } \\
\text { Canada as a country }\end{array}$ & $\begin{array}{l}\text { N/A - only one post in } \\
\text { this category }\end{array}$ & $\begin{array}{l}\text { Beautiful CANADA. I } \\
\text { love you. }\end{array}$ \\
\hline Personal & $\begin{array}{l}\text { Expressing/sharing } \\
\text { some personal } \\
\text { information }\end{array}$ & $\begin{array}{l}@ \text { CitImmCanada } \\
@ \text { HonJohnMcCallum I } \\
\text { will continue to Twt } \\
\text { requests for UPDATE to } \\
\text { E-CAS of my CZShp } \\
\text { Grant file,until itl's } \\
\text { fixed.\#cdnimm @Puglaas }\end{array}$ & $\begin{array}{l}\text { Happy Canada day! I } \\
\text { hope I'm permitted the } \\
\text { visa that is being } \\
\text { processed so I can visit } \\
\text { for my birthday next } \\
\text { month } ð \ddot{Y}^{\sim S}\end{array}$ \\
\hline Other & $\begin{array}{l}\text { Other categories, not } \\
\text { covered by those } \\
\text { provided above }\end{array}$ & N/A & N/A \\
\hline
\end{tabular}




\section{Appendix B. Codebook for IRCC Tweets and Posts}

\begin{tabular}{|c|c|c|c|}
\hline \multicolumn{4}{|c|}{ Type of message } \\
\hline $\begin{array}{l}\text { Type } \\
\text { Category }\end{array}$ & Description & Sample Tweet & Sample Post \\
\hline Information & $\begin{array}{l}\text { Provides } \\
\text { information about } \\
\text { program, service or } \\
\text { event }\end{array}$ & $\begin{array}{l}\text { Getting an Electronic } \\
\text { Travel Authorization } \\
\text { (eTA) will be a simple and } \\
\text { brief online process: } \\
\text { http://t.co/Ji5uJTzAjk } \\
\text { \#eTACanada }\end{array}$ & $\begin{array}{l}\text { Hey students - } \\
\text { considering Canadian } \\
\text { education? Our website } \\
\text { has info on study } \\
\text { permits student work } \\
\text { permits \& more. }\end{array}$ \\
\hline Responses & $\begin{array}{l}\text { Contains } \\
@ \text { username/ and } \\
\text { provides } \\
\text { information }\end{array}$ & $\begin{array}{l}\text { @ QuantumWrangler An } \\
\text { eTA costs \$7 CAD. Here } \\
\text { is a helpful video for more } \\
\text { information: } \\
\text { http://t.co/ndvWVcqWlO }\end{array}$ & $\begin{array}{l}\text { Hi Sara, we recommend } \\
\text { starting at our website } \\
\text { to learn about what } \\
\text { programs are available, } \\
\text { and to find out what } \\
\text { you may be eligible to } \\
\text { apply for: } \\
\text { http://www.cic.gc.ca/en } \\
\text { glish/index.asp }\end{array}$ \\
\hline RT/sharing & $\begin{array}{l}\text { Contains RT/ } \\
\text { "shared" message }\end{array}$ & $\begin{array}{l}\text { RT @Safety_Canada: } \\
\text { Bringing \#SyrianRefugees } \\
\text { to Canada is a great } \\
\text { undertaking and we can do } \\
\text { it w/ the help of our } \\
\text { partners from all levels } \\
\text { oâ } \epsilon_{\perp}^{\prime}\end{array}$ & $\begin{array}{l}\text { Canadian Immigration } \\
\text { and Citizenship shared } \\
\text { Canada s 150th } \\
\text { Anniversary of } \\
\text { Confederation s post. }\end{array}$ \\
\hline Other & $\begin{array}{l}\text { All other } \\
\text { tweets/posts that } \\
\text { could not be } \\
\text { categorized }\end{array}$ & $\begin{array}{l}\text { Who is the first African- } \\
\text { Canadian woman to be } \\
\text { elected to the House of } \\
\text { Commons? \#BHM }\end{array}$ & N/A \\
\hline
\end{tabular}

\section{Topic/theme for feedback}

\begin{tabular}{|l|l|l|l|}
\hline $\begin{array}{l}\text { Topic/theme } \\
\text { for responses } \\
\text { category }\end{array}$ & Description & Sample Tweet & Sample Post \\
\hline Application & $\begin{array}{l}\text { Provides response } \\
\text { related to } \\
\text { application (e.g. } \\
\text { how to pay the } \\
\text { fees, which forms } \\
\text { to fill, what } \\
\text { documents to } \\
\text { provide) }\end{array}$ & $\begin{array}{l}\text { @ randomSusana Here are } \\
\text { information on the } \\
\text { Criminal Record Check: } \\
\text { http://t.co/axM1nL0XyZ }\end{array}$ & $\begin{array}{l}\text { If you haven't } \\
\text { submitted the } \\
\text { documentation yet, you } \\
\text { haven't submitted a } \\
\text { complete work permit } \\
\text { application. Work } \\
\text { permit applications } \\
\text { received with an } \\
\text { expired LMIA will be } \\
\text { refused. }\end{array}$ \\
\hline
\end{tabular}




\begin{tabular}{|c|c|c|c|}
\hline $\begin{array}{l}\text { Case specific } \\
\text { information } \\
\text { and web } \\
\text { forms }\end{array}$ & $\begin{array}{l}\text { Asks to fill in a } \\
\text { special request that } \\
\text { will contain } \\
\text { personal } \\
\text { information about } \\
\text { the case or describe } \\
\text { a certain technical } \\
\text { issue }\end{array}$ & $\begin{array}{l}\text { @kkathylee Hi - Please } \\
\text { send us a case specific } \\
\text { enquiry form and we will } \\
\text { look into it for you: } \\
\text { https://t.co/bO9qpYdEir }\end{array}$ & $\begin{array}{l}\text { Hi. To assist you better, } \\
\text { we require more } \\
\text { information. Please fill } \\
\text { out a Case Specific } \\
\text { technical form with as } \\
\text { much information } \\
\text { possible. } \\
\text { https://secure.cic.gc.ca/ } \\
\text { enquiries- } \\
\text { renseignements/canada } \\
\text {-case-cas-eng.aspx }\end{array}$ \\
\hline $\begin{array}{l}\text { Technical } \\
\text { Issues }\end{array}$ & $\begin{array}{l}\text { Provides response } \\
\text { to a technical } \\
\text { difficulty } \\
\text { experienced by the } \\
\text { user, can provide } \\
\text { resolution }\end{array}$ & $\begin{array}{l}\text { @ hassanawad } 2012 \text { Are } \\
\text { you having trouble } \\
\text { accessing the form? If so, } \\
\text { please try opening it using } \\
\text { Int Explorer. }\end{array}$ & $\begin{array}{l}\text { Hi â€" The â€œcountry } \\
\text { or territoryâ€• drop- } \\
\text { down menu is working } \\
\text { on our end. Please try } \\
\text { using Internet Explorer } \\
\text { or another computer to } \\
\text { open this page: } \\
\text { http://www.cic.gc.ca/pp } \\
\text {-md/pp-list.aspx }\end{array}$ \\
\hline $\begin{array}{l}\text { Help } \\
\text { Centre/Web } \\
\text { site referral }\end{array}$ & $\begin{array}{l}\text { Refers the user to a } \\
\text { webpage to get an } \\
\text { answer to the } \\
\text { question, does not } \\
\text { contain any } \\
\text { information other } \\
\text { than referral }\end{array}$ & $\begin{array}{l}\text { @ nosillablair Hi - Our } \\
\text { Help Centre has an answer } \\
\text { for you: } \\
\text { http://t.co/RnTHLYVn8N }\end{array}$ & $\begin{array}{l}\text { Hi. We have an answer } \\
\text { online that may be } \\
\text { helpful: } \\
\text { http://www.cic.gc.ca/en } \\
\text { glish/helpcentre/answer } \\
\text {.asp?qnum=1180\&top= } \\
16\end{array}$ \\
\hline $\begin{array}{l}\text { Processing } \\
\text { times }\end{array}$ & $\begin{array}{l}\text { Provides } \\
\text { information about } \\
\text { processing times or } \\
\text { refers user to the } \\
\text { website and } \\
\text { explains where to } \\
\text { look for this } \\
\text { information }\end{array}$ & $\begin{array}{l}\text { @FREED1995 Hi. Our } \\
\text { website has estimated time } \\
\text { it takes to process an app. } \\
\text { from receipt to finalization } \\
\text { for most cases } \\
\text { http://t.co/ELV60zXYmC }\end{array}$ & $\begin{array}{l}\text { Hi - CIC does not } \\
\text { provide estimated } \\
\text { processing times for } \\
\text { background checks. } \\
\text { Our goal is to process } \\
\text { most complete } \\
\text { applications received } \\
\text { under Express Entry in } \\
\text { six months or less. }\end{array}$ \\
\hline $\begin{array}{l}\text { Programs/ } \\
\text { Services }\end{array}$ & $\begin{array}{l}\text { Provides } \\
\text { information about } \\
\text { immigration } \\
\text { programs and } \\
\text { services (e.g. ETA, } \\
\text { refugees, } \\
\text { sponsorship, } \\
\text { permanent } \\
\text { residence, working, } \\
\text { studying, visiting) }\end{array}$ & $\begin{array}{l}\text { @ rashi_atrey You may } \\
\text { apply for a stu per } \\
\text { extension from inside } \\
\text { Canada. If you are in India, } \\
\text { youl'd apply for a new SP } \\
\text { https://t.co/k1GSGVNUiF }\end{array}$ & $\begin{array}{l}\text { Hi Elissa Lee. The } \\
\text { change that requires } \\
\text { Canadian citizens, } \\
\text { including dual citizens, } \\
\text { to fly to Canada with a } \\
\text { valid Canadian } \\
\text { passport starts on } \\
\text { September } 30,2016 \text {. } \\
\text { As it can take time to } \\
\text { get a Canadian }\end{array}$ \\
\hline
\end{tabular}




\begin{tabular}{|l|l|l|l|}
\hline & & & $\begin{array}{l}\text { passport, your son-in- } \\
\text { law should apply for } \\
\text { one as soon as he can. }\end{array}$ \\
\hline Other & $\begin{array}{l}\text { Other categories, } \\
\text { not covered by } \\
\text { those provided } \\
\text { above }\end{array}$ & N/A & N/A \\
\hline
\end{tabular}

\section{Topic/theme for information}

\begin{tabular}{|c|c|c|c|}
\hline $\begin{array}{l}\text { Topic/them } \\
\text { e for } \\
\text { responses } \\
\text { category }\end{array}$ & Description & Sample Tweet & Sample Post \\
\hline \multirow{5}{*}{$\begin{array}{l}\text { Programs } \\
\text { and services } \\
\text { (ETA, } \\
\text { refugees, } \\
\text { newcomers, } \\
\text { immigration } \\
\text { programs, } \\
\text { passport, } \\
\text { studying, } \\
\text { sponsorship, } \\
\text { travelling, } \\
\text { visa, } \\
\text { visiting, } \\
\text { working, } \\
\text { citizenship) }\end{array}$} & \multicolumn{3}{|c|}{$\begin{array}{l}\text { Provides information about programs and services. Examples below include } \\
\text { eTA, refugee programs, programs for newcomers and immigration programs } \\
\text { as these were the most popular categories }\end{array}$} \\
\hline & eTA & $\begin{array}{l}\text { Find out if you'll need an } \\
\text { eTA to fly to \#Toronto or } \\
\text { any other location in } \\
\text { \#Canada: } \\
\text { http://t.co/zGc11KeH3k }\end{array}$ & $\begin{array}{l}\text { It only takes minutes to } \\
\text { apply for an Electronic } \\
\text { Travel Authorization } \\
\text { (eTA) to fly to Canada. } \\
\text { \#eTACanada }\end{array}$ \\
\hline & Refugees & $\begin{array}{l}\text { More refugees will be } \\
\text { issued visas by the end of } \\
\text { this year, without } \\
\text { compromising on security. } \\
\text { Find out more: } \\
\text { http://t.co/1e6GidVlkA }\end{array}$ & $\begin{array}{l}\text { We } \\
\text { \#WelcomeRefugees } \\
\text { and ours is an } \\
\text { ambitious plan that can } \\
\text { only work if we all } \\
\text { work together. Learn } \\
\text { about what you can do } \\
\text { to support global } \\
\text { Canadian and } \\
\text { community efforts. }\end{array}$ \\
\hline & Newcomers & $\begin{array}{l}\text { New to Canada? You can } \\
\text { create a settlement plan } \\
\text { using our Living In } \\
\text { Canada tool: } \\
\text { https://t.co/tKvij8ZRJq }\end{array}$ & $\begin{array}{l}\text { Preparing for life in } \\
\text { Canada? Find out about } \\
\text { cost of living sales tax } \\
\text { and how to plan your } \\
\text { household expenses. }\end{array}$ \\
\hline & $\begin{array}{l}\text { Immigration } \\
\text { programs }\end{array}$ & $\begin{array}{l}\text { Interested in immigrating } \\
\text { to Canada? Determine } \\
\text { your eligibility using our } \\
\text { Come to Canada tool: } \\
\text { https://t.co/4QJzkp0bmx }\end{array}$ & $\begin{array}{l}\text { Want to immigrate to } \\
\text { Canada? Find } \\
\text { information for } \\
\text { immigration and } \\
\text { sponsorship programs } \\
\text { such as Express Entry } \\
\text { Quebec-selected skilled } \\
\text { workers provincial }\end{array}$ \\
\hline
\end{tabular}




\begin{tabular}{|c|c|c|c|}
\hline & & & $\begin{array}{l}\text { nominees caregivers } \\
\text { and family sponsorship. }\end{array}$ \\
\hline $\begin{array}{l}\text { Technical/o } \\
\text { nline } \\
\text { maintenance }\end{array}$ & $\begin{array}{l}\text { Provides information } \\
\text { about scheduled and } \\
\text { unplanned website } \\
\text { maintenance, trouble } \\
\text { shooting tips }\end{array}$ & $\begin{array}{l}\text { Users of some online } \\
\text { services are experiencing } \\
\text { technical issues, which are } \\
\text { being examined. We } \\
\text { apologize for the } \\
\text { inconvenience. }\end{array}$ & $\begin{array}{l}\text { The cic.gc.ca website is } \\
\text { experiencing delays. } \\
\text { We are working to } \\
\text { resolve this issue. } \\
\text { Thank you for your } \\
\text { patience. }\end{array}$ \\
\hline Events & $\begin{array}{l}\text { Provides information } \\
\text { on events such as } \\
\text { fairs, presentations, } \\
\text { citizenship } \\
\text { ceremonies, etc. }\end{array}$ & $\begin{array}{l}\text { We will be participating! } \\
\text { Looking forward to } \\
\text { chatting about fraud } \\
\text { prevention. } \\
\text { @ CompBureau \#2G2BT } \\
\text { https://t.co/m9o37QYof7 }\end{array}$ & $\begin{array}{l}\text { Tomorrow is Canada } \\
\text { Day. What are you } \\
\text { doing to celebrate? If } \\
\text { you don t have plans } \\
\text { yet use our map to find } \\
\text { a citizenship ceremony } \\
\text { near you. } \\
\text { http://ow.ly/gVtc301Lit } \\
\mathrm{z}\end{array}$ \\
\hline Application & $\begin{array}{l}\text { Provides information } \\
\text { related to application } \\
\text { (e.g. how to pay the } \\
\text { fees, which forms to } \\
\text { fill, what documents } \\
\text { to provide) }\end{array}$ & $\begin{array}{l}\text { Are you looking for help } \\
\text { with your IRCC } \\
\text { application form? Check } \\
\text { out this video for useful } \\
\text { information: } \\
\text { https://t.co/hlHgCIpiY3 }\end{array}$ & $\begin{array}{l}\text { Many CIC clients can } \\
\text { check the status of their } \\
\text { application online } 24 \\
\text { hrs/day } 7 \text { days/week } \\
\text { http://ow.ly/ZFkY1 }\end{array}$ \\
\hline Help Centre & $\begin{array}{l}\text { Reminds about the } \\
\text { banks of frequently } \\
\text { asked questions and } \\
\text { provides information } \\
\text { the weblink }\end{array}$ & $\begin{array}{l}\text { See our \#HelpCentre for } \\
\text { the response to this } \\
\text { frequently asked question: } \\
\text { https://t.co/y0P6ums85e } \\
\text { https://t.co/tiJbWznTZs }\end{array}$ & $\begin{array}{l}\text { You have questions; we } \\
\text { have answers. In fact } \\
\text { our Help Centre has } \\
\text { over } 1000 \text { FAQs } \\
\text { making it the first place } \\
\text { to look if you need help } \\
\text { with your application. }\end{array}$ \\
\hline Fraud & $\begin{array}{l}\text { Provides tips on how } \\
\text { to recognize and } \\
\text { prevent fraud }\end{array}$ & $\begin{array}{l}\text { March is \#Fraud } \\
\text { Prevention Month. Learn } \\
\text { how to protect yourself } \\
\text { https://t.co/jbq8kuxn9U } \\
\text { \#FPM2016 } \\
\text { https://t.co/JoRt0oqQZA }\end{array}$ & $\begin{array}{l}\text { Be aware: No one can } \\
\text { guarantee you a visa to } \\
\text { Canada. Only } \\
\text { immigration officers in } \\
\text { Canada at Canadian } \\
\text { embassies high } \\
\text { commissions and } \\
\text { consulates can decide } \\
\text { to issue a visa. Protect } \\
\text { yourself from fraud. }\end{array}$ \\
\hline Other & $\begin{array}{l}\text { Other categories, not } \\
\text { covered by those } \\
\text { provided above }\end{array}$ & N/A & N/A \\
\hline
\end{tabular}




\section{Appendix C. Recruitment Email for Public Servants}

Topic: The Use of Social Media by Government Agencies

\section{Dear Mr./Ms XXXXX:}

My name is Maria Gintova and I am a PhD candidate in the Policy Studies program at Ryerson University. I am writing to invite you to participate in a research interview related to my doctoral research study about government use of social media. In this research, I am examining the use of social media platforms such as Twitter and Facebook by government agencies and the experiences of immigrants who used these resources.

I am inviting you to participate in this study because of your knowledge of social media platforms being used by [name of the agency]. I obtained your contact information from the Government Electronic Directory Services or the Ontario Employee and Organization Directory.

If you decide to participate in this study, you will be asked about your experiences, IRCC/MCI use of social media and general questions about government social media policies and guidelines. The interview will be held in a location of your choice or, if you prefer, via phone. The interview will take about 45 minutes.

Participation in this study is completely voluntary. If you have any questions about the study, please email me at maria.gintova@ryerson.ca or my supervisor Dr. Carolyn Johns in the Department of Politics and Public Administration at Ryerson at cjohns@ ryerson.ca.

If you are willing to participate, please reply and we can schedule a time to meet or talk on the phone.

This study was approved by the Ryerson Research Ethics Board.

Thank you very much. I look forward to hearing from you.

Sincerely,

Maria Gintova

Ph.D. Candidate

Ryerson University

maria.gintova@ ryerson.ca 


\section{Appendix D. Consent Form for Public Servants}

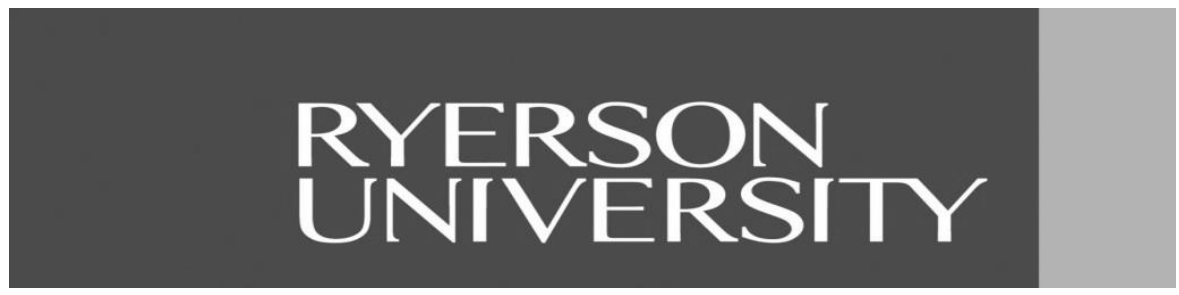

Consent to Participate in Research

You are being invited to participate in a research study. Please read this Consent Form so that you understand what your participation will involve. Before you consent to participate, please ask any questions necessary to be sure you understand what your participation will involve.

\section{Investigators:}

Researcher: Maria Gintova

$\mathrm{PhD}$ Candidate in Policy Studies

Ryerson University, maria.gintova@ ryerson.ca

Supervisor: Dr. Carolyn Johns

Department of Politics and Public Administration

Ryerson University

416-979-5000 ext. 6146, cjohns@ @olitics.ryerson.ca

If you have any questions or concerns about the research, please feel free to contact Maria or Dr. Johns.

\section{Title}

The Use of Social Media by Government Agencies

\section{Purpose of the Study}

The purpose of the study is to examine the use of social media (Facebook and Twitter) by government agencies.

\section{Description of the Study}

If you would like to participate in this study, you will be asked about your experiences in maintaining your agency's presence on social media and/or creating social media policies and guidelines. The interview will be held in a meeting room at your workplace, another location of your choice or, if you prefer, via phone. You will be asked questions about why and how your agency is using social media, what kind of information is your agency sharing on social media specifically for potential immigrants and general questions about effective use of social media. All information that can identify you that you share during the interview will remain completely confidential. Information collected during the interviews will used for reporting and future publications. No personal or identifying information will be shared and none of your comments or opinions will be directly attributed to you.

The interview will take approximately 45 minutes. With your permission, the interview will be audio-recorded. However, you can request the recording to be terminated at any time during the interview. 


\section{Risks or Discomforts}

There are few risks and no direct benefits to participating in the study.

The potential risks include psychological risks (e.g. feeling anxious, upset or uncomfortable answering certain question), social risks (e.g. potential loss of privacy or damage of professional reputation as a result of identity and opinion being revealed) and a risk of personal identity being revealed. However, the researcher will ensure the proper mitigation of those risks by not collecting any identifying information and not attributing any comments or opinions expressed during the interviews to participants who provided them. Furthermore, you do not have to answer any question you are not comfortable with or you can terminate your participation at any time.

\section{Potential Benefits}

There are no direct benefits from participating in the study. At the same time, you can greatly contribute to the understanding of the ways social media is used by government agencies. I cannot guarantee, however, that you will receive any benefits from participating in this study.

\section{Incentive to Participate}

You will not be paid for participating in this study.

\section{Confidentiality}

Information that could identify you will not be recorded. Information from all participants will be combined for analysis and reporting, so no individual's information will be shared in a way that can identify him or her. Only I and my dissertation committee members will have access to data provided during the interviews. The interview materials will be kept in a secure filing cabinet at Ryerson University until the data analysis is complete and then stored in the university for a period of 5 years. Please be advised that confidentiality will be maintained to the extent allowed by law.

\section{Voluntary Participation and Withdrawal}

Participation in this study is completely voluntary. You can choose whether to be in this study or not. If any question makes you uncomfortable, you can skip that question. If you choose to stop participating, you may also choose to not have your data included in the study. Your choice of whether or not to participate will not influence your future relations with Ryerson University.

\section{Research Findings}

Research findings will be disseminated in a form of journal articles, presentations and presented in my dissertation. I can also share my findings with you upon request.

Questions about the Study: You can ask questions about this study at any time.

You may contact:

Maria Gintova, Ryerson University at maria.gintova@ ryerson.ca or Dr. Carolyn Johns at cjohns@politics.ryerson.ca

This study has been reviewed by the Ryerson University Research Ethics Board. If you have questions regarding your rights as a participant in this study please contact:

Research Ethics Board

c/o Office of the Vice President, Research and Innovation 


\section{Ryerson University \\ 350 Victoria Street \\ Toronto, ON M5B 2K3 \\ 416-979-5042 \\ rebchair@ryerson.ca}

\section{Signature of Research Participant}

Your signature below indicates that you have read the information in this agreement and have had a chance to ask any questions you have about the study "The Use of Social Media by Government Agencies" as described herein. Your questions have been answered to your satisfaction, and you agree to participate in this study. You have been given a copy of this form.

Name of Participant (please print)

Signature of Participant

Date

Your signature below indicates that you will allow me to audio-record our interview

Signature of Participant

Date 


\section{Appendix E. Interview Questions (Themes) for Public Servants}

\section{Background information}

Department/agency

Position

Education

Agency specific questions/Organizational:

1. How long has your agency being using social media?

2. How many people are responsible for providing information on social media websites (prompt: is one person responsible for many social media accounts/only one, is it enough, why yes or no)?

3. Were there more positions created when the agency started using social media? Are there enough resources allocated to develop/publish social media content?

4. What is the process of getting a post published? A reply to somebodies post? How many people have to review a post before it is published? What are their positions?

Personal questions:

5. What is your preferred social media platform? Why?

6. How long have you been working with social media?

Questions about networks:

7. What are the goals for your agency's use of social media?

8. What information is provided? (prompt: is this information already available on the website or there is some information that is distributed only through social media?)

9. What kind of changes (if any) should be made to social media strategies to meet immigrants' needs?

10. How do you think your agency will be using social media in 5-10 years?

Questions about effective use:

11. In your opinion, what is the effective use of social media?

12. How is your agency evaluating the effectiveness of social media use? Would you suggest a different approach?

13. How can a user benefit from social media tools implemented by your agency?

14. Do you have any problems or concerns about use of social media in your agency? In government?

Other:

15. Is there anything you would like to add that you think I have missed or forgotten? Or anything you want to expand on that we have already discussed?

16. Is there anyone else you think I should interview? 


\section{Appendix F. Recruitment Messages for Social Media Users}

Initial Twitter post (this post cannot be more than 140 characters long)

Hi! My name is Maria and I'm a PhD candidate conducting a research study. [link to my blog with study description/consent forms]. Please DM if interested.

Recruitment script to be sent in a private message

My name is Maria Gintova and I am a PhD candidate in the Policy Studies program at Ryerson University in Toronto, Canada. I am writing to invite you to participate in my research study about government use of social media platforms such as Facebook and Twitter as well as the experiences of immigrants, workers, students, visitors to Canada as well as Canadian residents and citizen who used these resources. I am inviting you to participate in this study because you have posted your comments and/or questions on Immigration, Refugees and Citizenship Canada (IRCC - also known as CIC) and/or Ontario Ministry of Citizenship and Immigration (MCI) social media platforms.

If you decide to participate in this study, you will asked about your experiences with posting on and getting feedback on government social media resources. You will have a choice of participating in an Interview via Skype or phone. The interview will take about one hour. For your participation, you will receive a $\$ 20$ honorarium as Skype credit unique number that will be shared via Twitter, Facebook or Skype private message.

Your participation is completely voluntary. You can choose to be in the study or not. If you have any questions about your participation or you are interested in participating in this study, please simply respond to this message. You can also reach me at maria.gintova@ryerson.ca or you can contact my supervisor at cjohns@ ryerson.ca. This study was approved by the Ryerson Research Ethics Board.

Thank you so much,

Maria 


\section{Appendix G. Consent Form for Social Media Users}

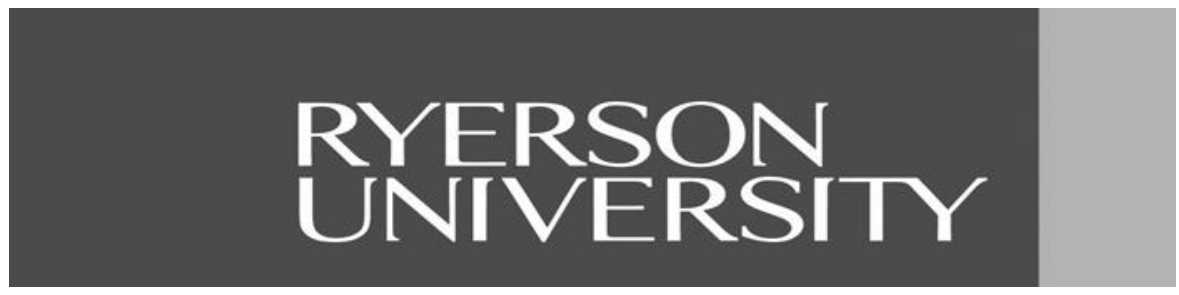

Consent to Participate in Research

You are being invited to participate in a research study. Please read this Consent Form so that you understand what your participation will involve. Before you consent to participate, please ask any questions necessary to be sure you understand what your participation will involve.

\section{Investigators:}

Researcher: Maria Gintova

PhD Candidate in Policy Studies

Ryerson University, maria.gintova@ ryerson.ca

Supervisor: Dr. Carolyn Johns

Department of Politics and Public Administration

Ryerson University

416-979-5000 ext. 6146, cjohns@ politics.ryerson.ca

If you have any questions or concerns about the research, please feel free to contact Maria or Dr. Johns.

\section{Title}

The Use of Social Media by Government Agencies

\section{Purpose of the Study}

The purpose of the study is to examine your experience of using immigration agency (such as Immigration, Refugees and Citizenship Canada (IRCC/CIC), Ontario Ministry of Citizenship and Immigration (MCI)) Facebook and/or Twitter accounts.

If you would like to participate in this study, you will be asked about your experiences with using government social media resources. Interviews will be held via Skype or phone or if you are in Toronto, Canada in person at Ryerson University library. You will be asked questions about whether you found information you were looking for on government social media resources, if this information was helpful and what you would like to see improved. There will be no questions about your immigration status but some basic demographic data (age, level of education, occupation) will be collected. All information that can identify you that you share during the interview will remain completely confidential. Information collected during the interviews will used for reporting and future publications. No personal or identifying information will be shared and none of your comments or opinions will be directly attributed to you.

The interview will take approximately one hour. With your permission, the interview will be audiorecorded. However, you can request the recording to be terminated at any time during the interview. 


\section{Risks or Discomforts}

There are few risks and no direct benefits to participating in the study. However, you do not have to answer any question you are not comfortable with or you can terminate your participation at any time.

\section{Potential Benefits}

There are no direct benefits from participating in the study. At the same time, you can share your opinion about the effectiveness of social media resources created by government immigration agencies. I cannot guarantee, however, that you will receive any benefits from participating in this study.

\section{Incentive to Participate}

You will receive a \$20 honorarium as Skype credit if you participate via Skype or phone or \$20 in cash if you participate in person.

\section{Confidentiality}

Information from all participants will be combined for analysis and reporting so no individual's information will be shared in a way that can identify him or her. Only I and my dissertation committee members will have access to the data provided during the interviews. The interview materials will be kept in a secure filing cabinet at Ryerson University until the data analysis is complete and then stored in the university for a period of 5 years. Please be advised that confidentiality will be maintained to the extent allowed by law.

\section{Voluntary Participation and Withdrawal}

Participation in this study is voluntary. You can choose whether to be in this study or not. If you volunteer to be in this study, you may withdraw at any time without consequences of any kind. If you choose to withdraw from this study, you may also choose to withdraw your data from the study. You may also choose not to answer any question(s) and still remain in the study. Your choice of whether or not to participate will not influence your future relations with Ryerson University.

\section{Questions about the Study}

You can ask questions about this study at any time. You may contact:

Maria Gintova, Ryerson University at maria.gintova@ ryerson.ca or Dr. Carolyn Johns at cjohns@politics.ryerson.ca

This study has been reviewed by the Ryerson University Research Ethics Board. If you have questions regarding your rights as a participant in this study please contact:

Research Ethics Board

c/o Office of the Vice President, Research and Innovation

Ryerson University

350 Victoria Street

Toronto, ON M5B 2K3

416-979-5042

rebchair@ryerson.ca 


\section{Signature of Research Participant}

Your signature below indicates that you have read the information in this agreement and have had a chance to ask any questions you have about the study "The Use of Social Media by Government Agencies" as described herein. Your questions have been answered to your satisfaction, and you agree to participate in this study. You have been given a copy of this form.

Name of Participant (please print)

Signature of Participant

Date

Your signature below indicates that you will allow me to audio-record our interview

Signature of Participant

Date 


\section{Appendix H. Interview Questions (Themes) for Social Media Users}

\section{Background Information}

Age

Occupation

Level of Education (Bachelor's, Master's, other)

Country

\section{Experience with Social Media}

1. Did you get information on the program/ service you were looking for somewhere else before interacting with IRCC - CIC on Twitter/Facebook?

2. How did you get to know about the IRCC Twitter/Facebook (searched on the Internet, found at the bottom of their website, etc)?

3. What information did you look for on Twitter/Facebook? (immigration, studying, working, visiting etc.)

4. What agency social media resources did you use?

- Immigration, Refugees and Citizenship Canada

- Ontario Ministry of Citizenship and Immigration

- Any other government immigration agency

- Other forums, blogs, Twitter etc.

5. Was this information sufficient? Did you have to use multiple social media sites? (why yes or why not)

6. Did you communicate with any other users of this social media platform? If yes, what information did you discuss/share? Do you think it is valuable when other people can answer your questions?

\section{Effective Use of Social Media}

7. Did you receive any response from government agency on your social media posts? What was it about?

8. Are you satisfied with government social media resources? Why yes/no?

9. How did the IRCC Twitter/Facebook help you?

10. Did you have any problems or concerns and what were these problems/concerns?

11. What is your preferred social media platform? Why? (i.e. why do you prefer Facebook to Twitter)

12. If you used any social media resources other than government social media resources $\rightarrow$ Why did you use them?

13. Is there anything you would like to add that you think I have missed or forgotten? Or anything you want to expand on that we have already discussed? 
Appendix I. Codebook -Public Servant Interviews

\begin{tabular}{|c|c|c|}
\hline Theme & Categories & Codes \\
\hline $\begin{array}{l}\text { Reasons for adopting social } \\
\text { media }\end{array}$ & $\begin{array}{l}\text { - New way to reach } \\
\text { audiences } \\
\text { - Cut costs }\end{array}$ & $\begin{array}{ll}\text { - } & \text { Marketing } \\
\text { - } & \text { Outreach } \\
\text { - } & \text { Engage in conversations } \\
\text { - } & \text { Mitigating risks } \\
\end{array}$ \\
\hline \multirow{3}{*}{$\begin{array}{l}\text { Main social media goals: } \\
\text { customer service tool, } \\
\text { marketing tool and alternative } \\
\text { to the call centre }\end{array}$} & $\begin{array}{l}\text { - Social media as a } \\
\text { customer service tool }\end{array}$ & $\begin{array}{l}\text { - } \quad \text { Responding to questions } \\
\text { - } \quad \text { No policy discussions }\end{array}$ \\
\hline & $\begin{array}{l}\text { - Social media as an } \\
\text { alternative to call } \\
\text { centre }\end{array}$ & $\begin{array}{ll}\text { - } & \text { Call centre } \\
\text { - } & \text { Decrease calls } \\
\text { - } & \text { Bank of responses } \\
\end{array}$ \\
\hline & $\begin{array}{l}\text { - Social media as a } \\
\text { marketing tool }\end{array}$ & $\begin{array}{ll}\text { - } & \text { Reach out audiences } \\
\text { - } & \text { Cheaper promotion } \\
\end{array}$ \\
\hline $\begin{array}{l}\text { No direct connection between } \\
\text { open government and social } \\
\text { media }\end{array}$ & $\begin{array}{l}\text { Lack of link to open } \\
\text { government } \\
\text { "Spirit" of open } \\
\text { government }\end{array}$ & $\begin{array}{ll}\text { - } & \text { Disconnect } \\
\text { - } & \text { Response on personal level } \\
\text { - } & \text { Allow content to remain } \\
\text { - } & \text { No engagement on policy } \\
& \text { proposals/initiatives } \\
\end{array}$ \\
\hline \multirow[t]{3}{*}{$\begin{array}{l}\text { Quality of content is } \\
\text { important but there is lack of } \\
\text { analysis of user posts }\end{array}$} & - Lack of analysis & 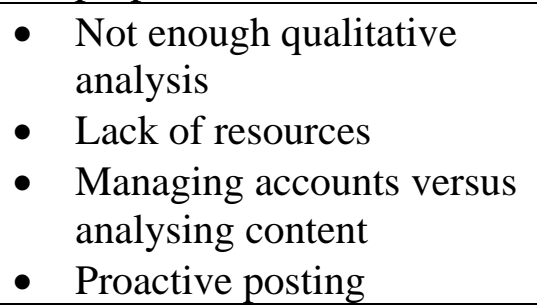 \\
\hline & - Monitoring user posts & $\begin{array}{ll}\text { - } & \text { Profanity filters } \\
\text { - } & \text { Hootsuite } \\
\text { - } & \text { Hide } \\
\text { - } & \text { Not delete } \\
\end{array}$ \\
\hline & - "Paid content" & $\begin{array}{ll}\text { - } & \text { Promotional campaign } \\
\text { - } & \text { "Paid content" vs organic } \\
\text { content } \\
\text { - } & \text { Budget } \\
\end{array}$ \\
\hline $\begin{array}{l}\text { Value of user-to-user } \\
\text { conversations }\end{array}$ & $\begin{array}{l}\text { No need to respond to } \\
\text { every conversation } \\
\text { - Information sharing } \\
\text { between users }\end{array}$ & $\begin{array}{l}\text { - User-to-user conversation } \\
\text { - Sharing experiences } \\
\text { - Creating space for users to } \\
\text { interact } \\
\text { - "Balance" in conversations }\end{array}$ \\
\hline $\begin{array}{l}\text { Levels of approvals and time } \\
\text { for approval differ for original } \\
\text { tweets/posts and responses }\end{array}$ & $\begin{array}{l}\text { - Approval time for } \\
\text { original tweets/posts } \\
\text { - } \quad \text { Approval of responses }\end{array}$ & $\begin{array}{l}\text { - Liaise with the program } \\
\text { area } \\
\text { - } \text { Bank of responses } \\
\text { - } \text { Response vs an original } \\
\text { message }\end{array}$ \\
\hline
\end{tabular}




\begin{tabular}{|c|c|c|}
\hline & & $\begin{array}{l}\text { - Cabinet Office/Minister's } \\
\text { Office }\end{array}$ \\
\hline $\begin{array}{l}\text { Difference in use between } \\
\text { Twitter and Facebook }\end{array}$ & $\begin{array}{l}\text { Difference in types of } \\
\text { questions } \\
\text { - } \begin{array}{l}\text { Difference between } \\
\text { platforms }\end{array}\end{array}$ & $\begin{array}{ll}\text { - } & \text { Character limit } \\
\text { - } & \text { Legitimate questions } \\
\text { - } & \text { Nature of platform } \\
\text { - } & \text { Proactive posting } \\
\text { - } & \text { More tweets than Facebook } \\
& \text { posts }\end{array}$ \\
\hline Effective use of social media & $\begin{array}{l}\text { - Social media is used } \\
\text { effectively considering } \\
\text { existing stuffing levels } \\
\text { - Need for more } \\
\text { interaction/engagement } \\
\text { - Role of senior } \\
\text { management/leadership }\end{array}$ & $\begin{array}{l}\text { - } \text { Engagement } \\
\text { - } \text { Interaction } \\
\text { - } \text { Personalized response } \\
\text { - } \text { Analysis of trends } \\
\text { - } \text { Getting advice from people } \\
\text { - } \quad \text { Senior management buy in } \\
\text { - Leadership } \\
\text { - Social media strategy }\end{array}$ \\
\hline
\end{tabular}


Appendix J. Codebook - User Interviews

\begin{tabular}{|c|c|c|}
\hline Theme & Categories & Codes \\
\hline \multirow[t]{3}{*}{$\begin{array}{l}\text { Experience with IRCC } \\
\text { social media }\end{array}$} & $\begin{array}{ll}\text { - } & \text { Reasons for social media } \\
\text { use }\end{array}$ & $\begin{array}{ll}\text { - } & \text { Contact IRCC } \\
\text { - } & \text { Express opinion } \\
\text { - } & \text { Interaction }\end{array}$ \\
\hline & - Satisfaction & $\begin{array}{ll}\text { - } & \text { Information that was } \\
\text { looking for } \\
\text { - } \\
\text { - } \\
\text { Information received } \\
\text { government remember [being on } \\
\text { goverial media] }\end{array}$ \\
\hline & - Social media preference & $\begin{array}{l}\text { - Social media used (Twitter, } \\
\text { Facebook, both) } \\
\text { - Skimming though messages } \\
\text { - Social media limitations }\end{array}$ \\
\hline $\begin{array}{l}\text { Importance of getting } \\
\text { response and its quality }\end{array}$ & - $\quad$ Response & $\begin{array}{ll}\text { - } & \text { No response } \\
\text { - } & \text { Copy-paste } \\
\text { - } & \text { Not personalized } \\
\text { - } & \text { Response time } \\
\text { - } & \text { Referral to website } \\
\end{array}$ \\
\hline $\begin{array}{l}\text { Value of answers by IRCC, } \\
\text { others and interaction }\end{array}$ & - Results of interaction & $\begin{array}{ll}\text { - } & \text { Direct response from IRCC } \\
\text { - } & \text { Lawyers/consultants } \\
\text { - Interaction with other users } \\
\text { - No interaction }\end{array}$ \\
\hline Language & $\begin{array}{l}\text { - Importance of plain } \\
\text { language }\end{array}$ & $\begin{array}{ll}\text { - } & \text { English } \\
\text { - } & \text { Other language } \\
\text { - } & \text { Robotic response } \\
\text { - } & \text { Do not understand } \\
\end{array}$ \\
\hline $\begin{array}{l}\text { IRCC Website and other } \\
\text { sources of information }\end{array}$ & $\begin{array}{ll}\text { - Information seeking } \\
\text { strategies }\end{array}$ & $\begin{array}{ll}\text { - } & \text { Website } \\
\text { - Other social media } \\
\text { - Other sources of } \\
\text { information } \\
\text { - Google search } \\
\text { - Contact options (call centre, } \\
\text { email, web form) }\end{array}$ \\
\hline \multirow[t]{2}{*}{ Privacy } & - Lack of privacy concerns & - No issues \\
\hline & - $\quad$ Privacy concerns & $\begin{array}{ll}\text { - } & \text { Revealing personal } \\
\text { information } \\
\text { - } & \text { Jeopardizing the case }\end{array}$ \\
\hline $\begin{array}{l}\text { Effective use of social } \\
\text { media by government }\end{array}$ & $\begin{array}{ll}\text { - } & \text { Interaction } \\
\text { - } & \text { Private messages } \\
\text { - } & \text { Facebook functionality } \\
\text { - } & \text { Need to hear from IRCC } \\
\end{array}$ & $\begin{array}{l}\text { - Suggestions for } \\
\text { improvement }\end{array}$ \\
\hline
\end{tabular}




\section{Bibliography}

Adams, Paul C. and Rina Ghose. 2003. "India. com: the construction of a space between". Progress in Human Geography. 27(4): 414-437.

Agranoff, Robert, Michael McGuire and Chris Silvia. 2013. "Governance, networks and intergovernmental systems" in Routledge Handbook of Public Policy edited by Eduard Araral, Scott Fritzen and Michael Howlett. 361-373. Independence, KY: Routledge.

Agranoff, Robert and Michael McGuire. 2003. Collaborative Public Management: New Strategies for Local Governments. Washington, DC: Georgetown Press.

Agranoff, Robert. 2014. "Bridging the Theoretical Gap and Uncovering the Missing Holes" in Network Theory in the Public Sector: Building New Theoretical Frameworks edited by Myrna P. Mandell, Robyn Keast and Robert Agranoff. 193-210. New York, NY: Routledge.

--. 2007. Managing within Networks: Adding Value to Public Organizations. Washington, DC: Georgetown University Press.

Akbari, Ather H. and Martha MacDonald. 2014. "Immigration policy in Australia, Canada, New Zealand, and the United Sates: An overview of recent trends". International Migration Review. 48(3): 801-822.

AlAwadi, Suha and Anne Morris. 2009. "Factors Influencing the Adoption of E-government Services". Journal of Software. 4(6): 584-590.

Alexa, Melina. 1997. "Computer-assisted text analysis methodology in the social sciences" Accessed on June 29, 2017

http://www.gesis.org/fileadmin/upload/forschung/publikationen/gesis_reihen/zuma_arbeitsbe richte/1997/97_07.pdf

Alonso, Andoni and Pedro J. Oiarzabal. 2010. "The Immigrant Worlds' Digital Harbours" in Diasporas in the New Media Age: Identity, Politics, and Community, edited by Andoni Alonso and Pedro J. Oiarzabal. 1-15. Reno, NV: University of Nevada Press.

Anttiroiko, Ari-Veikko. 2010. "Innovation in democratic e-governance: Benefitting from Web 2.0 applications in the public sector". International Journal of Electronic Government Research. 6(2): 18-36.

Australia. Australian Government. 2016. "Australia's First Open Government National Action Plan 2016-18". Accessed July 14, 2017. http://ogpau.pmc.gov.au/australias-firstopen-government-national-action-plan-2016-18

--. 2000. "Government Online. The Commonwealth Government's Strategy". Accessed July 14, 2017. http://www.finance.gov.au/agimoarchive/publications_noie/2000/04/govonline.html 
Australia. Australia Public Service Commission. 2016. "APS Values and Cond of Conduct in Practice". Accessed July 11, 2017. http://www.apsc.gov.au/publications-and-media/currentpublications/aps-values-and-code-of-conduct-in-practice

--. 2012. "Circular 2012/1: Revisions to the Commission's guidance on making public comment and participating online (social media).” Accessed July 11, 2017.

http://www.apsc.gov.au/publications-and-media/archive/circulars-archive/circular-20121

Australia. Department of Finance. 2012. "Australian Public Service Information and Communications Technology Strategy 2012 - 2015”. Accessed July 14, 2017.

http://www.finance.gov.au/files/2013/01/APS_ICT_Strategy.pdf

--. 2009. "Engage: Getting on with Government 2.0: Report of the Government 2.0

Taskforce". Accessed July 14, 2017

http://www.finance.gov.au/archive/publications/gov20taskforcereport/

Australia. Department of Immigration and Border Protection. 2017a. "Social Media." Accessed July 13, 2017. http://www.border.gov.au/about/news-media/social

--.2017b. “DIBP Australia Twitter Account”. Accessed July 13, 2017. https://twitter.com/dibpaustralia

--. 2015. Country Profiles. Accessed July 13, 2017. https://www.border.gov.au/about/reportspublications/research-statistics/statistics/live-in-australia/country-profiles\#

Australia. Department of the Prime Minister and Cabinet. 2016. "Engagement Update $-1^{\text {st }}$ March”. Accessed July 14, 2017. http://ogpau.pmc.gov.au/2016/03/01/engagement-update1st-march

Bannister, Judith. 2011. "Open government: From crown copyright to the creative commons and culture change". University of New South Wales Law Journal. 34(3): 1080-1103.

Bazeley, Patricia. 2007. Qualitative Data Analysis with NVivo. London, UK: SAGE Publications.

Benckler, Yochai. 2006. The Wealth of Networks: How Social Production Transforms Markets and Freedom. New Haven, CT: Yale University Press.

Bennett, Lamar V. and Aroon P. Manoharan. 2017. "The use of social media policies by US municipalities". International Journal of Public Administration. 40(4): 317-328.

Berry, Frances S., Ralph S. Brower, Sang Ok Choi, Wendy Xinfang Goa, HeeSoun Jang, Myungjung Kwon and Jessica Word. 2004. "Three traditions of network research: What the public management research agenda can learn from other research communities". Public Administration Review. 64(5): 539-552. 
Bertot, John Carlo, Paul T. Jaeger, Sean Munson and Tom Glaisyer. 2010. "Engaging the Public in Open Government: Social Media Technology and Policy for Government Transparency". IEEE Computer. 43(11): 53-59.

Bonson, Enrique, Lourdes Torres, Sonia Royo and Francisco Flores. 2012. "Local egovernment 2.0: Social media and corporate transparency in municipalities". Government Information Quarterly 29(2): 123-132.

Borgatti, Stephen P. and Daniel S. Halgin. 2011. "On Network Theory”. Organization Science. 22(5): 1168-1181.

Börzel, Tanja A. 1998. "Organizing Babylon - On the Different Conceptions of Policy Networks". Public Administration 76(2): 253-273.

boyd, danah and Nicole Ellison. 2007. "Social Network Sites: Definition, History, and Scholarship". Journal of Computer-Mediated Communication. 13(1): 210-230.

Boyle, Brendan and David Nicholson. 2003. "E-Government in New Zealand". Journal of Political Marketing. 2(3-4): 89-105.

Bourdieu, Pierre. 1986. "Forms of Capital" in Handbook of Theory and Research for the Sociology of Education edited by John G. Richardson. 241-258. Westport, CT: Greenwood.

Boyd, Monica. 1989. "Family and personal networks in international migration: Recent developments and new agendas". International Migration Review. 23: 638-670.

Burt, Ronald S. 2000. "The Network Structure of Social Capital" in Research in Organizational Behavior edited by Barry M. Staw and Robert I. Sutton. 345-423. Amsterdam, London and New York: Elsevier Science JAI.

-- 1992. Structural Holes: The Social Structure of Competition. Cambridge, Massachusetts and London: Harvard University Press.

Caidi, Nadia, Danielle Allard and Lisa Quirke. 2010. "Information practices of immigrants". Annual Review of Information Science and Technology. 44(1): 491-531.

Caidi, Nadia. 2008. "Information practices of ethno-cultural communities (IPEC)". CERIS The Ontario Metropolis Centre. Accessed August 25, 2015 http://ceris.metropolis.net/Virtual\%20Library/RFPReports/CaidiAllard2005.pdf

Canada. Government of Canada. 2016. "Third Biennial Plan to the Open Government Partnership". Accessed July 14, 2017. http://open.canada.ca/en/content/third-biennial-planopen-government-partnership 
--. 2014. "Canada's Action Plan on Open Government 2014-16". Accessed June 29, 2017.

http://open.canada.ca/en/content/canadas-action-plan-open-government-2014-16

--. 2012. "Canada's Action Plan on Open Government". Accessed July 11, 2017.

http://data.gc.ca/eng/canadas-action-plan-open-government

--. 2005. "Government On-Line 2006". Accessed July 14, 2017.

http://publications.gc.ca/collections/Collection/P4-1-2006E.pdf

Canada. Immigration, Refugees and Citizenship Canada. 2017a. "Departmental Overview"

Accessed June 29, 2017. http://www.cic.gc.ca/english/department/departmental-overview.asp

-- 2017b. "Express Entry". Accessed June 29, 2017.

http://www.cic.gc.ca/english/immigrate/express/express-entry.asp

--.2017c. "Terms and Conditions". Accessed July 14, 2017

http://www.cic.gc.ca/English/notices.asp

--. 2016a. "Facts and figures 2015 - Immigration overview: Permanent and temporary residents. Canada - Permanent residents by source country". Accessed June 29, 2017. http://open.canada.ca/data/en/dataset/2fbb56bd-eae7-4582-af7da197d185fc93?_ga=2.228789596.1187051393.1498753501-1201142243.1466696160

-- 2016b. "Notice - Government addresses spousal backlog and wait times" Accessed July 3, 2017. http://www.cic.gc.ca/english/department/media/notices/2016-06-13.asp

Canada. Treasury Board of Canada Secretariat. 2017. "End-of-Term Self-Assessment Report on Action Plan on Open Government 2014-2016”. Accessed June 29, 2017. http://open.canada.ca/en/end-of-term-self-assessment-report-action-plan-open-government$\underline{2014-2016}$

--.2016a. "Directive on the Management of Communications". Accessed June 29, 2017 https://www.tbs-sct.gc.ca/pol/doc-eng.aspx?id=30682

--. 2016b. "Technical specifications for social media accounts". Accessed June 29, 2017 https://www.canada.ca/en/treasury-board-secretariat/services/governmentcommunications/federal-identity-program/technical-specifications/social-mediaaccounts.html?=undefined\&wbdisable=false

--. 2014. "Standard on Social Media Account Management". Accessed June 29, 2017 https://www.tbs-sct.gc.ca/pol/doc-eng.aspx?id=27033

--. 2013. "Implementation of Canada's Action Plan on Open Government (Year-1) SelfAssessment Report". Accessed June 29, 2017. http://open.canada.ca/en/implementationcanadas-action-plan-open-government-year-1-self-assessment-report\#toc16 
Castells, Manuel. 2010. The Rise of the Network Society. Second edition with a new preface. Maiden, MA: Wiley-Blackwell.

Cavazos-Rehg, Patricia A., Shaina J. Sowles, Melissa J. Krauss, Vivian Agbonavbare, Richard Grucza, and Laura Bierut. 2016. "A content analysis of tweets about high-potency marijuana”. Drug and Alcohol Dependence. 166: 100-108.

Chase, Steven. 2012. "Canada needs to get competitive to attract skilled immigrants: Harper". The Globe and Mail. Accessed July 11, 2017 http://www.theglobeandmail.com/news/politics/canada-needs-to-get-competitive-to-attractskilled-immigrants-harper/article5179369/

Clarke, Amanda and Jonathan Craft. 2017. "The vestiges and vanguards of policy design in a digital context”. Canadian Public Administration. 60(4): 476-497.

Clarke, Amanda, Evert A. Lindquist and Jeffrey Roy. 2017. "Understanding governance in the digital era: An agenda for public administration research in Canada". Canadian Public Administration. 60(4): 457-475.

Clarke, Amanda and Mary Francoli. 2017. "Digital Government and Permanent Campaigning" in Permanent Campaigning in Canada edited by Alex Marland, Anna Esselment, and Thierry Giasson. 241-258. Vancouver: UBC Press

--. 2014. "What's in a name? Questioning the homogeneity of 'open government' programs across seven countries", Journal of e-Democracy and Open Government. 6(1): 248-266.

Clarke, Amanda. 2012. "Open dialogue' and the Government of Canada's use of social media: bureaucratic barriers to democratic engagement in the digital age". Paper presented at the 2012 Canadian Political Science Association Annual Conference University of Alberta Edmonton, Alberta June 14.

Coleman, James S. 1990. Foundations of Social Theory. Cambridge, MA: Belknap Press.

Corbin, Juliet and Anselm Strauss. 2008. Basics of Qualitative Research: Techniques and Procedures for Developing Grounded Theory. 3rd edition. Thousand Oaks, CA: SAGE Publications.

Craft, Jonathan. 2013. "The Promise and Paradox of Open Government in the Harper Era" in How Ottawa Spends 2012-2013: The Harper Majority, Budget Cuts and the New Opposition edited by G. Bruce Doerny and Christopher Stacey. 209-222. Montreal, QC: McGuillQueen's University Press.

Creswell, John W. 2015. A Concise Introduction to Mixed Methods Research. Thousand Oaks, CA: SAGE Publications. 
--. 2014. Research Design: Qualitative, Quantitative and Mixed Method Approaches. Thousand Oaks, CA: SAGE Publications.

--. 2013. Qualitative Inquiry and Research Design: Choosing Among Five Approaches. 3rd edition. Thousand Oaks, CA: SAGE Publications.

Criado, J. Ignacio, Rodrigo Sandoval-Almazan and J. Ramon Gil-Garcia. 2013. "Government innovation through social media". Government Information Quarterly. 30(4): 319-326.

Chung, Wingyan and Daniel Zeng. 2016. "Social-media-based public policy informatics: Sentiment and network analyses of U.S. immigration and border security". Journal of the Association for Information Science and Technology. 67(7): 1588-1606.

Dawes, Sharon, Anthony Cresswell and Theresa Pardo. 2009. "From "Need to Know" to "Need to Share": Tangled Problems, Information Boundaries, and the Building of Public Sector Knowledge Networks". Public Administration Review. 69(3): 391-402.

Dekker, Rianne, Godfried Engbersen, and Marije Faber. 2016. "The use of online media in migration networks". Population, Space and Place. 22(6): 539-551.

Dekker, Rianne and Godfried Engbersen. 2014. "How social media transform migrant networks and facilitate migration". Global Networks 14(4): 401-418.

Deschamps, Ryan and Kathleen McNutt. 2014. "Third Sector and Social Media". The Canadian Journal of Nonprofit and Social Economy Research. 5(2): 29-46.

Dixon, Brian E. 2010. "Towards e-Government 2.0: An assessment of where e-Government 2.0 is and where it is headed". Public Administration \& Management. 15(2): 418-454.

Doberstein, Carey. 2016. Building a Collaborative Advantage: Network Governance and Homelessness Policy-Making in Canada. Vancouver, BC: UBC Press.

Dowding, Keith. 1995. "Model or Metaphor? A Critical Review of the Policy Network Approach”. Political Studies. 43(1): 136-158.

Drisko, James W. and Tina Maschi. 2016. Content Analysis. New York, NY: Oxford University Press.

Dunleavy, Patrick and Helen Margetts. 2010. "The Second Wave of Digital Era Governance". Prepared for the 2010 Annual Meeting of the American Political Science Association, September 2-5, 2010. Accessed July 29, 2017. http://papers.ssrn.com/sol3/papers.cfm?abstract id $=1643850$

Dunleavy, Patrick, Helen Margetts, Simon Bastow and Jane Tinkler. 2006. "New Public Management is Dead: Long Live Digital Era Governance". Journal of Public Administration Research and Theory. 16(3): 467-494. 
Dutil, Patrice, Cosmo Howard, John Langford and Jeffrey Roy. 2010. The Service State: Rhetoric, Reality and Promise. Ottawa, ON: University of Ottawa Press.

Feiock, Richard C. and John Scholz. 2009. Self-organizing federalism: Collaborative mechanisms to mitigate institutional collective action. New York, NY: Cambridge University Press.

Field, John. 2003. Social Capital. London, UK: Routledge.

Flores-Yeffal, Nadia Y. 2013. Migration-trust networks: social cohesion in Mexican USbound emigration. College Station, TX: Texas A\&M University Press.

Frederickson, George H., Kevin B. Smith, Christopher Larimer and Michael J. Licari. 2012. The Public Administration Theory Primer. 2nd edition. Boulder CO: Westview Press.

Francoli, Mary. 2017. "Independent Reporting Mechanism (IRM): Canada End-of-Term Report 2014-2016.” Accessed July 13, 2017.

https://www.opengovpartnership.org/documents/canada-end-of-term-report-2014-2016

--. 2014. "Independent Reporting Mechanism Canada: Progress Report 2012-13". Accessed July 17, 2017.

http://www.opengovpartnership.org/sites/default/files/Canada_final_2012_Eng.pdf

--. 2011. “What Makes Governments 'Open'?” JeDEM. 3(2): 16-29. Accessed July 17, 2017 https://jedem.org/index.php/jedem/article/download/65/85

George, Usha and Ferzana Chaze. 2009a. "Social Capital and Employment: South Asian Women's Experiences”. Affilia: Journal of Women and Social Work. 24(4): 394-405.

--. 2009b. "Tell Me What I Need to Know": South Asian Women, Social Capital and Settlement”. Journal of International Migration and Integration. 10(3): 265-282.

Geist, Michael. 2013. "Ottawa's complete e-government failure: Geist”. Toronto Star, November 29. Accessed July14, 2017.

http://www.thestar.com/business/tech_news/2013/11/29/ottawas_complete_egovernment_fail ure_geist.html

Godfrey, Daniel, Caley Johns, Carol Sadek, Carl Meyer and Shaina Race. 2014. "A Case Study in Text Mining: Interpreting Twitter Data From World Cup Tweets". Cornell University Library. Open access to e-prints. Accessed July 3, 2017. https://arxiv.org/pdf/1408.5427.pdf 
Goncalves, Jorge, Yong Liu, Bin Xiao, Saad Chaudhry, Simo Hosio and Vassilis Kostakos. 2015. "Increasing the reach of government social media: A case study in modeling Government-Citizen interaction on Facebook". Policy \& Internet. 7(1): 80-102.

Granovetter. Mark S. 1983. "The Strength of Weak Ties: A Network Theory Revisited". Sociological Theory. 1: 201-233.

--. 1973. "The Strength of Weak Ties". American Journal of Sociology. 78(6): 1360-1380.

Gruzd, Anatoliy and Melissa Goertzen. 2013. "Wired Academia: Why Social Science Scholars are using Social Media". 46 ${ }^{\text {th }}$ Hawaii International Conference on System Sciences. 3332-3341.

Gupta, Kuhika. 2012. "Comparative public policy: Using the comparative method to advance our understanding of the policy process". Policy Studies Journal. 40 (S1): 11-26.

Hakim Silvio, Dominic. 2006. "The information needs and information seeking behaviour of immigrant southern Sudanese youth in the city of London, Ontario: An exploratory study". Library Review. 55 (4): 259-266.

Häuberer, Julia. 2011. Social Capital Theory. Towards a Methodological Foundation. Germany: VS Verlag.

Haug, Sonja. 2008. "Migration Networks and Migration Decision-Making”. Journal of Ethnic and Migration Studies. 34(4): 585-605.

Haythornthwaite, Caroline. 2005. "Social networks and Internet connectivity effects." Information, Communication \& Society. 8(2): 125-147.

--. 2002. "Strong, weak, and latent ties and the impact of new media". The Information Society. 18(5): 385-401.

Henman, Paul. 2010. Governing Electronically: E-Government and the Reconfiguration of Public Administration, Policy and Power. London, UK: Palgrave Macmillan.

Hiller, Harry and Tara Franz. 2004. "New ties, old ties and lost ties: the use of the Internet in diaspora". New Media \& Society. 6(6): 731-752.

Homburg, Vincent. 2008. Understanding E-Government: Information systems in public administration. New York, NY: Routledge.

Hrdinová, Jana, Natalie Helbig and Catherine Stollar Peters. 2010. Designing social media policy for government: Eight essential elements. Center for Technology in Government. Accessed July 29, 2017. http://www.ctg.albany.edu/publications/guides/social_media_policy 
Hsieh, Hsiu-Fang, and Sarah E. Shannon. 2005. "Three approaches to qualitative content analysis." Qualitative Health Research 15(9): 1277-1288.

Huang, Kuang-Yuan and Senem Güney. 2012. "Toward a Framework of Web 2.0-Driven Organizational Learning". Communications of the Association for Information Systems. 31(6): 128-152.

Johns, Carolyn. 2013. "Governance of the Great Lakes in North America and Transboundary Governance Capacity". Paper presented at the International Conference on Public Policy, Grenoble, France. Accessed July 27, 2017. archives.ippapublicpolicy.org/IMG/pdf/panel33_s1_johns.pdf

Johnson, Peter A., Renee Sieber, Teresa Scassa, Monica Stephens and Pamela Robinson. 2017. "The cost(s) of geospatial open data". Transactions in GIS. 21(3): 434-445.

Johnson, Peter and Pamela Robinson. 2014. "Civic hackathons: Innovation, procurement, or civic engagement?” Review of Policy Research. 31(4): 349-357.

Jukić, Tina and Manca Merlak. 2017. The use of social networking sites in public administration: The case of Slovenia. The Electronic Journal of E-Government. 15(1): 2-18.

International Association for Public Participation. 2018. "IAP2's Public Participation Spectrum". Accessed March 19, 2018.

https://c.ymcdn.com/sites/www.iap2.org/resource/resmgr/foundations_course/IAP2_P2_Spec trum_FINAL.pdf

Isett, Kimberley R, Ines Mergel, Kelly LeRoux, Pamela A. Mischen and R. Karl Rethemeyer. 2011. "Networks in Public Administration Scholarship: Where We Are and Where We Need to Go". Journal of Public Administration Research and Theory. 21(1): i157-i173.

Isett, Kimberley R. and Keith G. Provan. 2005. "The Evolution of Dyadic Interorganizational Relationships in a Network of Publicly Funded Nonprofit Agencies". Journal of Public Administration Research and Theory. 15(1):149-165.

Kavanaugh, Andrea L., Edward A. Fox, Steven D. Sheetz, Seungwon Yang, Lin Tzy Li, Donald J. Shoemaker, Apostol Natsev and Lexing Xie. 2012. "Social media use by government: From the routine to the critical". Government Information Quarterly. 29(4): 480-491.

Kagarise, Warren and Stacey M. Zavattaro, 2017. Social Media: How One City Opens the Evidence Black Box. Public Administration Review. 77(4): 486-488.

Keast, Robyn. 2014. "Network Theory Tracks and Trajectories: Where from, Where to?" in Network Theory in the Public Sector: Building New Theoretical Frameworks edited by Myrna P. Mandell, Robyn Keast and Robert Agranoff. 15-30. New York, NY: Routledge. 
Kickert, Walter J.M., Erik-Hans Klijn and Joop F.M. Koppenjan. 1997. "Introduction: A Management Perspective on Policy Networks" in Managing Complex Networks: Strategies for the Public Sector edited by Walter J.M. Kickert, Erik-Hans Klijn and Joop F.M. Koppenjan. 1-13. London, UK: SAGE Publications.

Klijn, Erik-Hans and Joop F. M. Koppenjan. 2000. "Public Management and Policy Networks: Foundations of a network approach to governance”. Public Management. 2(2): 135-158.

Knoke, David. 2011. "Policy Networks" in The Sage Book of Social Network Analysis edited by John Scott and Peter Carrington. 210-222. Thousand Oaks, CA: Sage.

Komito, Lee. 2011." Social media and migration: Virtual community 2.0". Journal of the American Society for Information Science and Technology. 62(6): 1075-1086.

Krippendorff, Klaus. 2004. Content analysis: An introduction to its methodology. 2nd edition. Thousand Oaks, CA: SAGE Publications.

Kumar, Vinod, Bhasker Mukerji, Irfan Butt and Ajax Persaud. 2007. "Factors for Successful e-Government Adoption: a Conceptual Framework". The Electronic Journal of eGovernmnent. 5(1):63-76.

Kvale, Steinar. 2007. Doing Interviews. Qualitative Research Kit. London, UK: SAGE Publications.

Lai, Linda S. L. and W. M. To. 2015. "Content Analysis of Social Media: A Grounded Theory Approach”. Journal of Electronic Commerce Research. 16 (2): 138-152.

Landsbergen, David. 2011. "Government as Part of the Revolution: Using Social Media to Achieve Public Goals" in Leading Issues in e-Government Research, Volume One, edited by Les Worrall, 147-172. Reading, UK: Academic Publishing International Ltd.

Lathrop, Daniel and Laurel Ruma. 2010. Preface to Open Government: Collaboration, Transparency, and Participation in Practice, edited by Daniel Lathrop and Laurel Ruma, xix-xxv. Sebastopol, CA: O'Reilly Media.

Lauriault, Tracy P. and Mary Francoli. 2017. "Openness, Transparency, and Participation" in Understanding Spatial Media, edited by Rob Kitchin, Tracey P. Lauriault and Matthew W. Wilson. London, UK: SAGE publications.

Lecy, Jesse D., Ines A. Mergel and Hans Peter Schmitz .2014. "Networks in public administration: current scholarship in review". Public Management Review. 16(5): 643 665. 
Lee, Nicole M. and Matthew S. VanDyke. 2015. "Set it and forget it: The one-way use of social media by government agencies communicating science”. Science Communication. 37(4): 533-541.

Liberal party of Canada. 2015. "Syrian Refugees" Assessed July 3, 2017 https://www.liberal.ca/realchange/syrian-refugees/

Linders, Dennis, Susan Copeland Wilson and John Carlo Bertot. 2013. "Open Government as a Vehicle for Government Transformation" in Public Sector Transformation through EGovernment: Experiences from Europe and North America edited by Vishanth Weerakkody and Christopher G Reddick. 9-24. New York, NY: Routledge.

Linders, Dennis. 2012. "From e-government to we-government: Defining a typology for citizen coproduction in the age of social media". Government Information Quarterly. 29(4): 446-454.

Lin, Fengyi, Seedy S. Fofanah, and Deron Liang. 2011. "Assessing Citizen Adoption of eGovernment Initiatives in Gambia: A Validation of the Technology Acceptance Model in Information Systems Success.” Government Information Quarterly. 28(2): 271-279.

Lin, Nan, Yang-chih Fu and Ray-May Hsung. 2001. "The Position Generator: Measurement Techniques for Investigations of Social Capital" in Social Capital. Theory and Research edited by Nan Lin, Karen Cook and Ronald S. Burt. New York, NY: Walter de Gruyter. 5779.

Lin, Nan. 1999. "Building a Network Theory of Social Capital”. Connections. 22(1): 28-51.

Liu, Mao-Mei. 2013. "Migrant Networks and International Migration: Testing Weak Ties". Demography. 50(4): 1243-1277.

Longo, Justin. 2017. "The evolution of citizen and stakeholder engagement in Canada, from Spicer to \#Hashtags”. Canadian Public Administration. 60(4): 517-537.

Loukis, Euripidis, Yannis Charalabidis and Aggeliki Androutsopoulou. 2017. "Promoting Open Innovation in the Public Sector through Social Media Monitoring". Government Information Quarterly. 34(1): 99-109.

Mandell, Myrna P. 2014. "Introduction: Understanding Theory” in Network Theory in the Public Sector: Building New Theoretical Frameworks edited by Myrna P. Mandell, Robyn Keast and Robert Agranoff. 3-14. New York, NY: Routledge.

Marsh, David and Martin Smith. 2000. "Understanding Policy Networks: towards a Dialectical Approach". Political Studies. 48(1): 4-21. 
Margetts, Helen 2012. "Electronic Government: A Revolution in Public Administration?" in The Sage Handbook of Public Administration edited by B. Guy Peters and Jon Pierre. 447463. SAGE Publications.

Massey, Douglas S., Rafael Alarcon, Jorge Durand and Humberto Gonzalez. 1987. Return to Aztlan: The Social Process of International Migration from West Mexico. Berkley, CA: University of California Press.

Massey, Douglas S., Joaquin Arango, Graeme Hugo, Ali Kouaouci, Adela Pellegrino and J. Edward Taylor. 1993. "Source Theories of International Migration: A Review and Appraisal”. Population and Development Review. 19(3): 431-466.

McNutt, Kathleen and Adam Wellstead. 2010. "Virtual policy networks in forestry and climate change in the U.S. and Canada: Government nodality, internationalization and actor complexity". Policy \& Internet 2(2): 33-59.

McNutt, Kathleen. 2014. "Public engagement in the Web 2.0 era: Social collaborative technologies in a public sector context". Canadian Public Administration. 57(1): 49-70.

--. 2010. "Virtual Policy Networks: Where all Roads Lead to Rome". Canadian Journal of Political Science. 43(4): 915-935.

--. 2006. "Research Note: Do Virtual Policy Networks Matter? Tracing Network Structure Online”. Canadian Journal of Political Science. 39(2): 391-405.

McGregor, Elaine and Melissa Siegel. 2013. "Social Media and Migration Research". UNUMERIT Working Paper Series. Accessed July 19, 2017 www.merit.unu.edu/publications/wppdf/2013/wp2013-068.pdf

McGuire, Michael and Robert Agranoff. 2014. "Network Management Behaviours: Closing the Theoretical Gap" in Network Theory in the Public Sector: Building New Theoretical Frameworks edited by Myrna P. Mandell, Robyn Keast and Robert Agranoff. 137-156. New York, NY: Routledge.

McGuire, Michael and Chris Silvia. 2009. "Does Leadership in Networks Matter? Examining the Effect of Leadership Behavior on Managers' Perceptions of Network Effectiveness". Public Performance and Management Review. 33(1): 34-62.

Medagliaa, Rony and Lei Zheng. 2017. (Forthcoming). "Mapping government social media research and moving it forward: A framework and a research agenda". Government Information Quarterly. Accessed Sertember 21, 2017 doi.org/10.1016/j.giq.2017.06.001.

Meijer, Albert and Marcel Thaens. 2013. "Social media strategies: Understanding the differences between North American police departments". Government Information Quarterly. 30(4): 343-350. 
Meijer, Albert, Nils Burger and Wolfgang Ebbers. 2011. "Citizens2Citizens: Mapping Participatory Practices on the Internet" in Leading Issues in e-Government Research, Volume One, edited by Les Worrall. 173-203. Reading, UK: Academic Publishing International Ltd.

Menjívar, Cecilia. 2000. Fragmented Ties: Salvadoran Immigrant Networks in America. Berkley, CA: University of California Press.

Mergel, Ines. 2017. "Building Holistic Evidence for Social Media Impact”. Public Administration Review. 77(4): 489-495.

--. 2014. "Social Media Practices in Local Emergency Management. Results from Central New York". Accessed July 29, 2017. http://sotechem.syr.edu/wpcontent/uploads/2014/11/SoTechEM_Executive_Report-mwedit111914.pdf

--. 2013a. "Designing a Social Media Strategy to Fulfill Your Agency's Mission". Public Manager. 42.1: 26-29.

--. 2013b. Social Media in the Public Sector. A guide to participation, collaboration and transparency in the networked world. John Wiley \& Sons: San Francisco, CA.

--.2013c. "Social media adoption and resulting tactics in the U.S. federal government". Government Information Quarterly. 30(2): 123-130.

--. 2012. "The social media innovation challenge in the public sector". Information Polity. 17: 281-292.

Mergel, Ines and Stuart I. Bretschneider. 2013. "Three-Stage Adoption Process for Social Media Use in Government”. Public Administration Review. 73(3): 390 - 400.

Mergel, Ines and Bill Greeves. 2013. Social Media in the Public Sector Field Guide: Designing and Implementing Strategies and Policies. San Francisco, CA: Jossey-Bass/Wiley.

Millar, Laurence. 2004. "Networking government: e-government in New Zealand". Public Sector Journal. 27(4): 1-10. Accessed July 14, 2017.

http://unpan1.un.org/intradoc/groups/public/documents/apcity/unpan021670.pdf

Milward, H. Brinton and Keith G. Provan. 2003. "Managing the Hollow State: Collaboration and Contracting". Public Management Review. 5(1): 1-18.

Nabatchi, Tina. 2012. "Putting the "public" back in public values research: Designing participation to identify and respond to values". Public Administration Review 72 (5): 699708.

Nam, Taewoo. 2012. "Citizens' attitudes toward open government and government 2.0". International Review of Administrative Sciences. 78 (2): 346-368. 
New Zealand. New Zealand Government. 2016. "New Zealand Second National Action Plan 2016-2018". Accessed July 7, 2017. https://www.opengovpartnership.org/documents/newzealand-second-national-action-plan-2016-2018

--. 2014. "New Zealand, First Action Plan, 2014-16". Accessed July 7, 2017. https://www.opengovpartnership.org/documents/new-zealand-first-action-plan-2014-16

--. 2013. "The Government ICT Strategy and Action Plan to 2017". Accessed July 7, 2017. http://ict.govt.nz/assets/Uploads/Government-ICT-Strategy-and-Action-Plan-to-2017.pdf

--. 2006. Enabling Transformation: a Strategy for E-government 2006. Accessed June 29, 2017. http://unpan1.un.org/intradoc/groups/public/documents/UNPAN/UNPAN025642.pdf

New Zealand. Department of Internal Affairs. 2014. "Social Media Guidance". Accessed June 29, 2017 https://webtoolkit.govt.nz/guidance/social-media/

--. 2012. "Social Media in Government. How to Handle a Mishap". Accessed June 29, 2017 https://webtoolkit.govt.nz/files/Social-Media-in-Government-How-to-Handle-a-Mishap-v1$0 . p d f$

--. 2011a. "Social Media in Government. High-level Guidance". Accessed June 29, 2017. https://webtoolkit.govt.nz/files/Social-Media-in-Government-High-level-Guidance-final.pdf

--. 2011b. "Social Media in Government. Hand-On Toolbox". Accessed June 29, 2017. https://webtoolkit.govt.nz/files/Social-Media-in-Government-Hands-on-Toolbox-final.pdf

--. 2010. "Directions and Priorities for Government ICT". Accessed June 29, 2017. https://www.dia.govt.nz/diawebsite.nsf/Files/DirectionsandPrioritiesforGovernmentICTdiagr am1/\$file/DirectionsandPrioritiesforGovernmentICTdiagram1.pdf

New Zealand. Ministry of Business, Innovation and Employment. 2017. "New Zealand Now: about". Facebook page. Accessed June 29, 2017.

https://www.facebook.com/pg/ImmigrationNewZealandOfficial/about/?ref=page_internal

--. 2016. "Migration Trends Report 2015-2016". Accessed June 29, 2017.

http://www.mbie.govt.nz/publications-research/research/migrants---monitoring/migrationtrends-and-outlook-2015-16.pdf

--. 2015. “A New to New Zealand's posting policy”. Facebook page. Accessed June 29, 2017. https://www.facebook.com/notes/new-to-new-zealand/new-to-new-zealands-postingpolicy/486167574868977/

OECD. 2018. "Digital Government". Accessed March 18, 2018 http://www.oecd.org/gov/digital-government/ 
OECD. 2011. "Australia" in the Call for Innovative and Open Government: An Overview of Country Initiatives. 26-33. OECD Publishing. Accessed June 29, 2017

http://dx.doi.org/10.1787/9789264107052-4-en

Ongley, Patrick and David Pearson. 1995. "Post-1945 International Migration: New Zealand, Australia and Canada Compared”. International Migration Review. 29(3): 765-793.

Open Government Partnership. 2017. "What Is the Open Government Partnership." Accessed June 29, 2017. http://www.opengovpartnership.org/about

Ontario. Government of Ontario. 2017a. "Open Government Partnership program". Accessed June 29, 2017 https://www.ontario.ca/page/open-government-partnership-program

--. 2017b. "Social Media Terms of Use". Accessed June 29, 2017

https://www.ontario.ca/page/social-media-terms-use

--. 2016. "September 2016 Mandate letter: Citizenship and Immigration". Accessed June 29, 2017 https://www.ontario.ca/page/september-2016-mandate-letter-citizenship-andimmigration

Ontario. Ministry of Citizenship and Immigration 2016. "Terms of Use/Posting Guidelines". Accessed February 20, 2017 [achieved version, no longer available]

Open Government Partnership. 2017. "From commitment to action". Accessed June 29, 2017 https://www.opengovpartnership.org/

Open Government Guide. 2013. "The New Zealand Government has developed social media guidance". Accessed June 29, 2017. http://www.opengovguide.com/country-examples/thenew-zealand-government-has-developed-social-media-guidance/

O'Toole, Laurence J. 1997. "Treating Networks Seriously: Practical and Research-based Agendas in Public Administration”. Public Administration Review. 57(1): 45 - 52.

Petróczi, Andrea, Tamás Nepusz and Fülöp Bazsó. 2007. "Measuring tie-strength in virtual social networks". Connections. 27(2): 39-52.

Portes, Alejandro. 1998. "Social Capital: Its Origins and Applications in Modern Sociology". The Annual Review Sociology. 24(1): 1-24.

Price, Steven. 2017. "New Zealand End-Of-Term Report 2014-2016". Accessed July 14, 2017. https://www.opengovpartnership.org/documents/new-zealand-end-of-term-report$\underline{2014-2016}$

Provan, Keith G. and H. Brinton Milward. 2001. "Do networks really work? A framework for evaluating public sector organizational networks". Public Administration Review 61(4): 414-423. 
Putnam, Robert D. 2000. Bowling Alone: The Collapse and Revival of American Community. New York, NY: Simon Schuster.

--. 1993. "The Prosperous Community: Social Capital and Public Life". The American Prospect. (13): 35-42.

Raab, Jörg and Patrick Kenis. 2007. "Taking Stock of Policy Networks: Do They Matter?” in Handbook of Public Policy Analysis Theory, Politics, and Methods edited by Frank Fischer, Gerald J. Miller and Mara S. Sidney. 187-200. Boca Raton, FL: CRC Press.

Rethemeyer, R. Karl. 2007. "Policymaking in the Age of Internet: Is the Internet Tending to Make Policy Networks More or Less Inclusive?" Journal of Public Administration Research and Theory. 17(2): $259-284$.

Rhodes, R.A.W. 1997. Understanding governance: policy networks, governance, reflexivity, and accountability. Buckingham, UK: Open University Press.

Rieder, Bernhard 2013. "Studying Facebook via Data Extraction: The Netvizz Application." In Proceedings of the 5th Annual ACM Web Science Conference. 346-355. Accessed June 29, 2017 http://rieder.polsys.net/files/rieder_websci.pdf

Ros, Adela. 2010. Interconnected Immigrants in the Information Society in Diasporas in the New Media Age: Identity, Politics, and Community edited by Andoni Alonso and Pedro J. Oiarzabal. 19-38. Reno, NV: University of Nevada Press.

Roy, Jeffrey. 2017. "Digital government and service delivery: An examination of performance and prospects”. Canadian Public Administration. 60(4): 538-561.

--. 2016. "Data, Dialogue, and Innovation: Opportunities and Challenges for "Open Government" in Canada". Journal of Innovation Management. 4(1): 22-38.

--. 2013. From Machinery to Mobility: Government and Democracy in a Participative Age. New York, NY: Springer Science and Business Media.

--. 2006. E-Government in Canada: transformation for the digital age. Ottawa, ON:

University of Ottawa Press.

Salancik, Gerald R. 1995. "WANTED: A Good Network Theory of Organization. Review Essay for Structural Holes: The Social Structure of Competition by Ronald S. Burt". Administrative Science Quarterly. 40(2): 345-349.

Saldaña, Johnny. 2009. The coding manual for qualitative researchers. Thousand Oaks, CA: SAGE publications. 
Segerberg, Alexandra and W. Lance Bennett. 2011. "Social media and the organization of collective action: Using twitter to explore the ecologies of two climate change protests". The Communication Review. 14(3): 197-215.

Shoham, Snunith and Sarah K. Strauss. 2008. "Immigrants' information needs: their role in the absorption process". Information Research. 13(4). Paper 359. Accessed July 29, 2017. http://www.informationr.net/ir/13-4/paper359.html

Skogstad, Grace. 2005. "Policy Networks and Policy Communities: Conceptual Evolution", paper presented at the annual meeting of the Canadian Political Science Association, University of Western Ontario, London, ON on June 2, 2005.

Skok, James E. 1995. "Policy Issue Networks and the Public Policy Cycle: A StructuralFunctional Framework for Public Administration." Public Administration Review. 55(4): 325 -332 .

Small, Tamara A. 2012. "e-Government in the Age of Social Media: An Analysis of the Canadian Government's Use of Twitter.” Policy \& Internet. 4(3-4): 91-111.

Song, Changsoo, and Jooho Lee. 2016. "Citizens' use of social media in government, perceived transparency, and trust in government". Public Performance \& Management Review. 39(2): 430-453.

Steinmo, Sven. 2003. "The evolution of policy ideas: Tax policy in the 20th century". British Journal of Politics and International Relations. 5(2): 206-236.

Thompson, Elizabeth. 2017. "Federal government blocking social media users, deleting posts". CBC News. Accessed November 14, 2017. http://www.cbc.ca/news/politics/twitterfacebook-socialmedia-porn-1.4394127

Veenhof, Ben, Barry Wellman, Carsten Quell and Bernie Hogan. 2008. 'How Canadians' Use of the Internet Affects Social Life and Civic Participation". Accessed July 27, 2017. http://www.statcan.gc.ca/pub/56f0004m/56f0004m2008016-eng.htm

Venkatesh, Viswanath, Michael G. Morris, Fred D. Davis, and Gordon B. Davis. 2003. "User acceptance of information technology: Toward a unified view". MIS Quarterly. 27(3): 425478.

Voets, Joris. 2014. "Developing Network Management Theory through Management Channels and Roles" in Network Theory in the Public Sector: Building New Theoretical Frameworks, edited by Myrna P. Mandell, Robyn Keast and Robert Agranoff, 118-134. New York, NY: Routledge.

Wachaus, Aaron. 2009. "Networks in Contemporary Public Administration: A Discourse Analysis". Administrative Theory and Praxis. 31(3): 59-77. 
Wang, Hui-Chih, Her-Sen Doong and Feng-Chang Lin. 2007. "Determinants of Egovernment service adoption: An innovation diffusion perspective". Paper for 2007 International Conference on Wireless Communications, Networking and Mobile Computing: $3458-3461$.

Wu, Chen-Yu and David Knoke. 2013. "Policy network models" in Routledge Handbook of Public Policy, edited by Eduard Araral, Scott Fritzen and Michael Howlett, 153-163. Independence, KY: Routledge.

Xue, Li. 2008. "Social Capital and Employment Entry of Recent Immigrants to Canada Evidence from the Longitudinal Survey of Immigrants to Canada (LSIC)". Accessed July 17, 2017. http://www.ci.gc.ca/english/pdf/research-stats/social-capital-w3-eng.pdf

Yeloglu, Hakki Okan and Mustafa Sagsan. 2009. "The diffusion of e-government innovations in Turkey: A conceptual framework". Journal of US - China Public Administration. 6(7): 17-23.

Yu, Harlan and David G. Robinson. 2012. "The New Ambiguity of 'Open Government"'. Information Society Project at Yale Law School. 59 UCLA L. Rev. Disc. 178. Accessed March 17, 2018. http://papers.ssrn.com/sol3/papers.cfm?abstract_id=2012489

Zhao, Jun, Li Xue and Tara Gilkinson. 2010. "Health Status and Social Capital of Recent Immigrants in Canada. Evidence from the Longitudinal Survey of Immigrants to Canada". Accessed July 29, 2017. http://www.cic.gc.ca/english/pdf/research-stats/immigrantsurvey.pdf 